\title{
Expose or protect?
}

Citation for published version (APA):

den Hollander, M. (2018). Expose or protect? fear of movement-related pain in complex regional pain syndrome type 1 . [Doctoral Thesis, Maastricht University, Katholieke Universiteit Leuven]. Maastricht University. https://doi.org/10.26481/dis.20181011mh

\section{Document status and date:}

Published: 01/01/2018

DOI:

10.26481/dis.20181011mh

Document Version:

Publisher's PDF, also known as Version of record

\section{Please check the document version of this publication:}

- A submitted manuscript is the version of the article upon submission and before peer-review. There can be important differences between the submitted version and the official published version of record.

People interested in the research are advised to contact the author for the final version of the publication, or visit the DOI to the publisher's website.

- The final author version and the galley proof are versions of the publication after peer review.

- The final published version features the final layout of the paper including the volume, issue and page numbers.

Link to publication

\footnotetext{
General rights Owners
rights.

- You may freely distribute the URL identifying the publication in the public portal. please follow below link for the End User Agreement:

www.umlib.nl/taverne-license

Take down policy

If you believe that this document breaches copyright please contact us at:

repository@maastrichtuniversity.nl

providing details and we will investigate your claim.
}

Copyright and moral rights for the publications made accessible in the public portal are retained by the authors and/or other copyright owners and it is a condition of accessing publications that users recognise and abide by the legal requirements associated with these

- Users may download and print one copy of any publication from the public portal for the purpose of private study or research.

- You may not further distribute the material or use it for any profit-making activity or commercial gain

If the publication is distributed under the terms of Article $25 \mathrm{fa}$ of the Dutch Copyright Act, indicated by the "Taverne" license above, 


\section{EXPOSE OR PROTECT?}

\section{Fear of movement-related pain in Complex Regional Pain Syndrome Type I}

\section{MARLIES DEN HOLLANDER}

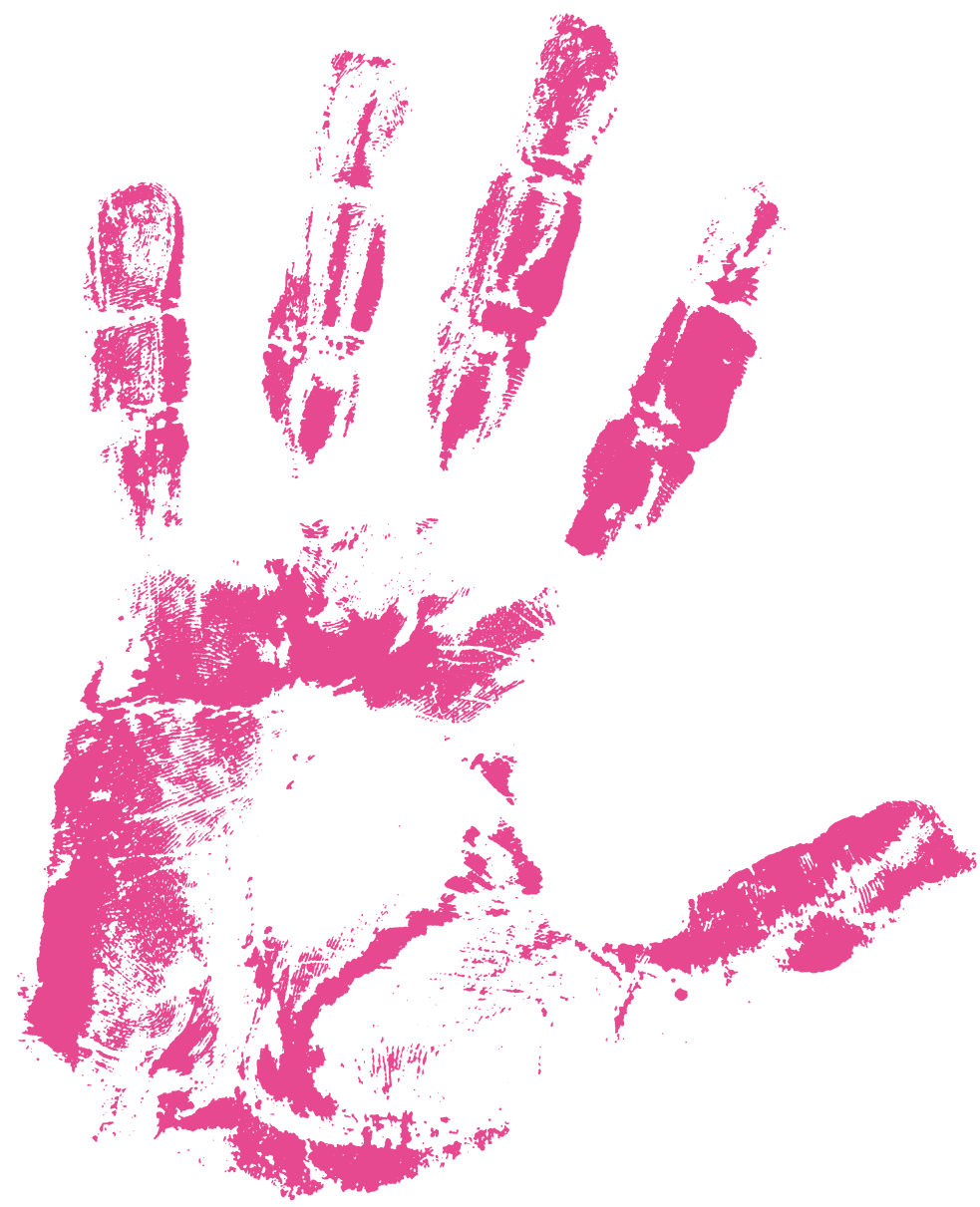

Joint doctorate under supervision of
prof. dr. J.W.S. Vlaeyen and prof. dr. R.J.E.M. Smeets 



\section{Expose or protect? \\ Fear of movement-related pain in Complex Regional Pain Syndrome Type I}

Marlies den Hollander 
ISBN: 978-90-9031151-7

Cover design: Jolanda Loomans and Marlies den Hollander

Layout, typesetting and printing: *studio Michał Stawiński, thesisprint.eu

@ 2018 M. den Hollander, Maastricht, the Netherlands

All rights reserved. No part of this publication may be reproduced or transmitted in any form or by any means, electronical or mechanical, including photocopy, recording or any information storage or retrieval system, without written permission of the copyright owner. 


\title{
Expose or protect? \\ Fear of movement-related pain in Complex Regional Pain Syndrome Type I
}

\author{
DISSERTATION \\ to obtain the degree of Doctor at Maastricht University \\ and Katholieke Universiteit Leuven on the authority \\ of the Rector Magnifici prof. dr. Rianne Letschert \\ and prof. dr. Luc Sels in accordance with the decision \\ of the Board of Deans, to be defended in public \\ on Thursday $11^{\text {th }}$ of October 2018, \\ at 16:00 hours in Maastricht
}

by

Marlies den Hollander

Born on the $15^{\text {th }}$ of November 1974

in Oosterhout, the Netherlands 


\section{Promotores}

Prof. dr. J.W.S Vlaeyen

Prof. dr. R.J.E.M. Smeets

\section{Co-promotores}

Dr. M.E.J.B. Goossens

Dr. J.R. de Jong

\section{Assessment Committee}

Prof. dr. M. Peters (chair), Maastricht University

Prof. dr. J. Verbunt, Maastricht University

Prof. dr. B. Morlion, KU Leuven

Prof. dr. M. van Kleef, Maastricht University

Prof. dr. J. Glombiewski, University Koblenz-Landau

Dr. B. Vervliet, KU Leuven

The research presented in this dissertation was performed at the department of Clinical Psychological Science (CPS) and the department of Rehabilitation Medicine (Care and Public Health Research Institute CAPHRI), Maastricht University, The Netherlands and at the Research Group Health Psychology, Katholieke Universiteit Leuven, Belgium. This research was funded by a grant from the Profileringsfonds azM (PF 261). 


\section{Table of contents}

$\begin{array}{ll}\text { Chapter } 1 & 7\end{array}$

General introduction

\section{Chapter 2}

Fear reduction in patients with chronic pain: a learning theory

perspective

\section{Chapter 3}

69

The effect of threat information on acquisition, extinction and reinstatement of experimentally conditioned fear of movement-related pain

\section{Chapter 4}

Generalization of Exposure

in vivo in Complex Regional Pain Syndrome Type I

\section{Chapter 5}

Expose or protect?

A randomized controlled trial of exposure in vivo versus

pain-contingent treatment as usual in patients with Complex Regional Pain Syndrome Type 1

\section{Chapter 6}

Exposure in vivo versus pain-contingent physical therapy in Complex Regional Pain Syndrome Type I: A cost-effectiveness analysis

\section{Chapter 7}

General discussion

Valorization addendum

Summary

Samenvatting

Dankwoord 



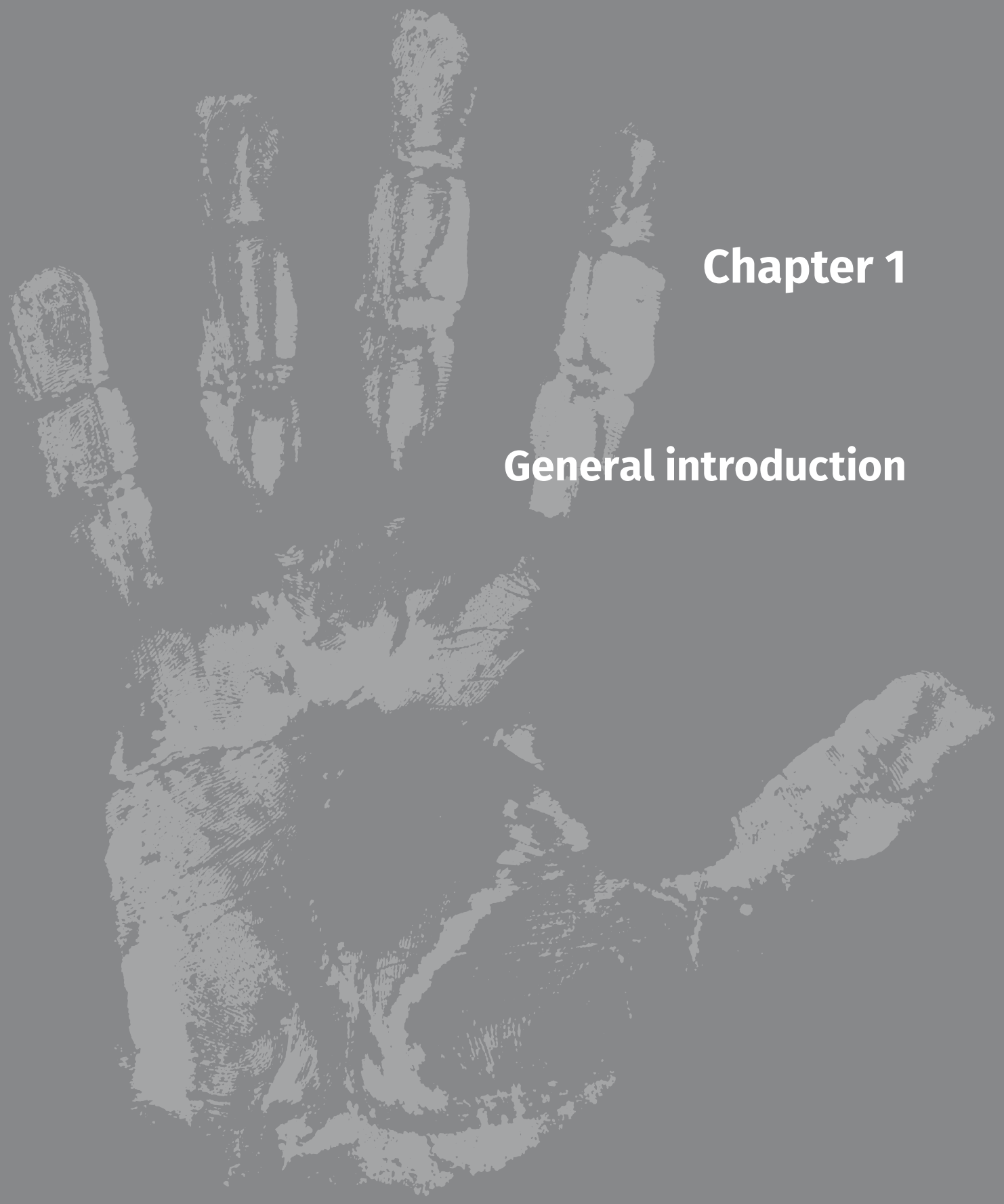





\section{Pain}

Pain is a universal human experience, and vital for survival. Traditionally, pain is defined as a signal of injury, harm or tissue damage and serves an adaptive function. Pain urges to attend to the source of injury and take measures to promote healing. The importance of pain as a warning signal is evident. When the ability to feel pain is absent, as it is in the rare group of individuals with congenital analgesia, this insensitivity results in the absence of punishment, and therefore in disabled learning from adaptive escape- and avoidance responses. Fatally, and as a direct consequence of continuous burns, bruises and fractures, these individuals have poor survival rates during childhood (Drummond \& Rose, 1975; Nagasako, Oaklander, \& Dworkin, 2003). In other words, pain is necessary for survival.

The idea that pain is a signal of bodily harm is consistent with the biomedical model that prevailed since the philosopher Descartes in the $16^{\text {th }}$ century. Descartes conceptualized pain as a reflex of the mind upon damage in body tissue. In his writings, he made the analogy with a bell in a church tower (central nervous system) that starts ringing when the ropes (ascending pathways) are being pulled. In essence, the Cartesian model suggests a one-to-one relationship between the extent of injury, and the intensity of pain. However, later insights have shown that the experience of pain is much more complex. A striking finding, inconsistent with the biomedical model, is that an initial injury can occur without pain, especially when escape from a threat source is urged first (Wall, 1979). This initial absence of pain enables "to fight or flight". Pain eventually arises, but not before being in a relatively safe context, where both humans and animals need to express behavior aimed at healing. This shows that the function of pain can better be conceived as initiating behavior aimed to escape from a dangerous situation, instead of signaling tissue damage. Several studies illustrate the weak relationship between pain and tissue damage. A prospective study that followed male participants for 15 years showed that physiological markers, such as muscle size, muscle composition and asymmetry, had a limited and uncertain role in the prediction of low back pain episodes, short term as well as up to 15 years (Fortin, Gibbons, Videman, \& Battie, 2015). A Magnetic Resonance Imaging (MRI) study, imaging the lower spine of people without pain, showed that abnormalities as bulging disks and protrusions were observed in the majority of pain-free individuals (Jensen et al., 1994). Thus, tissue damage is not always painful, but the opposite is true as well: pain can occur without injury. For example, in most cases of low back pain, no pathophysiology can be detected (Waddell, 2004). Another example is phantom limb pain. After amputation of a body part, patients can still experience 
their missing limb as painful (Giummarra \& Moseley, 2011). These studies show that in order to understand the complex experience of pain, a broader perspective than the Cartesian model is needed.

In the mid-sixties, the psychologist Ronald Melzack and neurophysiologist Patrick Wall proposed the so-called "Gate Control" theory (Melzack \& Wall, 1965), which dramatically changed the scientific approach to pain, and literally opened a new gate to research on the psychology of pain. They were the first to describe that the experience of pain is not just a bottom-up process, transporting peripheral nociceptive input via the spinal cord to the brain, but that central psychological mechanisms exert a top-down influence modulating the pain experience. In the dorsal horn of the spinal cord, ascending transmission of physiological information from the periphery to the brain is influenced by descending transmission of information from the brain, integrating purely sensory information with cognitive and affective information resulting in a unique pain experience (Melzack \& Wall, 1965).

To do justice to the complex experience of pain, the International Association for the Study of Pain (IASP) defines pain as "an unpleasant sensory and emotional experience associated with actual or potential tissue damage, or described in terms of such damage" (Mersky \& Bogduk, 1994). This definition, based on extensive research over the last 50 years, implies that pain involves both top-down influences (descending inhibition) as well as bottom-up information from the periphery (tissue damage). The definition is in line with biopsychosocial models of health and disease, which describe how sensory, emotional, cognitive and social factors jointly contribute to the health status of an individual (Engel, 1980).

\section{Acute and chronic pain}

The complexity of pain also increases over time, when the assumed relationship between tissue damage and pain becomes more elusive and questionable (Nederhand, Hermens, IJzerman, Groothuis, \& Turk, 2006; Waddell, 2004; Wilmink \& Patijn, 2001). When pain "exists beyond the expected period for healing" it is defined as chronic pain (Turk \& Okifuji, 2001). Protective behaviors that are adaptive in an acute pain context may paradoxically worsen the problem when engaged in the chronic stage. In the next paragraphs, the mechanisms that may be responsible for the transition from an acute episode to a disabling chronic pain condition will be highlighted. These mechanisms mainly involve psychological variables, such as cognitions and emotions. 


\section{Cognitions influence on the pain experience}

One of the psychological variables exerting its influence on the pain experience is cognition, for example in giving meaning to the experience of pain. An elegant experiment showed that exact the same physical stimulation can lead to differences in the amount of experienced pain when the threat-value of pain is being manipulated. Participants all received the same pain-stimulus: a cold bar that was placed in the neck. A stimulus of this temperature is so cold that it is just perceived as painful, instead of cold. The experimenters manipulated the threat-value of the stimulus by telling participants either that they would receive the stimulus from a hot bar, or a cold bar. Although the physical stimulation was exactly the same for both groups, participants receiving instruction that the bar was hot rated their pain as more intense than the group who believed that the bar was cold (Arntz \& Claassens, 2004). Interestingly, the authors also found that the relationship between the experimental heat/cold manipulation and the reported pain intensity was mediated by the perceived harmfulness of the stimulus, with the (assumed) heat stimulus perceived as more harmful to the skin than the cold stimulus.

A functional MRI study also showed that threat value influences the pain experience. Wiech et al. (2010) investigated brain responses during the anticipation and perception of laser stimuli under low and high threat instruction. Participants received physically identical laser stimulations around the pain threshold, with either the instruction that the stimulus was entirely save, inducing low threat; or potentially harmful, inducing high threat. In the high threat condition, significantly more stimuli were rated as painful (Wiech et al., 2010). These studies suggest a direct association between the meaning of pain in terms of potential harm, and its reported intensity.

\section{The role of emotions}

Another psychological variable affecting the experience of pain is emotion: both negative and positive emotions are known to impinge upon the experience of pain. In chronic pain patients, an experimentally induced positive mood led to a decreased pain experience, and increased tolerance of physical performance, whereas a negative induced mood showed the reversed pattern (Tang et al., 2008). Individuals with a history of depression are known to have a higher risk on chronic pain (Bair, Robinson, Katon, \& Kroenke, 2003). 
Even in healthy individuals, manipulations of mood state (negative or positive) influence the pain experience. Negative mood inductions were found to increase pain unpleasantness: women who immersed their hand in hot water rated pain as more unpleasant when they watched video's with scenes from disaster, than watching videos of neutral cityscapes (Loggia, Mogil, \& Bushnell, 2008). Negative mood, induced by hypnosis, was found to increase the reported pain intensity; this effect was found for both pain-related anger as well as pain-related sadness (Rainville, Bao, \& Chretien, 2005). Induction of positive mood was found to decrease pain intensity: healthy participants rated thermal heat stimuli as less intense when they listened to pleasant music compared to unpleasant music (Roy, Peretz, \& Rainville, 2008).

The evidence for cognitive and emotional influences on pain intensity confirms the complexity of pain, and addresses the need to take all these elements into account to explain the transition from acute to chronic pain from a biopsychosocial perspective.

\section{Fear avoidance model}

A biopsychosocial model that received extensive scientific attention is the fearavoidance model (Leeuw et al., 2007a; Lethem, Slade, Troup, \& Bentley, 1983; Slade, Troup, Lethem, \& Bentley, 1983; Vlaeyen, Crombez, \& Linton, 2016; Vlaeyen \& Linton, 2000,2012 ). This model states that an individual's reaction to a painful event might be either confrontation or avoidance.

The majority of individuals will evaluate the pain experience as unpleasant, but not as an extreme threat or catastrophe. As a result, they proactively confront their pain, resume valued daily activities, and in the long run report a decrease in experienced pain. On the other hand, a number of individuals assigns a catastrophic meaning to their pain experience, as a sign of harm or a predictor of worsening pain. Such catastrophic interpretations give rise to pain-related fears (e.g. fear of pain, fear of movement, fear of (re-)injury), which then induces hypervigilance (Crombez, Van Damme, \& Eccleston, 2005). Hypervigilance is defined as "an unintentional and efficient process that emerges when the threat value of pain is high, the fear system is activated, and the individual's current concern is to escape and avoid pain" (Crombez et al., 2005). Hypervigilance interferes with attention drawn to the accomplishment of daily life activities and might increase the detection of pain and other aversive bodily signs. Additionally, when fearful, the individual will react 
with defensive responses as avoidance behaviors. There is preliminary evidence that avoidance behaviors paradoxically increase fear, especially in situations when opportunities for avoidance are not available (Volders, Boddez, De Peuter, Meulders, \& Vlaeyen, 2015). In chronic pain patients, pain is typically no sign of actual danger (since the injury has healed, despite persistent pain) and avoidance behavior loses its adaptive function as a protective strategy (Zale, Lange, Fields, \& Ditre, 2013). Still, avoidance might be positively reinforced by a sense of safety or relief since it is assumed to protect oneself from an aversive event. The current opinion is that avoidance behavior is motivated and reinforced by nonconscious processes rather than reduction of conscious fear, and that avoidance can even become habitual behavior (LeDoux, Moscarello, Sears, \& Campese, 2017; Pittig, Schulz, Craske, \& Alpers, 2014; Volders et al., 2015). A fearful chronic pain patient does no longer verify whether movements and activities still adequately predict pain or damage, keeping the assumption of impending danger intact.

A recent idea is that the relation between fear and avoidance behavior is bidirectional: behavior also serves as a source of information about the situation. Hence, people do not only become fearful because there is danger, but also since they reason that when they behave fearful, i.e. when they avoid or escape, there must be danger (Gangemi, Mancini, \& van den Hout, 2012). This process is called "emotional reasoning". Fearful individuals tend to use their behavior as input, whereas non-fearful individuals do not infer danger from their own behavior, but rely more on objective danger. Many chronic pain patients keep on using pain-medication, despite the fact that they do not experience pain-reduction or pain control, which was the original goal for taking medication in the first place. They explain this by the fact that if they would not take medication, pain would increase. They use the fact that they still use medication as input for subsequent decision making, instead of adequately evaluating the costs and benefits of taking medication.

Summarizing, both pain and fear are important for the organism's' survival. Safety-seeking behaviors such as escape and avoidance are adaptive in an acute phase where tissue damage is (likely to be) involved. In a chronic state, or when tissue damage is undetectable or unlikely, responses driven by pain-related fear as avoidance behavior and hypervigilance, might not serve any function to recovery anymore, but give rise to disability and depression. The fear-avoidance model is a theoretical model derived from the biopsychosocial framework that may help to understand the transition from acute to chronic pain, and the relationship between experienced pain, fear and disability. 
Figure 1. Fear Avoidance Model (Vlaeyen, Crombez \& Linton (2016). The fear-avoidance model of pain. Pain, 157(8), 1588-1589. doi: 10.1097/j.pain.0000000000000574, permission for reprint granted by Wolters-Kluwer).

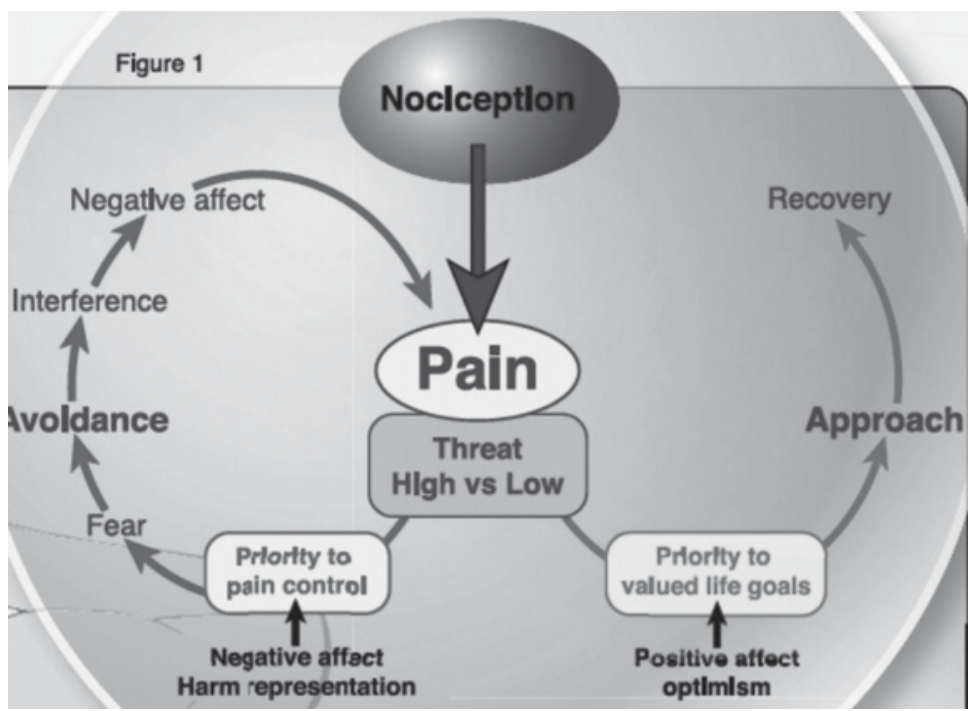

\section{Learning}

The central role that the fear-avoidance model allocates to fear in understanding pain-related disability urges us to take a closer look on how individuals become fearful. Research on fear and anxiety in general is abundant, and might serve as inspiration for the field of pain-related fear. The example of congenital analgesia in the first paragraph already showed that pain is an important motivator in learning, and that learning to protect oneself against harmful events is compromised when pain cannot be experienced. Learning theory indeed provides a solid theoretical framework to understand the acquisition, maintenance, generalization, and extinction of fear and anxiety by classical condition principles, and their subsequent influence on behavior by operant learning principles.

\section{Classical conditioning}

Classical or Pavlovian fear conditioning occurs when an emotionally neutral stimulus becomes associated with an inherently aversive experience, thereby acquiring the capability of evoking a fearful response on its own (Lissek et al., 2005). The inherently aversive experience is the unconditioned stimulus (US), the initially neutral stimulus that becomes associated with the aversive experience is the conditioned 
stimulus (CS), and the subsequent fear it elicits is the conditioned response (CR). Generally, fear conditioning is an adaptive form of learning. Nevertheless, such conditioning may become pathologic when fearful reactivity to a CS persists in the absence of a CS-US contingency (Lissek et al., 2005).

In the context of pain, during childhood we experience that (in many case minor) bodily harm causes pain. Pain can be considered an unconditioned stimulus because of this early-learned association with harm or injury. When pain is experienced in real life, it is present in a context with interoceptive, proprioceptive and exteroceptive stimuli. These stimuli might in itself become predictors of pain and its representation as a US. Especially proprioceptive (for example a sense of movement or a sense of the position of the limb) and interoceptive (for example a sense of tension in the muscles) stimuli have the propensity to serve as CSS for pain as US.

Meulders et al. (2011) indeed showed that movements, e.g. proprioceptive cues, could come to elicit fear and defensive responses because of their previous pairing with a painful electrocuteneous stimulus in a classical conditioning paradigm with pain-free participants (Meulders, Vansteenwegen, \& Vlaeyen, 2011). Participants moved a joystick to the left / right in the predictable condition, and upward/downward in the unpredictable condition, or vice versa. In the predictable condition, one movement (CS+) was followed by a painful electrical shock (US), whereas the other movement (CS-) was not. In the control condition, painful stimuli were administered in the interval between trials, i.e. unpredictably and not related to a specific movement. In the predictable condition, fear of movement-related pain emerged for the movement that was followed by pain, and not for the other (CS-) movement. Participants were also slower to initiate the CS+movement. In the control condition, no differences in fear of movement-related pain or response latencies occurred between the movements. This study provided experimental evidence for the since long suggested pathway on how patients learn to fear and avoid certain movements or activities (Meulders et al., 2011). We use this paradigm in Chapter III, to investigate the role of information on the threat-value of pain.

CS-US associations can be learned not only by direct experience of the CS-US contingency, but also indirectly by verbal information about and by observing CS-US contingencies (Helsen, Goubert, Peters, \& Vlaeyen, 2011; Olsson \& Phelps, 2004). This was shown in an experimental study, in which participants observed models performing several cold-pressor tasks. Depending on the colour of the water, the models in the video reacted either with a neutral (CS-) or a painful (CS + ) facial expression. As a next step, participants performed the same cold-pressor tasks themselves. When the water had the same colour as in the task they observed the model react with painful expressions, participants were more fearful to perform the task. They also reported to expect more pain from performing this task. Even after performing 
the cold-pressor tasks, fear of pain was still elevated for the colour previously paired with painful expressions in the model (Helsen et al., 2011). In the next chapter, we will further elaborate on the role of classical conditioning in pain-related fear. For more extensive reviews of the role of classical conditioning in the context of pain, we refer to Harvie et al. (2017) and Vlaeyen (2015) (Harvie, Moseley, Hillier, \& Meulders, 2017; Vlaeyen, 2015). Summarizing, classical conditioning is a process by which stimuli that signalled the onset of the US before, acquire threat-value by activating the representation of the US in memory, and they start to elicit fear and defensive responding on their own.

\section{Operant conditioning}

Defensive responses are initiated to anticipate potential threats, and usually involve escape, avoidance or subtle safety-seeking behaviors, such as always having medication or a mobile phone available, in case of a sudden or extreme pain episode. These behaviors are influenced by operant conditioning. Operant conditioning is the learning of associations between certain behavior and the consequences of that behavior. Behavior is likely to increase when it is followed by valued consequences (positive reinforcement: adding a reward; or negative reinforcement: taking away a punisher), and decrease when followed by negative consequences (positive punishment: adding a punisher; or negative punishment: taking away an anticipated reward).

In the area of pain, the operant learning paradigm started receiving attention in the late sixties, when the American psychologist Wilbert Fordyce introduced the concept of pain behavior. The main idea was that a person's behavior of pain and suffering is best understood in terms of events in the environment, and not in terms of stable characteristics of the individual (e.g. personality). Since the introduction of Fordyce's book "Behavioural methods for chronic pain and illness" (1976), there is some empirical evidence supporting the role of operant learning in modifying pain behaviors. For example, Joliffe and Nicholas presented healthy subjects with a stable or a decreasing pain stimulus. In each condition, half of the participants received verbal reinforcement if they reported increasing pain. Reinforced subjects reported significantly higher pain intensity than non-reinforced subjects, both for the stable as well as for the decreasing pain stimulus (Jolliffe \& Nicholas, 2004). In another study, either neutral or painful facial expressions were reinforced by the experimenter, leading to significant changes in facial expressions in the direction that was reinforced. A decline in facial pain displays, in the condition where a neutral facial expression was reinforced, predicted changes in the pain ratings 
(Kunz, Rainville, \& Lautenbacher, 2011). For a review on operant conditioning in pain, see Gatzounis et al. (2012) and Flor (2014) (Flor, 2014; Gatzounis, Schrooten, Crombez, \& Vlaeyen, 2012).

"Graded activity" is a clinical treatment that uses operant principles to reduce disability in patients with chronic pain. Graded activity aims to improve functional ability by positive reinforcement of the gradual, time-contingent resumption of activity levels (Leeuw et al., 2008; Verbunt \& Smeets, 2016). After identification of individually relevant goals, patients establish their current tolerance level of that specific activity in a pain-contingent manner. Subsequently, patients start to perform the activity in a time-contingent manner and gradually proceed to their predefined goal. Healthy behaviors are shaped through positive reinforcement of the predefined activity quotas (Fordyce, 1976; Vlaeyen, de Jong, Sieben, \& Crombez, 2002). This gradual resumption of activities in a time-contingent manner aims to decrease pain-related disability in the long run.

\section{Generalization of pain-related fear}

Over the course of life, almost everybody will experience pain, and probably during or after a specific movement (CS). If only this specific CS would be avoided, it would probably not lead to extensive disability and the maintenance of chronic pain. Apparently, individuals tend to not only expect the US from the CS that was originally paired with it during acquisition. US-expectancies tend to generalize to other CSs: stimuli that are similar to, but not identical with the conditioned stimulus also come to elicit a learned fear response. This process is referred to as generalization: the ability to infer predictive value from a stimulus that was actually experienced, to a novel, similar stimulus without having to actually experience this similar stimulus (Meulders, Meulders, Stouten, De Bie, \& Vlaeyen, 2017). In our natural environment, stimuli rarely occur exactly the same from one encounter to another. Therefore, generalization is essential and serves an adaptive, self-preserving function. On the other hand, specificity is of equal importance: discriminating between different stimuli and events, and thereby limiting generalization. These processes interact in a delicate balance facilitating survival in a dynamic environment, by applying learning only when appropriate (Dunsmoor \& Paz, 2015).

Individuals vulnerable for pathological fear have been shown to "overgeneralize": stimuli that are actually safe are interpreted as dangerous, because they share certain features with the danger cue (Lissek et al., 2008; Lissek et al., 2010; Vervliet, Kindt, Vansteenwegen, \& Hermans, 2010). During the acquisition of fear, this overgeneralization might label many CSs that are actually safe, as predictors of dangerous 
USs and thereby safe CSS come to elicit fear, a finding that was confirmed in fear of movement related pain (Meulders, Vandebroek, Vervliet, \& Vlaeyen, 2013). A recent idea is that not an exaggerated conditioned response to threat might put individuals at risk to develop pain-related fear, but mere a failure to inhibit fear responding in the presence of safety cues (Harvie et al., 2017). A systematic review revealed preliminary evidence that individuals with chronic pain might differ from healthy individuals in their ability to identify indicators of threat and safety, since they show reduced differential learning and flatter generalization gradients with respect to US-expectancy and fear-potentiated startle responses (Harvie et al., 2017), although the authors clearly state that more research in the altered classical conditioning in chronic pain patients is warranted.

\section{Extinction of pain-related fear}

Fear extinction occurs when repeated presentations of the CS, in absence of the US, lead to a gradual decay of anticipatory fear reactions (Meulders \& Vlaeyen, 2012; Vervliet, Baeyens, Van den Bergh, \& Hermans, 2013). In patients with pain-related fear, this would imply multiple presentations of proprioceptive (movements, activities) and interoceptive (pain or other sensations) stimuli, without the occurrence of extreme negative consequences (US), such as expected harm or unbearable increases in pain. The current scientific opinion is that extinction is a fragile and context-dependent process. Extinction does not erase the original acquisition memory (CS-US), rather it creates a new extinction memory (CS-noUS) that co-exists and competes with the original memory when the CS is encountered again (Bouton \& King, 1983). The context is merged in the representation of the extinction memory (CS-noUS), whereas this is not the case for the acquisition memory (CS-US). After extinction, the CS both activates and deactivates the representation of the US. Hence, the CS will sometimes elicit fear and sometimes not, depending on the context (Vervliet et al., 2013).

Phenomena such as renewal, reinstatement, spontaneous recovery and rapid reacquisition indeed show that extinction does not result in "unlearning" or "forgetting" the CS-US association, but in an inhibition of the original CS-US association. Renewal refers to the context-specificity of extinction, since fear might return in a new context, different from the context in which extinction took place. A patient with pain-related fear might have performed sports activities during treatment in a rehabilitation-center, but when he starts to go to a regular gym, fear might return due to this switch of contexts. Reinstatement occurs when an unsignalled or unpaired US is encountered after extinction (Dirikx, Hermans, Vansteenwegen, Baeyens, \& Eelen, 2004; Hermans et al., 2005; Meulders \& Vlaeyen, 2013). Fearful 
low-back pain patients might experience a sudden shooting pain after a pain free period of time, and this again gives rise to fear. Spontaneous recovery is a return of fear just by the passage of time after successful extinction. Rapid reacquisition refers to the observation that fear easily returns when CS-US pairings are again experienced after successful extinction. Even though a patient might have rotated in a normal manner after treatment many times, the experience of a sudden "crack" in his back can reactivate the thought that rotation should be avoided. To offset these effects and prevent return of fear in the long run, optimizing inhibitory learning to aim at maximal retrieval of the CS-nouS association over contexts and time is crucial (Craske et al., 2008). In patients with pain-related fear, awareness and understanding of the fact that fear might possibly return can help to prevent relapse in disability. Empirical studies on return of pain-related fear after successful extinction are scarce, and are still waited.

\section{Generalization of extinction}

Whereas generalization to other CSs than the CS that was originally paired with the US seems relatively easy, generalization of extinction is not self-evident. In chronic low back pain patients, generalization of fear-extinction was studied in four experimental studies. In the first study (Goubert, Francken, Crombez, Vansteenwegen, \& Lysens, 2002), participants performed two movements (bending forward and straight leg raising) two times. Baseline, expected and experienced pain were recorded during all four trials. Participants characterized as "high pain catastrophizers" showed an initial overprediction of pain, but when repeating the same movement, they corrected their pain expectancies. Nevertheless, when they had to perform the new movement, the initial overprediction of pain returned. This pattern did not emerge in patients scoring low on pain catastrophizing (Goubert et al., 2002). Crombez et al. (2002) replicated these findings. Additionally, they documented scores for harm (baseline, expected and experienced). The prediction of harm was not corrected when the same movement was repeated, i.e. no effect of exposure on harm-expectancies could be established, so generalization could not be evaluated (Crombez, Eccleston, Vlaeyen, Vansteenwegen, Lysens, \& Eelen, 2002). In a third experiment, participants made either three times the same movement (AAA, BBB or CCC) or three different movements $(A B C)$. Next, they were asked to perform a new movement $D$. Predicted and experienced pain intensity were measured, but no differences between conditions were found (Goubert, Crombez, \& Lysens, 2005). Only the fourth study found successful generalization of pain expectancy corrections from one movement to another. This study differed from previous studies in that four similar movements of 
increasing intensity were made. It was found that highly fearful participants showed successful generalization of pain expectancy corrections across movement tasks (Trost, France, \& Thomas, 2008).

A recent experimental study showed that, although extinction of fear to generalized stimuli occurred, fibromyalgia patients still showed elevated fear responses despite corrective feedback, compared to healthy controls (Meulders et al., 2017). When pain-related fear to generalized stimuli keeps present despite corrective feedback, this might maintain long-term chronic pain disability.

\section{Clinical application: Exposure in vivo}

Exposure in vivo treatment is the clinical equivalent of an experimental fear-extinction procedure. In patients with pain-related fear, exposure in vivo specifically aims to reduce disability by challenging erroneous expectancies about pain indicating harm, activities causing harm, pain being unbearable or sensations indicating worsening of the condition. Detailed descriptions of the exposure-protocol in pain-related fear can be found elsewhere (Verbunt \& Smeets, 2016; Vlaeyen, Morley, Linton, Boersma, \& de Jong, 2012), but the steps that treatment consists of will briefly be summarized here. To assess if pain-related fear is present, questionnaires such as the Pain Catastrophizing Scale (Sullivan, Bishop, \& Pivik, 1995), the Fear of Pain Questionnaire (Roelofs, Peters, Deutz, Spijker, \& Vlaeyen, 2005) and the Tampa Scale for Kinesiophobia (Miller, Kori, \& Todd, 1991) can be used. A cognitivebehavioral analysis of the pain-problem helps evaluating whether a patient might benefit from exposure treatment. The Photographic Series of Daily Activities or PHODA (Leeuw, Goossens, van Breukelen, Boersma, \& Vlaeyen, 2007b) consists of photographs depicting movements and activities that are rated along a thermometer based on their perceived harmfulness. The PHODA is a reliable and valid tool to evaluate which CSs predict the US harm. Furthermore, it is important to enhance the patient's engagement in a treatment that might not readily be perceived as credible. A thorough explanation of the current scientific evidence during the educational session aims to enhance credibility and engagement. The educational session provides an alternative explanation of ongoing pain and disability in the absence of biomedical pathology. It was shown that education does reduce the threat-value of pain, but that actual exposure to fear-provoking activities is necessary to change 
disability (de Jong et al., 2005b). During the actual exposure sessions, behavioral experiments are performed, exposing patients to stimuli that have come to predict danger (CSs) without the occurrence of the feared aversive event that it has come to predict (US). In pain-related fear, CSS might be proprioceptive (movements or activities) or interoceptive (sensations, such as pain), USs are representations of harm or uncontrollability.

\section{Scientific evidence for exposure in vivo in pain- related fear}

Exposure in vivo was found to be effective in reducing fear, disability and pain in lowback pain patients with pain-related fear. This was shown in several $\mathrm{N}=1$ experimental designs (Vlaeyen, de Jong, Geilen, Heuts, \& van Breukelen, 2001; Vlaeyen, de Jong, Geilen, Heuts, \& van Breukelen, 2002; Vlaeyen, de Jong, Onghena, KerckhoffsHanssen, \& Kole-Snijders, 2002) as well as in group randomized controlled trials (Leeuw et al., 2008; Linton et al., 2008; Woods \& Asmundson, 2008). Effectiveness was also shown for post-traumatic neck pain (de Jong et al., 2008), work-related upper-limb pain (de Jong, Vlaeyen, van Eijsden, Loo, \& Onghena, 2012) and Complex Regional Pain Syndrome Type I (CRPS-I) (de Jong et al., 2005a). In table 1, an overview of the studies, design and effects of exposure in vivo on disability, pain-related fear, catastrophizing and pain intensity is shown. Bailey et al. (2010) provide an extensive review of treatments addressing pain-related fear and anxiety in chronic pain patients (Bailey, Carleton, Vlaeyen, \& Asmundson, 2010).

Early research on exposure in pain-related fear focused on musculoskeletal pain syndromes. The fact that the pain experience also varies across individuals with pain that is assumed to be of biomedical origin raised the idea that psychological treatments such as exposure in vivo might be effective for patients with pain-related fears in these conditions as well. Complex Regional Pain Syndrome is an example of a condition in which pain is assumed to be neuropathic, but in which pain-related fear might also be present (Philips, 1987). Indeed, a subgroup of patients presents with pain-related fear (de Jong, Vlaeyen, de Gelder, \& Patijn, 2011), and in a first $\mathrm{N}=1$ experimental design, exposure in vivo reduced not only pain-related fear and disability, but decreased the pain-experience as well as self-reported symptoms (de Jong et al., 2005a). 
Table 1. Overview of the available studies ( $N=1$ experimental designs and RCTS) on the effectiveness of exposure in vivo in chronic pain.

\begin{tabular}{|c|c|c|c|c|c|c|c|}
\hline & & & & \multirow{2}{*}{\multicolumn{4}{|c|}{ Effect }} \\
\hline \multirow[b]{2}{*}{ Source } & \multirow[b]{2}{*}{ Design } & \multirow[b]{2}{*}{$\begin{array}{l}\text { Control } \\
\text { treatment }\end{array}$} & \multirow[b]{2}{*}{ Diagnosis } & & & & \\
\hline & & & & $\begin{array}{c}\text { Reduction } \\
\text { disability }\end{array}$ & Fear reduction & $\begin{array}{l}\text { Pain- } \\
\text { reduction }\end{array}$ & $\begin{array}{c}\text { Reduction } \\
\text { catastrophizing }\end{array}$ \\
\hline $\begin{array}{l}\text { Vlaeyen et } \\
\text { al., } 2002\end{array}$ & $\begin{array}{l}\text { Case study } \\
\mathrm{N}=2 \\
\mathrm{AB}\end{array}$ & $\begin{array}{l}\text { None (no- } \\
\text {-treatment } \\
\text { baseline) }\end{array}$ & CLBP & $+(\mathrm{RDQ})$ & $+($ TSK, PHODA $)$ & $+($ VAS $)$ & Not assessed \\
\hline $\begin{array}{l}\text { Vlaeyen et } \\
\text { al., } 2001\end{array}$ & $\begin{array}{l}\text { SCED } \\
N=4 \\
A B C \text { or } A C B\end{array}$ & $\mathrm{GA}$ & CLBP & $+(\mathrm{RDQ})$ & $+($ TSK, PHODA $)$ & Not assessed & $+(\mathrm{PCS})$ \\
\hline $\begin{array}{l}\text { Vlaeyen et } \\
\text { al., } 2002\end{array}$ & $\begin{array}{l}\text { SCED } \\
N=6 \\
A B C\end{array}$ & GA & CLBP & $\begin{array}{l}+(\mathrm{RDQ}, \\
\text { activity } \\
\text { monitoring) }\end{array}$ & $+($ TSK, PHODA $)$ & $+($ VAS $)$ & $+(\mathrm{PCS})$ \\
\hline $\begin{array}{l}\text { Linton et al., } \\
2002\end{array}$ & $\begin{array}{l}\text { SCED } \\
\mathrm{N}=2 \\
\text { Pre-post }\end{array}$ & None & CLBP & $+(\mathrm{RDQ})$ & $+($ TSK, PHODA $)$ & Not assessed & Not assessed \\
\hline $\begin{array}{l}\text { Boersma et } \\
\text { al., } 2004\end{array}$ & $\begin{array}{l}\text { SCED } \\
\mathrm{N}=6 \\
\text { multiple } \\
\text { baseline }\end{array}$ & None & CLBP & $\begin{array}{l}\text { +(Orebro } \\
\text { scales, PAIRS) }\end{array}$ & $\begin{array}{l}+(\mathrm{PHODA}, \mathrm{TSK} \\
\text { FABQ })\end{array}$ & $+($ VAS) & Not assessed \\
\hline $\begin{array}{l}\text { de Jong et } \\
\text { al., 2005a }\end{array}$ & $\begin{array}{l}\text { SCED } \\
N=8 \\
A B C\end{array}$ & $\begin{array}{l}\text { None (no- } \\
\text {-treatment } \\
\text { baseline) }\end{array}$ & CRPS-I & $\begin{array}{l}+(W A Q \\
\text { RASQ })\end{array}$ & $+($ TSK, PHODA) & +(VAS) & Not assessed \\
\hline $\begin{array}{l}\text { de Jong et } \\
\text { al., 2005b }\end{array}$ & $\begin{array}{l}\text { SCED } \\
\mathrm{N}=8 \\
\mathrm{ABC} / \mathrm{ABD}\end{array}$ & $\begin{array}{l}\text { Education } \\
\text { followed } \\
\text { by GA or GE }\end{array}$ & CLBP & $+(\mathrm{RDQ})$ & +(TSK, PHODA) & - (VAS) & Not assessed \\
\hline $\begin{array}{l}\text { de Jong et } \\
\text { al., } 2008\end{array}$ & $\begin{array}{l}\text { SCED } \\
N=8 \\
A B C\end{array}$ & GA & PTNP & $+(\mathrm{NDI})$ & $+($ TSK, PHODA $)$ & $+($ VAS $)$ & Not assessed \\
\hline $\begin{array}{l}\text { de Jong et } \\
\text { al., } 2012\end{array}$ & $\begin{array}{l}\text { SCED } \\
N=8 \\
A B C\end{array}$ & $\begin{array}{l}\text { None (no- } \\
\text {-treatment } \\
\text { baseline) }\end{array}$ & WRUEP & $+($ DASH $)$ & $+($ TSK, PHODA $)$ & $+($ VAS $)$ & $+(\mathrm{PCS})$ \\
\hline $\begin{array}{l}\text { Leeuw et al., } \\
2008\end{array}$ & $\begin{array}{l}\mathrm{RCT} \\
\mathrm{N}=85\end{array}$ & $\begin{array}{l}\text { GA } \\
\text { (ITT analysis) }\end{array}$ & CLBP & $\begin{array}{l}\text { NS (QBPDS, } \\
\text { PSC) }\end{array}$ & $+($ PHODA $)$ & NS (MPQ) & $+(\mathrm{PCS})$ \\
\hline $\begin{array}{l}\text { Linton et al., } \\
2008\end{array}$ & $\begin{array}{l}\mathrm{RCT} \\
\mathrm{N}=46\end{array}$ & $\begin{array}{l}\text { WLC-TAU } \\
\text { (intermediate } \\
\text { scenario) }\end{array}$ & CLBP & $\begin{array}{l}\text { +(ADL scale) } \\
\text { NS (QBPDS) }\end{array}$ & $\begin{array}{l}+(\text { TSK) } \\
\text { NS (PHODA) }\end{array}$ & NS (ÖMPSO) & NS (PCS) \\
\hline $\begin{array}{l}\text { Woods \& } \\
\text { Admundson, } \\
2008\end{array}$ & $\begin{array}{l}\text { RCT } \\
N=44\end{array}$ & $\begin{array}{l}\text { GA, WLC } \\
\text { (ITT analysis) }\end{array}$ & CLBP & $\begin{array}{l}\text { GA: NS } \\
\text { WLC: NS }\end{array}$ & $\begin{array}{l}\text { GA: + } \\
\text { (PASS, FABQ, TSK) } \\
\text { WLC: + } \\
\text { (PASS, FABQ, TSK) }\end{array}$ & $\begin{array}{l}\text { GA: NS } \\
\text { WLC:+(MPQ) }\end{array}$ & $\begin{array}{l}\text { GA: NS } \\
\text { WLC: +(PCS) }\end{array}$ \\
\hline
\end{tabular}

Abbreviations: CLBP = Chronic Low Back Pain, CRPS-I = Complex Regional Pain Syndrome Type 1, FABQ = Fear Avoidance Beliefs Questionnaire (Waddell, Newton, Henderson, Somerville, \& Main, 1993), GA = Graded Activity, NDI = Neck Disability Index (Vernon \& Mior, 1991), NS = Difference Not Significant, ÖMPSQ = Örebro Musculoskeletal Pain Screening Questionnaire (Linton \& Hallden, 1998), PASS = Pain Anxiety Symptoms Scale (McCracken, Zayfert, \& Gross, 1992), PCS = Pain Catastrophizing Scale (Sullivan et al., 1995), PHODA = Photographic Hierarchy of Daily Activities (Leeuw et al., 2007b), PSC=Patient Specific Complaints (Beurskens, de Vet, \& Koke, 1996), PTNP = Post-Traumatic Neck Pain, RASQ = Radboud Skills Questionnaire (Oerlemans, Cup, DeBoo, Goris, \& Oostendorp, 2000), RDQ = Roland Disability Questionnaire (Roland \& Morris, 1983), SCED=single case experimental design, VAS = Visual Analogue Scale, WLC = Wait List Control, WRUEP = Work-Related Upper Extremity Pain. 


\section{CRPS-I}

Complex Regional Pain Syndrome Type I (CRPS-I) is an intriguing clinical manifestation of chronic pain. CRPS-I is characterized by severe pain that is disproportionate to the inciting event (Mersky \& Bogduk, 1994), localized in a distal part of an extremity and accompanied by abnormal swelling, changes in skin-color and temperature, as well as in sweating patterns that deviate from normal. Different sets of criteria are proposed; the criteria from the International Association for the Study of Pain (IASP) that we use in the studies presented in this thesis have a high sensitivity, but are criticized for false positive diagnoses (Harden et al., 2010). Since 2012, both signs (observable) and symptoms (reported by the patient) are required to diagnose CRPS-I according to the Budapest-criteria (Harden et al., 2010).

\section{IASP criteria:}

1. The presence of an initiating noxious event or a cause of immobilization.

2. Continuing pain, allodynia, or hyperalgesia with which the pain is disproportionate to any inciting event.

3. Evidence at some time of edema, changes in skin blood flow, or abnormal sudomotor activity in the region of pain.

4. This diagnosis is excluded by the existence of conditions that would otherwise account for the degree of pain and dysfunction.

\section{Budapest criteria:}

1. Continuing pain, which is disproportionate to any inciting event.

2. Must report at least one symptom in three of the four following categories:

a. Sensory: reports of hyperesthesia and/or allodynia

b. Vasomotor: reports of temperature asymmetry and/or skin color changes and/or skin color asymmetry

c. Sudomotor/edema: reports of edema and/or sweating changes and/or sweating asymmetry

d. Motor/trophic: reports of decreased range of motion and/or motor dysfunction (weakness, tremor, dystonia) and/or trophic changes (hair, nail, skin) 
3. Must display at least one sign at time of evaluation in two or more of the following categories:

a. Sensory: evidence of hyperalgesia (to pinprick) and/or allodynia (to light touch and/ or deep somatic pressure and/or joint movement)

b. Vasomotor: evidence of temperature asymmetry and/or skin color changes and/or asymmetry

c. Sudomotor/edema: evidence of edema and/or sweating changes and/or sweating asymmetry

d. Motor/trophic: evidence of decreased range of motion and/or motor dysfunction (weakness, tremor, dystonia) and/or trophic changes (hair, nail, skin)

4. There is no other diagnosis that better explains the signs and symptoms.

The pathophysiology of CRPS-I is still unknown. Extensive research on CRPS-I in the last decade has shed some light on possible mechanisms, but the evidence is still inconclusive. CRPS is hypothesized to emerge from central (sympathetic dysfunction) and peripheral (neurogenic inflammation, hypoxia) nervous system pathology and psychological factors should also be considered (de Mos, Sturkenboom, \& Huygen, 2009; Marinus et al., 2011). CRPS Type II refers to a comparable clinical manifestation, but in type II there is some degree of nerve-damage detectable, whereas in type I no such damage is present. CRPS-I has an incidence of 40.4 per 100.000 person years at risk for females and 11.9 for males (de Mos et al., 2007b).

Years after onset, patients still experience CRPS-I related pain and disability (Vaneker, Wilder-Smith, Schrombges, \& Oerlemans, 2006). The majority of patients with CRPS-I experiences problems with performing activities related to self-care, household, work and leisure. The percentage of patients that reports to be disabled due to CRPS complaints ranges from 62\% (Geertzen, de Bruijn-Kofman, de Bruijn, van de Wiel, \& Dijkstra, 1998) to even 96\% (Sharma, Agarwal, Broatch, \& Raja, 2009). These disability rates are corroborated by extremely low return to work rates that have been found in CRPS-I, ranging from one out of five that completely returns to work (Harden, 2005), to $31 \%$ being completely incapable to work and another $28 \%$ only being able to work with adjustments (de Mos et al., 2007a), indicating that CRPS-I not only leads to extensive suffering, but also results in high costs for society.

\section{Current treatment of CRPS-I}

Since the pathophysiology of CRPS-I remains unclear; there is no gold standard for treatment. CRPS-I is treated following national and international guidelines, consisting of a variety of mainly medical treatments. Despite different interventions, 
$16 \%$ of patients report their CRPS-I as severely progressive over time (de Mos et al., 2009). To illustrate the severe consequences of pain in CRPS-I: some patients experience a pain so extreme that they finally opt for amputation of the limb (Bodde, Dijkstra, den Dunnen, \& Geertzen, 2011; Bodde et al., 2014). A recent Cochrane review (O'Connell, Wand, McAuley, Marston, \& Moseley, 2013) concluded that some effective medical treatments have been reported, but these are often invasive and might have adverse effects. All these treatments are primarily focused on pain reduction; positive effects on disability are rarely found.

Besides medical treatment, guidelines recommend physical therapy to aim at functional recovery (Nelson, 2002). Nevertheless, a standardized physical therapy treatment was found to be effective in reducing pain and CRPS-I signs and symptoms, but not in reducing disability, compared to occupational therapy and a social work control group (Oerlemans, Oostendorp, de Boo, \& Goris, 1999; Oerlemans, Oostendorp, et al., 2000; Severens et al., 1999). Recently, graded motor imagery has been reported to have a positive effect on disability (O'Connell et al., 2013), but this treatment focuses on decreasing pain and CRPS-I signs and symptoms (Bowering et al., 2013), not specifically on reducing disability in daily life functioning.

\section{Exposure in vivo in CRPS-I}

It might be stated that when pain-experiences in CRPS-I are not or no longer associated with biomedical abnormalities it is actually "safe" to perform all kind of activities, despite the pain-experience. Since one of the possible explanations for the persistence of signs and symptoms in CRPS-I is disuse (Frölke, van Dongen, \& van de Meent, 2015; Terkelsen, Bach, \& Jensen, 2008), it is not only safe, but highly recommended to use the affected limb. For CRPS-I patients, irrational thoughts and subsequent fear might be important motivators for avoidance. Patients might believe that when pain or swelling increases after using the limb, it is unwise to do so. Therefore, it is worthwhile to assess underlying motives for avoiding activities, as well as for performing activities in an adapted way to detect safety behaviors. Since, when fear is involved in the maintenance of disability in CRPS-I as it is in other 
chronic pain syndromes, it might be worthwhile to assess if a reduction of painrelated fear could reduce CRPS-I-related disability as well. It was found that painrelated fear, measured with the PHODA in the perceived harmfulness of activities, contributes to functional limitations in patients with chronic CRPS-I (de Jong et al., 2011). Therefore, a repeated single-case experimental design with 8 participants was conducted and showed that exposure indeed was effective in reducing disability, pain-related fear, pain intensity, as well as self-reported CRPS-I signs and symptoms (de Jong et al., 2005a).

\section{Unresolved issues}

The positive results of the aforementioned study in CRPS-I (de Jong et al., 2005a) warrant replication. We wanted not only to replicate these findings, but we were also interested in the generalization of activities performed during extinction to activities not addressed during EXP. Earlier research showed that generalization of fearextinction is not self-evident (Crombez et al., 2002; Goubert et al., 2005; Goubert et al., 2002), and only one study showed successful generalization of pain-expectancy corrections (Trost et al., 2008). The generalization of exposure in pain-related fear has never been studied in a clinical setting over the course of treatment. Would performance of many activities, or the repetition of the same activities in different contexts, facilitate generalization to a new threatening movement?

Replication of the results of exposure in vivo is warranted in a group randomized controlled trial with systematic application of the treatment protocol of exposure in vivo. A group RCT has the advantage that it also can shed light on long-term differential effects. Comparing exposure in vivo with a control treatment will help to evaluate which treatment is more effective in reducing disability and other measures, such as pain intensity, pain-related fear and health-related quality of life. When a RCT would confirm that exposure is effective in reducing CRPS-I related disability, clinical implementation of exposure in vivo is warranted from a patient perspective.

Where research shows that exposure is cost-effective in chronic low back pain (Goossens et al., 2015), in other diagnoses such as CRPS-I, cost-effectiveness of this treatment has not been studied yet. Is exposure in vivo cost-effective in CRPS-I patients with pain-related fear? When a cost-effectiveness study would show that exposure in vivo is good value for money, implementation is also warranted from a health-care and societal perspective.

As mentioned earlier, pain-related fear may be acquired via verbal transmission. Information retrieved on the internet as well as information received from health-care professionals may contribute to pain-related fear. Therefore we were 
interested whether it is possible to manipulate the threat-value of pain in healthy, pain-free individuals, by manipulation of verbal and visual information about pain and harm. Differences in information given reflect the potential damaging effect of the pain stimulus. We were interested in how the manipulation of the threat-value of pain would influence not only the acquisition, but also the extinction and return of pain-related fear (a single presentation of the US after extinction: i.e. a reinstatement procedure) in an experimental setting.

\section{Outline of this thesis}

The current chapter has shown some remaining issues in our understanding of painrelated fear that warrant further research. Summarizing, this thesis aims to answer the following questions:

1. How can we understand the acquisition and extinction of pain-related fear from a learning theory perspective?

2. Does verbal and visual manipulation of threat influence acquisition, extinction and return of fear in pain-free individuals?

3. Is generalization of exposure in vivo treatment facilitated when many different activities are performed or when a few activities are repeated several times?

4. Is exposure in vivo an effective treatment in reducing disability as primary outcome, but also in reducing pain-related fear and pain intensity, as well as in improving quality of life in patients with Complex Regional Pain Syndrome Type 1 and pain-related fear?

5. Is exposure in vivo cost-effective in CRPS-I patients with pain-related fear, compared to pain-contingent physical therapy?

These research questions are addressed in the subsequent chapters. In chapter II, a narrative review of the literature on fear conditioning and extinction specifically applied to pain-related fear will be presented (Question 1). The mechanisms underlying the acquisition of pain-related fear, and its extinction through cognitive-behavioral treatment will be discussed. Chapter III concerns an experimental study on the influence of threatening information on the acquisition, extinction, and return of fear after reinstatement in healthy subjects (Question 2). Chapter IV describes a treatment outcome study with a repeated single case experimental design in 8 patients with CRPS-I. The aim of this study was twofold: to replicate previous findings (de Jong et al., 2005a) that exposure in vivo is a viable treatment for CRPS-I, and to test the generalizability of two different ways of delivering exposure in patients with CRPS-I: maximizing variation in stimuli, or repeated stimuli in various contexts (Question 3). 
In Chapter V, a randomized controlled trial on the effectiveness of exposure versus treatment as usual (pain-contingent physical therapy) on disability is presented. The trial was conducted in patients suffering from Complex Regional Pain Syndrome type I, who had at least moderate levels of pain-related fear (Question 4). Chapter VI concerns the economic evaluation of exposure versus treatment as usual in patients with CRPS-I (Question 5). Patients participating in the RCT completed cost-diaries before, during and after treatment, providing data about their health-care costs, productivity losses and personal as well as family costs. In a full economic analysis, the costs of exposure and treatment as usual were compared. In the final Chapter VII, the findings of the different chapters will be discussed and placed in the light of the extant literature. Furthermore, theoretical and clinical implications and recommendations for future research will be considered. 


\section{References}

Arntz, A., \& Claassens, L. (2004). The meaning of pain influences its experienced intensity. Pain, 109(12), 20-25. doi: 10.1016/j.pain.2003.12.030

Bailey, K. M., Carleton, R. N., Vlaeyen, J. W., \& Asmundson, G. J. (2010). Treatments addressing painrelated fear and anxiety in patients with chronic musculoskeletal pain: a preliminary review. Cogn Behav Ther, 39(1), 46-63. doi: 10.1080/16506070902980711

Bair, M. J., Robinson, R. L., Katon, W., \& Kroenke, K. (2003). Depression and pain comorbidity: a literature review. Arch Intern Med, 163(20), 2433-2445. doi: 10.1001/archinte.163.20.2433

Beurskens, A. J., de Vet, H. C., \& Köke, A. J. (1996). Responsiveness of functional status in low back pain: a comparison of different instruments. Pain, 65(1), 71-76

Bodde, M. I., Dijkstra, P. U., den Dunnen, W. F., \& Geertzen, J. H. (2011). Therapy-resistant complex regional pain syndrome type I: to amputate or not? J Bone Joint Surg Am, 93(19), 1799-1805. doi: $10.2106 /$ jbjs.j. 01329

Bodde, M. I., Dijkstra, P. U., Schrier, E., van den Dungen, J. J., den Dunnen, W. F., \& Geertzen, J. H. (2014). Informed Decision-Making Regarding Amputation for Complex Regional Pain Syndrome Type I. J Bone Joint Surg Am, 96(11), 930-934. doi: 10.2106/jbjs.m.00788

Bouton, M. E., \& King, D. A. (1983). Contextual control of the extinction of conditioned fear: tests for the associative value of the context. J Exp Psychol Anim Behav Process, 9(3), 248-265

Bowering, K. J., O'Connell, N. E., Tabor, A., Catley, M. J., Leake, H. B., Moseley, G. L., \& Stanton, T. R. (2013). The effects of graded motor imagery and its components on chronic pain: a systematic review and meta-analysis. J Pain, 14(1), 3-13. doi: 10.1016/j.jpain.2012.09.007

Craske, M., Kircanski, K., Zelikowsky, M., Mystkowski, J., Chowdhury, N., \& Baker, A. (2008). Optimizing inhibitory learning during exposure therapy. Behav Res Ther, 46(1), 5-27. doi: 10.1016/j.brat.2007.10.003

Crombez, G., Eccleston, C., Vlaeyen, J. W., Vansteenwegen, D., Lysens, R., \& Eelen, P. (2002). Exposure to physical movements in low back pain patients: restricted effects of generalization. Health Psychol, 21(6), 573-578

Crombez, G., Van Damme, S., \& Eccleston, C. (2005). Hypervigilance to pain: an experimental and clinical analysis. Pain, 116(1-2), 4-7. doi: 10.1016/j.pain.2005.03.035

de Jong, J. R., Vangronsveld, K., Peters, M. L., Goossens, M. E., Onghena, P., Bulte, I., \& Vlaeyen, J. W. (2008). Reduction of pain-related fear and disability in post-traumatic neck pain: a replicated single-case experimental study of exposure in vivo. J Pain, 9(12), 1123-1134. doi: 10.1016/j.jpain.2008.06.015

de Jong, J. R., Vlaeyen, J. W., de Gelder, J. M., \& Patijn, J. (2011). Pain-related fear, perceived harmfulness of activities, and functional limitations in complex regional pain syndrome type I. J Pain, 12(12), 1209-1218. doi: 10.1016/j.jpain.2011.06.010

de Jong, J. R., Vlaeyen, J. W., Onghena, P., Cuypers, C., den Hollander, M., \& Ruijgrok, J. (2005a). Reduction of pain-related fear in complex regional pain syndrome type I: the application of graded exposure in vivo. Pain, 116(3), 264-275. doi: 10.1016/j.pain.2005.04.019 
de Jong, J. R., Vlaeyen, J. W., Onghena, P., Goossens, M. E., Geilen, M., \& Mulder, H. (2005b). Fear of movement/(re)injury in chronic low back pain: education or exposure in vivo as mediator to fear reduction? Clin J Pain, 21(1), 9-17; discussion 69-72

de Jong, J. R., Vlaeyen, J. W., van Eijsden, M., Loo, C., \& Onghena, P. (2012). Reduction of pain-related fear and increased function and participation in work-related upper extremity pain (WRUEP): effects of exposure in vivo. Pain, 153(10), 2109-2118. doi: 10.1016/j.pain.2012.07.001

de Mos, M., de Bruijn, A. G. J., Huygen, F. J. P. M., Dieleman, J. P., Stricker, B. H. C., \& Sturkenboom, M. C. J. M. (2007a). The incidence of complex regional pain syndrome: A population-based study. Pain, 129(1-2), 12-20. doi: http://dx.doi.org/10.1016/j.pain.2006.09.008

de Mos, M., de Bruijn, A. G. J., Huygen, F. J. P. M., Dieleman, J. P., Stricker, C. B. H., \& Sturkenboom, M. C. J. M. (2007b). The incidence of complex regional pain syndrome: a population-based study. Pain, 129(1-2), 12-20. doi: 10.1016/j.pain.2006.09.008

de Mos, M., Sturkenboom, M. C., \& Huygen, F. J. (2009). Current understandings on complex regional pain syndrome. Pain Pract, 9(2), 86-99. doi: 10.1111/j.1533-2500.2009.00262.x

Dirikx, T., Hermans, D., Vansteenwegen, D., Baeyens, F., \& Eelen, P. (2004). Reinstatement of extinguished conditioned responses and negative stimulus valence as a pathway to return of fear in humans. Learn Mem, 11(5), 549-554. doi: 10.1101/Im.78004

Drummond, R. P., \& Rose, G. K. (1975). A twenty-one-year review of a case of congenital indifference to pain. J Bone Joint Surg Br, 57(2), 241-243

Dunsmoor, J. E., \& Paz, R. (2015). Fear Generalization and Anxiety: Behavioral and Neural Mechanisms. Biol Psychiatry, 78(5), 336-343. doi: 10.1016/j.biopsych.2015.04.010

Engel, G. L. (1980). The clinical application of the biopsychosocial model. Am J Psychiatry, 137(5), 535-544. doi: 10.1176/ajp.137.5.535

Flor, H. (2014). Physiological, behavioral and verbal aspects of operant conditioning in chronic pain: A tribute to Wilbert E. Fordyce. In C. Main, F. Keefe, M. B. Jensen, J. W. S. Vlaeyen \& K. Vowles (Eds.), Fordyce's Behavioral Methods for chronic Pain and Illness republished with invited commentaries (pp. 120-130). Philadelphia: IASP and Wolters-Kluwer

Fordyce, W. E. (1976). Behavioral methods for chronic pain and illness. St Louis, MO: C. V. Moseby

Fortin, M., Gibbons, L. E., Videman, T., \& Battie, M. C. (2015). Do variations in paraspinal muscle morphology and composition predict low back pain in men? Scand J Med Sci Sports, 25(6), 880-887. doi: 10.1111/sms.12301

Frölke, J. P., van Dongen, R. T., \& van de Meent, H. (2015). [Complex regional pain syndrome type 1: negating the myth]. Ned Tijdschr Geneeskd, 159, A8370

Gangemi, A., Mancini, F., \& van den Hout, M. (2012). Behavior as information: "If I avoid, then there must be a danger". J Behav Ther Exp Psychiatry, 43(4), 1032-1038. doi: 10.1016/j.jbtep.2012.04.005

Gatzounis, R., Schrooten, M. G., Crombez, G., \& Vlaeyen, J. W. (2012). Operant learning theory in pain and chronic pain rehabilitation. Curr Pain Headache Rep, 16(2), 117-126. doi: 10.1007/s11916-012-0247-1 
Geertzen, J. H., de Bruijn-Kofman, A. T., de Bruijn, H. P., van de Wiel, H. B., \& Dijkstra, P. U. (1998). Stressful life events and psychological dysfunction in Complex Regional Pain Syndrome type I. Clin J Pain, 14(2), 143-147

Giummarra, M. J., \& Moseley, G. L. (2011). Phantom limb pain and bodily awareness: current concepts and future directions. Curr Opin Anaesthesiol, 24(5), 524-531. doi: 10.1097/ACO.0b013e32834a105f

Goossens, M. E., de Kinderen, R. J., Leeuw, M., de Jong, J. R., Ruijgrok, J., Evers, S. M., \& Vlaeyen, J. W. (2015). Is exposure in vivo cost-effective for chronic low back pain? A trial-based economic evaluation. BMC Health Serv Res, 15, 549. doi: 10.1186/s12913-015-1212-6

Goubert, L., Crombez, G., \& Lysens, R. (2005). Effects of varied-stimulus exposure on overpredictions of pain and behavioral performance in low back pain patients. Behav Res Ther, 43(10), 1347-1361. doi: 10.1016/j.brat.2004.10.006

Goubert, L., Francken, G., Crombez, G., Vansteenwegen, D., \& Lysens, R. (2002). Exposure to physical movement in chronic back pain patients: no evidence for generalization across different movements. Behav Res Ther, 40(4), 415-429

Harden, R. N. (2005). The rationale for integrated functional restoration. In P. R. Wilson, M. StantonHicks \& R. N. Harden (Eds.), CRPS: Current Diagnosis and Treatment (Vol. 32, pp. 163-171). Seattle: IASP Press

Harden, R. N., Bruehl, S., Perez, R. S., Birklein, F., Marinus, J., Maihofner, C., .. Vatine, J. J. (2010). Validation of proposed diagnostic criteria (the "Budapest Criteria") for Complex Regional Pain Syndrome. Pain, 150(2), 268-274. doi: 10.1016/j.pain.2010.04.030

Harvie, D. S., Moseley, G. L., Hillier, S. L., \& Meulders, A. (2017). Classical Conditioning Differences Associated With Chronic Pain: A Systematic Review. J Pain, 18(8), 889-898. doi: 10.1016/j. jpain.2017.02.430

Helsen, K., Goubert, L., Peters, M. L., \& Vlaeyen, J. W. (2011). Observational learning and pain-related fear: an experimental study with colored cold pressor tasks. J Pain, 12(12), 1230-1239. doi: 10.1016/j. jpain.2011.07.002

Hermans, D., Dirikx, T., Vansteenwegen, D., Baeyens, F., Van den Bergh, O., \& Eelen, P. (2005). Reinstatement of fear responses in human aversive conditioning. Behav Res Ther, 43(4), 533-551. doi: 10.1016/j.brat.2004.03.013

Jensen, M. C., Brant-Zawadzki, M. N., Obuchowski, N., Modic, M. T., Malkasian, D., \& Ross, J. S. (1994). Magnetic resonance imaging of the lumbar spine in people without back pain. N Engl J Med, 331(2), 69-73. doi: 10.1056/nejm199407143310201

Jolliffe, C. D., \& Nicholas, M. K. (2004). Verbally reinforcing pain reports: an experimental test of the operant model of chronic pain. Pain, 107(1-2), 167-175

Kunz, M., Rainville, P., \& Lautenbacher, S. (2011). Operant conditioning of facial displays of pain. Psychosom Med, 73(5), 422-431. doi: 10.1097/PSY.0b013e318218db3e

LeDoux, J. E., Moscarello, J., Sears, R., \& Campese, V. (2017). The birth, death and resurrection of avoidance: a reconceptualization of a troubled paradigm. Mol Psychiatry, 22(1), 24-36. doi: 10.1038/ mp.2016.166 
Leeuw, M., Goossens, M. E., Linton, S. J., Crombez, G., Boersma, K., \& Vlaeyen, J. W. (2007a). The fearavoidance model of musculoskeletal pain: current state of scientific evidence. J Behav Med, 30(1), 77-94. doi: 10.1007/s10865-006-9085-0

Leeuw, M., Goossens, M. E., van Breukelen, G. J., Boersma, K., \& Vlaeyen, J. W. (2007b). Measuring perceived harmfulness of physical activities in patients with chronic low back pain: the Photograph Series of Daily Activities-short electronic version. J Pain, 8(11), 840-849. doi: 10.1016/j.jpain.2007.05.013

Leeuw, M., Goossens, M. E., van Breukelen, G. J., de Jong, J. R., Heuts, P. H., Smeets, R. J., . . Vlaeyen, J. W. (2008). Exposure in vivo versus operant graded activity in chronic low back pain patients: results of a randomized controlled trial. Pain, 138(1), 192-207. doi: 10.1016/j.pain.2007.12.009

Lethem, J., Slade, P. D., Troup, J. D., \& Bentley, G. (1983). Outline of a Fear-Avoidance Model of exaggerated pain perception-I. Behav Res Ther, 21(4), 401-408

Linton, S. J., Boersma, K., Jansson, M., Overmeer, T., Lindblom, K., \& Vlaeyen, J. W. (2008). A randomized controlled trial of exposure in vivo for patients with spinal pain reporting fear of work-related activities. Eur J Pain, 12(6), 722-730. doi: 10.1016/j.ejpain.2007.11.001

Linton, S. J., \& Hallden, K. (1998). Can we screen for problematic back pain? A screening questionnaire for predicting outcome in acute and subacute back pain. Clin J Pain, 14(3), 209-215

Lissek, S., Biggs, A. L., Rabin, S. J., Cornwell, B. R., Alvarez, R. P., Pine, D. S., \& Grillon, C. (2008). Generalization of conditioned fear-potentiated startle in humans: experimental validation and clinical relevance. Behav Res Ther, 46(5), 678-687. doi: 10.1016/j.brat.2008.02.005

Lissek, S., Powers, A. S., McClure, E. B., Phelps, E. A., Woldehawariat, G., Grillon, C., \& Pine, D. S. (2005). Classical fear conditioning in the anxiety disorders: a meta-analysis. Behav Res Ther, 43(11), 13911424. doi: 10.1016/j.brat.2004.10.007

Lissek, S., Rabin, S., Heller, R. E., Lukenbaugh, D., Geraci, M., Pine, D. S., \& Grillon, C. (2010). Overgeneralization of conditioned fear as a pathogenic marker of panic disorder. Am J Psychiatry, 167(1), 47-55. doi: 10.1176/appi.ajp.2009.09030410

Loggia, M. L., Mogil, J. S., \& Bushnell, M. C. (2008). Experimentally induced mood changes preferentially affect pain unpleasantness. J Pain, 9(9), 784-791. doi: 10.1016/j.jpain.2008.03.014

Marinus, J., Moseley, G. L., Birklein, F., Baron, R., Maihofner, C., Kingery, W. S., \& van Hilten, J. J. (2011). Clinical features and pathophysiology of complex regional pain syndrome. Lancet Neurol, 10(7), 637-648. doi: 10.1016/s1474-4422(11)70106-5

McCracken, L. M., Zayfert, C., \& Gross, R. T. (1992). The Pain Anxiety Symptoms Scale: development and validation of a scale to measure fear of pain. Pain, 50(1), 67-73

Melzack, R., \& Wall, P. D. (1965). Pain Mechanisms: A new theory. Science, 150, 971-979

Mersky, H., \& Bogduk, N. (Eds.). (1994). Classification of chronic pain: descriptions of chronic pain syndromes and definitions of pain terms (2 ed.). Seattle, WA: IASP Press

Meulders, A., Meulders, M., Stouten, I., De Bie, J., \& Vlaeyen, J. W. (2017). Extinction of Fear Generalization: A Comparison Between Fibromyalgia Patients and Healthy Control Participants. J Pain, 18(1), 79-95. doi: 10.1016/j.jpain.2016.10.004 
Meulders, A., Vandebroek, N., Vervliet, B., \& Vlaeyen, J. W. (2013). Generalization gradients in cued and contextual pain-related fear: an experimental study in healthy participants. Front Hum Neurosci, 7, 345. doi: 10.3389/fnhum.2013.00345

Meulders, A., Vansteenwegen, D., \& Vlaeyen, J. W. (2011). The acquisition of fear of movement-related pain and associative learning: a novel pain-relevant human fear conditioning paradigm. Pain, 152(11), 2460-2469. doi: 10.1016/j.pain.2011.05.015

Meulders, A., \& Vlaeyen, J. W. (2012). Reduction of fear of movement-related pain and pain-related anxiety: An associative learning approach using a voluntary movement paradigm. Pain, 153(7), 1504-1513. doi: 10.1016/j.pain.2012.04.013

Meulders, A., \& Vlaeyen, J. W. (2013). Mere intention to perform painful movements elicits fear of movement-related pain: an experimental study on fear acquisition beyond actual movements. J Pain, 14(4), 412-423. doi: 10.1016/j.jpain.2012.12.014

Miller, R. P., Kori, S. H., \& Todd, D. D. (1991). The Tampa Scale

Nagasako, E. M., Oaklander, A. L., \& Dworkin, R. H. (2003). Congenital insensitivity to pain: an update. Pain, 101(3), 213-219

Nederhand, M. J., Hermens, H. J., IJzerman, M. J., Groothuis, K. G. M., \& Turk, D. C. (2006). The Effect of Fear of Movement on Muscle Activation in Posttraumatic Neck Pain Disability. Clin J Pain, 22(6), 519-525

Nelson, D. (Ed.). (2002). Treating patients with complex regional pain syndrome (2 ed.). New York: Guilford

O'Connell, N. E., Wand, B. M., McAuley, J., Marston, L., \& Moseley, G. L. (2013). Interventions for treating pain and disability in adults with complex regional pain syndrome. Cochrane Database Syst Rev(4), CD009416. doi: 10.1002/14651858.CD009416.pub2

Oerlemans, H. M., Cup, E. H., DeBoo, T., Goris, R. J., \& Oostendorp, R. A. (2000). The Radboud skills questionnaire: construction and reliability in patients with reflex sympathetic dystrophy of one upper extremity. Disabil Rehabil, 22(5), 233-245

Oerlemans, H. M., Oostendorp, R. A., de Boo, T., \& Goris, R. J. (1999). Pain and reduced mobility in complex regional pain syndrome I: outcome of a prospective randomised controlled clinical trial of adjuvant physical therapy versus occupational therapy. Pain, 83(1), 77-83

Oerlemans, H. M., Oostendorp, R. A., de Boo, T., van der Laan, L., Severens, J. L., \& Goris, J. A. (2000). Adjuvant physical therapy versus occupational therapy in patients with reflex sympathetic dystrophy/complex regional pain syndrome type I. Arch Phys Med Rehabil, 81(1), 49-56

Olsson, A., \& Phelps, E. A. (2004). Learned fear of “unseen" faces after Pavlovian, observational, and instructed fear. Psychol Sci, 15(12), 822-828. doi: 10.1111/j.0956-7976.2004.00762.x

Philips, H. C. (1987). Avoidance behavior and its role in sustaining chronic pain. Behav Res Ther, 25(4), 273-279

Pittig, A., Schulz, A. R., Craske, M. G., \& Alpers, G. W. (2014). Acquisition of behavioral avoidance: taskirrelevant conditioned stimuli trigger costly decisions. J Abnorm Psychol, 123(2), 314-329. doi: $10.1037 / \mathrm{a} 0036136$ 
Rainville, P., Bao, Q. V., \& Chretien, P. (2005). Pain-related emotions modulate experimental pain perception and autonomic responses. Pain, 118(3), 306-318. doi: 10.1016/j.pain.2005.08.022

Roelofs, J., Peters, M. L., Deutz, J., Spijker, C., \& Vlaeyen, J. W. (2005). The Fear of Pain Questionnaire (FPQ): further psychometric examination in a non-clinical sample. Pain, 116(3), 339-346. doi: 10.1016/j.pain.2005.05.003

Roland, M., \& Morris, R. (1983). A study of the natural history of back pain. Part I: development of a reliable and sensitive measure of disability in low-back pain. Spine (Phila Pa 1976), 8(2), 141-144

Roy, M., Peretz, I., \& Rainville, P. (2008). Emotional valence contributes to music-induced analgesia. Pain, 134(1-2), 140-147. doi: 10.1016/j.pain.2007.04.003

Severens, J. L., Oerlemans, H. M., Weegels, A. J., van 't Hof, M. A., Oostendorp, R. A., \& Goris, R. J. (1999). Cost-effectiveness analysis of adjuvant physical or occupational therapy for patients with reflex sympathetic dystrophy. Arch Phys Med Rehabil, 80(9), 1038-1043

Sharma, A., Agarwal, S., Broatch, J., \& Raja, S. N. (2009). A web-based cross-sectional epidemiological survey of complex regional pain syndrome. Reg Anesth Pain Med, 34(2), 110-115. doi: 10.1097/ AAP.0b013e3181958f90

Slade, P. D., Troup, J. D., Lethem, J., \& Bentley, G. (1983). The Fear-Avoidance Model of exaggerated pain perception-II. Behav Res Ther, 21(4), 409-416

Sullivan, M. J. L., Bishop, S. R., \& Pivik, J. (1995). The Pain Catastrophizing Scale: Development and validation. Psychological Assessment, 7(4), 524-532

Tang, N. K., Salkovskis, P. M., Hodges, A., Wright, K. J., Hanna, M., \& Hester, J. (2008). Effects of mood on pain responses and pain tolerance: an experimental study in chronic back pain patients. Pain, 138(2), 392-401. doi: 10.1016/j.pain.2008.01.018

Terkelsen, A. J., Bach, F. W., \& Jensen, T. S. (2008). Experimental forearm immobilization in humans induces cold and mechanical hyperalgesia. Anesthesiology, 109(2), 297-307. doi: 10.1097/ ALN.0b013e31817f4c9d

Trost, Z., France, C. R., \& Thomas, J. S. (2008). Exposure to movement in chronic back pain: evidence of successful generalization across a reaching task. Pain, 137(1), 26-33. doi: 10.1016/j.pain.2007.08.005

Turk, D. C., \& Okifuji, A. (2001). Pain terms and taxonomies. In J. D. Loeser, S. H. Butler, C. R. Chapman \& D. C. Turk (Eds.), Bonica's management of pain (3 ed., pp. 18-25). New York: Lippincott Williams \& Wilkins

Vaneker, M., Wilder-Smith, O. H., Schrombges, P., \& Oerlemans, H. M. (2006). Impairments as measured by ISS do not greatly change between one and eight years after CRPS 1 diagnosis. Eur J Pain, 10(7), 639-644. doi: 10.1016/j.ejpain.2005.10.003

Verbunt, J. A., \& Smeets, R. J. E. M. (2016). Graded Exposure. Houten: Bohn Stafleu van Loghum Vernon, H., \& Mior, S. (1991). The Neck Disability Index: a study of reliability and validity. J Manipulative Physiol Ther, 14(7), 409-415

Vervliet, B., Baeyens, F., Van den Bergh, O., \& Hermans, D. (2013). Extinction, generalization, and return of fear: a critical review of renewal research in humans. Biol Psychol, 92(1), 51-58. doi: 10.1016/j. biopsycho.2012.01.006 
Vervliet, B., Kindt, M., Vansteenwegen, D., \& Hermans, D. (2010). Fear generalization in humans: impact of verbal instructions. Behav Res Ther, 48(1), 38-43. doi: 10.1016/j.brat.2009.09.005

Vlaeyen, J. W. (2015). Learning to predict and control harmful events: chronic pain and conditioning. Pain, 156 Supplement 1:S86-S93

Vlaeyen, J. W., Crombez, G., \& Linton, S. J. (2016). The fear-avoidance model of pain. Pain, 157(8), 15881589. doi: $10.1097 /$ j.pain.0000000000000574

Vlaeyen, J. W., de Jong, J., Geilen, M., Heuts, P. H., \& van Breukelen, G. (2001). Graded exposure in vivo in the treatment of pain-related fear: a replicated single-case experimental design in four patients with chronic low back pain. Behav Res Ther, 39(2), 151-166

Vlaeyen, J. W., de Jong, J. R., Geilen, M., Heuts, P. H., \& van Breukelen, G. (2002). The treatment of fear of movement/(re)injury in chronic low back pain: further evidence on the effectiveness of exposure in vivo. Clin J Pain, 18(4), 251-261

Vlaeyen, J. W., de Jong, J. R., Onghena, P., Kerckhoffs-Hanssen, M., \& Kole-Snijders, A. M. (2002). Can pain-related fear be reduced? The application of cognitive-behavioral exposure in vivo. Pain Res Manag, 7(3), 144-153

Vlaeyen, J. W., de Jong, J. R., Sieben, J. M., \& Crombez, G. (2002). Graded Exposure in Vivo for Painrelated Fear. Psychological approaches to pain management. A practitioner's handbook. New York: Guilford Press

Vlaeyen, J. W., \& Linton, S. J. (2000). Fear-avoidance and its consequences in chronic musculoskeletal pain: a state of the art. Pain, 85(3), 317-332

Vlaeyen, J. W., \& Linton, S. J. (2012). Fear-avoidance model of chronic musculoskeletal pain: 12 years on. Pain, 153(6), 1144-1147

Vlaeyen, J. W., Morley, S., Linton, S. J., Boersma, K., \& de Jong, J. R. (2012). Pain-Related Fear: ExposureBased Treatment for Chronic Pain: IASP Press

Volders, S., Boddez, Y., De Peuter, S., Meulders, A., \& Vlaeyen, J. W. (2015). Avoidance behavior in chronic pain research: a cold case revisited. Behav Res Ther, 64, 31-37. doi: 10.1016/j.brat.2014.11.003

Waddell, G. (2004). The biopsychosocial model. In G. Waddell (Ed.), The Back Pain Revolution (pp. 265-282). Edinburgh: Churchill Livingston

Waddell, G., Newton, M., Henderson, I., Somerville, D., \& Main, C. J. (1993). A Fear-Avoidance Beliefs Questionnaire (FABQ) and the role of fear-avoidance beliefs in chronic low back pain and disability. Pain, 52(2), 157-168

Wall, P. D. (1979). On the relation of injury to pain the John J. Bonica Lecture. Pain, 6(3), 253-264

Wiech, K., Lin, C. S., Brodersen, K. H., Bingel, U., Ploner, M., \& Tracey, I. (2010). Anterior insula integrates information about salience into perceptual decisions about pain. J Neurosci, 30(48), 16324-16331. doi: 10.1523/jneurosci.2087-10.2010

Wilmink, J., \& Patijn, J. (2001). MR imaging of alar ligament in whiplash-associated disorders: an observer study. Neuroradiology, 43(10), 859-863 
Woods, M. P., \& Asmundson, G. J. G. (2008). Evaluating the efficacy of graded in vivo exposure for the treatment of fear in patients with chronic back pain: A randomized controlled clinical trial. Pain, 136(3), 271-280

Zale, E. L., Lange, K. L., Fields, S. A., \& Ditre, J. W. (2013). The relation between pain-related fear and disability: a meta-analysis. J Pain, 14(10), 1019-1030. doi: 10.1016/j.jpain.2013.05.005 


\section{Chapter 2}

Fear reduction in patients with chronic pain: a learning theory

perspective

Published as: den Hollander, M., de Jong, J.R., Volders, S., Goossens, M.E.J.B., Smeets, R.J.E.M. \& Vlaeyen, J.W.S. (2010). Fear reduction in patients with chronic pain: a learning theory perspective.

Expert Review of Neurotherapeutics, 10, 1733-45. 


\section{Abstract}

Acute pain informs the individual that there is imminent threat of body damage, and is associated with the urge to escape and avoid. Fear learning takes place when neutral stimuli receive the propensity to predict the occurrence of pain, and when defensive responses are initiated in anticipation to potential threat to the integrity of the body. Fear-avoidance models have been put forward featuring the role of individual differences in catastrophic interpretations of pain in the modulation of learning and avoidance. Based on extensive literature on fear reduction in anxiety disorders, cognitive-behavioral treatments have been developed and applied to patients with chronic pain reporting substantial pain-related fear. In this review, we discuss mechanisms underlying the acquisition, the assessment, and extinction of pain-related fear through the cognitive-behavioral treatment of pain-related fear. Finally, we provide a number of critical notes and directions for future research in the field of chronic pain and pain-related fear. 


\section{Fear and avoidance in chronic pain}

Chronic pain is defined as "pain that extends beyond the expected period of healing" (Turk \& Okifuji, 2001). In a large pan-European survey, $19 \%$ of the population was found to suffer from chronic pain of moderate to severe intensity, with serious effect on the quality of their social and working lives. The reported pain was mainly of musculoskeletal origin, but headaches were also included (Breivik, Collett, Ventafridda, Cohen, \& Gallacher, 2006). Chronic pain patients are at increased risk for the development of psychiatric conditions; 12,5 to $16,6 \%$ of the population in developed and developing countries meets DSM-criteria for anxiety disorders and depression (Tsang et al., 2008), and an even larger part reports complaints in the anxiety and depression spectrum (Nelson \& Novy, 1997). Besides the individual burden, chronic pain accounts for high socioeconomic costs (Goossens, 2002), due to healthcare utilization (Pizzi et al., 2005), sick leave from work (Linton \& Ryberg, 2001) and reduced work effectiveness (van Leeuwen, Blyth, March, Nicholas, \& Cousins, 2006). Due to both human suffering and high economic costs, it has been acknowledged that there is "a worldwide chronic pain crises" (Gatchel \& Okifuji, 2006).

An important feature of chronic pain is that biomedical models can mostly not adequately explain the experience of pain and disability, since these models presume a direct relationship with structural and biomedical abnormalities which cannot be found in many patients with chronic pain (Nederhand, Hermens, IJzerman, Groothuis, \& Turk, 2006; Waddell, 2004; Wilmink \& Patijn, 2001). The mechanisms by which pain patients might be "trapped" in a downward spiral of increasing avoidance, disability and pain are captured in several fear-avoidance models (Lethem, Slade, Troup, \& Bentley, 1983; Norton \& Asmundson, 2003). These models assume that individuals who (mis-)interpret pain in terms of its worst possible, most extreme negative consequences, called pain catastrophizing (Sullivan, Bishop, \& Pivik, 1995), are likely to develop fear of pain for events and situations they associate with pain. This fear initiates avoidance and escape behaviors which can have pain reducing effects at short term. Nevertheless, a long term consequence of sustained avoidance of activities is the risk for increased disability, which may in turn reinforce further pain experiences and negative thoughts, completing a downward spiral (Vangronsveld, Peters, Goossens, Linton, \& Vlaeyen, 2007; Vlaeyen \& Linton, 2000).

Fear avoidance beliefs might lead to the development and maintenance of chronic pain (Leeuw et al., 2007a). Cross-sectional studies showed that pain-related fear predicts self- reported disability and physical performance in acute (SwinkelsMeewisse, Roelofs, Oostendorp, Verbeek, \& Vlaeyen, 2006) and chronic pain (Crombez, Vlaeyen, Heuts, \& Lysens, 1999; Vlaeyen, Kole-Snijders, Boeren, \& van Eek, 1995). The same relation was found in some prospective studies (Picavet, Vlaeyen, \& Schouten, 
2002; Sieben et al., 2005b). However, not all evidence is supporting the role between pain related fear and chronicity. A review of 9 studies measuring fear of pain at baseline concluded that a causal link between fear avoidance and poor long term outcomes is weak (Pincus, Vogel, Burton, Santos, \& Field, 2006). Some evidence was found that the role of fear is more prominent in a chronic pain state (Pincus et al., 2006). Lakke et al. (2009) reviewed risk and prognostic factors for non-specific musculoskeletal pain in 9 cohort studies and concluded that fear avoidance beliefs are not a prognostic factor for low back pain (Lakke, Soer, Takken, \& Reneman, 2009). This conclusion is in line with the findings from a recent prospective cohort study (Foster, Thomas, Bishop, Dunn, \& Main, 2010) evaluating 20 possible factors to influence outcome at 6 months. Catastrophizing and fear avoidance were not significantly related to outcome at 6 months, neither was depression. Factors that were found to be related to outcome in primary care were perception of personal control, acute-chronic timeline, illness identify and pain self-efficacy (Foster et al., 2010). A recent path analysis solved some methodological weaknesses from earlier studies and found supporting evidence for the different factors of the fear avoidance model (Gheldof et al., 2010).

Summarizing, chronic pain is a problem that needs scientific and clinical attention. Fear-avoidance models describe possible mechanisms for the development and maintenance of chronic pain, but since evidence is not conclusive, more research is needed.

\section{A learning perspective on pain-related fear}

By virtue of its biological significance, pain is an important motivator in learning. Indeed, pain informs the individual that there is the imminent or actual threat of body damage. Therefore, pain is an unconditioned stimulus (US) that activates an immediate defensive response. In this paragraph, we first address the adaptive value of fear in acute versus chronic pain and vulnerability factors to acquire pain-related fear. Next, learning mechanisms by which pain-related fear can be acquired and the different forms of defensive behaviors in acute and chronic pain will be described.

Both pain and fear are important for the organisms' survival. From this point of view, pain is adaptive in evoking fear since it stimulates a response aimed at protecting the integrity of the body. In acute pain, this is an adaptive response to prevent further blood loss or damage. In chronic pain, the complexity of pain increases and the role of physical damage often becomes questionable (Nederhand et al., 2006; Waddell, 2004; Wilmink \& Patijn, 2001). A response driven by pain-related fear, such as avoidance and hypervigilance, might not serve any function to recovery 
anymore but may lead to detrimental effects as described in the fear-avoidance models. An initial injury can occur without pain, especially when escape from a threat source is urged first (Wall, 1979). When being in a relatively safe context, both humans and animals need to express behavior aimed at healing. Wall concludes that pain is initiating this behavior, instead of signaling tissue damage. Anxiety is described as being part of the acute pain experience, aimed at providing a safe environment for recovery. In the period that follows, inactivity promotes recovery of tissue damage. Wall already mentioned that this state might be prolonged beyond the necessary time for healing. He concludes that the presence and intensity of pain are too poorly related to the degree of damage to be considering pain as a signal of tissue damage, an idea that has been extensively proved to be right (Jarvik, Hollingworth, Heagerty, Haynor, \& Deyo, 2001; van Tulder, Assendelft, Koes, \& Bouter, 1997; Waddell, 2004; Wilmink \& Patijn, 2001).

Despite the salience of pain experiences, there is individual variation in the extent to which pain is experienced as aversive. According to personal characteristics, the threat value of pain (US) may vary between individuals; pain catastrophizing (Goubert, Crombez, \& Van Damme, 2004) and anxiety sensitivity (Esteve \& Camacho, 2008) have been suggested to account for these individual differences. Pain catastrophizing is defined as an exaggerated negative interpretation of actual and anticipated pain experience (Goubert, Crombez, \& Van Damme, 2004; Roelofs, Peters, McCracken, \& Vlaeyen, 2003). For example, people with high levels of catastrophizing are convinced that pain means that their body is vulnerable and needs careful protection to prevent further harm. Anxiety sensitivity is a cognitive style by which the individual tends to interpret anxiety-related symptoms in a way that give rise to a fearful reaction (Stewart \& Asmundson, 2006). Pain catastrophizing and anxiety sensitivity make people more responsive to painful stimuli and more vulnerable to learn to anticipate the potential occurrence of threatening pain (Esteve \& Camacho, 2008; Goubert, Crombez, \& Van Damme, 2004; Severeijns, van den Hout, Vlaeyen, \& Picavet, 2002; Severeijns, Vlaeyen, van den Hout, \& Weber, 2001). For example, people with high levels of anxiety sensitivity who experience increased muscle tension are more likely to attend to these internal bodily sensations, and may believe that they are at risk for a new pain episode (Vancleef, Peters, Gilissen, \& De Jong, 2007).

In direct response to the presence of threat and the activation of fear, defensive behaviors arise (Quinn, Fanselow, Craske, Hermans, \& Vansteenwegen, 2006) that may have cognitive, motivational and physiological features. Cognitive shifts occur to detect threat and narrow attention to potential threat cues (=hypervigilance) (Crombez, Van Damme, \& Eccleston, 2005; de Gier, Peters, \& Vlaeyen, 2003). Pain captures attention to orient the individual to the source of threat and engage in behaviors that in acute pain promote healing, such as escape and avoidance 
behavior (Vlaeyen et al., 1995). Physiological arousal may be associated with muscle contractions around the injured area; it is suggested that in acute pain these muscle contractions and associated immobilization may have the function to protect the body from further injury (Goubert, Crombez, \& Peters, 2004). Safety seeking behavior is defined as a behavior performed as a strategy intended to prevent or minimize a feared catastrophe (Salkovskis, 1996; Salkovskis, Clark, \& Gelder, 1996). Safety seeking behavior in chronic pain includes not only avoidance (e.g., "I won't lift anything heavy because that would damage my back") and escape behaviors (e.g., "I'll stop sweeping the floor at the first sign of pain because pain means that I damage my back") but also subtle behaviors which are performed to prevent the feared catastrophe while remaining in the feared situation (e.g., "I'd make sure that I don't lean forward when I'm holding something heavy because that might break my spine") (Tang et al., 2007).

Regardless of the threat value, people have the urge to reduce the impact of any aversive US. This innate mechanism drives learning, since people search for stimuli that predict or signal the possible threat of the occurrence of the biologically relevant US in order to be able to properly adjust their behavior. Learning about the associations between stimuli is based on classical (or respondent) conditioning, learning what is adequate behavior regarding this new meaning is based on instrumental (or operant) conditioning. For example, a tennis player who experiences a shooting pain in the back during a game (classical conditioning) may start avoiding tennis (instrumental conditioning). By associative learning a former neutral stimulus becomes a conditioned stimulus (CS), acquires a new "predictive" meaning by being causally or functionally associated with a US (Hermans, Craske, Mineka, \& Lovibond, 2006). This can be understood from the classical conditioning paradigm; an association between playing tennis (CS) and the shooting pain (US) is made. CSs not only elicit the memory of the US ("during that tennis game, I had a shooting pain in my back"), but create the expectancy of the US as well ("if I will play tennis, then I will experience this pain again"). The relation of the CS and the US is both associative (evaluative learning) and predictive (expectancy learning) in nature (Bouton, Mineka, \& Barlow, 2001). Because of the CS-US association, the thought of playing tennis evokes an avoidance response (Conditioned Response, CR). The maintenance of this new behavioral response can be understood from an instrumental paradigm, since avoiding tennis is reinforced by avoidance of both the negative pain experience as well as avoidance of the negative experience of being fearful for a situation leading to pain. However, there is evidence that avoidance responses paradoxically increase the threat value of the US, rather than diminishing it (Lovibond, Mitchell, Minard, Brady, \& Menzies, 2009). 
In sum, the anticipation of pain engages similar defensive responses as occur following actual exposure to a painful stimulus. In chronic pain, defensive behaviors are the result of the learning of propositional (if ..., then ...) knowledge about the association between stimuli and the reinforcement of avoidance/escape behavior, and they may be less adaptive since they all have a maintaining relation with the pain experience.

\section{Three ways to acquire pain-related fear}

There are three ways in which propositional knowledge about the relationship between stimuli and pain can be acquired and by which behavior is determined. The former example about the tennis-player is an example of learning by direct experience; the person actually experiences the CS-US relation and his response (avoidance of playing tennis) is reinforced by no longer experiencing pain and fear.

Research findings suggest that fear learning in chronic pain patients also occurs through verbal threat information. Beside illness information that a person gathers from the social environment, media sources as internet or television can provide threatening information. Health care providers can also unintentionally be a source of threatening information in the diagnostic phase and during treatment. Most chronic pain patients with pain-related fear appear to found their conviction about vulnerability to (re-)injury on the results of diagnostic tests. Diagnostic information might be interpreted as being more threatening than intended by the medical specialist (Ash et al., 2008). Patients contact several health care providers in their continuing search for effective treatment. The different beliefs and orientations of these providers can play a role in the patient's complaints (Houben et al., 2005; Rainville, Bagnall, \& Phalen, 1995). Health care providers often tell patients not to perform certain activities or movements. For example, a patient with WAD is told not to work above shoulder-height. This process is referred to as rule-governed learning; the verbal transmitted rule of the therapist may govern the patients' behavior, who did not actually experience the negative consequences by himself. Health care providers' advice for chronic pain patients may vary substantially. A biomedically orientated health care provider may suggest that all pain-inducing activities should be avoided, thereby suggesting a strong CS-US association between activities and damage (Vlaeyen \& Linton, 2006). On the contrary, health care providers holding a more biopsychosocial orientation may recommend high levels of activity despite continued pain, suggesting no relationship between activities and harm (Houben et al., 2005; Rainville et al., 1995). In a study by Bishop et al. (2008) the attitudes 
and beliefs of health care providers were associated with their advice about return to work. Nearly $30 \%$ of the respondents would advise a described patient to stay off work, contrary to the UK-guideline. This advice correlated with a biomedical approach of the health care provider, opposed to a more behavioral orientation (Bishop, Foster, Thomas, \& Hay, 2008).

Olsson and Phelps (2004) describe an experiment in which they found evidence for observational learning or modeling of the association between pain and fear. They directly compared three pathways to fear and found that CSs acquired their threat value (US) through being paired with a painful shock (direct experience), with observed fear expression in another person (observational learning) or with the experimenter's verbal instructions (learning by verbal threat information). Fear responses to the CS were of comparable magnitude after the three kinds of learning (Olsson \& Phelps, 2004). Likewise, Helsen et al. (2009) showed that healthy subjects can acquire pain-related fear (CR) by observing a human model performing a cold pressor task, in which the color of the water (orange or pink water serving as CS + or CS-) indicated the US: the models facial expression showing either pain (negative US) or relaxation (positive US). When tested themselves, the subjects fear- and pain scores show that they learned the CS-US associations they previously observed in the model, despite equal temperatures of both orange and pink cold pressors.

Summarizing, pain-related fear in patients with chronic pain can be a learned, conditioned response that can be acquired through at least three pathways. One of the difficulties is that through learning individuals can remain engaged in defensive behaviors, even when the source of threat has diminished. In the next paragraph, ways to assess pain-related fear will be summarized.

\section{Assessment of pain-related fear}

Different methods can be used to assess pain-related fear. Questionnaires may help to specify the characteristics of the US; what is the content of the patient's fear (e.g. harm, (re-)injury, increasing pain, losing a job or losing independence)? Pictorial stimuli of movements and activities can be used to assess the different fear evoking stimuli (CSs) and the amount of fear that these stimuli elicit. The interview aims to gather information about the whole chronic pain problem and the associations between the different aspects. 


\section{Questionnaires}

Frequently used questionnaires are the Fear Avoidance Beliefs Questionnaire (FABQ) to assess beliefs about how work and physical activities affect low back pain (Waddell, Newton, Henderson, \& Somerville, 1993). The Pain Anxiety Symptom Scale (PASS) measures cognitive anxiety symptoms, escape and avoidance responses, fearful appraisals of pain and physiologic anxiety symptoms related to pain (McCracken, Zayfert, \& Gross, 1992). To evaluate fear of (re-)injury due to movement, the Tampa Scale for Kinesiophobia (TSK) can be used (Kori, Miller, \& Todd, 1990; Roelofs et al., 2007). All three questionnaires have proven to be reliable and valid (FABQ: (Lee, Chiu, \& Lam, 2006; Waddell et al., 1993), PASS: (Roelofs, McCracken, et al., 2004), TSK: (Goubert, Crombez, Van Damme, et al., 2004; Roelofs, Goubert, Peters, Vlaeyen, \& Crombez, 2004)). For clinical purposes, questionnaires seem to be appropriate as a first screening, but they are not sufficient to tell the exact nature of the perceived threat.

\section{Pictorial presentation of fear-evoking stimuli}

A limitation of the aforementioned questionnaires is that these questionnaires do not provide information about which specific movements and activities (CSs) the patient fears or avoids (Leeuw, Goossens, van Breukelen, Boersma, \& Vlaeyen, 2007). For the purpose of this, sets of pictures were designed, each showing a person performing a specific movement or activity. The pictorial sets can be used to determine the overall severity of fear of movement as well as to guide treatment by constructing a fear hierarchy. To assess fear in patients with low back pain, the Photograph Series of Daily Activities (PHODA) is appropriate. A short electronic version is freely available [http://fac.ppw.kuleuven.be/clep/Phoda-SEV/Phoda-SeV. $\mathrm{htm}$ ]. The Pictorial Fear of Activity Scale-Cervical (PFActS-C) is designed to assess fear in patients with cervical pain (Turk, Robinson, Sherman, Burwinkle, \& Swanson, 2008). In both sets, patients have to organize photographs of various daily activities (PHODA) or movements (PFActS-C) in ascending order, based on the extent to which they believe that performing these activities would be harmful. By doing so, a personal hierarchy of fear-eliciting activities can be established which can also be used to guide exposure based treatment. Both sets have shown good test-retest reliability, stability over time, internal consistency and construct validity (Leeuw, Goossens, van Breukelen, et al., 2007; Turk et al., 2008). 


\section{Interview}

A semi-structured interview can be used to obtain additional information about the cognitive, behavioral and psychophysiological aspects of the patient's chronic pain with the aim to estimate the role of pain-related fear in the maintenance of the problem. The interview may help to gather information about the patient's propositional knowledge and assumptions regarding the relationship between physical activities, pain and (re-)injury. For example "if I worked for a whole day, I would be over-using my back resulting in more pain and finally damage" (Vlaeyen, de Jong, Sieben, \& Crombez, 2002).

Concluding, different instruments can help to gather information about painrelated fear. A point of weakness is that most of them rely on self-report. A start has been made in the development of implicit measures (Leeuw, Peters, Wiers, \& Vlaeyen, 2007). In the next paragraph we will highlight the research on extinction. This is important before treatments of pain-related fear will be discussed, since the treatment of fear has its laboratory analog in extinction studies of conditioned fear (Bouton et al., 2001).

\section{Extinction of pain-related fear}

Extinction is the reduction of conditioned fear responses as a result of repeated exposure to the CS in absence of the US. In pain-related fear, this implicates patients being exposed to movements and activities without the feared consequences in terms of pain, harm or (re)-injury. Knowledge of the circumstances that facilitate or hamper extinction learning may help to sharpen treatments for pain-related fear in such a way that treatment outcome can be maximized in the short run (therapy efficacy) as well as in the long run (relapse prevention) (Hermans et al., 2006).

Generally, there is a marked asymmetry between the ease by which acquisition of fear occurs as compared to the difficulty by which extinction takes place. For example, learning that bending the back results in a shooting pain and experiencing thoughts about being handicapped or being in a wheelchair can be established with only one experience/exposure to this CS-US association. Extinction of this association has shown to be more difficult. It is not so easy to understand what is learned during exposure. Previously, extinction was conceived as unlearning or forgetting the association between CS and US, due to presenting the CS (movement or activity) without the US (the catastrophic representation of pain), resulting in a decrease of fear responses (the CR) upon the presentation of the CS. There is now growing consensus that extinction does not result in simple unlearning or forgetting the association between CS 
and US (Bouton \& Swartzentruber, 1991). Rather, there is evidence showing that a new form of learning occurs that modifies the CS-US contingency in such a way that the CS no longer signals an aversive event and thereby inhibits the expression of the fear response. Exposure to the CS without US creates an exception to the rule and competes with the previously learned knowledge, namely that the US follows the CS (Crombez et al., 2002). With extinction, the CS becomes an ambiguous stimulus. Exposure results in a form of acquired inhibition that suppresses a fear response (Hofmann, 2008).

Extinction can also be viewed as additional learning that in a particular context the CS-US association does not exist. Therefore, it is very difficult to generalize the extinction of fear to other dissimilar contexts, making relapse likely to occur (Bouton, 2002; Mineka \& Zinbarg, 2006). Phenomena as spontaneous recovery, reinstatement, renewal and rapid reacquisition show that the formerly learned association is still a weak spot after successful extinction.

\section{Interventions to reduce pain-related fear}

Once the pain-related fear has been thoroughly assessed, treatment aims at restoring functional levels by lowering pain-related fear. Since there are three ways to acquire pain-related fear, it can be argued that reducing fear should address the same three ways. Pain-related fear could be reduced by giving verbal information (often referred to as education), by observational learning (modeling) and by direct experience with fear reduction (exposure) and correcting catastrophic misinterpretations (exposure with behavioral experiments). All interventions aim at facilitating inhibitory learning; the previous assumption that activities are harmful and dangerous is overruled by the new one that activities do not cause damage (even though pain can occur).

\section{Reducing fear by giving verbal information}

Patients who are convinced that certain movements will harm their body will be reluctant to immediately start falsifying their basic assumptions about the sequence movement-pain-injury. By giving verbal information about these relations, the threatening value of the US is aimed to decrease.

In exposure-based protocols, an educational session is usually included during which the therapist provides verbal information about misconceptions regarding the association between movement, pain and harm. The aim of this session is to make a patient view his pain as a common condition that can be selfmanaged, rather than as a serious disease or a condition that needs protection. The 
difference between acute and chronic pain is explained first. The patient is explained that the meaning of pain in an acute situation can be body damage, but that the pain signal becomes a "false alarm" in chronic pain. Understanding that the message is false can enhance the patient's ability to expose to painful behaviors during treatment. Each patient is given a careful explanation of the fear-avoidance model, using the patient's individual complaints, beliefs and behaviors to illustrate how vicious circles (pain > catastrophic thoughts > fear > avoidance > disability > pain) maintain the pain problem (de Jong et al., 2005a; Vlaeyen, de Jong, Leeuw, \& Crombez, 2004; Vlaeyen et al., 2002). This helps the patient to understand that the consequences of pain are catastrophically overestimated. Education is the first step to enhance the commitment of the patient to engage in feared activities during the actual exposure in vivo. In a study using daily measures, results showed that education reduces pain-related fear and catastrophizing, with ongoing improvement when exposure in vivo started. Education alone was not enough to change behavior: performance of relevant daily activities was not affected by the educational session and improved significantly only with exposure in vivo (de Jong et al., 2005b).

Another field of research has focused on preventing chronicity of low back pain by giving adequate written information. Burton et al. (1999) studied the impact of an educational booklet on the beliefs and functional outcome of patients seeking primary care for an acute or recurrent episode of low back pain. Patients receiving this biopsychosocially oriented booklet showed significantly more positive beliefs about activities and consequences of low back pain. This positive effect maintained over a 1 year follow up period. This group also showed a tendency to become less disabled then the group who received information that was biomedically oriented (Burton, Waddell, Tillotson, \& Summerton, 1999). In another study, the experimental group was enrolled in a self-care program. This program consisted of two group sessions, an individual meeting with the psychologist leading the program in which a plan was made to enhance self-care and problem solving related to back pain. One follow-up phone call was made to evaluate the progress of this plan. Additional information was given by videos and a book, both emphasizing the importance of resuming daily life activities. Controls only received a book about usual back pain care. The repeated verbal information in the experimental group led to decreased pain-related fear, and to a lesser extent to reduced pain intensity and daily life interference, although a substantial part remained to have back problems at 6 months follow-up (Moore, Von Korff, Cherkin, Saunders, \& Lorig, 2000). This is in line with the above-mentioned findings in a chronic pain population (de Jong et al., 2005b) where a verbal intervention was found to be effective in lowering pain-related fear, but actual experience was needed to change patients' behavior. 


\section{Reducing pain-related fear with observational learning (modeling)}

Congruent with the scarcity in research regarding observational learning in acquiring pain-related fear, no studies have systematically evaluated the effect of modeling in order to reduce pain-related fear. Protocols for graded exposure often suggest that before the patient is invited to perform a feared activity, the therapist "models" it first (Vlaeyen et al., 2004) (page 327). A related study by Colloca and Benedetti (2009) investigated whether placebo analgesia could be induced by social observational learning. Subjects learned by observing the analgesic experience of others, by a direct conditioning procedure or by verbal information. Interestingly, the magnitudes of the placebo-effects of the social learning condition were similar to the magnitudes in the group that learned by direct experience. For learning by verbal information, smaller effects were found (Colloca \& Benedetti, 2009).

\section{Reducing pain-related fear by experiencing the absence of the expected threat}

For fearful patients it is far more convincing to actually experience themselves behaving differently, than any rational arguments that could be given. The fear hierarchy established with the PHODA (Leeuw et al., 2007b) or PFActSv (Turk et al., 2008) has been used to gradually expose patients to more threatening activities. The exposure is personally tailored to the functional goals the patient has formulated. Patients are encouraged to engage in the fearful activity as much as possible until anxiety levels have decreased. If so, the patient chooses the next activity from the fear-hierarchy, and this is repeated until even the most highly scored activities from the hierarchy can be performed.

Additional behavioral experiments give patients an opportunity to challenge the validity of their catastrophic assumptions. In a behavioral experiment, the patient is challenged to systematically test whether the anticipated threat during exposure to a CS is overestimated or not. Subsequently, a feared activity or movement (CS) is performed until disconfirmation of harm beliefs for this specific activity or movement has occurred (no US), with fear reduction as a consequence (lower CR). In clinical practice, behavioral experiments are hard to separate from exposure, and they can best be used simultaneously. By conducting hypotheses about the expected harmful consequences (US) of movements and activities (CS) the patient receives the opportunity to evaluate catastrophic beliefs (Hofmann, 2008). Hypotheses are assumptions 
taking the form of "If..., then..." statements (e.g., "If I carry a bag with groceries, then nerves in my wrist will get blocked and I will have to let go of the bag") and are empirically tested during a behavioral experiment. Treatment is considered to be successful if the patient no longer avoids activities, indicating that the CS (activity or movement) no longer signals the US (catastrophes associated with experiencing pain) and the CR (fear) is decreased. To enhance generalization and maintain exposure effects over time, exposure is provided to the full spectrum of contexts and natural settings in which fear has been experienced. The stimuli are varied; for example, walking can be done indoors and outdoors, on grass, sand or on the street, uphill as well as downhill, quick and slowly, and so on (Vlaeyen et al., 2004).

\section{Effectiveness of interventions aimed at reducing pain-related fear}

In a narrative review on fear reducing techniques, Lohnberg (2007) concludes that graded exposure in vivo (GEXP) appears to be the most effective treatment for chronic pain in individuals with increased fear and avoidance, based on the early single case studies (Boersma et al., 2004; de Jong et al., 2005b; Linton, Overmeer, Janson, Vlaeyen, \& de Jong, 2002; Lohnberg, 2007; Vlaeyen, de Jong, Geilen, Heuts, \& van Breukelen, 2001; Vlaeyen, de Jong, Geilen, Heuts, \& van Breukelen, 2002; Vlaeyen, de Jong, Onghena, Kerckhoffs-Hanssen, \& Kole-Snijders, 2002). A more recent review on treatments available to address fear-avoidance beliefs in patients with chronic musculoskeletal pain suggests that GEXP and acceptance and commitment therapy (ACT) result in the best outcomes for treating fear-avoidance beliefs (Bailey, Carleton, Vlaeyen, \& Asmundson, 2010). A systematic review included four trials that compared graded activity to GEXP and two trails that compared GEXP to a waiting list or usual care (Macedo, Smeets, Maher, Latimer, \& McAuley, 2010). The authors conclude that GEXP is as effective as minimal treatment or graded activity in reducing pain and disability for persistent low back pain. Effects on pain-related fear were not reported in this review, and the authors estimate that the small number and quality of trials does not allow a good comparison to be made (Macedo et al., 2010).

So far, the published Randomized Controlled Trials on the effectiveness of GEXP in chronic low back pain found mixed results. Woods \& Asmundson (2008) randomly assigned 44 patients to GEXP, graded activity or a wait-list condition. They found that, in comparison with the graded activity condition, patients in the GEXP condition demonstrated significantly larger improvements on measures of fear of pain/movement, fear avoidance beliefs and pain-related anxiety, but only trend differences for 
pain-related disability and pain self-efficacy. When GEXP was compared to the wait list control group, GEXP showed significantly greater improvements on measures of fear-avoidance beliefs, fear of pain/movement, pain-related anxiety, pain catastrophizing, pain experience, anxiety and depression. Over a three-month follow-up, the GEXP condition maintained improvements (Woods \& Asmundson, 2008).

Linton et al. (2008) randomized 46 participants into a GEXP plus usual treatment or waiting list control plus usual treatment group. After the waiting period, the control group crossed over and received GEXP. The exposure group scored better on function, but not on fear nor on pain, and the effect sizes were modest. When the control group crossed over to treatment significant treatment effects were noted for fear and function. Compared to a group receiving usual treatment and waiting for exposure, GEXP demonstrated a significantly larger improvement on function. Overall, GEXP had moderate effects on function, fear and pain intensity. The authors conclude that GEXP may be important in treatment, but that it is not recommended as a stand-alone intervention that is added to usual care (Linton et al., 2008).

A multi-center trial included 85 patients in either a GEXP or a graded activity program (Leeuw et al., 2008). It was demonstrated that GEXP, despite excelling in diminishing pain catastrophizing and perceived harmfulness of activities, was equally effective as graded activity in improving functional disability and main complaints, although the group difference almost reached statistical significance favoring exposure. Treatment conditions did not differ in changing pain intensity and daily activity levels, nor was GEXP superior to graded activity in the subgroup of highly fearful patients. Irrespective of treatment, approximately half the patients reported clinically relevant improvements in main complaints and functional disability; although for the latter outcome the group difference was almost significant favoring GEXP. This study demonstrates that up to 6 months after treatment exposure is an effective treatment, but not more effective than graded activity, in moderately to highly fearful patients, although its superiority in altering pain catastrophizing and perceived harmfulness of activities is clearly established (Leeuw et al., 2008). An interesting additional finding of this study is that the differential effects of both treatments on disability are mediated by changes in the perceived harmfulness of physical activities.

All the above-mentioned studies have included patients with chronic low back pain. Single case studies have shown that GEXP can also be successfully applied to other chronic pain conditions as Complex Regional Pain Syndrome Type I (de Jong et al., 2005a), post traumatic neck pain (de Jong et al., 2008) and vaginismus (ter Kuile et al., 2009). 


\section{Expert Commentary}

\section{Pain-related fear as a predictor of future disability}

Whereas it is well established that pain-related fear is a maintaining factor once chronic pain has developed, more caution is needed with regard to the role of pain-related fear in the transition of acute pain to the chronic stage. Although it is suggested that pain-related fear is a potential risk factor for the inception of chronic pain and even a potential vulnerability factor for the inception of acute pain in painfree individuals (Leeuw et al., 2007a), some studies raise doubt about this (e.g. (Leeuw et al., 2007a; Sieben, Portegijs, Vlaeyen, \& Knottnerus, 2005a; Sieben et al., 2005b)) and call for more longitudinal investigation. Given that aversive stimuli may activate a network of fear processes simultaneously, and given the bi-directional relationship between safety behaviors and threat appraisals, a different methodology such as path analytic analyses is needed (Gheldof et al., 2010).

\section{Working mechanisms of different treatments for chronic pain}

Other techniques that are not primarily aimed at reducing pain related fear have been shown to have a fear reducing effect as well. This has been the case for physical therapy (e.g. aerobic and muscle strength training) (Smeets, Vlaeyen, Kester, \& Knottnerus, 2006), Graded Activity (Leeuw et al., 2008; Macedo et al., 2010) and Acceptance and Commitment Therapy (McCracken \& Keogh, 2009; McCracken, Vowles, \& Eccleston, 2005; Wicksell, Ahlqvist, Bring, Melin, \& Olsson, 2008). It has been argued that the working mechanism behind these techniques is also the reduction of perceived threat (Hofmann \& Asmundson, 2008). Different cognitive techniques or strategies that could serve to enhance the effects of exposure therapy have been proposed. For example, acceptance strategies have received increasing attention and are starting to establish a small evidence base. In a randomized controlled trial, the effectiveness of exposure and acceptance strategies was compared to a multidisciplinary treatment program to improve functioning and quality of life in longstanding pediatric pain (Wicksell, Melin, Lekander, \& Olsson, 2009). Results were in favor of the Acceptance and Commitment Therapy (ACT). These results are in line with a previous study in which a group of 21 chronic pain patients and whiplash associated disorders who received treatment emphasizing exposure and acceptance strategies showed more improvement than a waiting list group with regard to pain 
disability, life satisfaction, fear of movements, depression and psychological inflexibility (Wicksell et al., 2008). Linton (2010) recently described a case study in which dialectical behavioral therapy (DBT) is applied to a patient with a complex persistent pain, depression and disability syndrome. DBT is a technique that relies on training of emotional regulation, which supports acceptance of the patient and his behavior without judgment, while at the same time working on the things that can change or improve (Linton, 2010). The intervention program lasted about 6 months and consisted of 16 sessions in which different intervention techniques were used: validation and education, interoceptive exposure (including focusing on inner physiological feelings in a nonjudgmental way), savoring, emotional regulation (including identifying thoughts and feelings in a nonjudgmental manner), dialectical behavioral experiments, activity monitoring and a maintenance program. The patient made a considerable progress, both on self-report measures and objective measures, and even despite the presence of some pain, sleeping problems, emotional discomfort, the patient was able to function on a more satisfying level (Linton, 2010). The effective component in this case remains unsure, but Linton argues that the emotional focus might have helped the patient to fully engage in the exposure (Linton, 2010).

It would be worthwhile to compare these treatments to address the question "what works for whom?" Although these treatments differ in their therapy goals, in respectively enabling the patient to live a valued life (ACT) and reducing pain-related fear (GEXP), the commonality is that both treatments require patients to involve in daily life activities. The question remains if treatment necessarily has to work through fear reduction or that by acceptance of fear the same improvements in enhancing daily functioning and quality of life can be established. As long as this question is not answered, in our opinion it would be a missed opportunity not to give clients an opportunity to rectify their dysfunctional beliefs that cause pain-related fear. The effectiveness of GEXP on pain-reduction might be explained by an increase in the acceptance of pain, exposure to previously avoided situations is considered to be the core intervention, emphasizing acceptance of what can not be directly changed (thoughts, emotions, bodily sensations) as a way of engaging in activities that are meaningful but possibly painful or fear provoking (Hayes, 2004; Wicksell et al., 2008). It seems interesting in future GEXP studies to determine to which extent the results are not mediated by a change in acceptance and commitment. Related to discussion about acceptance is the issue of relatively high drop-out rates in GEXP. In the review from Bailey et al. (2010) 9 studies on GEXP included 246 participants of whom 96 (39\%) dropped out. In ACT the drop-out rate was $28,5 \%$ and in mixed CBT protocols $15 \%$ [83]. A possible explanation of the high drop-out rate of GEXP can be found in that that exposure to feared activities 
similarly implies exposure to painful activities, which might not be acceptable for all patients. It would be interesting to study if this subgroup could benefit from additional acceptance strategies.

\section{Extinction of pain-related fear by verbal instruction and modeling}

Existing treatments to reduce pain-related fear seem to rely dominantly on learning by direct experience using exposure in vivo techniques. Less is known about how pain-related fear can be decreased using verbal information, and the existing research is limited to using booklets in primary care settings. Likewise, the observational learning on extinction of pain-related fear in chronic pain patients has not been studied yet. Since both Olsson and Phelps (2004) and Colloca and Benedetti (2009) showed that the learning curves for observational learning were of the same magnitude as learning by direct experience, it might be worthwhile to examine whether verbal instruction and observational learning could produce or enhance fear reduction during exposure in vivo treatment (Colloca \& Benedetti, 2009; Olsson $\&$ Phelps, 2004, 2007). Although current exposure protocols advocate verbal instruction and the modeling role of the therapist, their effects have not been systematically studied yet. This issue also revives a discussion about whether exposure based treatment could be delivered as a group-program (Bliokas, Cartmill, \& Nagy, 2007). Conceivably, seeing a group member perform a feared activity is more valid than seeing the therapist modeling the activity, despite the evident disadvantage that it will be more difficult for the therapist to monitor idiosyncratic safety-seeking behaviors in each individual patient. A related issue that is raised by several authors (Dahl \& Nilsson, 2001; Macedo et al., 2010) is who should deliver exposure-based interventions. An important difference from most anxiety problems is that pain-related fear is treated not in mental health services but in multidisciplinary rehabilitation centre. This implies that they see other disciplines, such as physical or occupational therapists and nurses delivering exposure-based treatments. The question if nonpsychologist can deliver a psychological intervention for pain-related fear has not been studied yet, this is warranted since it might have a major effect on the success of treatment and cost-effectiveness. 


\section{Return of fear after successful extinction}

Exposure in vivo therapy is widely and successfully applied to reduce pain-related fear and pain-related disability, but patients and therapists alike keep struggling with problems of relapse and prematurely ending treatment. Extinction, the laboratory analog of exposure, is viewed upon as a process which establishes new inhibitory associations, rather than it is a type of "unlearning" of previously established associations (Bouton et al., 2001). Relapse after an extinction procedure such as exposure, could be explained by insufficient generalization of what has been learned in therapy, i.e. disconfirming beliefs, to other situations and contexts. Response generalization is hindered by the competition of the original meaning of the stimuli and the new meaning learned during exposure (Bouton, 1994). Several studies have investigated generalization of exposure to movements in a laboratory setting, and reveal that repeated exposure on the same or different movements does not necessarily generalize to a new movement, suggesting that the corrective impact of exposure in vivo may be limited (Crombez et al., 2002; Goubert, Crombez, \& Danneels, 2005; Goubert, Francken, Crombez, Vansteenwegen, \& Lysens, 2002). Only one study showed successful generalization of pain expectancy corrections across four reaching tasks of increasing intensity, in chronic low back pain patients reporting high levels of pain-related fear (Trost, France, \& Thomas, 2008). In the aforementioned experimental studies, subjects are exposed to movements in an artificial environment with little ecological validity only several times in a short time span. To what extent this is comparable to GEXP treatment, where a patient is repeatedly exposed to fearful daily life activities over a longer period of time remains open for future research. Current treatment mainly takes place in the artificial context of a hospital or rehabilitation center, it would be interesting to study which entities (repetition, movement vs. activity, time span, context) enhance generalization to optimize treatment effect in both results and costs. In the study by Linton et al. (2008), the authors describe that patients were exposed to activities that were within "normal" limits (Trost et al., 2008). It would be interesting to study if pain-related fear can be diminished by exposing patients only to regular daily life activities or that patients would benefit in the long term from exposure to their most highly feared activities. 


\section{Safety-seeking behavior and safety signals: protection from extinction?}

Contradicting opinions exist regarding the use of safety-seeking behavior during exposure. Some authors advocate a judicious use to make the start of exposure less aversive (Rachman, Radomsky, \& Shafran, 2008). Others advocate that safetyseeking behaviors should be minimized during exposure therapy because of their maintaining effect on anxiety generating beliefs and that patients should be given a clear cognitive rationale for doing so (Lovibond et al., 2009; Salkovskis, Clark, Hackmann, Wells, \& Gelder, 1999). Illustrative on safety-seeking behavior is the research in claustrophobia that suggests it is not the actual use of safety behavior that interferes with fear reduction, but that the perception of their availability is disruptive (Powers, Smits, \& Telch, 2004). This study found that safety aids do not need to be actually used in order to exert their detrimental effects, consistent with countless clinical observations of patients carrying rescue pain medication or other safety aids without actually using them. Safety signals are stimuli that signal that an aversive outcome is highly unlikely. A patient may learn that bending over does not hurt the back, but only in the presence of the safety signal, such as the therapist. In the absence of the therapist, the previously learned rule that movement can hurt the back can be activated again.

There is considerable evidence that a return of fear might be due to the presence of concurrent safety signals or safety-seeking behavior during the extinction procedure (Hermans et al., 2006; Lovibond, 2004; Vervliet, Vansteenwegen, Hermans, \& Eelen, 2007). The most commonly accepted theoretical explanation for this effect is protection from extinction, which posits that patients attribute the absence of the feared outcome to the safety signal or to their safety behavior, and thus fail to update their threat beliefs. Protection from extinction has been demonstrated in a study during which stimulus $A$ is associated with the presence of a threatening US, whereas stimulus B signals the absence of the US. The presence of the inhibitory cue B during extinction of stimulus A cancels out the expectancy of the US, causing no more discrepancy between what is expected (nothing) and what actually happens (nothing), thus leaving threat beliefs intact (Lovibond, Davis, \& O'Flaherty, 2000; Lovibond et al., 2009). Protection from extinction has been demonstrated when an external stimulus was used as a safety signal (Lovibond et al., 2000) and when avoidance was used as safety-seeking behavior (Lovibond et al., 2009). Consequently, clinicians using exposure treatments should assist the patient in identifying threat-relevant safety strategies and encourage them to not only discard their use (safety-seeking behavior; not using a protective splint during exposure) but also their availability (safety signal; carrying the splint in one's purse). 


\section{Fear reduction or optimizing inhibitory learning?}

There is some evidence suggesting that exposure in patients who catastrophize about pain is less successful as compared to exposure in low catastrophizers (Flink, Nicholas, Boersma, \& Linton, 2009). One possible mechanism is that high pain catastrophizers have more difficulty in inhibiting their defensive responses (Seminowicz \& Davis, 2006). Indeed, Craske et al. (2008) conclude that not fear reduction should be the goal of exposure, but optimizing inhibitory learning. Reductions in fear and physiological arousal are not indicative of corrective learning. Since extinction is no longer seen as unlearning, but as learning a new rule that co-exist with the old rule, the context determines which rule is valid. Treatment should be aimed at enhancing retrievability of the newly learned associations in different contexts and at different times (Craske et al., 2008). The examination of this assumption in the reduction of pain-related fear is warranted.

\section{5 year view}

Recent developments in the field of acquisition and extinction of fear and anxiety in general might inspire new research avenues in the field of pain-related fear, in particular with regard to the effectiveness and efficiency of current treatment strategies.

\section{Exteroceptive versus interoceptive exposure}

Graded exposure in pain-related fear has focused on the learned association between activities and predicted pain and harm. Recent ideas focus on the fact that not only movements, activities and actions can serve as CSs. Internal sensations in the body can have predictive value as well (De Peuter, Van Diest, Vansteenwegen, Van den Bergh, \& Vlaeyen, 2011). For example, mild pain or a specific body position (CS) can become a predictor for intense pain (US). Interoceptive conditioning is seen as more resistant to extinction than extinction of exteroceptive conditioning (Sinha, Papp, \& Gorman, 2000), providing new challenges in future research and treatment. A recent study compared interoceptive exposure with distraction/relaxation in six individuals with chronic back pain with regard to the reduction of threat value of pain (Flink et al., 2009). Results showed a general trend towards reduced pain-related distress, even after a 3-month follow-up period. Even though these interventions only encompassed a single type of intervention, both techniques were about equally effective in reducing pain-related distress (Flink et al., 2009). 


\section{An affective-motivational approach}

A number of authors have recently called for an expanded affective-motivational approach with a prominent focus on behavior in the context of multiple goals (Van Damme, Crombez, \& Eccleston, 2008; Vlaeyen, Crombez, \& Linton, 2009). In their attempt to resume daily life activities, pain patients engage in several goals, some of which are directly related to dealing with pain whereas others are not painrelated. These multiple goals may facilitate each other, or they can be conflicting. For example, the goal to satisfy others by resuming work-related activities may conflict with goal to protect bodily integrity by staying home. Unfortunately, unresolved painrelated goal conflicts may fuel fear (Karoly, Okun, Ruehlman, \& Pugliese, 2008). An emerging and intriguing question is whether cognitive-behavioral therapies aimed at the re-evaluation of major life goals and at the resolution of enduring goal conflicts help to counter fear-driven and disabling avoidance behavior (Van Damme et al., 2008; Vlaeyen et al., 2009). An illustration of such a motivational approach is provided by Christiansen and colleagues who evaluated a brief goal-pursuit intervention to improve physical capacity through exercising in chronic back pain patients (Christiansen, Oettingen, Dahme, \& Klinger, 2010). In order to facilitate the realization of intended goals, the following strategies were utilized): (1) mental contrasting to increase the patient's expectations about achieving the promoted goal, (2) problem solving techniques to help the patient to overcome obstacles associated with exercising, and (3) implementation intentions to help the patient to prioritize the intended goal in future conflict situations. This intervention led to greater improvements in physical capacity as compared with the treatment as usual. It would be worthwhile to examine whether the effects of fear-reduction treatments can be enhanced by adding a motivational component focused at the resolution of goal conflicts (Schrooten \& Vlaeyen, 2010).

\section{Financial and competing interests disclosure}

The contribution of Mariëlle Goossens was supported by ZonMW, program Rehabilitation Research, Grant No. 60-60500-98015. Participation of Johan W.S. Vlaeyen was supported by the NWO Social Science Research Council of the Netherlands, VICI Grant No. 453-04-003, and an Odysseus Grant by the Fund for Scientific ResearchFlanders, Belgium (FWO). The authors have no other relevant affiliations or financial involvement with any organization or entity with a financial interest in or financial conflict with the subject matter or materials discussed in the manuscript apart from the disclosed. No writing assistance was utilized in the production of this manuscript. 


\section{Key issues}

- Fear avoidance models explain that pain perception can be catastrophically interpreted, resulting in a state of fear that makes a patient hypervigilant for signs of threat and evokes avoidance behavior. Negative consequences of this behavior are disability and disuse, which have detrimental long-term effects on the pain experience.

- Dysfunctional pain-related fear arises when neutral stimuli (movements, activities) become predictors for the occurrence of pain and associated harm. The learning of this association can be based on direct experience, on observation and on receiving threatening information.

- Questionnaires (TSK, FABQ, PASS) as well as pictorial sets (PHODA, PFActS-C) are available to specify the nature of pain-related threat. A semi-structured interview may be considered to gain insight in additional aspects of the chronic pain problem.

- Extinction is the reduction of conditioned fear responses as a result of repeated exposure to the conditioned stimulus (CS) in absence of the unconditioned stimulus (US). By inhibitory learning this results in a changed CS-US relationship, the CS becomes an ambiguous stimulus for which the context determines a positive or negative outcome.

- Treatments for pain-related fear have mainly focused on written or verbal information about the paradoxical effects of avoidance and escape behaviors. Recently, exposure-based treatments have been developed during which patients engage in fearful activities to disconfirm threat-beliefs and reduce fear. The role of observational learning during treatment warrants further study.

- Protection from extinction is a phenomenon that explains how both context features and behavior can leave a CS-US relation intact during exposure; patients attribute the absence of the feared outcome to safety signals or to their own safety behaviors and fail to correct catastrophic interpretations.

- Graded exposure in vivo seems the treatment of choice for reducing pain-related fear. Further evidence is needed regarding the change in pain and disability and the exact working mechanism of exposure treatment.

- Future directions in the field of pain-related fear will study how internal cues can serve as CSs and how this will affect treatment. Studies that examine whether the effects of exposure can be magnified when adding a motivational component during which patients are coached in managing their goal-conflicts. 


\section{Abbreviations}

CS Conditioned Stimulus

US Unconditioned Stimulus

CR Conditioned Reaction

FABQ Fear Avoidance Beliefs Questionnaire

PASS Pain Anxiety Symptom Scale

TSK Tampa Scale for Kinesiophobia

PHODA Photograph Series of Daily Activities

PFActS-C Pictorial Fear of Activity Scale-Cervical

CRPS-I Complex Regional Pain Syndrome Type I

ACT Acceptance and Commitment Therapy

GEXP Graded Exposure in Vivo

GA Graded Activity

DBT Dialectical Behavioral Therapy 


\section{References}

Ash, L. M., Modic, M. T., Obuchowski, N. A., Ross, J. S., Brant-Zawadzki, M. N., \& Grooff, P. N. (2008). Effects of diagnostic information, per se, on patient outcomes in acute radiculopathy and low back pain. American Journal of Neuroradiology, 29(6), 1098-1103

Bailey, K. M., Carleton, R. N., Vlaeyen, J. W., \& Asmundson, G. J. (2010). Treatments addressing painrelated fear and anxiety in patients with chronic musculoskeletal pain: a preliminary review. Cogn Behav Ther, 39(1), 46-63. doi:10.1080/16506070902980711

Bishop, A., Foster, N. E., Thomas, E., \& Hay, E. M. (2008). How does the self-reported clinical management of patients with low back pain relate to the attitudes and beliefs of health care practitioners? A survey of UK general practitioners and physiotherapists. Pain, 135(1), 187-195

Bliokas, V. V., Cartmill, T. K., \& Nagy, B. J. (2007). Does systematic graded exposure in vivo enhance outcomes in multidisciplinary chronic pain management groups? The Clinical Journal of Pain, 23(4), 361-374

Boersma, K., Linton, S., Overmeer, T., Jansson, M., Vlaeyen, J., \& de Jong, J. (2004). Lowering fearavoidance and enhancing function through exposure in vivo. A multiple baseline study across six patients with back pain. Pain, 108(1), 8-16

Bouton, M. E. (1994). Context, ambiguity, and classical conditioning. Current Directions in Psychological Science, 3(2), 49-53

Bouton, M. E. (2002). Context, ambiguity, and unlearning: Sources of relapse after behavioral extinction. Biological Psychiatry, 52(10), 976-986

Bouton, M. E., Mineka, S., \& Barlow, D. H. (2001). A modern learning theory perspective on the etiology of panic disorder. Psychological Review, 108(1), 4-32

Bouton, M. E., \& Swartzentruber, D. (1991). Sources of relapse after extinction in Pavlovian and instrumental learning. Clinical Psychology Review, 11(2), 123-140

Breivik, H., Collett, B., Ventafridda, V., Cohen, R., \& Gallacher, D. (2006). Survey of chronic pain in Europe: Prevalence, impact on daily life, and treatment. European Journal of Pain, 10(4), 287-333

Burton, K. A., Waddell, G., Tillotson, M. K., \& Summerton, N. (1999). Information and Advice to Patients With Back Pain Can Have a Positive Effect. A Randomized Controlled Trial of a Novel Educational Booklet in Primary Care. Spine, 24(23), 2484-2491

Christiansen, S., Oettingen, G., Dahme, B., \& Klinger, R. (2010). A short goal-pursuit intervention to improve physical capacity: A randomized clinical trial in chronic back pain patients. Pain, 149(3), 444-452. doi: 10.1016/j.pain.2009.12.015

Colloca, L., \& Benedetti, F. (2009). Placebo analgesia induced by social observational learning. Pain, 144(1-2), 28-34

Craske, M. G., Kircanski, K., Zelikowsky, M., Mystkowski, J., Chowdhury, N., \& Baker, A. (2008). Optimizing inhibitory learning during exposure therapy. Behaviour Research and Therapy, 46(1), 5-27

Crombez, G., Eccleston, C., Vlaeyen, J. W. S., Vansteenwegen, D., Lysens, R., \& Eelen, P. (2002). Exposure to physical movement in low back pain patients: Restricted effects of generalization. Health Psychology, 21(6), 573-578 
Crombez, G., Van Damme, S., \& Eccleston, C. (2005). Hypervigilance to pain: An experimental and clinical analysis. Pain, 116(1-2), 4-7

Crombez, G., Vlaeyen, J. W. S., Heuts, P. H. T. G., \& Lysens, R. (1999). Pain-related fear is more disabling than pain itself: Evidence on the role of pain-related fear in chronic back pain disability. Pain, 80(1), 329-339

Dahl, J. C., \& Nilsson, A. (2001). Evaluation of randomized preventive behavioural medicine work site intervention for public health workers at risk for developing chronic pain. European Journal of Pain, 5(4), 421-432

de Gier, M., Peters, M. L., \& Vlaeyen, J. W. S. (2003). Fear of pain, physical performance, and attentional processes in patients with fibromyalgia. Pain, 104(1-2), 121-130

de Jong, J. R., Vangronsveld, K., Peters, M. L., Goossens, M. E. J. B., Onghena, P., Bulté, I., \& Vlaeyen, J. W. S. (2008). Reduction of Pain-Related Fear and Disability in Post-Traumatic Neck Pain: A Replicated Single-Case Experimental Study of Exposure In Vivo. The Journal of Pain, 9(12), 1123-1134

de Jong, J. R., Vlaeyen, J. W. S., Onghena, P., Cuypers, C., den Hollander, M., \& Ruijgrok, J. (2005a). Reduction of pain-related fear in complex regional pain syndrome type I: The application of graded exposure in vivo. Pain, 116(3), 264-275

de Jong, J. R., Vlaeyen, J. W. S., Onghena, P., Goossens, M. L. E. J. B., Geilen, M., \& Mulder, H. (2005b). Fear of Movement/(Re)injury in Chronic Low Back Pain: Education or Exposure In Vivo as Mediator to Fear Reduction? The Clinical Journal of Pain, 21(1), 9-17

De Peuter, S., Van Diest, I., Vansteenwegen, D., Van den Bergh, O., \& Vlaeyen, J. W. (2011). Understanding fear of pain in chronic pain: interoceptive fear conditioning as a novel approach. Eur J Pain, 15(9), 889-894. doi:10.1016/j.ejpain.2011.03.002

Esteve, M. R., \& Camacho, L. (2008). Anxiety sensitivity, body vigilance and fear of pain. Behaviour Research and Therapy, 46(6), 715-727

Flink, I. K., Nicholas, M. K., Boersma, K., \& Linton, S. J. (2009). Reducing the threat value of chronic pain: A preliminary replicated single-case study of interoceptive exposure versus distraction in six individuals with chronic back pain. Behaviour Research and Therapy, 47(8), 721-728

Foster, N. E., Thomas, E., Bishop, A., Dunn, K. M., \& Main, C. J. (2010). Distinctiveness of psychological obstacles to recovery in low back pain patients in primary care. Pain, 148(3), 398-406. doi:10.1016/j. pain.2009.11.002

Gatchel, R. J., \& Okifuji, A. (2006). Evidence-Based Scientific Data Documenting the Treatment and Cost-Effectiveness of Comprehensive Pain Programs for Chronic Nonmalignant Pain. The Journal of Pain, 7(11), 779-793

Gheldof, E. L., Crombez, G., Van den Bussche, E., Vinck, J., Van Nieuwenhuyse, A., Moens, G., ... Vlaeyen, J. W. (2010). Pain-related fear predicts disability, but not pain severity: a path analytic approach of the fear-avoidance model. Eur J Pain, 14(8), 870 e871-879. doi:10.1016/j.ejpain.2010.01.003

Goossens, M. E. J. B. (2002). Economic aspects of chronic musculoskeletal pain. In S. Linton (Ed.), New avenues of the prevention of chronic musculoskeletal pain and disability: Elsevier Science 
Goubert, L., Crombez, G., \& Danneels, L. (2005). The reluctance to generalize corrective experiences in chronic low back pain patients: A questionnaire study of dysfunctional cognitions. Behaviour Research and Therapy, 43(8), 1055-1067

Goubert, L., Crombez, G., \& Peters, M. (2004). Pain-related fear and avoidance: A conditioning perspective. In G. J. G. Asmundson, J. W. S. Vlaeyen, \& G. Crombez (Eds.), Understanding and treating fear of pain (pp. 25-50). Oxford: University Press

Goubert, L., Crombez, G., \& Van Damme, S. (2004). The role of neuroticism, pain catastrophizing and pain-related fear in vigilance to pain: A structural equations approach. Pain, 107(3), 234-241

Goubert, L., Crombez, G., Van Damme, S., Vlaeyen, J. W. S., Bijttebier, P., \& Roelofs, J. (2004). Confirmatory Factor Analysis of the Tampa Scale for Kinesiophobia: Invariant Two-Factor Model Across Low Back Pain Patients and Fibromyalgia Patients. The Clinical Journal of Pain, 20(2), 103-110

Goubert, L., Francken, G., Crombez, G., Vansteenwegen, D., \& Lysens, R. (2002). Exposure to physical movement in chronic back pain patients: No evidence for generalization across different movements. Behaviour Research and Therapy, 40(4), 415-429

Hayes, S. C. (2004). Acceptance and Commitment Therapy, Relational Frame Theory, and the Third Wave of Behavioral and Cognitive Therapies. Behavior Therapy, 35(4), 639-665

Hermans, D., Craske, M. G., Mineka, S., \& Lovibond, P. F. (2006). Extinction in Human Fear Conditioning. Biological Psychiatry, 60(4), 361-368

Hofmann, S. G. (2008). Cognitive processes during fear acquisition and extinction in animals and humans: Implications for exposure therapy of anxiety disorders. Clinical Psychology Review, 28(2), 199-210

Hofmann, S. G., \& Asmundson, G. J. G. (2008). Acceptance and mindfulness-based therapy: New wave or old hat? Clinical Psychology Review, 28(1), 1-16

Houben, R. M. A., Ostelo, R. W. J. G., Vlaeyen, J. W. S., Wolters, P. M. J. C., Peters, M., \& Stomp-van den Berg, S. G. M. (2005). Health care providers' orientations towards common low back pain predict perceived harmfulness of physical activities and recommendations regarding return to normal activity. European Journal of Pain, 9(2), 173-183

Jarvik, J., Hollingworth, W., Heagerty, P., Haynor, D., \& Deyo, R. (2001). The Longitudinal Assessment of Imaging and Disability of the Back (LAIDBack) Study: Baseline Data. Spine, 26(10), 1158-1166

Karoly, P., Okun, M. A., Ruehlman, L. S., \& Pugliese, J. A. (2008). The impact of goal cognition and pain severity on disability and depression in adults with chronic pain: An examination of direct effects and mediated effects via pain-induced fear. Cognitive Therapy and Research, 32(3), 418-433

Kori, S., Miller, R., \& Todd, D. (1990). Kinesiophobia: A new view on chronic pain behavior. Pain Management(Jan/Feb), 35-43

Lakke, S. E., Soer, R., Takken, T., \& Reneman, M. F. (2009). Risk and prognostic factors for non-specific musculoskeletal pain: A synthesis of evidence from systematic reviews classified into ICF dimensions. Pain, 147(1-3), 153-164

Lee, K.C., Chiu, T. T. W., \& Lam, T.H. (2006). Psychometric properties of the Fear-Avoidance Beliefs Questionnaire in patients with neck pain. Clinical Rehabilitation, 20(10), 909-920 
Leeuw, M., Goossens, M. E. J. B., Linton, S. J., Crombez, G., Boersma, K., \& Vlaeyen, J. W. S. (2007a). The fear-avoidance model of musculoskeletal pain: Current state of scientific evidence. Journal of Behavioral Medicine, 30(1), 77-94

Leeuw, M., Goossens, M. E. J. B., van Breukelen, G. J. P., Boersma, K., \& Vlaeyen, J. W. S. (2007b). Measuring perceived harmfulness of physical activities in patients with chronic low back pain: The Photograph Series of Daily Activities-short electronic version. The Journal of Pain, 8(11), 840-849

Leeuw, M., Goossens, M. E. J. B., van Breukelen, G. J. P., de Jong, J. R., Heuts, P. H. T. G., Smeets, R. J. E. M., . .. Vlaeyen, J. W. S. (2008). Exposure in vivo versus operant graded activity in chronic low back pain patients: Results of a randomized controlled trial. Pain, 138(1), 192-207

Leeuw, M., Peters, M. L., Wiers, R. W., \& Vlaeyen, J. W. S. (2007c). Measuring Fear of Movement/(Re)injury in Chronic Low Back Pain Using Implicit Measures. Cognitive Behaviour Therapy, 36(1), 52-64

Lethem, J., Slade, P. D., Troup, J. D., \& Bentley, G. (1983). Outline of a fear-avoidance model of exaggerated pain perception. Behaviour Research and Therapy, 21(4), 401-408

Linton, S. (2010). Applying dialectical behavior therapy to chronic pain: A case study. Scandinavian Journal of Pain, 1(1), 50-54

Linton, S. J., Boersma, K., Jansson, M., Overmeer, T., Lindblom, K., \& Vlaeyen, J. W. S. (2008). A randomized controlled trial of exposure in vivo for patients with spinal pain reporting fear of work-related activities. European Journal of Pain, 12(6), 722-730

Linton, S. J., Overmeer, T., Janson, M., Vlaeyen, J. W. S., \& de Jong, J. R. (2002). Graded in-vivo exposure treatment for fear-avoidant pain patients with functional disability: A case study. Cognitive Behaviour Therapy, 31(2), 49-58

Linton, S. J., \& Ryberg, M. (2001). A cognitive-behavioral group intervention as prevention for persistent neck and back pain in a non-patient population: a randomized controlled trial. Pain, 90(1-2), 83-90

Lohnberg, J. A. (2007). A review of outcome studies on cognitive-behavioral therapy for reducing fearavoidance beliefs among individuals with chronic pain. Journal of Clinical Psychology in Medical Settings, 14(2), 113-122

Lovibond, P. F. (2004). Cognitive processes in extinction. Learning \& Memory, 11(5), 495-500

Lovibond, P. F., Davis, N. R., \& O'Flaherty, A. S. (2000). Protection from extinction in human fear conditioning. Behaviour Research and Therapy, 38(10), 967-983

Lovibond, P. F., Mitchell, C. J., Minard, E., Brady, A., \& Menzies, R. G. (2009). Safety behaviours preserve threat beliefs: Protection from extinction of human fear conditioning by an avoidance response. Behaviour Research and Therapy, 47(8), 716-720

Macedo, L. G., Smeets, R. J. E. M., Maher, C. G., Latimer, J., \& McAuley, J. H. (2010). Graded activity and graded exposure for persistent non-specific low back pain: a systematic review. Physical Therapy, 90(6), 860-879. doi: 10.2522/ptj.20090303

McCracken, L. M., \& Keogh, E. (2009). Acceptance, mindfulness, and values-based action may counteract fear and avoidance of emotions in chronic pain: An analysis of anxiety sensitivity. The Journal of Pain, 10(4), 408-415 
McCracken, L. M., Vowles, K. E., \& Eccleston, C. (2005). Acceptance-based treatment for persons with complex, long standing chronic pain: A preliminary analysis of treatment outcome in comparison to a waiting phase. Behaviour Research and Therapy, 43(10), 1335-1346

McCracken, L. M., Zayfert, C., \& Gross, R. T. (1992). The Pain Anxiety Symptoms Scale: Development and validation of a scale to measure fear of pain. Pain, 50(1), 67-73. doi:10.1016/0304-3959(92)90113-p

Mineka, S., \& Zinbarg, R. (2006). A contemporary learning theory perspective on the etiology of anxiety disorders: It's not what you thought it was. American Psychologist, 61(1), 10-26

Moore, J. E., Von Korff, M., Cherkin, D., Saunders, K., \& Lorig, K. (2000). A randomized trial of a cognitivebehavioral program for enhancing back pain self care in a primary care setting. Pain, 88, 145-153

Nederhand, M. J., Hermens, H. J., IJzerman, M. J., Groothuis, K. G. M., \& Turk, D. C. (2006). The Effect of Fear of Movement on Muscle Activation in Posttraumatic Neck Pain Disability. The Clinical Journal of Pain, 22(6), 519-525

Nelson, D. V., \& Novy, D. M. (1997). Self-report differentiation of anxiety and depression in chronic pain. Journal of Personality Assessment, 69(2), 392-407

Norton, P. J., \& Asmundson, G. J. G. (2003). Amending the fear-avoidance model of chronic pain: What is the role of physiological arousal? Behavior Therapy, 34(1), 17-30

Olsson, A., \& Phelps, E. A. (2004). Learned Fear of 'Unseen' Faces After Pavlovian, Observational, and Instructed Fear. Psychological Science, 15(12), 822-828

Olsson, A., \& Phelps, E. A. (2007). Social learning of fear. Nature Neuroscience, 10(9), 1095-1102

Picavet, H. S. J., Vlaeyen, J. W. S., \& Schouten, J. S. A. G. (2002). Pain Catastrophizing and Kinesiophobia: Predictors of Chronic Low Back Pain. American Journal of Epidemiology, 156(11), 1028-1034

Pincus, T., Vogel, S., Burton, K. A., Santos, R., \& Field, A. P. (2006). Fear Avoidance and Prognosis in Back Pain. Arthritis \& Rheumatism, 54(12), 3999-4010

Pizzi, L. T., Carter, C. T., Howell, J. B., Vallow, S. M., Crawford, A. G., \& Frank, E. D. (2005). Work Loss, Healthcare Utilization, and Costs among US Employees with Chronic Pain. Disease Management \& Health Outcomes, 13(3), 201-208

Powers, M. B., Smits, J. A. J., \& Telch, M. J. (2004). Disentangling the Effects of Safety-Behavior Utilization and Safety-Behavior Availability During Exposure-Based Treatment: A Placebo-Controlled Trial. Journal of Consulting and Clinical Psychology, 72(3), 448-454

Quinn, J. J., Fanselow, M. S., Craske, M. G., Hermans, D., \& Vansteenwegen, D. (2006). Defenses and Memories: Functional Neural Circuitry of Fear and Conditional Responding Fear and learning: From basic processes to clinical implications. (pp. 55-74). Washington, DC US: American Psychological Association

Rachman, S., Radomsky, A. S., \& Shafran, R. (2008). Safety behaviour: A reconsideration. Behav Res Ther, 46(2), 163-173. doi:10.1016/j.brat.2007.11.008

Rainville, J., Bagnall, D., \& Phalen, L. (1995). Health care providers' attitudes and beliefs about functional impairments and chronic back pain. The Clinical Journal of Pain, 11(4), 287-295

Roelofs, J., Goubert, L., Peters, M. L., Vlaeyen, J. W. S., \& Crombez, G. (2004). The Tampa Scale for Kinesiophobia: Further examination of psychometric properties in patients with chronic low back pain and fibromyalgia. European Journal of Pain, 8(5), 495-502 
Roelofs, J., McCracken, L., Peters, M. L., Crombez, G., van Breukelen, G., \& Vlaeyen, J. W. S. (2004). Psychometric Evaluation of the Pain Anxiety Symptoms Scale (PASS) in Chronic Pain Patients. Journal of Behavioral Medicine, 27(2), 167-183. doi:10.1023/B:JOBM.0000019850.51400.a6

Roelofs, J., Peters, M. L., McCracken, L., \& Vlaeyen, J. W. S. (2003). The pain vigilance and awareness questionnaire (PVAQ): Further psychometric evaluation in fibromyalgia and other chronic pain syndromes. Pain, 101(3), 299-306

Roelofs, J., Sluiter, J. K., Frings-Dresen, M. H. W., Goossens, M., Thibault, P., Boersma, K., \& Vlaeyen, J. W. S. (2007). Fear of movement and (re)injury in chronic musculoskeletal pain: Evidence for an invariant two-factor model of the Tampa Scale for Kinesiophobia across pain diagnoses and Dutch, Swedish, and Canadian samples. Pain, 131(1-2), 181-190

Salkovskis, P. M. (1996). The cognitive approach to anxiety: Threat beliefs, safety-seeking behavior, and the special case of health anxiety and obsessions. New York: Guilford

Salkovskis, P. M., Clark, D. M., \& Gelder, M. G. (1996). Cognition-behaviour links in the persistence of panic. Behaviour Research and Therapy, 34(5-6), 453-458

Salkovskis, P. M., Clark, D. M., Hackmann, A., Wells, A., \& Gelder, M. G. (1999). An experimental investigation of the role of safety-seeking behaviours in the maintenance of panic disorder with agoraphobia. Behaviour Research and Therapy, 37(6), 559-574

Schrooten, M. G., \& Vlaeyen, J. W. S. (2010). Becoming active again? Further thoughts on goal pursuit in chronic pain. Pain, 149(3), 422-423. doi: 10.1016/j.pain.2010.02.038

Seminowicz, D. A., \& Davis, K. D. (2006). Cortical responses to pain in healthy individuals depends on pain catastrophizing. Pain, 120(3), 297-306

Severeijns, R., van den Hout, M. A., Vlaeyen, J. W. S., \& Picavet, H. S. J. (2002). Pain catastrophizing and general health status in a large Dutch community sample. Pain, 99(1-2), 367-376

Severeijns, R., Vlaeyen, J. W. S., van den Hout, M. A., \& Weber, W. E. J. (2001). Pain catastrophizing predicts pain intensity, disability, and psychological distress independent of the level of physical impairment. The Clinical Journal of Pain, 17(2), 165-172

Sieben, J. M., Portegijs, P. J. M., Vlaeyen, J. W. S., \& Knottnerus, J. A. (2005a). Pain-related fear at the start of a new low back pain episode. European Journal of Pain, 9(6), 635-641

Sieben, J. M., Vlaeyen, J. W. S., Portegijs, P. J. M., Verbunt, J. A., van Riet-Rutgers, S., Kester, A. D. M., . . Knottnerus, J. A. (2005b). A longitudinal study on the predictive validity of the fear-avoidance model in low back pain. Pain, 117(1-2), 162-170

Sinha, S., Papp, L. A., \& Gorman, J. M. (2000). How study of respiratory physiology aided our understanding of abnormal brain function in panic disorder. Journal of Affective Disorders, 61(3), 191-200

Smeets, R. J. E. M., Vlaeyen, J. W. S., Kester, A. D. M., \& Knottnerus, J. A. (2006). Reduction of Pain Catastrophizing Mediates the Outcome of Both Physical and Cognitive-Behavioral Treatment in Chronic Low Back Pain. The Journal of Pain, 7(4), 261-271

Stewart, S. H., \& Asmundson, G. J. G. (2006). Anxiety sensitivity and its impact on pain experiences and conditions: A state of the art. Cognitive Behaviour Therapy, 35(4), 185-188 
Sullivan, M. J. L., Bishop, S. R., \& Pivik, J. (1995). The Pain Catastrophizing Scale: Development and validation. Psychological Assessment, 7(4), 524-532

Swinkels-Meewisse, I. E. J., Roelofs, J., Oostendorp, R. A. B., Verbeek, A. L. M., \& Vlaeyen, J. W. S. (2006) Acute low back pain: Pain-related fear and pain catastrophizing influence physical performance and perceived disability. Pain, 120(1), 36-43

Tang, N. K. Y., Salkovskis, P. M., Poplavskaya, E., Wright, K. J., Hanna, M., \& Hester, J. (2007). Increased use of safety-seeking behaviors in chronic back pain patients with high health anxiety. Behaviour Research and Therapy, 45(12), 2821-2835

ter Kuile, M. M., Bulté, I., Weijenborg, P. T. M., Beekman, A., Melles, R., \& Onghena, P. (2009). Therapistaided exposure for women with lifelong vaginismus: A replicated single-case design. Journal of Consulting and Clinical Psychology, 77(1), 149-159

Trost, Z., France, C. R., \& Thomas, J. S. (2008). Exposure to movement in chronic back pain: Evidence of successful generalization across a reaching task. Pain, 137(1), 26-33

Tsang, A., Von Korff, M., Lee, S., Alonso, J., Karam, E., Angermeyer, M. C., .. Watanabe, M. (2008). Common Chronic Pain Conditions in Developed and Developing Countries: Gender and Age Differences and Comorbidity With Depression-Anxiety Disorders. The Journal of Pain, 9(10), 883-891

Turk, D. C., \& Okifuji, A. (2001). Pain terms and taxonomies. In J. D. Loeser, S. H. Butler, C. R. Chapman, \& D. C. Turk (Eds.), Bonica's management of pain (3 ed., pp. 18-25). New York: Lippincott Williams \& Wilkins

Turk, D. C., Robinson, J. P., Sherman, J. J., Burwinkle, T., \& Swanson, K. (2008). Assessing fear in patients with cervical pain: Development and validation of the Pictorial Fear of Activity Scale-Cervical (PFActS-C). Pain, 139(1), 55-62

Van Damme, S., Crombez, G., \& Eccleston, C. (2008). Coping with pain: A motivational perspective. Pain, 139(1), 1-4

van Leeuwen, M. T., Blyth, F. M., March, L. M., Nicholas, M. K., \& Cousins, M. J. (2006). Chronic pain and reduced work effectiveness: The hidden cost to Australian employers. European Journal of Pain, 10(2), 161-166

van Tulder, M. W., Assendelft, W. J. J., Koes, B. W., \& Bouter, L. M. (1997). Spinal Radiographic Findings and Nonspecific Low Back Pain: A Systematic Review of Observational Studies. Spine, 22(4), 427-434

Vancleef, L. M. G., Peters, M. L., Gilissen, S. M. P., \& De Jong, P. J. (2007). Understanding the role of injury/ illness sensitivity and anxiety sensitivity in (automatic) pain processing: An examination using the extrinsic affective Simon task. The Journal of Pain, 8(7), 563-572

Vangronsveld, K., Peters, M., Goossens, M. E., Linton, S., \& Vlaeyen, J. W. (2007). Applying the fearavoidance model to the chronic whiplash syndrome. Pain, 131(3), 258-261

Vervliet, B., Vansteenwegen, D., Hermans, D., \& Eelen, P. (2007). Concurrent excitors limit the extinction of conditioned fear in humans. Behaviour Research and Therapy, 45(2), 375-383

Vlaeyen, J. W. S., Crombez, G., \& Linton, S. J. (2009). The fear-avoidance model of pain: We are not there yet. Comment on Wideman et al. "A prospective sequential analysis of the fear-avoidance model of pain" [Pain, 2009] and Nicholas "First things first: reduction in catastrophizing before fear of movement" [Pain, 2009]. Pain, 146(1-2), 222-222 
Vlaeyen, J. W. S., de Jong, J. R., Geilen, M., Heuts, P. H. T. G., \& van Breukelen, G. (2001). Graded exposure in vivo in the treatment of pain-related fear: A replicated single-case experimental design in four patients with chronic low back pain. Behaviour Research and Therapy, 39(2), 151-166

Vlaeyen, J. W. S., de Jong, J. R., Geilen, M., Heuts, P. H. T. G., \& van Breukelen, G. (2002). The treatment of fear of movement/(re)injury in chronic low back pain: Further evidence on the effectiveness of exposure in vivo. The Clinical Journal of Pain, 18(4), 251-261

Vlaeyen, J. W. S., de Jong, J. R., Leeuw, M., \& Crombez, G. (2004). Fear reduction in chronic pain; Graded exposure in vivo with behavioral experiments. In G. J. G. Asmundson, J. W. S. Vlaeyen, \& G. Crombez (Eds.), Understanding and treating fear of pain (pp. 313-343). Oxford: University Press

Vlaeyen, J. W. S., de Jong, J. R., Onghena, P., Kerckhoffs-Hanssen, M., \& Kole-Snijders, A. M. J. (2002). Can pain-related fear be reduced? The application of cognitive-behavioural exposure in vivo. Pain Research \& Management, 7(3), 144-153

Vlaeyen, J. W. S., de Jong, J. R., Sieben, J. M., \& Crombez, G. (2002). Graded Exposure In Vivo for PainRelated Fear. In D. C. Turk \& R. J. Gatchel (Eds.), Psychological approaches to pain management: a practitioner's handbook (2 ed., pp. 210-233). New York: Guilford Press

Vlaeyen, J. W. S., Kole-Snijders, A. M. J., Boeren, R. G. B., \& van Eek, H. (1995). Fear of movement/(re)injury in chronic low back pain and its relation to behavioral performance. Pain, 62(3), 363-372

Vlaeyen, J. W. S., \& Linton, S. J. (2000). Fear-avoidance and its consequences in chronic musculoskeletal pain: A state of the art. Pain, 85(3), 317-332

Vlaeyen, J. W. S., \& Linton, S. J. (2006). Are we 'fear-avoidant?' Pain, 124(3), 240-241

Waddell, G. (2004). The biopsychosocial model. In G. Waddell (Ed.), The Back Pain Revolution (pp. 265-282). Edinburgh: Churchill Livingston

Waddell, G., Newton, M., Henderson, I., \& Somerville, D. (1993). A Fear-Avoidance Beliefs Questionnaire (FABQ) and the role of fear-avoidance beliefs in chronic low back pain and disability. Pain, 52(2), 157-168 Wall, P. D. (1979). On the relation of injury to pain the John J. Bonica Lecture. Pain, 6(3), 253-264

Wicksell, R. K., Ahlqvist, J., Bring, A., Melin, L., \& Olsson, G. L. (2008). Can exposure and acceptance strategies improve functioning and life satisfaction in people with chronic pain and whiplashassociated disorders (WAD)? A randomized controlled trial. Cognitive Behaviour Therapy, 37(3), 1-14 Wicksell, R. K., Melin, L., Lekander, M., \& Olsson, G. L. (2009). Evaluating the effectiveness of exposure and acceptance strategies to improve functioning and quality of life in longstanding pediatric pain-A randomized controlled trial Pain, 141(3), 248-257

Wilmink, J., \& Patijn, J. (2001). MR imaging of alar ligament in whiplash-associated disorders: an observer study. Neuroradiology, 43(10), 859-863

Woods, M. P., \& Asmundson, G. J. G. (2008). Evaluating the efficacy of graded in vivo exposure for the treatment of fear in patients with chronic back pain: A randomized controlled clinical trial. Pain, 136(3), 271-280 


\section{Chapter 3}

\section{The effect of threat}

information on acquisition, extinction and reinstatement of experimentally conditioned fear of movement-related pain

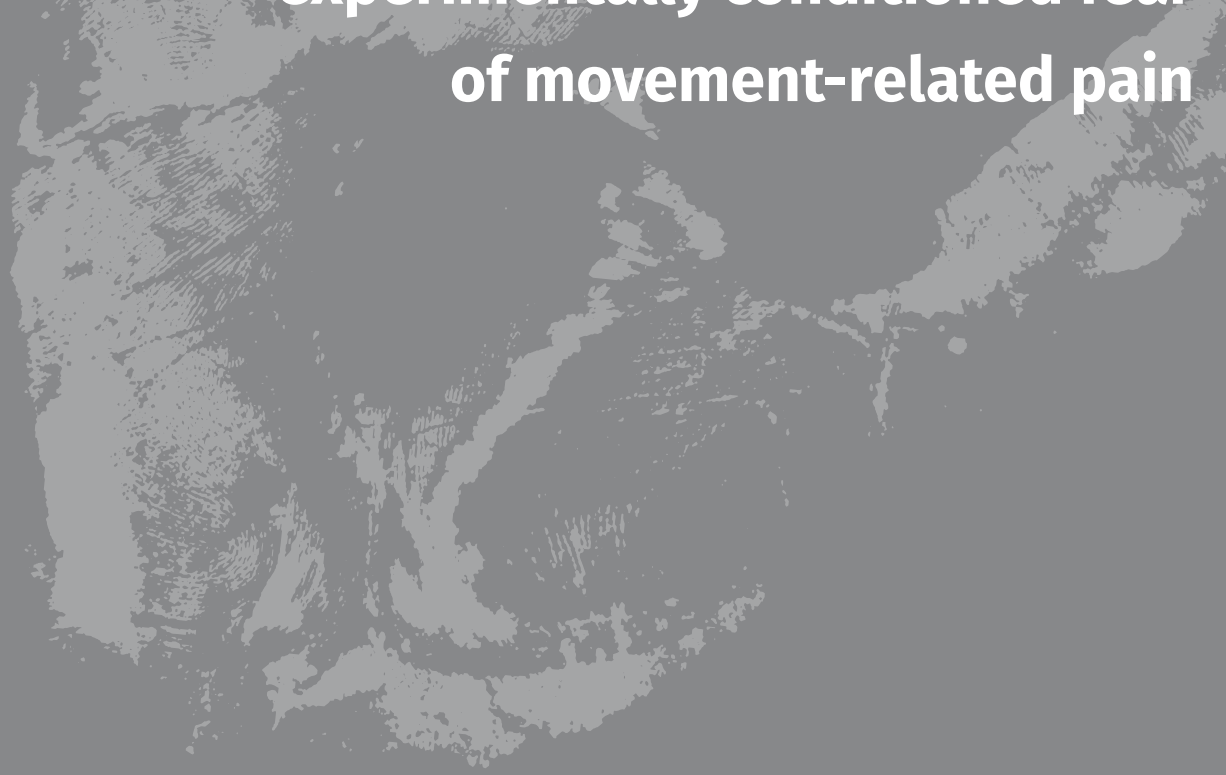

Published as: den Hollander, M., Meulders, A., Jakobs, M. \& Vlaeyen, J.W.S. (2015). The effect of threat information on acquisition, extinction and reinstatement of experimentally conditioned fear of movement-related pain. Pain Medicine, 16, 2302-15. 


\section{Abstract}

\section{Objective}

The experiential acquisition of pain-related fear has been demonstrated by pairing a painful electrocutaneous stimulus (pain-US) with one movement (CS+) but not with another (CS-). However, it is expected that during acquisition through direct experience, pain-related fear can be intensified or weakened by verbally/visually transmitted information about the pain and its meaning.

\section{Method}

Participants received threatening information (US-inflation), safety information (US-deflation), or no information about the pain-US (US-same). Additionally, we measured return of fear after a reinstatement procedure: two unsignaled pain-USS were presented in the experimental groups, but not in the control groups.

\section{Results}

We replicated the acquisition and extinction of experimentally induced fear of movement-related pain in healthy subjects both in the verbal reports and the eyeblink startle measures. Two reinstating pain-US presentations led to a differential return of self-reported fear and a non-differential return of fear in the eye-blink startle responses. Although we failed to find an effect of verbal/visual information regarding the meaning of the pain-US on the acquisition, extinction or reinstatement of pain-related fear, we did observe a pain sensitization effect over time suggesting that our threat manipulation induced an increase of perceived threat in all groups.

\section{Conclusion}

The results suggest that our threat manipulation might not have worked or that it was not sensitive enough to yield group-specific effects. We replicated acquisition, extinction, and return of experimentally conditioned fear of movement-related pain, but the threat manipulation failed to generate any additional effects. 


\section{Introduction}

Current fear-avoidance models consider pain-related fear pivotal in the development and maintenance of chronic pain disability (Leeuw et al., 2007; Vlaeyen \& Linton, 2000; Zale, Lange, Fields, \& Ditre, 2013), and suggest that it is acquired through associative learning. Indeed, healthy participants can learn to fear a painful movement in an experimental setting (Meulders, Vansteenwegen, \& Vlaeyen, 2011). Using a differential fear conditioning paradigm, in which one movement (Conditioned Stimulus, CS +) is repeatedly paired with a painful stimulus (Unconditioned Stimulus, Pain-US), and another (CS-) movement is not, defensive fear/avoidance responses (CRs) emerged in response to the CS +. This Voluntary Joystick Movement (VJM) paradigm has also been used to demonstrate extinction (Meulders \& Vlaeyen, 2012) and generalization (Meulders, Vandebroek, Vervliet, \& Vlaeyen, 2013; Meulders \& Vlaeyen, 2013a) of fear of movement-related pain.

After fear acquisition, the strength of the CR can be altered by changing the intensity of the US, which is called US-revaluation (Davey, 1989). Increased CRS often occur after exposure to a more intense US (US-inflation) (De Jong, Merckelbach, Koertshuis, \& Muris, 1994; White \& Davey, 1989); the opposite can occur after exposure to a milder US (US-deflation) (Hosoba, Iwanaga, \& Seiwa, 2001). Interestingly, it is not even necessary to actually experience the US to change its affective value; verbally transmitted information (Wiech et al., 2010) or observation of another's experience (Trost, France, Vervoort, Lange, \& Goubert, 2014) can also result in US-revaluation, although findings are inconsistent (De Jong et al., 1994; De Jong, Muris, \& Merckelbach, 1996; Devriese, De Peuter, Van Diest, Van de Woestijne, \& Van den Bergh, 2006; Winters et al., 2003). Additionally, it has been shown that pain intensity reports vary depending on the perceived threat of the US (Arntz \& Claassens, 2004).

Chronic pain patients often report that the way they perceive their pain (in being associated with harm and (re-)injury) is not only based on their own experiences, but also on information (i.e. doctors, internet, other patients). Information can "inflate" (Ash et al., 2008) as well as "deflate" (de Jong et al., 2005) the threat-value of pain. For example, reading information on the internet can raise more worries about pain (example inflation: "I read that my pain might be a caused by a herniated disc. I should be careful when lifting, and bend my knees, so I'll make sure I won't damage my nerves") or reassure about painful experiences (example deflation: "Even if my pain would be caused by a herniated disk, I read here that I am still allowed to move my back").

The first aim was to investigate whether information (verbal and visual) about pain can influence pain-related fear levels in an experimental setting. Chronic pain patients report enhanced levels of the threat-value of pain, thus to enhance 
ecological validity and leaving room to detect effects in both directions, moderate threat was induced for all participants at the start of the experiment. Participants received visual feedback that indicated respectively increasing threat (US-inflation group), decreasing threat (US-deflation group) or constant threat (no-US manipulation control group). Also to strengthen the similarity with fear of movement observed in chronic pain, a proprioceptive predictor (CS+) for the pain-US was used. We adapted the VIM paradigm (Meulders et al., 2011) by adding bogus feedback on skin-vulnerability to manipulate the threat-value of the pain-US in an experimental setting with healthy subjects. A second aim was to investigate the return of fear after extinction. This is a relevant issue, since estimates of return of fear after successful treatment in anxiety disorders range from 19 to 62\% (Craske \& Mystkowski, 2006). A standard procedure to investigate return of fear in the lab (Dirikx, Hermans, Vansteenwegen, Baeyens, \& Eelen, 2004; Dirikx, Hermans, Vansteenwegen, Baeyens, \& Eelen, 2007; Dirikx, Vansteenwegen, Eelen, \& Hermans, 2009; LaBar \& Phelps, 2005; Norrholm et al., 2006) is presenting an unexpected US after successful fear extinction. This procedure has shown to reactivate fearful responding to the original CS + (but not to the CS-), but also non-differential return of fear (increased fear to both the CS + and CS-) has been observed (Dirikx, Vansteenwegen, Eelen, \& Hermans, 2009). This procedure is referred to as reinstatement. It is commonly accepted that extinction learning is not unlearning, but rather the behavioral inhibition of an original CS-US association, by a new CS-noUS association (Bouton, 1984, 1994, 2000, 2002). As a consequence, the acquisition memory is never erased but exists besides the extinction memory. The extinction memory is known to be more context-dependent and more fragile. In line with this reasoning, the mechanism underlying reinstatement might be that the presentation of the US activates the memory representation of the CS, and therefore acquisition memory is reactivated leading to a return of conditioned fear. A clinical example relating to this lab procedure may be the following: a patient successfully treated with graded exposure in vivo might start to avoid activities (CS) again after suddenly experiencing back pain (US) during rest (no experienced association between pain and activity). We hypothesized that threat inflation of the pain-US would heighten fear responses to the CS + during acquisition, slow down extinction, and increase the return of fear after reinstatement, compared to both the US-deflation- and no-US control groups. In addition, a differential return of fear was expected for the reinstatement group (receiving two unsignalled USs), but not for controls. To our knowledge, the role of US-revaluation on acquisition, extinction, and return of fear after a reinstatement procedure has not been studied in the field of fear of movement-related pain yet. 


\section{Materials and methods}

\section{Participants}

Ninety-six healthy male participants $\left(M_{\text {age }}=21\right.$ years, $S D_{\text {age }}=5.63$, range $=16-37$ years $)$ participated and received course credit or $8 €$. Only male participants were selected, because women typically rate the same physical pain-US as increasingly painful over time (Meulders, Vansteenwegen, \& Vlaeyen, 2012), which could confound our results. Exclusion criteria were respiratory, cardiovascular, neurological diseases, other severe medical conditions, psychiatric disorders, chronic pain, hearing problems, pain at the dominant hand/wrist. The ethics committee of the Department of Psychology of the University of Leuven approved the study protocol. Participants provided informed consent (and parental informed consent for 4 participants $<18$ years). Six experimental groups were created, crossing three levels of verbal threat information (inflation, deflation and same threat; INFL, DEFL, and SAME) with two levels of the reinstatement manipulation (reinstatement and control; EXP and CTRL). Data of 13 participants were excluded because of technical problems with their psychophysiological data.

\section{Stimulus material and experimental setting}

Two proprioceptive stimuli i.e. moving a joystick (Logitech Attack 3, Newark, CA) to the left/right, served as CSs. An electrocutaneous stimulus of $2 \mathrm{~ms}$, delivered by a commercial stimulator (DS7A, Digitimer, Welwyn Garden City, United Kingdom) through surface Sensormedics electrodes (8 mm) (SensorMedics Corp, Yorba Linda, Calif) filled with K-Y gel (Johnson \& Johnson, New Brunswick, NJ) was used as pain-US, its intensity was personally selected during calibration (see Procedure). The experiment was programmed using Affect 4.0 (Spruyt, Clarysse, Vansteenwegen, Baeyens, \& Hermans, 2010). Participants were seated in an armchair (0.6m distance from the computer screen) in a sound-attenuated room with dimmed lights, adjacent to the experimenter's room. Verbal communication was possible through an intercom system and observation through a closed-circuit TV-installation. 


\section{Measures and manipulation check}

\section{Self-reported fear of movement-related pain}

The question "How afraid were you to perform the left/right movement?" was rated after each block on an 11-point Likert scale (range 0-10) with anchor points 'not afraid at all' to 'very afraid.'

\section{Eye-blink startle modulation}

Traditionally, electromyographic (EMG) activity of the Orbicularis Oculi upon an acoustic startle probe is used as an index of fear learning (Weike, Schupp, \& Hamm, 2007). Eye-blink responses elicited by probes delivered during CSs served as an index for fear of movement-related pain. Orbicularis Oculi EMG was recorded with three Ag/ AgCl Sensormedics electrodes $(0.25 \mathrm{~cm})$ filled with electrolyte gel, placed following the Blumenthal et al. guidelines (Blumenthal et al., 2005). The raw signal was amplified by a Coulbourn isolated bioamplifier with bandpass filter (LabLinc v75-04). The recording bandwidth of the EMG signal was between $90 \mathrm{~Hz}$ and $1 \mathrm{kHz}( \pm 3 \mathrm{~dB})$. The signal was rectified online and smoothed by a Coulbourn multifunction integrator (LabLinc v76-23A) with a time constant of 20 ms. The EMG signal was digitized at 1000 $\mathrm{Hz}$ from $200 \mathrm{~ms}$ before the startle probe until $1000 \mathrm{~ms}$ after probe onset. The startle probe was a $100 \mathrm{dBA}$ burst of white noise with instantaneous rise time presented binaurally for 50 ms through headphones (Philips, Stereo headphones, SHP2500).

\section{Pain-US intensity}

Participants rated painfulness ("How painful did you find the electrocutaneous stimulus in the previous block?") after each acquisition block (A1-3) on an 11-point Likert scale (range 0-10) with anchor points 'not painful at all' to 'extremely painful'.

\section{Manipulation check}

Retrospective pain-US expectancy was assessed after extinction (E3). Participants indicated their expectancy of the pain-US for CS + and CS- on an 11-point Likert scale (range 0-10) with labels 'not at all' to 'very much'. 
To measure affective valence of CSs, the Self-Assessment Manikin scale (Bradley \& Lang, 1994), consisting of 5 pictographs, was completed. Participants indicated how (un)happy/distressed they felt when performing both CS movements before acquisition and after extinction.

\section{Behavioral task}

After the experiment, participants were asked to perform a similar pain task with a colleague whose participant did not show up as a sham procedure. Forced choice (yes/no) was recorded.

\section{Procedure}

We adapted the VJM paradigm (Meulders et al., 2011; Meulders \& Vlaeyen, 2012, 2013a) to manipulate the threat-value of the pain-US by bogus feedback using a "skin sensitivity indicator" (see Figure 1). A pointer moved along the coloured bar to inform participants of the vulnerability of their skin to possible injury caused by the electrocutaneous stimuli. The detailed between-subject design is shown in Figure 2. During acquisition and extinction, all participants performed the same task, but received different bogus feedback about their skin-vulnerability (INFL, DEFL, SAME). During acquisition, the left (CS+) movement was followed by the pain-US, whereas the right (CS-) movement was not (CS + /CS- counterbalanced). During extinction, the $\mathrm{CS}+$ movement was no longer reinforced. During the reinstatement phase, the experimental group (EXP) received two unsignalled pain-USs, whereas the control group (CTRL) did not. Next, we tested the return of fear in the different groups.

\section{Preparation}

After participants provided informed consent, EMG electrodes (under the left eye and on the forehead), pain-US stimulation electrodes (wrist dominant hand), and a bogus sensor (between the stimulation electrodes) were attached. 


\section{Practice}

Participants moved the joystick to the left/right after the starting signal "+" (presented in the centre of the screen). Within each block, eight movements were made (4 left/right), in a freely chosen order. The corresponding counter bar coloured blue after each successful movement (see Figure 1). Two blocks of eight trials were run without presenting pain-USs or startle probes.

\section{Startle probe habituation}

Because startle responses to the first probes are usually larger, a habituation phase including eight trials of $24 \mathrm{~s}$, with one probe per trial (between $1^{\text {st }}-2^{\text {nd }}$ second, at $10^{\text {th }}$ second/between $15^{\text {th }}-17^{\text {th }}$ second) and no pain-USs was added. Participants wore headphones, and only dimmed light was available.

Pain-US calibration

To select the pain-US intensity, participants received electrocutaneous stimuli of increasing intensity and rated how intense/painful each stimulus was on a 1-10 scale (1: "you feel something but this is not painful, it is merely a sensation" up to 10: "this is the worst pain you can imagine"). A subjective stimulus intensity of ' 8 ' ("significantly painful and demanding some effort to tolerate") was targeted (mean $=7.98, S D=0.38$, range 6-9). The stimulus intensity in $\mathrm{mA}$ was 43.39 ( $S D=23.07$, range 11-99 mA).

\section{Threat induction}

To maximize the chance to detect inflation and deflation effects, all participants were initially provided with threatening information about their skin-vulnerability (Wiech et al., 2010); after skin inspection around the (bogus) sensor, it was explained that the sensor measures skin-vulnerability online. Participants were asked to carefully monitor this sensor, because their skin reacted obviously stronger during calibration, indicated by the pointer being in orange (verbatim instructions available in supplementary material). In reality, the pointer was fixed in the orange zone (= middle of the coloured bar) for all participants at the onset of the experiment. During acquisition, the pointer moved from orange to almost red during in the inflation group; from orange to almost green in the deflation group, and in the same threat group the pointer remained in the orange zone throughout the experiment. To increase the 
credibility of the bogus feedback, the position of the pointer was updated right after the pain-US administration and the pointer made minimal random fluctuations (1 $\mathrm{mm}$ ) in both directions throughout the procedure.

Figure 1. Flow chart of an exemplary trial in the VJM paradigm.

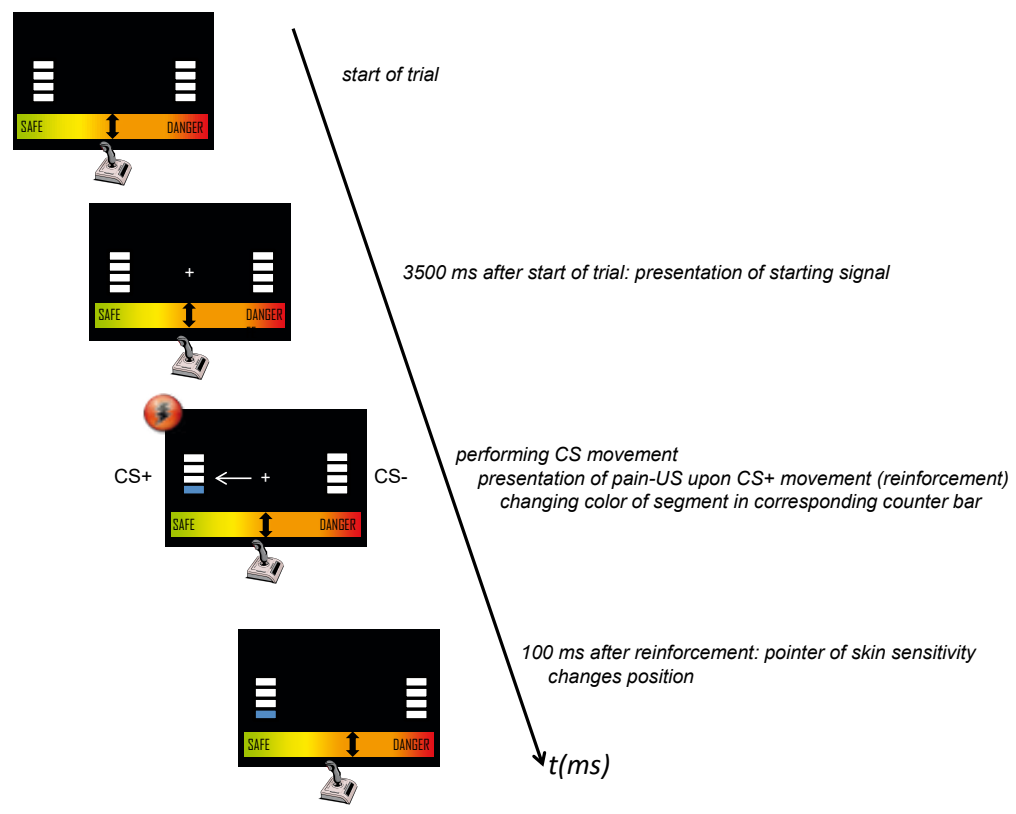

Note: the pointer changes direction after CS + trials depending on threat condition. For INFL, the pointer moves to the right, into the danger zone (as shown here). For DEFL, the pointer moves to the left, into the safe zone. For SAME, the pointer stays in the same place during the entire experiment. The " + fixation cross represents the starting signal to initiate a movement, a lightning bolt represents the presentation of a painful electrocutaneous stimulus (pain-US), the white arrow represents the CS movement that a participant performs on that certain trial. CS + refers to a reinforced movement (pain US), CS- refers to a non-reinforced movement (no pain US). The coloring of a segment bar indicates a successful movement, and white segment bars represent movements that still ought to be performed. 


\section{Fear acquisition}

The task was largely identical as in the practice phase with the exception that 1) pain-USs and startle probes were presented, 2) three blocks (A1-3) of eight trials were run. The pain-US was presented immediately after each CS + movement. In each block, three startle probes were presented during three CS + and three CS- movements. Note that participants were never informed about the contingencies between the movements (CSs) and the pain-US. Acquisition started with the pointer of the skin-vulnerability indicator in the orange position (A1). Then (A2), the pointer moved after each CS + movement: from orange to almost red (INFL), from orange to almost green (DEFL), or remained in place in the orange zone (SAME). For all participants, the pointer was kept in that same location during the third acquisition block (A3). After each block, fear of movement-related pain of the CSs was rated on a numerical 11-point scale with text labels "not afraid at all"-and "very afraid" on the extremes.

Figure 2. Experimental flow chart.

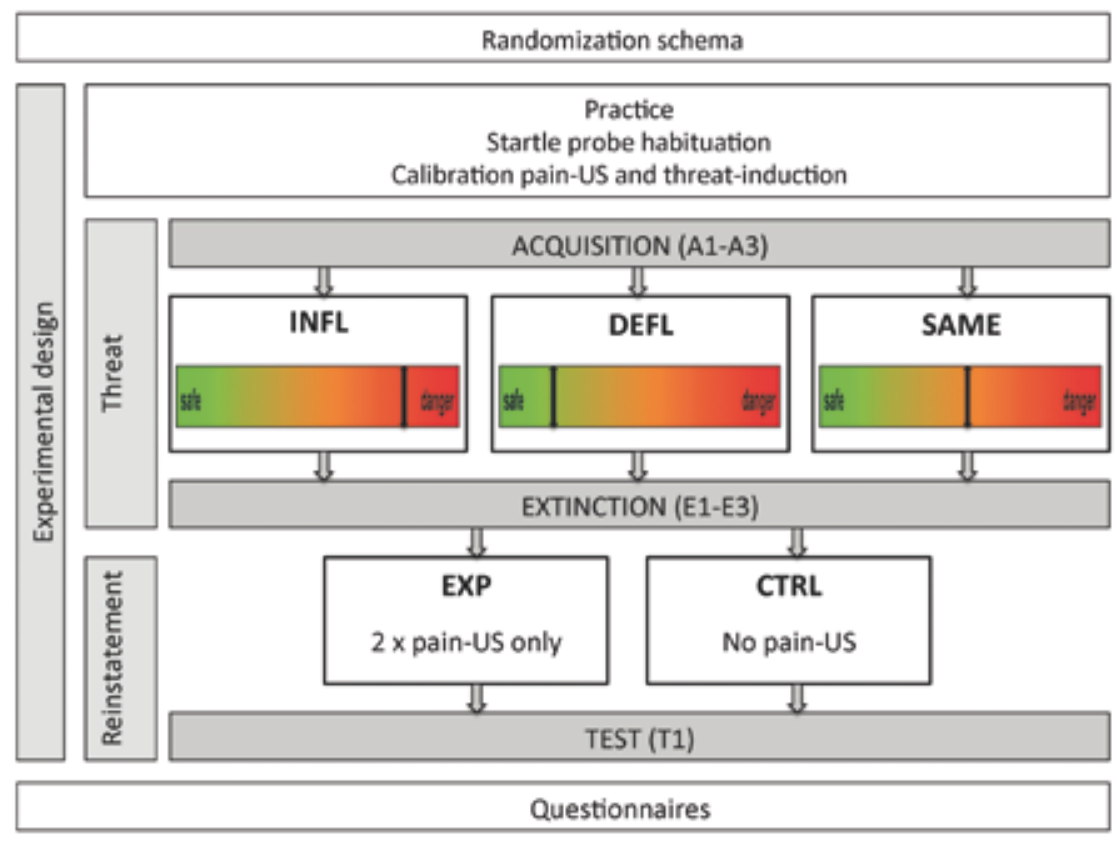




\section{Fear extinction}

Extinction (E1-3) was identical to acquisition, except that no pain-USs were presented anymore. During extinction, the pointer was kept almost in green for DEFL, in orange for SAME and almost in red for INFL. After each block, fear of movement-related pain of the CSs was rated on the same numerical 11-point scale used during acquisition.

\section{Reinstatement phase}

Between E3 and T1 (see Figure 1), the experimental groups received two unsignalled reinstating pain-USS, whereas the control groups did not. Next, we tested return of fear under extinction by presenting one test block (T1; 4 left/4 right movements).

\section{Data reduction and statistical analyses}

Using PsychopHysiological Analysis (PSPHA) (De Clercq, Verschuere, De Vlieger, \& Crombez, 2006), we calculated the peak amplitudes (maximum of the response curve within 21-175 ms after the startle probe onset). Each peak amplitude was scored by subtracting its baseline score (averaged EMG level between 1 and 20 ms after the probe onset). Raw scores were transformed to T-scores to account for interindividual differences in physiological reactivity. Averages were calculated per block for responses during the CS movements.

Separate repeated measures (RM) ANOVAs were run to examine the acquisition, extinction, and reinstatement effects in a total sample of 83 on different dependent measures. Since the reinstatement procedure only took place after extinction, no interactions with this variable were anticipated during acquisition or extinction. Greenhouse-Geisser corrections are reported when appropriate. Uncorrected degrees of freedom and corrected $p$-values are reported together with $\varepsilon$ and the effect size indication $\left(\eta_{p}^{2}\right)$ Because we had clear a priori hypotheses, data were further analyzed using follow-up planned comparisons. 


\section{Results}

\section{Descriptives for the pain-US intensity measures and psychological trait variables}

We analyzed the mean self-reported and physical pain-US intensity levels (in mA) to check whether the groups were comparable at baseline (see Table 1). One-way ANOVAs revealed no significant differences between groups (self-reported pain-USintensity, $F(5,77)=0.50, p=.774$; physical pain-US intensity, $F(5,77)=1.54, p=.188)$.

Table 1. Summary of one-way ANOVAs testing differences in age and pain-US intensity measures with mean and standard deviation per group.

\begin{tabular}{|c|c|c|c|c|c|c|c|c|}
\hline & $\begin{array}{l}\text { INFL-EXP } \\
\left(n=14^{*}\right)\end{array}$ & $\begin{array}{c}\text { DEFL-EXP } \\
(n=12)\end{array}$ & $\begin{array}{c}\text { SAME-EXP } \\
\left(n=13^{*}\right)\end{array}$ & $\begin{array}{c}\text { INFL-CTRL } \\
(n=12)\end{array}$ & $\begin{array}{c}\text { DEFL- CTRL } \\
\left(n=16^{*}\right)\end{array}$ & $\begin{array}{c}\text { SAME- CTRL } \\
(n=16)\end{array}$ & \multirow[t]{2}{*}{$F(\mathrm{df})$} & \multirow[t]{2}{*}{$p$} \\
\hline $\begin{array}{l}\text { Total } \\
N=83\end{array}$ & $M(S D)$ & $M(S D)$ & $M(S D)$ & $M(S D)$ & $M(S D)$ & $M(S D)$ & & \\
\hline Age & $22.71(6.16)$ & $18.5(1.38)$ & $20.38(3.80)$ & 20.42 (3.15) & $20.94(3,32)$ & $21.56(5,64)$ & $1.37(5,77)$ & .244 \\
\hline $\begin{array}{l}\text { Self-reported } \\
\text { pain-US intensity }\end{array}$ & $7.86(0.53)$ & $8.00(0.00)$ & $7.92(0.64)$ & $8.00(0.43)$ & $8.00(0.00)$ & $8.06(0.25)$ & $0.50(5,77)$ & .774 \\
\hline $\begin{array}{l}\text { Physical pain-US } \\
\text { intensity (mA) }\end{array}$ & $53.00(26.14)$ & $39.83(20.00)$ & $52.77(33.67)$ & 38.67 (13.14) & 35.69 (14.92) & $39.00(24.39)$ & $1.50(5,77)$ & .198 \\
\hline
\end{tabular}

* In each of these groups, 1 participant failed to complete the online questionnaires.

\section{Manipulation checks}

\section{Retrospective pain-US expectancy}

Mean retrospective pain-US expectancy was analyzed as $2 \times 2 \times 3$ [Stimulus Type (CS + CS-) $\times$ Reinstatement (EXP/CTRL) $\times$ Threat (INFL/DEFL/SAME)] RM ANOVA (see Table 2). A significant main effect for stimulus type $(p<.001)$ emerged; participants expected the pain-US more after performing the CS+movement than after CS- movement. Threat manipulation did not modulate this effect (Stimulus Type $\times$ Threat interaction, $p=.811$ ). Pain-US expectancy was rated after extinction; so no significant effect of the reinstatement manipulation was anticipated and this was confirmed (Stimulus Type $\times$ Reinstatement $(p=.834)$ ). Planned comparisons confirmed that all threat groups learned that the pain-US was paired with CS + movements and not with CS- movements (INFL: $F(1,79)=56.75, p<.001$; DEFL: $F(1,79)=48.08, p<.001$; SAME: $F(1,79)=60.78$, $p<.001)$. These results confirm that the conditioning procedure was successful. 


\section{Affective valence}

A $2 \times 2 \times 2 \times 3$ [Stimulus Type (CS + /CS-) $\times$ Time (PRE/POST) $\times$ Reinstatement (EXP/CTRL) $\times$ Threat (INFL/DEFL/SAME)] RM ANOVA on the mean retrospective affective valence scores showed a significant Time $x$ Stimulus Type interaction $(p<.01)$, indicating that the difference in the affective valence between CS + and CS- changed over time (see Table 2). The CS+becomes more aversive because of its pairing with the pain-US (evaluative conditioning), whereas the CS- does not. We found no interaction effects with the threat variable (Stimulus Type $\times$ Time $\times$ Threat, $p=.207$ ), indicating that the threat manipulation did not result in a group-specific effect on affective valence. No significant effect of the reinstatement manipulation was expected at this point (rating was obtained before reinstatement phase) and this was confirmed (Stimulus Type $\times$ Time $\times$ Reinstatement, $p=.934$ ).

Table 2. Summary of RM ANOVA Manipulation checks.

\begin{tabular}{|c|c|c|c|c|c|c|}
\hline Effect $(N=83)$ & SS & df & MSE & $F$ & $p$ & $\eta_{p}^{2}$ \\
\hline \multicolumn{7}{|l|}{ Pain-US expectancy } \\
\hline Threat & 4,63 & 2,79 & 2.31 & 0.50 & .610 & 0.01 \\
\hline Reinstatement & 1,84 & 1,79 & 1.84 & 0.39 & .532 & 0.00 \\
\hline Stimulus Type & 594,35 & 1,79 & 594.35 & 165.24 & $<.001^{\star \star \star}$ & 0.68 \\
\hline Stimulus Type $\mathrm{x}$ Threat & 1,51 & 2,79 & 0.76 & 0.21 & .811 & 0.01 \\
\hline Stimulus Type x Reinstatement & 0,16 & 1,79 & 0.16 & 0.04 & .834 & 0.00 \\
\hline \multicolumn{7}{|c|}{ Affective valence ratings of the CS movements } \\
\hline Threat & 1.81 & 2,79 & 0.90 & 1.68 & .192 & 0.04 \\
\hline Reinstatement & 0.03 & 1,79 & 0.03 & 0.05 & .816 & 0.00 \\
\hline Stimulus Type & 4.96 & 1,79 & 4.96 & 21.17 & $<.001^{\star \star \star}$ & 0.21 \\
\hline Stimulus Type $\mathrm{x}$ Threat & 0.16 & 2,79 & 0.08 & 0.34 & .712 & 0.01 \\
\hline Stimulus Type x Reinstatement & 0.01 & 1,79 & 0.01 & 0.05 & .830 & 0.00 \\
\hline Block & 6.60 & 1,79 & 6.60 & 21.76 & $<.001^{\star \star *}$ & 0.22 \\
\hline Block x Threat & 0.08 & 2,79 & 0.04 & 0.14 & .872 & 0.00 \\
\hline Block $x$ Reinstatement & 0.06 & 1,79 & 0.06 & 0.19 & .664 & 0.00 \\
\hline Stimulus Type x Block & 1.92 & 1,79 & 1.92 & 7.93 & $<.01^{\star *}$ & 0.09 \\
\hline Stimulus Type x Block x Threat & 0.78 & 2,79 & 0.39 & 1.61 & .207 & 0.04 \\
\hline Stimulus Type $x$ Block $x$ Reinstatement & 0.00 & 1,79 & 0.00 & 0.01 & .934 & 0.00 \\
\hline
\end{tabular}




\section{Self-reported fear of movement-related pain}

\section{Acquisition}

A $2 \times 2 \times 3 \times 3$ [Stimulus Type (CS + /CS-) $\times$ Reinstatement $(E X P / C T R L) \times$ Block (A1/A2/A3) $\times$ Threat (INFL/DEFL/SAME)] RM ANOVA was conducted on the mean fear of movement-related pain ratings (see Table 3 and Figure 3 ). Analyses revealed a significant main effect for Stimulus Type $(p<.001)$ and Block $(p<.05)$. As expected, the difference in reported fear in response to the CS + movement compared with the response to the CS- movement became larger across the three blocks of the acquisition phase (Stimulus Type $\times$ Block interaction, $p<.001$ ). These effects indicate that acquisition was successful; participants acquired differential fear of movement-related pain. This was further confirmed by testing our a priori hypothesis with planned comparisons: the fear ratings for the CS + movement were significantly higher than for the CS- movement at the end of acquisition $(A 3)(F(1,79)=160.65, p<0.001)$. Contrary to our hypotheses, we found no significant differences between groups as a result of our threat manipulation (Stimulus Type $\times$ Block $\times$ Threat interaction, $p=.352$ ). Since the procedure in the experimental and control groups did not differ during acquisition, no significant interaction effect with the reinstatement variable was expected at this point (Stimulus Type $\times$ Block $\times$ Reinstatement interaction, $p=.359$ ).

\section{Extinction}

A $2 \times 2 \times 2 \times 3$ [Stimulus Type $(\mathrm{CS}+/ \mathrm{CS}-) \times$ Block $(\mathrm{A} 3 / \mathrm{E} 3) \times$ Reinstatement $(\mathrm{EXP} / \mathrm{CTRL})$ $\times$ Threat (INFL/DEFL/SAME)] RM ANOVA was conducted on the mean fear of movement-related pain ratings for the CS movements comparing the end of acquisition (A3) with the end of extinction (E3) (see Table 3 and Figure 3). Analyses yielded significant main effects for Stimulus Type $(p<.001)$ and Block $(p<.001)$. The difference in fear of movement-related pain ratings in response to the CS + and CS- was significantly reduced from the end of acquisition to the end of extinction (Block $\times$ Stimulus Type interaction, $p<.001)$, indicating that extinction was successful. Against our expectations, extinction of movement-related pain did not significantly differ between threat manipulation groups (Stimulus Type $\times$ Block $\times$ Threat interaction, $p=.909$ ). Again, no interaction effect with the reinstatement variable was anticipated during extinction (Stimulus Type $\times$ Block $\times$ Reinstatement interaction, $p=.849$ ). 
Return of fear of movement-related pain

A $2 \times 2 \times 2 \times 3$ [Stimulus Type (CS + /CS- $) \times$ Block (E3/T1) $\times$ Reinstatement (EXP/CTRL) $\times$ Threat (INFL/DEFL/SAME)] RM ANOVA was conducted on the mean fear of movementrelated pain ratings for the CS movements comparing the end of extinction (E3) with test (T1) (see Table 3 and Figure 3). There were significant main effects for Stimulus Type $(p<.001)$, Block $(p<.001)$ and Reinstatement $(p<.05)$. The Block $\times$ Reinstatement interaction was also significant $(p<.001)$. In line with our hypothesis, we found a significant differential (stronger for the CS + than for the CS-) return of fear depending on the reinstatement manipulation (Stimulus Type $\times$ Block $\times$ Reinstatement interaction, $p<.05)$. Planned within-group comparisons revealed that the difference in fear of movement-related pain between CS + and CS- movements increased from the end of extinction to test in the experimental group $(F(1,79)=6.63, p<.01)$, but not in the control group $(F(1,79)=0.25, p=.622)$. This larger increase in the fear of movementrelated pain ratings for CS + movements than CS- movements from the end of extinction to test indicates a differential return of fear of movement-related pain in the experimental group, and not in the control group as a result of the reinstatement manipulation. In line with our findings for acquisition and extinction, but against our hypotheses, our threat manipulation again did not have an effect on return of fear after a reinstatement procedure (Stimulus Type $\times$ Block $\times$ Threat interaction, $p=.374$ ).

\section{Eye-blink startle responses}

\section{Acquisition}

A $2 \times 2 \times 3 \times 3$ [Stimulus Type (CS + /CS-) $\times$ Reinstatement $(E X P / C T R L) \times$ Block $(A 1 / A 2 / A 3)$ $\times$ Threat (INFL/DEFL/SAME)] RM ANOVA was conducted on the startle responses for both CS movements collected during acquisition (see Table 4 and Figure 4).

We found no significant interaction effect for Block $\times$ Stimulus type $(p=.19)$, however, the analysis did yield significant main effects for Stimulus type $(p<.001)$ and Block $(p<.001)$. In line with our expectations, planned comparisons showed that at the end of acquisition (A3), startle responses were significantly higher for the CS + movement than for the CS- movement $(F(1,79)=11.17, p<.01)$

Against our hypotheses, threat manipulation did not have an effect on startle responses during acquisition (Block $\times$ Stimulus $\times$ Threat interaction $(p=.284)$ ). As 
anticipated since the procedure for experimental and control groups did not differ during acquisition, neither did the reinstatement manipulation (Block $\times$ Stimulus $\times$ Re instatement interaction, $p=.067$ ).

Table 3. Summary of RM ANOVAs testing acquisition, extinction, and return of fear in self-reported fear of movement-related pain.

\begin{tabular}{|c|c|c|c|c|c|c|c|}
\hline Effect $(N=83)$ & SS & $\mathrm{df}$ & MSE & $F$ & $p$ & $\eta_{p}^{2}$ & $\varepsilon$ \\
\hline \multicolumn{8}{|l|}{ Acquistion effects } \\
\hline Threat & 37.71 & 2,79 & 18.85 & 1.41 & .249 & 0.03 & \\
\hline Reinstatement & 22.13 & 1,79 & 22.13 & 1.66 & .201 & 0.02 & \\
\hline Stimulus Type & 1252.06 & 1,79 & 1252.06 & 177.81 & $<.001^{* * *}$ & 0.69 & 1 \\
\hline Stimulus Type $\mathrm{x}$ Threat & 8.78 & 2,79 & 4.39 & 0.62 & .539 & 0.02 & 1 \\
\hline Stimulus Type $x$ Reinstatement & 1.63 & 1,79 & 1.63 & 0.23 & .632 & 0.00 & 1 \\
\hline Block & 10.02 & 2,158 & 5.01 & 3.98 & .021 * & 0.05 & 0.74 \\
\hline Block x Threat & 1.36 & 4,158 & 0.34 & 0.27 & .897 & 0.01 & 0.74 \\
\hline Block x Reinstatement & 0.96 & 2,158 & 0.48 & 0.38 & .684 & 0.00 & 0.74 \\
\hline Stimulus Type x Block & 55.01 & 2,158 & 27.51 & 24.25 & $<.001 * * *$ & 0.23 & 0.78 \\
\hline Stimulus Type $x$ Block $x$ Threat & 5.05 & 4,158 & 1.26 & 1.11 & .352 & 0.03 & 0.78 \\
\hline Stimulus Type x Block x Reinstatement & 2.34 & 2,158 & 1.17 & 1.03 & .359 & 0.01 & 0.78 \\
\hline \multicolumn{8}{|l|}{ Extinction effects } \\
\hline Threat & 18.65 & 2,79 & 9.33 & 1.58 & .211 & 0.04 & \\
\hline Reinstatement & 0.82 & 1,79 & 0.82 & 0.14 & .710 & 0.00 & \\
\hline Stimulus Type & 405.13 & 1,79 & 405.13 & 152.98 & $<.001 * * *$ & 0.66 & \\
\hline Stimulus Type $\mathrm{x}$ Threat & 1.70 & 2,79 & 0.85 & 0.32 & .726 & 0.01 & \\
\hline Stimulus Type x Reinstatement & 0.15 & 1,79 & 0.15 & 0.06 & .813 & 0.00 & \\
\hline Block & 153.51 & 1,79 & 153.51 & 77.54 & $<.001 * * *$ & 0.50 & \\
\hline Block $x$ Threat & 13.29 & 2,79 & 6.65 & 3.36 & .040 * & 0.08 & \\
\hline Block $x$ Reinstatement & 5.84 & 1,79 & 5.84 & 2.95 & .090 & 0.04 & \\
\hline Stimulus Type x Block & 211.63 & 1,79 & 211.63 & 126.17 & $<.001 * * *$ & 0.61 & \\
\hline Stimulus Type x Block x Threat & 0.32 & 2,79 & 0.16 & 0.10 & .909 & 0.00 & \\
\hline Stimulus Type x Block x Reinstatement & 0.06 & 1,79 & 0.06 & 0.04 & .849 & 0.00 & \\
\hline \multicolumn{8}{|l|}{ Reinstatement effects } \\
\hline Threat & 15.34 & 2,79 & 7.67 & 1.09 & .340 & 0.03 & \\
\hline Reinstatement & 34.32 & 1,79 & 34.32 & 4.89 & .030 * & 0.06 & \\
\hline Stimulus Type & 45.69 & 1,79 & 45.69 & 35.01 & $<.001 * * *$ & 0.31 & \\
\hline Stimulus Type $x$ Threat & 0.80 & 2,79 & 0.40 & 0.30 & .738 & 0.01 & \\
\hline Stimulus Type x Reinstatement & 2.43 & 1,79 & 2.43 & 1.86 & .177 & 0.02 & \\
\hline Block & 20.41 & 1,79 & 20.41 & 17.33 & $<.001^{* * *}$ & 0.18 & \\
\hline Block $x$ Threat & 4.94 & 2,79 & 2.47 & 2.10 & .130 & 0.05 & \\
\hline Block x Reinstatement & 18.90 & 1,79 & 18.90 & 16.04 & $<.001 * \star *$ & 0.17 & \\
\hline Stimulus Type x Block & 1.39 & 1,79 & 1.39 & 2.35 & .129 & 0.03 & \\
\hline Stimulus Type x Block x Threat & 1.18 & 2,79 & 0.59 & 1.00 & .374 & 0.02 & \\
\hline Stimulus Type $\mathrm{x}$ Block $\mathrm{x}$ Reinstatement & 2.88 & 1,79 & 2.88 & 4.87 & .030 * & 0.06 & \\
\hline
\end{tabular}


Table 4. Summary of RM ANOVAs testing acquisition, extinction, and return of fear in the eye-blink startle responses.

\begin{tabular}{|c|c|c|c|c|c|c|c|}
\hline Effect $(N=83)$ & SS & df & MSE & $F$ & $p$ & $\eta_{p}^{2}$ & $\varepsilon$ \\
\hline \multicolumn{8}{|l|}{ Acquistion effects } \\
\hline Threat & 147.04 & 2,79 & 74 & 1.58 & .213 & 0.04 & 1 \\
\hline Reinstatement & 194.25 & 1,79 & 194 & 4.17 & $.044^{*}$ & 0.05 & 1 \\
\hline Stimulus Type & 489.70 & 1,79 & 490 & 12.02 & $.001^{\star * \star}$ & 0.13 & 1 \\
\hline Stimulus Type $\mathrm{x}$ Threat & 177.90 & 2,79 & 89 & 2.18 & .119 & 0.05 & 1 \\
\hline Stimulus Type x Reinstatement & 79.96 & 1,79 & 80 & 1.96 & .165 & 0.02 & 1 \\
\hline Block & 3007.80 & 2,158 & 1504 & 27.39 & $<.001 * * *$ & 0.26 & 0.80 \\
\hline Block x Threat & 184.37 & 4,158 & 46 & 0.84 & .502 & 0.02 & 0.80 \\
\hline Block x Reinstatement & 70.74 & 2,158 & 35 & 0.64 & .526 & 0.01 & 0.80 \\
\hline Stimulus Type x Block & 117.28 & 2,158 & 59 & 1.68 & .190 & 0.02 & 1 \\
\hline Stimulus Type x Block x Threat & 177.60 & 4, 158 & 44 & 1.27 & .284 & 0.03 & 1 \\
\hline Stimulus Type x Block x Reinstatement & 192.39 & 2,158 & 96 & 2.75 & .067 & 0.03 & 1 \\
\hline \multicolumn{8}{|l|}{ Extinction effects } \\
\hline Threat & 24.06 & 2,79 & 12.0 & 0.69 & .505 & 0.02 & \\
\hline Reinstatement & 6.19 & 1,79 & 6.2 & 0.35 & .553 & 0.00 & \\
\hline Stimulus Type & 517.05 & 1,79 & 517.1 & 18.66 & $<.001 * * *$ & 0.19 & \\
\hline Stimulus Type $\mathrm{x}$ Threat & 30.28 & 2,79 & 15.1 & 0.55 & .581 & 0.01 & \\
\hline Stimulus Type x Reinstatement & 44.08 & 1,79 & 44.1 & 1.59 & .211 & 0.02 & \\
\hline Block & 360.19 & 1,79 & 360.2 & 7.86 & $.006^{* *}$ & 0.09 & \\
\hline Block x Threat & 125.16 & 2,79 & 62.6 & 1.37 & .261 & 0.03 & \\
\hline Block x Reinstatement & 41.23 & 1,79 & 41.2 & 0.90 & .346 & 0.01 & \\
\hline Stimulus Type x Block & 25.17 & 1,79 & 25.2 & 1.02 & .316 & 0.01 & \\
\hline Stimulus Type x Block x Threat & 2.38 & 2,79 & 1.2 & 0.05 & .953 & 0.00 & \\
\hline Stimulus Type x Block x Reinstatement & 77.04 & 1,79 & 77.0 & 3.12 & .081 & 0.04 & \\
\hline \multicolumn{8}{|l|}{ Reinstatement effects } \\
\hline Threat & 103.04 & 2,79 & 51.5 & 1.64 & .201 & 0.04 & \\
\hline Reinstatement & 385.94 & 1,79 & 385.9 & 12.27 & $.001^{* * *}$ & 0.13 & \\
\hline Stimulus Type & 143.63 & 1,79 & 143.6 & 7.27 & $.009^{* \star}$ & 0.08 & \\
\hline Stimulus Type $x$ Threat & 64.39 & 2,79 & 32.2 & 1.63 & .203 & 0.04 & \\
\hline Stimulus Type x Reinstatement & 70.97 & 1,79 & 71.0 & 3.59 & .062 & 0.04 & \\
\hline Block & 387.29 & 1,79 & 387.3 & 13.93 & $<.001 * * *$ & 0.15 & \\
\hline Block x Threat & 73.02 & 2,79 & 36.5 & 1.31 & .275 & 0.03 & \\
\hline Block x Reinstatement & 246.86 & 1,79 & 246.9 & 8.88 & $.004^{* *}$ & 0.10 & \\
\hline Stimulus Type x Block & 32.91 & 1,79 & 32.9 & 1.83 & .180 & 0.02 & \\
\hline Stimulus Type x Block x Threat & 88.98 & 2,79 & 44.5 & 2.47 & .091 & 0.06 & \\
\hline Stimulus Type $x$ Block $x$ Reinstatement & 48.89 & 1,79 & 48.9 & 2.71 & .103 & 0.03 & \\
\hline
\end{tabular}


Figures $\mathbf{3 A}$ and 3B. Mean self-reported fear of movement-related pain for experimental and control groups separately.
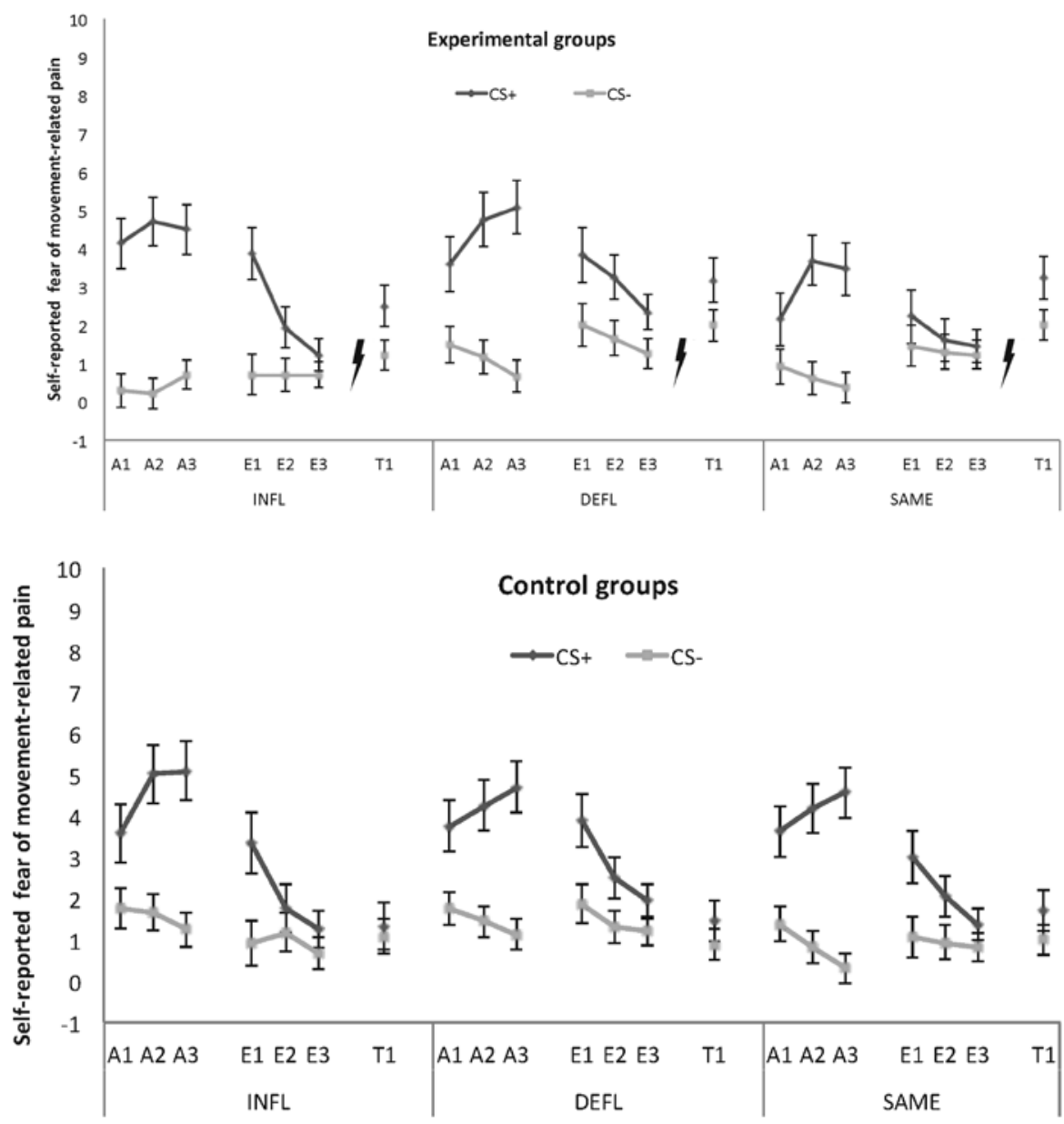

\section{Extinction}

A $2 \times 2 \times 2 \times 3$ [Stimulus Type $(C S+/ C S-) \times$ Block $(A 3 / E 3) \times$ Reinstatement $(E X P / C T R L)$ $\times$ Threat (INFL/DEFL/SAME)] RM ANOVA was conducted on the startle responses for the CS movements comparing the end of acquisition (A3) with the end of extinction (E3) (see Table 4 and Figure 4).

We found a main effect for Stimulus Type $(p<.001)$ and Block $(p<.01)$, but no significant two-way interaction (Stimulus Type $\times$ Block, $p=.316$ ), indicating that 
the difference between CS + and CS- startle responses did not decrease significantly from the end of acquisition to the end of extinction. It is highly likely that the lack of interaction is due to habituation effects in overall startle responding. Planned comparisons revealed that in general startle responses on the CS + movements declined significantly from the end of acquisition to the end of extinction $(C S+: F(1,79)=8.53, p=.005)$, and not for the CS- $(F(1,79)=2.68, p=.106)$. Again, no differences in startle responses were found as a result of threat manipulation (Stimulus Type $\times$ Block $\times$ Threat interaction, $p=.953$ ) or reinstatement manipulation (Stimulus Type $\times$ Block $\times$ Reinstatement interaction, $p=.081$ ).

\section{Return of fear of movement-related pain}

A $2 \times 2 \times 2 \times 3$ [Stimulus Type $($ CS + /CS- $) \times$ Block $($ EXT3/TEST) $\times$ Reinstatement $($ EXP/CTRL) $\times$ Threat (INFL/DEFL/SAME)] RM ANOVA was conducted on the startle responses for the CS movements comparing the end extinction (E3) with test (T1) (see Table 4 and Figure 4). We found significant main effects of Stimulus Type $(p<.01)$, Block $(p<.001)$ and Reinstatement $(p<.001)$. The Block $\times$ Reinstatement interaction was also significant $(p<.01)$, but the Stimulus Type $\times$ Block $\times$ Reinstatement interaction was not $(p=103)$. To test our a priori hypotheses, planned within-group comparisons were conducted. For the experimental group, we found no differential return of fear after the reinstatement procedure $(F(1,79)=0.04, p=.836)$. Further planned comparisons within the experimental group revealed a significant increase in startle responses for the CS $+(F(1,79)=10.57, p<.01)$ as well as for the CS- $(F(1,79)=17.50, p<.001)$. These results suggest that there is a non-differential return of movement-related fear of pain in the experimental group. For the control group, however, a significant difference in response to the CS + compared to the CS- was found from the end of acquisition to the end of extinction $(F(1,79)=4.77, p<.05)$, also indicating a differential return of fear. Visual inspection of figure 4 , however shows an effect in the opposite direction. So, we tested responses from E3 to T1 to the CS + and CS-, respectively, with post-hoc comparisons corrected for multiple testing $(p \leq .025)$. These comparisons show that responses to the CS- $(F(1,79)=4.66, p=.034)$ as well as the $C S+(F(1,79)=0.69, p=.410)$ did not increase from E3 to T1 after correction for multiple testing. Furthermore, we tested the difference between CS + /CS- responding at T1 in the control group, and this planned comparison showed no significant effect $(F(1,79)=0.79, p=.378)$. We assume that in the control group, further extinction took place. In line with the rest of our results, threat manipulation did not have an effect on startle responses after the reinstatement manipulation (Stimulus Type $\times$ Block $\times$ Threat interaction, $p=.091$ ). 
Figure 4. Startle responses for the experimental and the control groups.

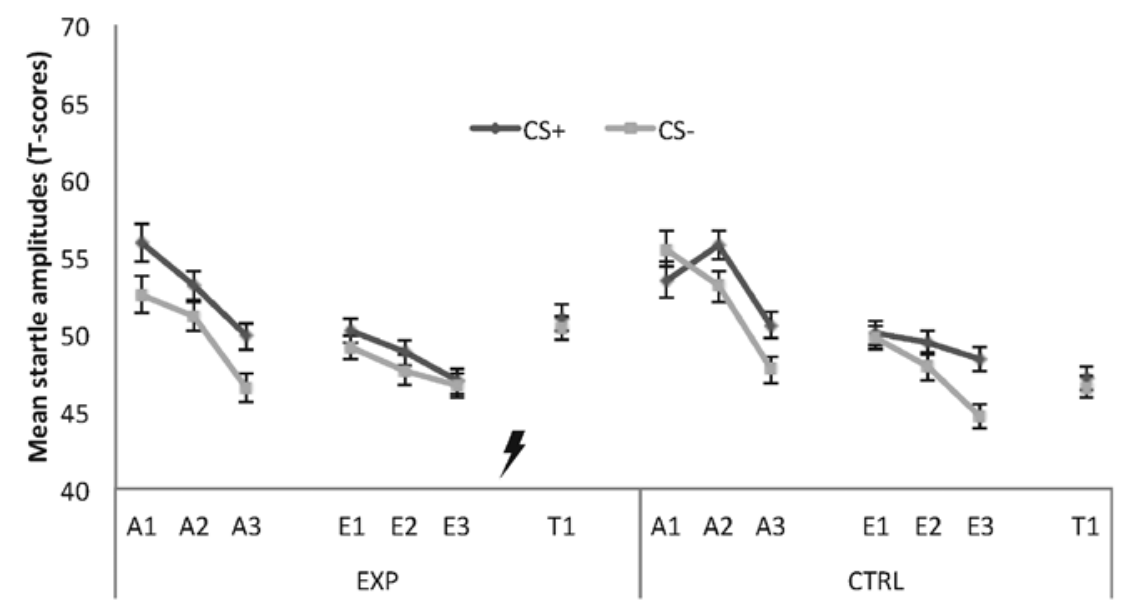

\section{Pain-US intensity ratings}

A $3 \times 2 \times 3$ [Block $(A 1 / A 2 / A 3) \times$ Reinstatement $(E X P / C T R L) \times$ Threat $(I N F L / D E F L / S A M E)$ ] RM ANOVA on the experienced pain-US intensity revealed an unexpected significant main effect for Block $(F(2,158)=11.56, p<.001)$, indicating that participants rated the same pain-US as increasingly painful over time (increasing from 5.55 to 6.06 to 6.16 during acquisition). This effect did not depend on the verbal threat manipulation (Block $\times$ Threat interaction, $F(4,158)=1.21, p=.309)$. No interaction effect of reinstatement was anticipated since the pain-US intensities were rated before the reinstatement manipulation (Block $\times$ Reinstatement interaction, $F(2,158)=0.77, p=.466$ ).

\section{Behavioral measure}

Three participants in the DEFL $(n=28)$ as well as in the SAME $(n=29)$ group were not willing to participate in a similar experiment. From the 26 participants in the INFL group, 7 refused further participation. Participants confronted with a higher threat (INFL) seemed less inclined (refusal rate 27\%) to take part than participants in the lower (DEFL, refusal rate 11\%) or constant (SAME, refusal rate 10\%) threat group, although this observation was not statistically corroborated (Fisher exact test, $p=.179$ ). 


\section{Discussion}

Patients with chronic pain report to base their ideas about the meaning of pain on information they received from health-care providers or media sources. Information can raise (inflate) the threat value of pain as well as decrease it (deflation). For example, being informed about the harmful consequences of certain movements by a therapist makes the experience of pain more threatening. Another clinical phenomenon is return of fear; patients might start to avoid activities again after successful exposure treatment when they experience an unexpected pain-increase.

Based on these clinical examples from patients with chronic pain, we aimed to investigate if pain-related fear could be intensified (inflation) or weakened (deflation) by verbally/visually transmitted information about pain and its meaning, and if this would influence return of fear after extinction, the experimental equivalent of exposure treatment.

We adapted the VJM paradigm to investigate the role of verbally and visually transmitted US-information on the acquisition, extinction and on the return of fear of movement related pain, using a between-subjects design with three levels of threat manipulation (US-inflation vS. US-deflation vs. no US manipulation) and two levels of reinstatement (experimental vs. control). We induced moderate threat levels at the start of the experiment, so that inflation- as well as deflation effects could be detected. We expected that increasing the threat value of the US would result in more fear of movement-related pain (measured with self-reports and eyeblink startle responses) during acquisition, slower fear extinction, and an increased return of fear after reinstatement in the experimental groups but not in the control groups, compared to a sustained verbal threat information and a verbal safety information regarding the pain-US. A second aim of this study was to investigate the return of fear after extinction. We hypothesized that chances for the return of fear increase in individuals with inflated fear responses and increased perceived threat of the pain-US.

We successfully replicated the acquisition and extinction of fear of movementrelated pain in both self-reported fear measures and eye-blink startle responses using the VJM paradigm. Contrary to our hypotheses, we did not observe any effects of our threat manipulation on the acquisition, extinction nor reinstatement of fear of movement-related pain. As expected, our reinstatement manipulation did yield different effects for the experimental and control groups. More specifically, we found a differential return of fear in the self-reports, but a non-differential return of fear in startle eyeblink EMG responses in the experimental groups receiving two unsignalled pain-USs, but not in the control groups. 
Some remarkable findings deserve further attention. First, we chose a threat induction inspired by Wiech et al. (Wiech et al., 2010) that enabled us to investigate both inflation as well as deflation effects and to prevent floor effects. This threat induction also seemed more ecologically valid with respect to highly fearful chronic pain patients, confronted with information that might increase their worries about pain as well as reassure them. The initial mild-threat induction for all participants may have led to a general increase in perceived threat in all groups, making it possible that the crucial between-group manipulation was not strong enough to overrule this overall initial threat induction provided. In line with this post-hoc explanation is the unusual increase in self-reported intensity of the pain-US, which was physically kept constant, and was not found for male participants in previous experiments using the VJM paradigm (Meulders et al., 2012). This might indeed indicate a general increase in perceived threat across conditions. To further verify this post-hoc explanation, future studies might add measures about the perceived harmfulness of the pain-US, possibly mediating pain intensity ratings. Another indication that the overall threatinduction had some effect was the higher refusal-rate to participate in a similar experiment in the inflation group, although this finding was not statistically significant. However, our threat manipulation may not have been powerful enough to reach the threshold to actually affect the pain-related fear ratings and startle responses. For future experiments using the same task, we suggest adding a neutral control group with reassuring information about their skin-vulnerability at baseline, and/or online feedback that their skin sensitivity is safe during the task. This could amplify the contrasts between threat and control groups.

Creating threat in an experimentally controlled setting is a real challenge, and participants may simply not have believed the skin sensitivity indicator manipulation. One of the reasons why human fear conditioning studies reveal relatively small and at best transitory effects is that healthy participants are involved in experiments they know to be ethically approved and they know they can stop their participation at any given time. This is different from the clinical context in which patients often cannot escape their pain, or a daily life situation where harm is indeed a small but inevitable risk. Second, our reinstatement manipulation resulted in more return of fear in the experimental groups as compared with the control groups. Interestingly, we found that this return of fear that was stronger for the CS+movement than for the CS- movement in self-reports, indicating differential return of movementrelated fear after reinstatement (two unsignalled USs). For startle responses, on the other hand, a non-differential return of fear was observed. The latter is in line with previous findings on self-reported fear of movement-related pain (Meulders \& Vlaeyen, 2013b). Although a differential return of fear has not been reported using the VJM paradigm yet (possibly due to lack of statistical power), it is in line with the 
retrieval failure model (Bouton, 1993), the most prominent learning model on return of fear. This model states that after acquisition and subsequent extinction, people's representation of the CS-US association is twofold (during acquisition, the CS + was followed by the US, whereas during extinction the CS + was not followed by the US) and becomes ambiguous. According to Bouton's model, the context will determine which memory trace is prevalent, and since the US-presentations after extinction will selectively reactivate memories obtained during acquisition, the originally conditioned fear response re-emerges (Bouton, 1993; Dirikx, Hermans, Vansteenwegen, Baeyens, \& Eelen, 2004; Dirikx et al., 2007; Hermans et al., 2005).

Some strengths of the current study should be mentioned. First, the use of proprioceptive cues as CSs, in contrast with previous studies using interoceptive or visual cues. Proprioceptive cues are probably more ecologically valid when studying pain-related fear. Second, a male sample was selected to reduce the temporal sensitization of pain-USS that might interfere with our manipulations. A third methodological strength is that we used a fluctuating, instead of a fixed pointer to provide feedback to participants, to enhance the credibility of our threat manipulation. To make it even more realistic, the pointer moved directly after a pain US was delivered, strengthening the relation between pain and provided feedback on skin sensitivity.

Some limitations should be mentioned as well: first, inclusion of a manipulation check, for example a rating for the perceived harmfulness of the pain US, would have helped to assess the validity of the threat manipulation. Second, painfulness was measured three times during acquisition, but not after the reinstatement procedure since not all participants received pain-USs. It would have been interesting, however, to evaluate pain intensity after reinstatement, especially since self-reported painfulness increased during acquisition. A third limitation is that our Pavlovian extinction paradigm not totally reflects what happens during an exposure in vivo session with patients. During Pavlovian extinction, it is essential that the US is absent, whereas chronic pain patients per definition experience pain all the time. This relates to the question what the actual US is in these patients, pain or its mental representation such as impending injury, and how this can be translated to experimental research. A fourth limitation was the low power of our analyses. We choose a medium effect size for our initial power calculations, so small real-world effects of our threat manipulation might not have been picked up due to a low sample size.

To summarize, we found evidence that experimentally conditioned painrelated fear returns upon an unexpected pain-experience after successful extinction. However, we failed to find an effect of our verbal information regarding the meaning of the pain-US on the acquisition, extinction, and the reinstatement of pain-related fear; we suspect that this is due to a general increase of perceived threat in all conditions. 


\begin{abstract}
Verbatim instructions (threat-induction):
"Skin-vulnerability varies between people. In order to prevent skin damage due to the electrocutaneous stimuli that you are going to receive, it is important that you monitor your own skin sensitivity during this experiment. You can do this by checking the skin sensitivity indicator that will be displayed at the bottom of the computer screen during the task. This indicator can vary on a continuum from a green, safe zone to an orange, and a red, danger zone. (While explaining this, the researcher shows a picture of the indicator to the participant). A pointer will move along this continuum to indicate how your skin reacts to the electrocutaneous stimuli. Green indicates that your skin reacts perfectly normal. The more the pointer moves to the orange and red side of the bar, the more strongly your skin reacts to the electrocutaneous stimuli. If the pointer moves into the unsafe (danger) zone, your skin could get seriously damaged, for example by burnings or painful blisters due to the electrocutaneous stimuli. Therefore, I want to ask you to monitor this pointer carefully during the experiment. Furthermore, I have to tell you that your skin is obviously more vulnerable to the electrocutaneous stimulus than the average skin, as the pointer already moved into the orange zone during the calibration phase."
\end{abstract}

Acknowledgment of support. The authors would like to thank Jeroen Clarysse for technical assistance.

Disclosure information. This study was supported by the Odysseus Grant "The Psychology of Pain and Disability Research Program" (GD90208N) funded by the Research Foundation, Flanders, Belgium (FWO Vlaanderen) and an EFIC-Grünenthal Research Grant to Ann Meulders. Ann Meulders is a postdoctoral researcher of the Research Foundation, Flanders, Belgium (12E3714N) (FWO Vlaanderen). The authors report no conflict of interest. 


\section{References}

Arntz, A., \& Claassens, L. (2004). The meaning of pain influences its experienced intensity. Pain, 109 (1-2), 20-25. doi:http://dx.doi.org/10.1016/j.pain.2003.12.030

Ash, L. M., Modic, M. T., Obuchowski, N. A., Ross, J. S., Brant-Zawadzki, M. N., \& Grooff, P. N. (2008). Effects of diagnostic information, per se, on patient outcomes in acute radiculopathy and low back pain. American Journal of Neuroradiology, 29 (6), 1098-1103

Blumenthal, T. D., Cuthbert, B. N., Filion, D. L., Hackley, S., Lipp, O. V., \& Van Boxtel, A. (2005). Committee report: Guidelines for human startle eyeblink electromyographic studies. Psychophysiology, 42 (1), 1-15. doi:10.1111/j.1469-8986.2005.00271.x

Bouton, M. E. (1984). Differential control by context in the inflation and reinstatement paradigms. Journal of Experimental Psychology: Animal Behavior Processes, 10, 56-74

Bouton, M. E. (1993). Context, time, and memory retrieval in the interference paradigms of Pavlovian learning. Psychological Bulletin, 114 (1), 80-99. doi:10.1037/0033-2909.114.1.80

Bouton, M. E. (1994). Context, ambiguity, and classical conditioning. Current Directions in Psychological Science, $3(2), 49-53$

Bouton, M. E. (2000). A learning theory perspective on lapse, relapse, and the maintenance of behavior change. Health psychology, 19 (1 Suppl), 57-63

Bouton, M. E. (2002). Context, ambiguity, and unlearning: sources of relapse after behavioral extinction. Biological Psychiatry, 52 (10), 976-986

Bradley, M. M., \& Lang, P. J. (1994). Measuring emotion: The self-assessment manikin and the semantic differential. Journal of Behavior Therapy and Experimental Psychiatry, 25 (1), 49-59. doi:http:// dx.doi.org/10.1016/0005-7916 (94)90063-9

Craske, M. G., \& Mystkowski, J. L. (2006). Exposure Therapy and Extinction: Clinical Studies. In M. G. Craske, D. Hermans, \& D. Vansteenwegen (Eds.), Fear and learning: From basic processes to clinical implications. (pp. 217-233). Washington, DC US: American Psychological Association

Davey, G. C. L. (1989). UCS revaluation and conditioning models of acquired fears. Behaviour Research and Therapy, 27 (5), 521-528. doi:http://dx.doi.org/10.1016/0005-7967 (89)90086-7

De Clercq, A., Verschuere, B., De Vlieger, P., \& Crombez, G. (2006). Psychophysiological analysis (PSPHA): a modular script based program for analyzing psychophysiological data. Behavior Research Methods, 38, 504-510

de Jong, J. R., Vlaeyen, J. W. S., Onghena, P., Goossens, M. E. J. B., Geilen, M., \& Mulder, H. (2005). Fear of Movement/ (Re)injury in Chronic Low Back Pain: Education or Exposure In Vivo as Mediator to Fear Reduction? The Clinical Journal of Pain, 21 (1), 9-17

De Jong, P. J., Merckelbach, H., Koertshuis, G., \& Muris, P. (1994). UCS-inflation and acquired fear responses in human conditioning. Advances in Behaviour Research \& Therapy, 16 (3), 131-165. doi:10.1016/0146-6402 (93)e0001-s

De Jong, P. J., Muris, P., \& Merckelbach, H. (1996). UCS inflation and human aversive autonomic conditioning. Biological Psychology, 43, 227-239 
Devriese, S., De Peuter, S., Van Diest, I., Van de Woestijne, K. P., \& Van den Bergh, O. (2006). US-inflation in a differential odor-conditioning paradigm is not robust: Relevance for medically unexplained symptoms. Journal of Behavior Therapy and Experimental Psychiatry, 37 (4), 314-332

Dirikx, T., Hermans, D., Vansteenwegen, D., Baeyens, F., \& Eelen, P. (2004). Reinstatement of extinguished conditioned responses and negative stimulus valence as a pathway to return of fear in humans. Learning and Memory, 11, 549-554

Dirikx, T., Hermans, D., Vansteenwegen, D., Baeyens, F., \& Eelen, P. (2004). Reinstatement of extinguished conditioned responses and negative stimulus valence as a pathway to return of fear in humans. Learning \& Memory, 11 (5), 549-554

Dirikx, T., Hermans, D., Vansteenwegen, D., Baeyens, F., \& Eelen, P. (2007). Reinstatement of conditioned responses in human differential fear conditioning. Journal of Behavior Therapy and Experimental Psychiatry, 38 (3), 237-251. doi:http://dx.doi.org/10.1016/j.jbtep.2006.04.001

Dirikx, T., Vansteenwegen, D., Eelen, P., \& Hermans, D. (2009). Non-differential return of fear in humans after a reinstatement procedure. Acta Psychologica, 130 (3), 175-182. doi:http://dx.doi.org/10.1016/j. actpsy.2008.12.002

Hermans, D., Dirikx, T., Vansteenwegenin, D., Baeyens, F., Van den Bergh, O., \& Eelen, P. (2005). Reinstatement of fear responses in human aversive conditioning. Behaviour Research and Therapy, 43 (4), 533-551

Hosoba, T., Iwanaga, M., \& Seiwa, H. (2001). The effect of UCS inflation and deflation procedures on 'fear' conditioning. Behaviour Research and Therapy, 39 (4), 465-475. doi:http://dx.doi.org/10.1016/ S0005-7967 (00)00025-5

LaBar, K. S., \& Phelps, E. A. (2005). Reinstatement of conditioned fear in humans is context dependent and impaired in amnesia. Behav Neurosci, 119 (3), 677-686. doi:10.1037/0735-7044.119.3.677

Leeuw, M., Goossens, M. E. J. B., Linton, S. J., Crombez, G., Boersma, K., \& Vlaeyen, J. W. S. (2007). The fear-avoidance model of musculoskeletal pain: Current state of scientific evidence. Journal of Behavioral Medicine, 30 (1), 77-94

Meulders, A., Vandebroek, N., Vervliet, B., \& Vlaeyen, J. W. S. (2013). Generalization gradients in cued and contextual pain-related fear: An experimental study in healthy participants. Frontiers in Human Neuroscience, 7. doi:10.3389/fnhum.2013.00345

Meulders, A., Vansteenwegen, D., \& Vlaeyen, J. W. S. (2011). The acquisition of fear of movement-related pain and associative learning: A novel pain-relevant human fear conditioning paradigm. Pain, 152 (11), 2460-2469. doi:http://dx.doi.org/10.1016/j.pain.2011.05.015

Meulders, A., Vansteenwegen, D., \& Vlaeyen, J. W. S. (2012). Women, but not men, report increasingly more pain during repeated (un)predictable painful electrocutaneous stimulation: Evidence for mediation by fear of pain. Pain, 153 (5), 1030-1041. doi:http://dx.doi.org/10.1016/j.pain.2012.02.005

Meulders, A., \& Vlaeyen, J. W. S. (2012). Reduction of fear of movement-related pain and pain-related anxiety: an associative learning approach using a voluntary movement paradigm. Pain, 153 (7), 1504-1513. doi:http://dx.doi.org/10.1016/j.pain.2012.04.013 
Meulders, A., \& Vlaeyen, J. W. S. (2013a). The acquisition and generalization of cued and contextual pain-related fear: An experimental study using a voluntary movement paradigm. Pain, 154 (2), 272-282. doi:http://dx.doi.org/10.1016/j.pain.2012.10.025

Meulders, A., \& Vlaeyen, J. W. S. (2013b). Mere Intention to Perform Painful Movements Elicits Fear of Movement-Related Pain: An Experimental Study on Fear Acquisition Beyond Actual Movements. The Journal of Pain, 14 (4), 412-423. doi:http://dx.doi.org/10.1016/j.jpain.2012.12.014

Norrholm, S. D., Jovanovic, T., Vervliet, B., Myers, K. M., Davis, M., Rothbaum, B. O., \& Duncan, E. J. (2006). Conditioned fear extinction and reinstatement in a human fear-potentiated startle paradigm. Learn Mem, 13 (6), 681-685. doi:10.1101//m.393906

Spruyt, A., Clarysse, J., Vansteenwegen, D., Baeyens, F., \& Hermans, D. (2010). Affect 4.0: A Free Software Package for Implementing Psychological and Psychophysiological Experiments. Experimental Psychology, 57 (1), 36-45

Trost, Z., France, C. R., Vervoort, T., Lange, J.M., \& Goubert, L. (2014). Learning about pain through observation: The role of pain-related fear. Journal of Behavioral Medicine, 37(2), 257-265. doi: 10.1007 s10865-012-9483-4

Vlaeyen, J. W. S., \& Linton, S. J. (2000). Fear-avoidance and its consequences in chronic musculoskeletal pain: A state of the art. Pain, 85 (3), 317-332

Weike, A. I., Schupp, H. T., \& Hamm, A. O. (2007). Fear acquisition requires awareness in trace but not delay conditioning. Psychophysiology, 44 (1), 170-180. doi:10.1111/j.1469-8986.2006.00469.x

White, K., \& Davey, G. C. L. (1989). Sensory preconditioning and UCS inflation in human 'fear' conditioning. Behaviour Research and Therapy, 27 (2), 161-166. doi:http://dx.doi.org/10.1016/0005-7967 (89) $90074-0$

Wiech, K., Lin, C., Brodersen, K. H., Bingel, U., Ploner, M., \& Tracey, I. (2010). Anterior Insula Integrates Information about Salience into Perceptual Decisions about Pain. Journal of Neuroscience, 30 (48), 16324-16331

Winters, W., Devriese, S., Van Diest, I., Nemery, B., Veulemans, H., Eelen, P., . . Van den Bergh, O. (2003). Media warnings about environmental pollution facilitate the acquisition of symptoms in response to chemical substances. Psychosomatic Medicine, 65 (3), 332-338. doi:10.1097/01. psy.0000041468.75064.be

Zale, E. L., Lange, K. L., Fields, S. A., \& Ditre, J. W. (2013). The Relation Between Pain-Related Fear and Disability: A Meta-Analysis. The Journal of Pain, 14 (10), 1019-1030. doi:http://dx.doi.org/10.1016/j. jpain.2013.05.005 


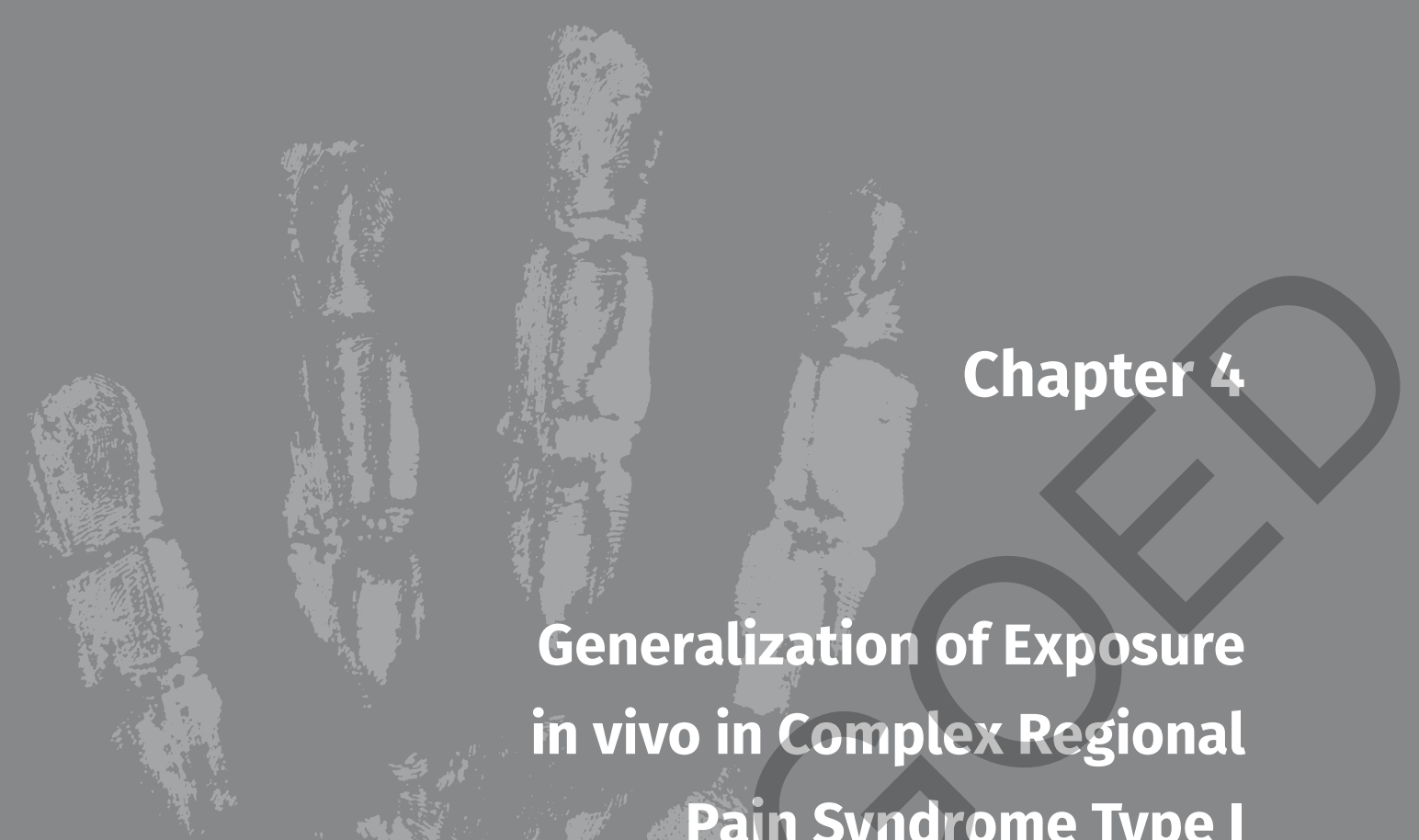

\section{Generalization of Exposure} in vivo in complex Regional Pain Syndrome Type I

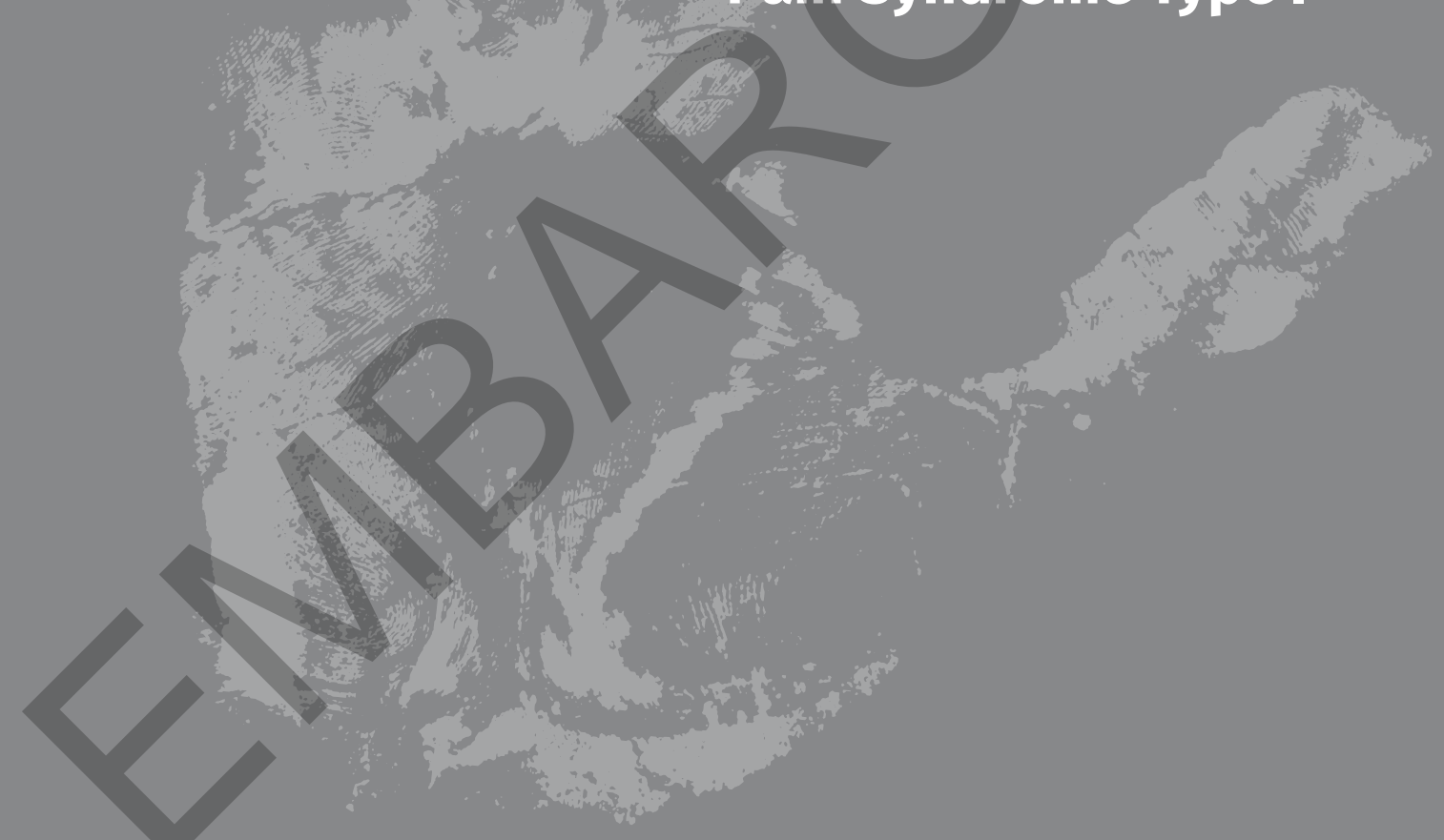

This chapter is submitted for publication as: den Hollander, M.*, de Jong, J.R.*, Onghena, P. \& Vlaeyen, J.W.S. Generalization of Exposure in Vivo in Complex Regional Pain Syndrome type I.

* shared first authorship 


\section{Chapter 5}

\section{Expose or protect?}

A randomized controlled trial of exposure in vivo versus

pain-contingent treatment as usual in patients with Complex Regional Pain Syndrome Type 1

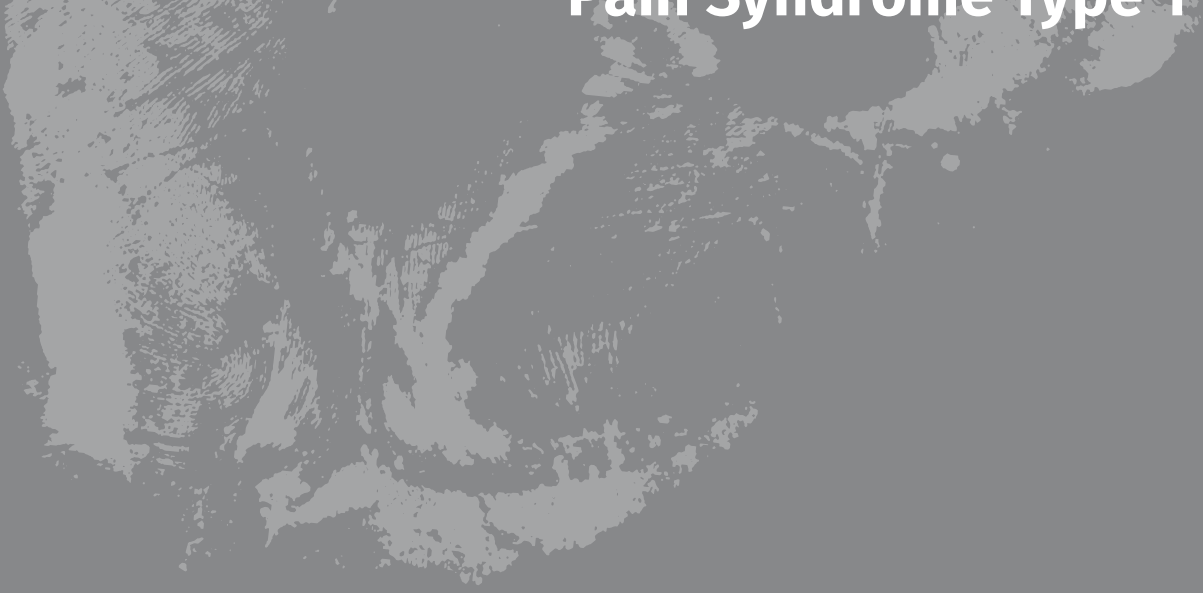

This chapter is published as: den Hollander, M., Goossens, M.E.J.B., de Jong, J.R., Ruijgrok, J., Oosterhof, J., Onghena, P., Smeets, R.J.E.M. \& Vlaeyen, J.W.S. (2016). Expose or protect? A randomized controlled trial of exposure in vivo versus pain-contingent treatment as usual in patients with Complex Regional Pain Syndrome Type 1. 


\section{Abstract}

Complex Regional Pain Syndrome Type I (CRPS-I) highly affects patients' ability to perform daily life activities. Pain-related fear might be a key target to reduce disability in chronic pain. Current treatments aiming at reducing pain show little improvements on pain and disability, whereas novel exposure-based treatments targeting painrelated fears have shown to be promising. We conducted a randomized controlled trial $(N=46)$ comparing exposure in vivo $(E X P)$ with pain-contingent treatment as usual (TAU), for CRPS-I patients with at least moderate levels of pain-related fear. Primary outcome is self-reported disability, for upper and lower extremity respectively. Secondary outcomes are self-reported pain-intensity, pain-catastrophizing, perceived harmfulness of physical activity, and health-related quality of life. Preto post-treatment and pre-treatment to 6-months follow-up change scores were tested using randomization-based inference. EXP was superior to TAU in reducing upper extremity disability from pre- to post-treatment (between-group difference 1.082; 95\% confidence interval $[\mathrm{Cl}]$ 0.563-1.601; $\mathrm{p}<0.001)$ and from pre-treatment to 6-months follow-up $(1.303 ; 95 \% \mathrm{Cl} 0.917-1.690 ; \mathrm{p}<0.001)$. EXP was superior in reducing lower extremity disability from pre-treatment to 6-months follow-up $(3.624 ; 95 \% \mathrm{Cl}$ 0.467-6.781; $p=0.02$ ), but not from pre- to post-treatment $(3.055 ; 95 \% \mathrm{Cl}-0.018-6.128$; $p=0.054)$. All secondary outcomes significantly favored EXP pre- to post-treatment, as well as pre-treatment to 6-months follow-up. Exposure to daily activities shows to be more effective than a protective pain-contingent treatment as usual in reducing self-reported disability in daily life of CRPS-I patients with at least moderate levels of pain-related fear. 


\section{Introduction}

Complex Regional Pain Syndrome Type I (CRPS-I) is a disabling chronic pain condition, affecting 0.26 per mille each year (de Mos et al., 2007). The underlying pathophysiology is still unknown and the condition cannot be cured (Marinus et al., 2011; O'Connell, Wand, McAuley, Marston, \& Moseley, 2013; Perez et al., 2007; StantonHicks et al., 1998). Symptoms such as allodynia, edema, skin color, and temperature changes make it reasonable to protect the affected limb against stimuli that increase pain. Guidelines recommend pain reduction as a prerequisite for rehabilitative efforts (Perez et al., 2007; Stanton-Hicks et al., 1998), although bio-behavioral factors are increasingly being considered as well (Bruehl, 2015; Harden et al., 2013; Simons, 2016). In particular, pain-related fear has shown to be related with increased CRPS-I disability (de Jong, Vlaeyen, de Gelder, \& Patijn, 2011) and functional connectivity related to the fear circuitry in the brain is correlated with higher anxiety, and painrelated fear scores in patients with CRPS (Geha et al., 2008; Simons et al., 2014).

The relation between pain-related fear and disability has shown to be quite robust across several chronic pain conditions (Zale, Lange, Fields, \& Ditre, 2013). Painrelated fear emerges when pain is interpreted as "catastrophic", i.e. being a sign of bodily harm or a predictor of increasing symptoms and uncontrollable pain, urging patients to avoid painful activity or cues that predict pain and pain increases (Leeuw, Goossens, Linton, et al., 2007; Vlaeyen, 2015; Vlaeyen \& Linton, 2000). Avoidance behaviors may be adaptive in the short run, but paradoxically increase dysfunction and quality of life later on, resulting in withdrawal from valued daily-life activities (Nederhand, IJzerman, Hermens, Turk, \& Zilvold, 2004; Turk \& Wilson, 2010; Vlaeyen \& Linton, 2012). Recently, cognitive-behavioral exposure in vivo treatments have been developed, specifically targeting catastrophic (mis)interpretations of bodily symptoms including pain (Vlaeyen, Morley, Linton, Boersma, \& de Jong, 2012). These fear-reducing techniques are based on experimental and clinical findings that when individuals expose themselves to painful movement, rather than avoid them, they can readjust their expectancies about the associations between movements and increased pain (Meulders \& Vlaeyen, 2012; Vlaeyen, de Jong, Leeuw, \& Crombez, 2004; Vlaeyen, Kole-Snijders, Boeren, \& van Eek, 1995). Exposure in vivo treatments have successfully been applied in patients with chronic musculoskeletal pain (Bailey, Carleton, Vlaeyen, \& Asmundson, 2010). Outcome studies have shown that exposure treatments are especially effective in reducing pain-related fear and the perceived harmfulness of physical activity (Leeuw et al., 2008; Woods \& Asmundson, 2008), and smaller trials with non-randomized controlled experimental designs also showed reduced pain reports and the successful resumptions of personal goals (de Jong et al., 2005; de Jong, Vlaeyen, van Eijsden, Loo, \& Onghena, 2012). 
For the treatment of CRPS-I a few evidence-based treatment regimens are available so far (O'Connell et al., 2013). Despite recommendations that cognitivebehavioral treatments (CBT) are valuable in CRPS-I (Bruehl \& Chung, 2006), there is a lack of randomized controlled trials (RCTs) assessing the effects of CBT in CRPS-I (supplementary material). An experimental replicated single case study demonstrated that exposure is a promising treatment for reducing disability, pain, and self-reported symptoms in CRPS-I patients with pain-related fear (de Jong et al., 2005). Interestingly, this approach challenges current best-evidence treatment for CRPS-I, aiming at the opposite: protecting patients against painful events. A paincontingent treatment as usual approach, aimed at protecting the limb against worsening of the symptoms has shown to be effective in reducing pain and CRPS-I signs and symptoms, but not disability (Oerlemans, Oostendorp, de Boo, \& Goris, 1999; Oerlemans, Oostendorp, et al., 2000). The objective of the current study is to compare the effectiveness of exposure in vivo (EXP) with a pain-contingent treatment as usual approach (TAU), in reducing disability for CRPS-I patients who report moderate to high pain-related fear. Secondary outcome measures are pain-intensity, pain-catastrophizing, perceived harmfulness of activities, and health-related quality of life.

\section{Methods}

\section{Study design and participants}

The effectiveness of both interventions was compared using a randomized controlled design. Adult CRPS-I-patients reporting substantial pain-related disability despite former treatment were included. A physiatrist confirmed CRPS-I at time of inclusion using the IASP Orlando-criteria (Mersky \& Bogduk, 1994). Patients reporting at least moderate pain-related fear (Photographic Series of Daily Activities (PHODA) (Dubbers, Vikström, \& de Jong, 2003; Jelinek, Germes, Leyckes, \& de Jong, 2003) mean score 234 ), were eligible. Patients with CRPS-I in both legs/arms, generalized pain, dystonia, pregnancy, severe psychopathology (Symptom Check List-90) (Derogatis, 1977), involvement in a litigation procedure regarding CRPS-I, and insufficient comprehension of Dutch language were excluded. Participants provided written informed consent before inclusion. The Medical Ethics Committee approved the study protocol before data collection started (METC-azM reg.nr.20067), and the trial was registered (NCT00625976). 
Table 1. Summary of the contents of Exposure in vivo (EXP) and Treatment as usual (TAU).

\begin{tabular}{|c|c|c|}
\hline & Exposure in vivo & Treatment as usual \\
\hline $\begin{array}{l}\text { Number of sessions } \\
\text { and treatment } \\
\text { schedule }\end{array}$ & $\begin{array}{l}17 \text { weeks, } 17 \text { hours, } 1 \text { h sessions } \\
\text { Week 1-4: } 2 \text { sessions } \\
\text { Week } 5-9: 1 \text { session } \\
\text { Week 10-17: every other week } 1 \text { session }\end{array}$ & $\begin{array}{l}17 \text { weeks, } 17 \text { hours, } 30 \text { min sessions } \\
\text { Week } 1-4: 3 \text { sessions } \\
\text { Week } 5-13: 2 \text { sessions } \\
\text { Week } 14-17: 1 \text { session }\end{array}$ \\
\hline Therapists & $\begin{array}{l}\text { Psychologist and physical- or occupational } \\
\text { therapist with experience in EXP. }\end{array}$ & $\begin{array}{l}\text { Physical therapist with specific training for the } \\
\text { current protocol. }\end{array}$ \\
\hline Underlying paradigm & $\begin{array}{l}\text { Cognitive behavioral; fear avoidance } \\
\text { models }\end{array}$ & Biomedical; pain-contingent, ergonomics \\
\hline Main treatment aim & $\begin{array}{l}\text { Reduce disability by lowering levels of } \\
\text { pain-related fear. }\end{array}$ & $\begin{array}{l}\text { Increase control over pain and optimize coping with } \\
\text { CRPS-I. }\end{array}$ \\
\hline Way to deal with pain & "No pain, no gain" & "With pain no gain" \\
\hline Treatment overview & $\begin{array}{l}\text { Session 1: Intake; cognitive-behavioral } \\
\text { analysis of complaints (pain and its } \\
\text { consequences) } \\
\text { Session 2: Identify movements/activities } \\
\text { that are threatening using PHODA. } \\
\text { Session 3: education about treatment } \\
\text { rationale; completing personalized fear } \\
\text { avoidance model. } \\
\text { Session 4-17: Exposure with behavioral } \\
\text { experiments; systematic and repeated } \\
\text { exposure to feared movements, activities } \\
\text { and/or sensations. Catastrophic inter- } \\
\text { pretations regarding these stimuli are } \\
\text { challenged and corrected, to lower the } \\
\text { threat-value of these stimuli. }\end{array}$ & $\begin{array}{l}\text { Session 1: Intake; analysis of pain and complaints } \\
\text { Session 2: Establish the current level of control } \\
\text { over pain (low-moderate-high) and explanation of } \\
\text { treatment rationale. } \\
\text { Session 3-34: depending on the level of control over } \\
\text { pain: } \\
\text { - Extinguish source of ongoing pain by rest of the } \\
\text { affected limb } \\
\text { - Connective tissue massage } \\
\text { - Transcutaneous electric nerve stimulation (TENS) } \\
\text { - Exercises aiming at pain-reduction (stimulation of } \\
\text { kinetic receptors type I and II) } \\
\text { - Improving skills by practicing co"mpensatory } \\
\text { strategies } \\
\text { - Training skills and instructions about body position }\end{array}$ \\
\hline Available evidence & $\begin{array}{l}\text { EXP is the standard treatment for anxiety } \\
\text { disorders, and has been shown to be } \\
\text { effective in reducing pain-related fear and } \\
\text { disability in chronic low-back pain. }\end{array}$ & $\begin{array}{l}\text { TAU has shown to be more effective in reducing } \\
\text { pain and CRPS signs and symptoms than active } \\
\text { control treatment with occupational therapy, and } \\
\text { a social-therapy control treatment for patients with } \\
\text { CRPS-I of less than one year. }\end{array}$ \\
\hline
\end{tabular}

\section{Randomisation and masking}

A computerized "adaptive biased urn randomization" was used to generate a randomization schedule (Schouten, 1995), with parallel assignment in a 1:1 ratio, pre-stratifying by gender, affected extremity (upper, lower, both), and pain-related fear level (PHODA score $\leq 58$ and $>58$ ), resulting in eight strata. This schedule was generated by an independent statistician, and was only accessible to one researcher who was not involved in selection, treatment, and measurement. The physiatrist enrolled participants. Participants knew that they would receive one of two possible treatments. The content of allocated treatment was revealed in the first 
treatment session, the content of the other treatment remained unaddressed. The trial required separation between staff performing the outcome measurements and staff delivering interventions. Research assistants were not informed about treatment assignment. Their coordinating role in receiving data (audio-tapes, planning of measurements) made it practically impossible to keep them fully blinded. Since all questionnaires were completed electronically using the online platform EMIUM (Janssen, 2005) in their home setting, this could not have affected outcomes.

\section{Procedures}

Participants completed two identical pre-assessments within two weeks. Posttreatment assessments were completed within two weeks after treatment, at 6-month, and 12-month follow-up. The current report includes post-treatment and 6-month follow-up data. After 6-month follow-up assessment, participants were offered the possibility to receive the alternative treatment. Adhering to intentionto-treat analyses, participants who withdrew from treatment were invited to perform measurements at all time points. Assessments took place at Maastricht University. Treatments took place at the department of Rehabilitation at Maastricht University Medical Center (MUMC), consisting of 17 hours over a period of 17 weeks. Therapists were provided with treatment manuals (Table 1 provides a summary of the content of treatments), and they audiotaped each session. Treatment fidelity (protocol adherence and contamination) was assessed using the Method of assessing Protocol Adherence and Contamination (MPAC) (Leeuw, Goossens, de Vet, \& Vlaeyen, 2009). After explanation of the treatment rationale, participants and therapist(s) completed the Credibility/Expectancy Questionnaire (CEQ-m) (Smeets et al., 2008), which has shown high internal consistency and sufficient test-retest reliability (Smeets et al., 2008).

\section{Outcomes}

Self-reported disability was the primary outcome. For participants with upper limb CRPS-I, disability was measured with the Radboud Skills Questionnaire (RASQ), which has shown reliability in terms of response stability (Oerlemans, Cup, DeBoo, Goris, \& Oostendorp, 2000). A mean overall score was calculated. For lower limb disability, the Walking Ability Questionnaire (WAQ) composed of items from the Walking Ability and the Rising and Sitting Questionnaire was used (Roorda, Roebroeck, Lankhorst, 
van Tilburg, \& Bouter, 1996; Roorda et al., 2005). The WAQ is obtained from the Dutch CRPS research consortium Trauma RElated Neuronal Dysfunction (http:/ / www.trendconsortium.nl). A mean score over domain-scores was calculated.

As secondary outcome measures, pain intensity, pain catastrophizing, perceived harmfulness of activities, and health-related quality of life were assessed. The Neuropathic Pain Scale (NPS) (Galer \& Jensen, 1997) is a reliable and valid questionnaire to assess pain intensity (Fishbain et al., 2008; Galer \& Jensen, 1997). The mean total score of the 10 numerical scales was used. The Pain Catastrophizing Scale (PCS) (Sullivan, Bishop, \& Pivik, 1995) has excellent psychometric properties (Goubert et al., 2004). Perceived harmfulness of activities was assessed with the PHODA (Dubbers et al., 2003; Jelinek et al., 2003), instructing participants to imagine performing the activity displayed on the picture, and rate the perceived harmfulness along a thermometer. As different activities might be perceived as harmful depending on the location of CRPS-I complaints, PHODA upper and lower extremity were used (Dubbers et al., 2003; Jelinek et al., 2003). These versions are similar to the PHODA-SeV for lower back, which has shown to be reliable and valid (Leeuw, Goossens, van Breukelen, Boersma, \& Vlaeyen, 2007). The Short Form-36 (SF-36) is a widely used self-report rendering psychometrically-based physical and mental health summary scores. The Physical (SF36-PCS), and Mental (SF36-MCS) Component Summary Measures were used as supported by factor analyses (Ware, Kosinski, \& Keller, 1994). The current paper reports on the results based on questionnaires measuring main outcomes. Although a measure for participation was initially included (IPA; Impact on Participation and Autonomy questionnaire (Cardol, de Haan, van den Bos, de Jong, \& de Groot, 1999)), it was deleted due to reported floor/ceiling effects, limited evidence of responsiveness and the absence of a total score (Magasi \& Post, 2010). Physical measures including physical activity in daily life and body function will be reported elsewhere.

\section{Statistical analyses}

To calculate sample size, data from de Jong et al. (EXP, $N=8$ ) (de Jong et al., 2005) and Oerlemans et al. (TAU, $N=135$ ) (Oerlemans, Oostendorp, et al., 2000) were used. Disability measured with the RASQ was used as dependent variable in an ANCOVA with baseline measurement as covariate to compute "partial eta squared" $(=0.095)$. The square root from this partial eta squared $(r=308)$ was used as effect estimator in the software program nQuery Advision 5.0 with alpha 0.05, 2-tailed, and statistical power of 0.80 , resulting in 39 participants per condition. Taking into account the duration of 
the trial, required effort from participants, and drop-out rates from previous studies (EXP 33\% (Maaike Leeuw et al., 2008) and TAU 23\% (Oerlemans, Oostendorp, et al., 2000)), 55 participants per condition was aimed for. However, given the relatively low inclusion rate within the available time window, we deemed nonparametric randomization tests more appropriate (Edgington \& Onghena, 2007). Compared to inferential procedures from the general linear model framework, randomization tests have the advantage of being valid for experiments with small sample sizes without making distributional assumptions, are easy to apply, and extremely versatile for even the most complex designs (Onghena \& Edgington, 2005). Randomization tests are permutation tests based on random assignment to test a null hypothesis about treatment effect in randomized experiments. Data were analyzed using an intentionto-treat approach; no participants were excluded from data analyses. Analyses were performed using RT4Win (Huo \& Onghena, 2012). A mean score was calculated for all questionnaires revealing no significant differences between both pre-treatment measurements.

Individual change scores between pre- and post-treatment assessment were calculated for each variable (=DIF1), and between pre-treatment and 6-month followup assessment (=DIF2). The number of Monte Carlo randomizations was set at 500000 . To correct for multiple testing, a Bonferroni-Holm correction over the total number of randomization tests was performed per phase (DIF1 and DIF2, respectively). Cohen's d was chosen to calculate effect-sizes. The Leeds Reliable Change Indicator (LRCI) was used as a measure of reliable improvement (Morley \& Dowzer, 2014).

Per condition, the proportion of participants with a reliable change was calculated, and tested using Z-tests. Protocol adherence was considered sufficient when at least $70 \%$ of essential treatment elements were observed. Contamination was considered acceptable when maximally $10 \%$ of prohibited treatment elements occurred. Fisher's Exact Tests were used to test whether essential and prohibited elements were observed equally frequent in both conditions. 
Figure 1. CONSORT flow chart.

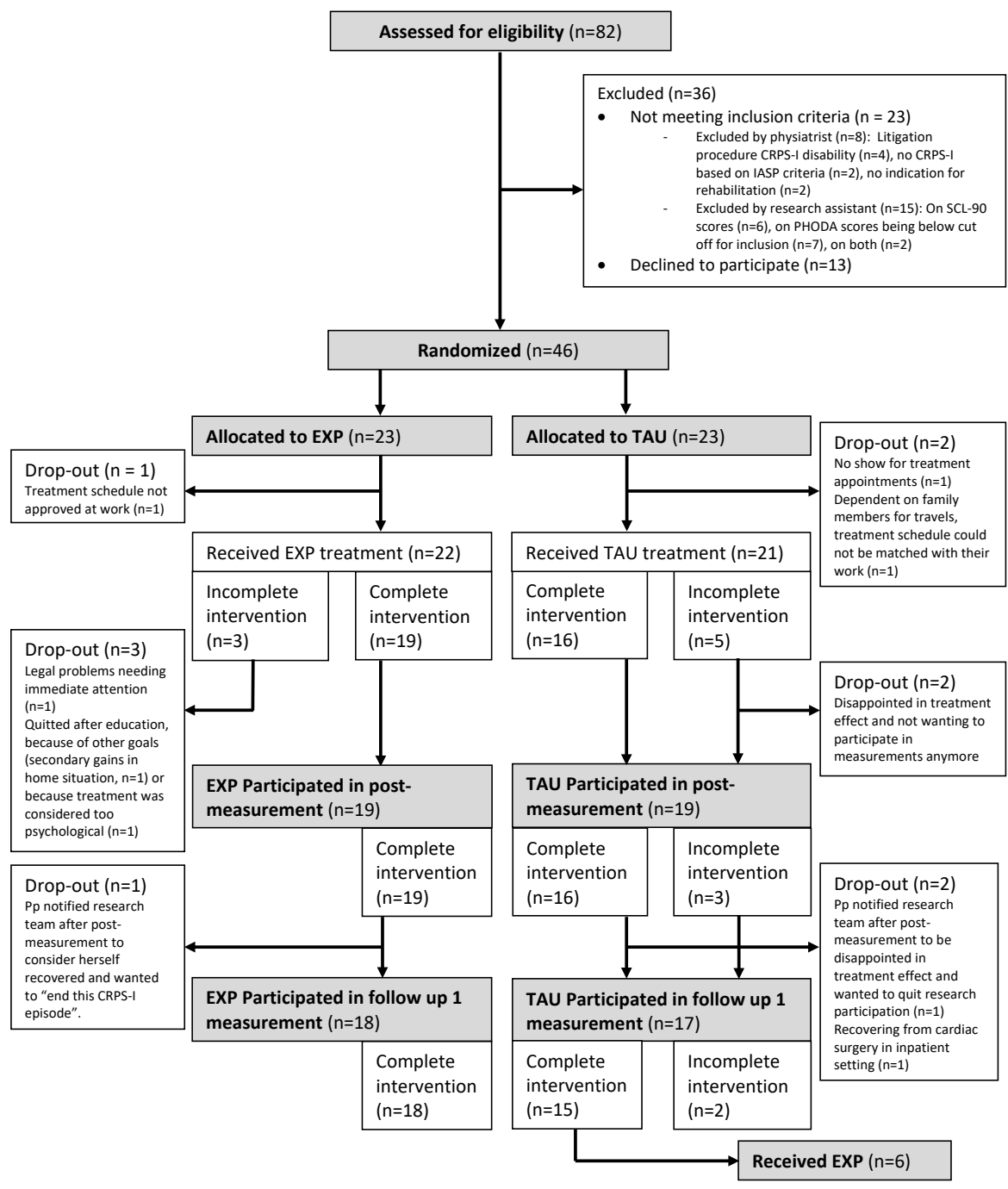

Explanatory legend for figure 1: EXP = Exposure in vivo treatment, TAU = Treatment as usual, CRPS-I = Complex Regional Pain Syndrome Type I, IASP = International Association for the Study of Pain, SCL-90= Symptom Checklist 90, PHODA = Photographic Series of Daily Activities 
Table 2. Demographic and baseline characteristics, for total group and per treatment condition.

\begin{tabular}{|c|c|c|c|}
\hline & & & \\
\hline & Total $(N=46)$ & $\operatorname{EXP}(N=23)$ & $\operatorname{TAU}(N=23)$ \\
\hline Age, mean (SD) & $44,85(11,23)$ & $45,83(11,26)$ & $43,87(11,37)$ \\
\hline Gender (\% male) & $9(20 \%)$ & $5(22 \%)$ & $4(17 \%)$ \\
\hline \multicolumn{4}{|l|}{ Education } \\
\hline$\%$ Low & $27(59 \%)$ & $12(52 \%)$ & $15(65 \%)$ \\
\hline$\%$ Middle & $14(30 \%)$ & $8(35 \%)$ & $6(21 \%)$ \\
\hline$\%$ High & $5(11 \%)$ & $3(13 \%)$ & $2(9 \%)$ \\
\hline \multicolumn{4}{|l|}{ Workstatus } \\
\hline \% Working (contract hours) & $2(4 \%)$ & $1(4 \%)$ & $1(4 \%)$ \\
\hline \% Partly working, partly sick leave & $14(30 \%)$ & $7(30 \%)$ & $7(30 \%)$ \\
\hline$\%$ Sick leave for full contract hours & $8(17 \%)$ & $1(4 \%)$ & $7(30 \%)$ \\
\hline$\%$ Disability pension & $17(37 \%)$ & $11(48 \%)$ & $6(26 \%)$ \\
\hline$\%$ Other (study, household) & $5(11 \%)$ & $3(13 \%)$ & $2(9 \%)$ \\
\hline Mean duration of complaints in years (SD) & $5,1(5,4)$ & $\begin{array}{c}5,3(5,6) \\
\text { (range: } 0.33-17)\end{array}$ & $\begin{array}{c}4,9(5,4) \\
\text { (range: } 0.33-20)\end{array}$ \\
\hline$\%$ Currently using medication & $36(78 \%)$ & $15(65 \%)$ & $21(91 \%)$ \\
\hline$\%$ Invasive treatment before & $25(54 \%)$ & $10(44 \%)$ & $15(65 \%)$ \\
\hline \% Sympathectomy before & $5(11 \%)$ & $2(9 \%)$ & $3(13 \%)$ \\
\hline \% Physiotherapy before & $37(80 \%)$ & $16(70 \%)$ & $21(91 \%)$ \\
\hline \% Psychology before & $10(22 \%)$ & $4(17 \%)$ & $6(26 \%)$ \\
\hline Mean treatment credibility patients (SD) & & $6,63(1,81)(N=18)^{a}$ & $6,76(1,66)(N=19)^{a}$ \\
\hline Mean treatment expectancy patients (SD) & & $7,07(1,79)$ & $6,79(1,74)$ \\
\hline Mean treatment credibility therapists (SD) & & $7,82(0,37)(N=19)^{a}$ & $3,60(1,78)(N=21)^{a}$ \\
\hline Mean treatment expectancy therapists (SD) & & $6,74(1,21)$ & $4,45(2,19)$ \\
\hline \multicolumn{4}{|l|}{ Disability (mean and SD) } \\
\hline Radboud Skills Questionnaire $(1-5)^{b}$ & $3,31(0,93)(N=30)$ & $3,14(0,89)(N=15)$ & $3,49(0,96)(N=15)$ \\
\hline Walking Ability Questionnaire $(0-10)^{b}$ & $6,98(2,07)(N=19)$ & $6,97(2,48)(N=9)$ & $6,99(1,76)(N=10)$ \\
\hline \multicolumn{4}{|l|}{ Pain-related fear (mean and SD) } \\
\hline Pain Catastrophizing Scale $(0-52)^{c}$ & $16,96(11,11)$ & $17,15(9,65)$ & $16,76(12,63)$ \\
\hline Perceived harmfulness of activities $(0-100)^{d}$ & $67,01(16,83)$ & $64,87(16.19)$ & $69,15(17,54)$ \\
\hline \multicolumn{4}{|l|}{ Health related quality of life (mean and SD) } \\
\hline SF-36 Physical Component Scale (0-100)e & $39,95(14,22)$ & $40,01(12,57)$ & $39,89(15,98)$ \\
\hline SF-36 Mental Component Scale $(0-100)^{f}$ & $60,32(17,89)$ & $58,92(15,52)$ & $61,72(20,25)$ \\
\hline \multicolumn{4}{|l|}{ Pain intensity (mean and SD) } \\
\hline Neuropathic Pain Scale $(0-10)^{s}$ & $5,55(1,93)$ & $5,48(2,22)$ & $5,63(1,63)$ \\
\hline
\end{tabular}

a Note that these scores reflect all available responses from patients and therapists ${ }^{b}$ Lower scores indicate less disability cLower scores indicate less catastrophizing about pain ${ }^{d}$ Lower scores reflect lower perceived harmfulness of activities ${ }^{\mathrm{eH}} \mathrm{Higher}$ scores indicate better physical health ${ }^{\mathrm{f} H i g h e r}$ scores indicate better mental health sLower scores indicate less pain intensity 


\section{Results}

The study ran between January 2009 and June 2013. Figure 1 shows the CONSORT flow chart. Eighty-two patients were assessed for eligibility, 23 did not meet the inclusion criteria, and 13 declined or withdrew before randomization, resulting in 46 participants being randomized (23 to each condition) with a mean age of 44.9 (SD 11.23) and a mean CRPS-I duration of 5.1 years (SD 5.4). Table 2 shows the baseline characteristics of the participants. A mean pre-treatment score was calculated since no significant differences appeared over both pre-measurement scores $(p \geq 0.313)$. Three participants did not have any treatment contact (1 EXP, 2 TAU). Eight participants ( 3 EXP, 5 TAU) did not complete treatment protocol; they were requested to complete further measurements, but only 3 (all TAU) continued testing, resulting in 38 post-measurements (19 EXP, 19 TAU). At 6-months follow up, 35 participants (18 EXP, 17 TAU) completed the measurements. Thereafter, 6 TAU participants crossed over to EXP because they were dissatisfied with treatment results and requested further rehabilitation treatment during the consultation with their physiatrist. No EXP-participants crossed over to TAU.

Randomization tests showed no differences between conditions in participants' credibility and expectancy ratings $(p=0.661)$. Therapists' ratings indicated that EXP-therapists found EXP a more credible treatment than TAU-therapists found TAU $(p<0.001)$, and had also higher expectancies of EXP-outcomes than TAU-therapists had of TAU-outcomes $(p<0.001)$. Therapists audiotaped $63 \%$ of delivered treatments for the treatment fidelity check (MPAC) (Leeuw et al., 2009), 30 audiotapes (15 from each treatment condition) were randomly selected. Four (1 EXP, 3 TAU) could not be used due to technical problems, resulting in 26 audiotapes rated by two independent raters. The inter-rater reliability was excellent for the identification of treatment condition (Cohen's $\mathrm{k}=0.84$ ), and good for identification of treatment elements (Cohen's k = 0.71). Raters identified sessions correctly as TAU or EXP in $96 \%$, supporting sufficient differentiation between conditions. Protocol adherence was sufficient; 86.6\% of essential elements occurred in EXP, and $88.4 \%$ in TAU (Fisher's Exact Test, $\mathrm{p}=0.72$ ). Prohibited elements occurred in $3.6 \%$ in EXP, and 1.3\% in TAU (Fisher's Exact Test, $p=0.24)$, indicating that contamination was minimal and acceptable in both treatments.

Table 3 displays mean change scores over pre- to post (DIF1) and pre- to 6 months follow-up (DIF2) per treatment (see also figure 2), differences between both treatments, and results of the randomization tests with effect sizes. Upper extremity disability decreased more after EXP than after TAU (RASQ DIF1\&2; $p<0.001$ ). For lower extremity disability, the difference between EXP and TAU was not significant at DIF1 (WAQ, $p=0.054)$, but it was at DIF2 $(p=0.02)$. Patients receiving EXP reported 
less pain-catastrophizing (PCS DIF1\&2; $p<0.001$ ), decreased perceived harmfulness of activities (PHODA DIF1\&2; $p<0.001$ ), less pain-intensity (NPS DIF1 $p=0.001$; DIF2 $p<0.001$ ), and increased physical (SF36-PCS DIF1\&2; $<<0.001$ ) and mental (SF36-MCS DIF1 $p=0.001$; DIF2 $p<0.001$ ) health-related quality of life. Summarizing, all change scores on DIF1 and DIF2, except for the WAQ DIF1 score, showed statistically significant differences favoring EXP. Similar results were obtained with the Bonferroni-Holm correction for multiple testing. Cohen's d was > 1.10 for all measures, indicating large effects. Additionally, the proportion of participants showing a reliable improvement on disability (WAQ and RASQ pooled data) in EXP was significantly larger than in TAU (DIF1 84\% versus 37\%, respectively, $Z=2.99, p=0.003$; DIF2 94\% versus 18\%, $Z=4.59$, $p<0.001)$. For all secondary outcomes, even after correction for multiple testing, the proportion of participants in EXP showing a reliable change was also larger than in TAU (see Table 4 and Figure 3). For both treatments, no adverse effects were reported.

\section{Discussion}

This study convincingly shows that EXP is more successful than TAU in reducing disability in CRPS-I patients reporting moderate to high pain-related fear over preto post treatment, and up to 6-months follow-up. Only for lower extremity disability, EXP was not superior directly after treatment. Over both timespans, EXP was also superior to TAU in reducing pain-intensity, perceived harmfulness of activities, pain-catastrophizing, and in increasing quality of life. Additionally, the proportion of participants showing a reliable change was structurally higher in EXP on all measures. Our findings clearly confirm previous results (de Jong et al., 2005), and are in line with results in other chronic pain syndromes (de Jong et al., 2008; de Jong et al., 2012; Leeuw et al., 2008), suggesting that exposure-based treatments can be helpful in reducing disability in chronic CRPS-I (Leeuw, Goossens, Linton, et al., 2007; Vlaeyen \& Linton, 2000). To our knowledge, the current RCT is the first comparison between a CBT and a non-CBT treatment in CRPS-I. 
Table 3. Primary and secondary outcomes per condition (means and standard deviation (SD)) at pre-treatment, post-treatment, and 6 months follow-up.

\begin{tabular}{cccccc}
\hline Pre-treatment & & Post-treatment & \multicolumn{3}{c}{ Follow-up } \\
\hline mean (SD) & $N$ & mean (SD) & $N$ & mean (SD) & $N$
\end{tabular}

\section{Primary outcome: disability}

Disability upper extremity (Radboud Skills Questionnaire, 0-5a)

$\begin{array}{lrrrrrr}\text { EXP } & 3.14(0.89) & 15 & 1.86(0.91) & 14 & 1.87(0.62) & 13 \\ \text { SPT } & 3.49(0.96) & 15 & 3.02(1.19) & 12 & 3.08(1.23) & 11 \\ \begin{array}{l}\text { Sability lower extremity (Walking Ability Questionnaire, } \\ \text { (1) }\end{array} & & & & & & \\ \text { EXP } & 6.97(2.48) & 9 & 1.44(2.15) & 6 & 1.56(2.23) & 6 \\ \text { SPT } & 6.99(1.76) & 10 & 4.57(2.90) & 7 & 5.35(3.10) & 6\end{array}$

\section{Secondary outcomes}

Pain-related fear

Pain catastrophizing (PCS, $\left.0-52^{b}\right)$

$\begin{array}{lcccccc}\text { EXP } & 17.15(9.65) & 23 & 6.84(6.18) & 19 & 8.11(7.08) & 18 \\ \text { SPT } & 16.76(12.63) & 23 & 14.74(13.58) & 19 & 13.35(10.13) & 17\end{array}$

Perceived harmfulness of activities (PHODA, 0-100')

$\begin{array}{lllllll}\text { EXP } & 64.87(16.19) & 23 & 13.77(16.26) & 19 & 14.65(18.42) & 18 \\ \text { SPT } & 69.15(17.54) & 23 & 54.51(23.80) & 19 & 57.88(19.28) & 17\end{array}$

Health-related quality of life

Physical Health (Physical Component Scale SF-36, 100-0 $)$

$\begin{array}{lllllll}\text { EXP } & 40.01(12.57) & 23 & 72.82(17.64) & 19 & 66.20(23.81) & 18 \\ \text { SPT } & 39.89(15.98) & 23 & 48.15(23.28) & 19 & 47.96(22.35) & 17\end{array}$

Mental health (Mental Component Scale SF-36, 100-0

$\begin{array}{lllllll}\text { EXP } & 69.48(16.12) & 23 & 76.61(14.92) & 19 & 72.05(17.58) & 18 \\ \text { SPT } & 71.17(20.73) & 23 & 67.23(21.69) & 19 & 60.02(23.61) & 17\end{array}$

Pain

Pain intensity (Neuropathic Pain Scale, $0-10^{f}$ )

\begin{tabular}{lllllll} 
EXP & $5.48(2.22)$ & 23 & $2.79(2.25)$ & 19 & $2.88(2.47)$ & 18 \\
SPT & $5.63(1.63)$ & 23 & $4.98(2.16)$ & 19 & $5.54(1.80)$ & 17 \\
\hline
\end{tabular}

aLower scores indicate less disability bLower scores indicate less catastrophizing about pain cLower scores reflect lower perceived harmfulness of activities ${ }^{\mathrm{d} H i g h e r}$ scores indicate better physical health ${ }^{\mathrm{H}} \mathrm{Higher}$ scores indicate better mental health fLower scores indicate less pain intensity 


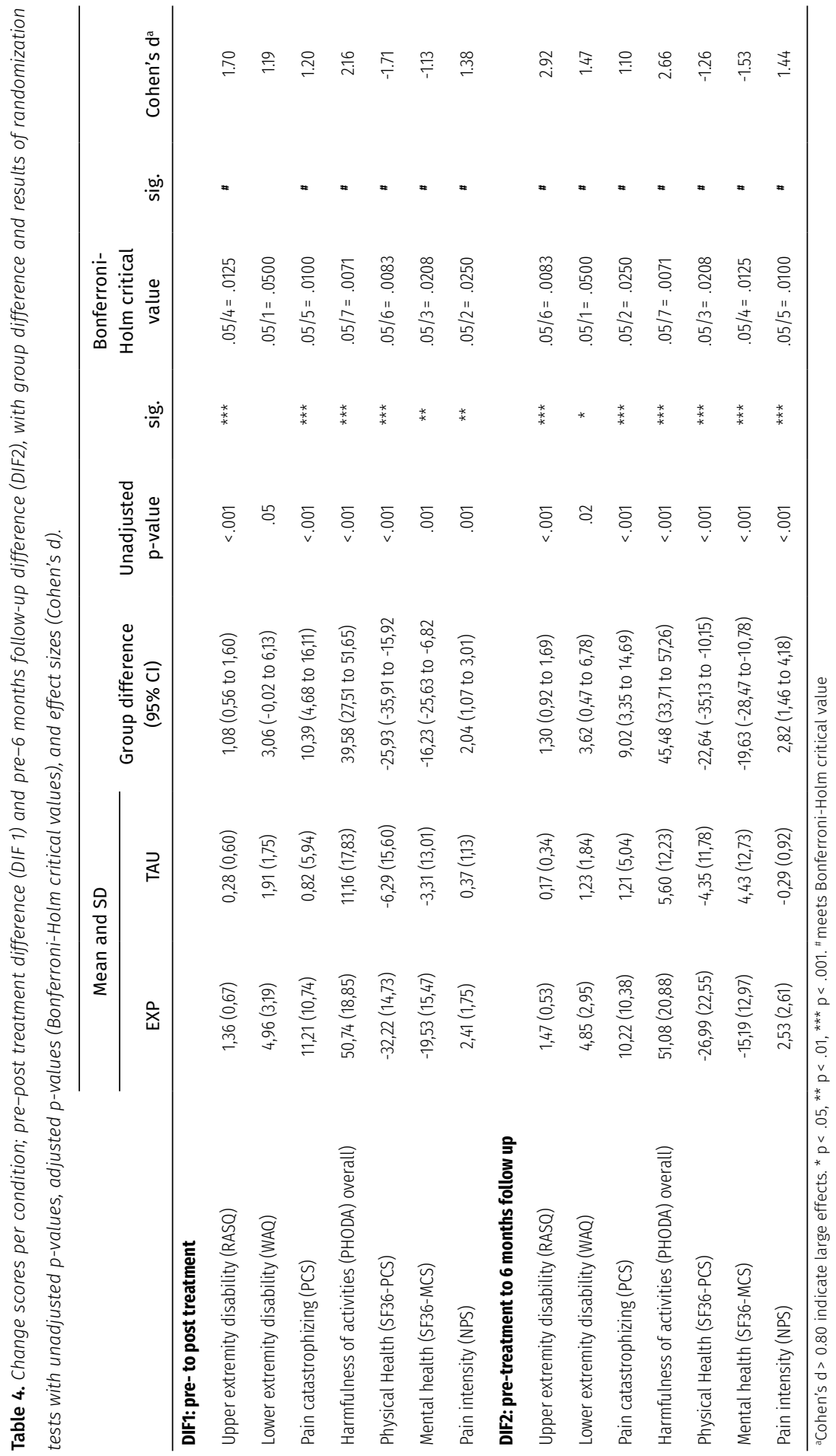


Table 5. Proportion reliable change per condition with Z-scores, unadjusted p-values and Bonferroni-Holm critical values over DIF1 and DIF2.

\begin{tabular}{|c|c|c|c|c|c|c|c|}
\hline & \\
\hline & $\begin{array}{l}\text { Proportion } \\
\text { reliable } \\
\text { change } \\
\text { in EXP }\end{array}$ & $\begin{array}{l}\text { Proportion } \\
\text { reliable } \\
\text { change } \\
\text { in TAU }\end{array}$ & Z-score & $\begin{array}{l}\text { Unadjusted } \\
\text { p-value }\end{array}$ & sig. & $\begin{array}{l}\text { Bonferroni } \\
\text { Holm } \\
\text { critical } \\
\text { value }\end{array}$ & sig. \\
\hline \multicolumn{8}{|l|}{ DIF1: pre- to post treatment } \\
\hline Physical Health (SF36-PCS) & 0,95 & 0,21 & 4,60 & $<.001$ & $* * *$ & $.05 / 6=.0083$ & $\#$ \\
\hline Mental health (SF36-MCS) & 0,68 & 0,00 & 4,45 & $<.001$ & $* * \star$ & $.05 / 5=.0100$ & $\#$ \\
\hline $\begin{array}{l}\text { Harmfulness of activities (PHODA } \\
\text { overall) }\end{array}$ & 1,00 & 0,58 & 3,18 & .001 & ** & $.05 / 4=.0125$ & $\#$ \\
\hline Disability (RASQ and WAQ pooled) & 0,84 & 0,37 & 2,99 & .003 & ** & $.05 / 3=.0208$ & $\#$ \\
\hline Pain catastrophizing (PCS) & 0,42 & 0,05 & 2,67 & .008 & ** & $.05 / 2=.0250$ & $\#$ \\
\hline Pain intensity (NPS) & 0,32 & 0,05 & 2,09 & .04 & * & $.05 / 1=.0500$ & $\#$ \\
\hline \multicolumn{8}{|l|}{$\begin{array}{l}\text { DIF2: pre-treatment to } 6 \text { months } \\
\text { follow up }\end{array}$} \\
\hline Disability (RASQ and WAQ pooled) & 0,94 & 0,18 & 4,59 & $<.001$ & $* * *$ & $.05 / 6=.0083$ & $\#$ \\
\hline Physical Health (SF36-PCS) & 0,89 & 0,12 & 4,56 & $<.001$ & $* * *$ & $.05 / 5=.0100$ & $\#$ \\
\hline $\begin{array}{l}\text { Harmfulness of activities (PHODA } \\
\text { overall) }\end{array}$ & 1,00 & 0,47 & 3,58 & $<.001$ & $* * *$ & $.05 / 4=.0125$ & $\#$ \\
\hline Mental health (SF36-MCS) & 0,61 & 0,06 & 3,44 & $<.001$ & $* * *$ & $.05 / 3=.0208$ & $\#$ \\
\hline Pain intensity (NPS) & 0,39 & 0,00 & 2,87 & .004 & ** & $.05 / 2=.0250$ & $\#$ \\
\hline Pain catastrophizing (PCS) & 0,39 & 0,06 & 2,32 & .02 & * & $.05 / 1=.0500$ & $\#$ \\
\hline
\end{tabular}

${ }^{*} p<.05,{ }^{* \star} p<.01,{ }^{\star \star *} p<.001 . "$ meets Bonferroni-Holm critical value

The results are remarkable for several reasons. First, EXP is based on the idea that disability and pain are driven by pain-related fear and associated avoidance behavior. Therefore, patients are encouraged to expose themselves to painful activities rather than protect themselves against pain. The most likely explanation for our positive effects is that EXP is based on a completely different paradigm, favoring approach-behavior towards valued life goals, rather than avoiding painful activity, which is the premise of TAU. Although CRPS-I is a painful condition and accompanied by disturbing physical symptoms, the pathophysiology is still unknown, and there is no evidence that performing activities does any harm (van de Meent et al., 2011). Whereas avoiding activities is an obvious and automatic reaction in an acute phase, this study challenges the common sense idea that protective avoidance is also functional in chronic CRPS-I (Vaneker, Wilder-Smith, Schrombges, \& Oerlemans, 2006). Second, these results contradict those of a previous study describing a painexposure approach delivered by physical therapists. The treatment protocol in that 
study was different, and several components were omitted such as the selection of patients with increased pain-related fear, multidisciplinary pain education, and the use of a fear hierarchy (Barnhoorn et al., 2015).

Future studies might also address whether EXP is successful in earlier, subacute stages of CRPS-I. It could be argued that patients with CRPS-I failing to achieve a higher activity level because of aversive body sensations, and without biomedical restrictions for becoming more active, can benefit from a cognitive-behavioral treatment as EXP. Since in CRPS-I, long-term disuse seems to result in irreversible physical impairments (Guttmann \& Wykes, 2008; Sharma, Agarwal, Broatch, \& Raja, 2009), it is essential that such treatments are offered as soon as possible. Of course, the current study needs replication, and when the present conclusions are corroborated, EXP should be considered an effective treatment to reduce disability in guidelines for CRPS-I. Given the absence of a treatment fidelity check in that study, it cannot be ruled out that limited treatment outcomes may be due to the provision of a weak treatment. Third, despite the resumption of valued activities in daily life, pain levels did not increase, but diminished significantly. Indeed, fear and pain share some common brain networks, and reductions in fear may ultimately produce reductions in pain as well (Hayes \& Northoff, 2012; Vogt, 2005). 
Figure 2. Boxplots depicting individual difference scores (DIF1: pre- to post treatment, DIF2: pre-treatment to 6 months follow up) for upper (RASQ) and lower (WAQ) extremity disability from Exposure in vivo (EXP) and Treatment as usual (TAU) with mean and quartiles.

DIF1: Pre- to post treatment
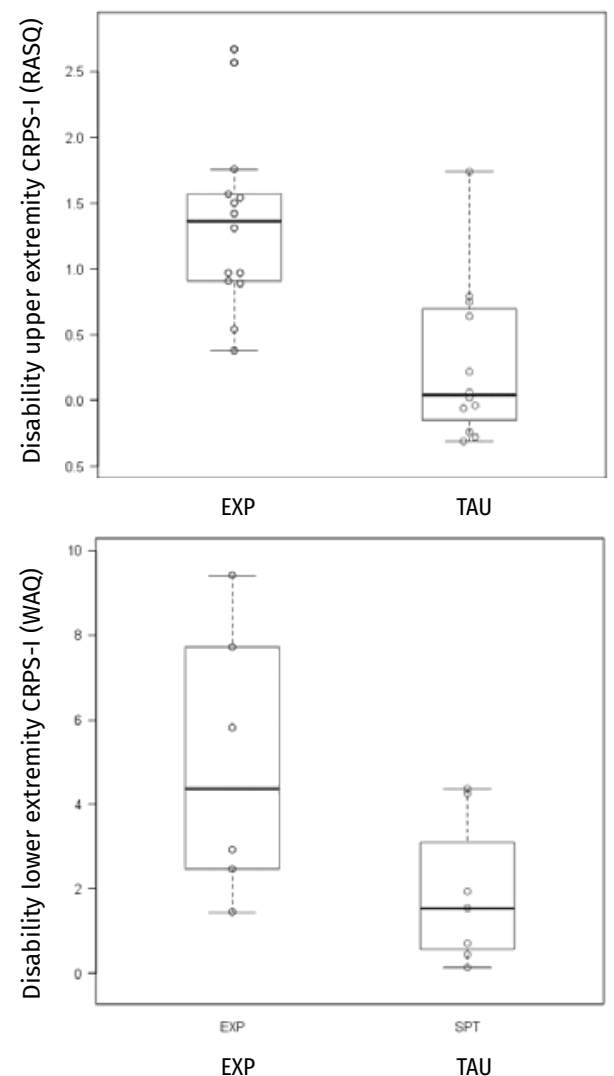

DIF2: Pre-treatment to 6 months FU
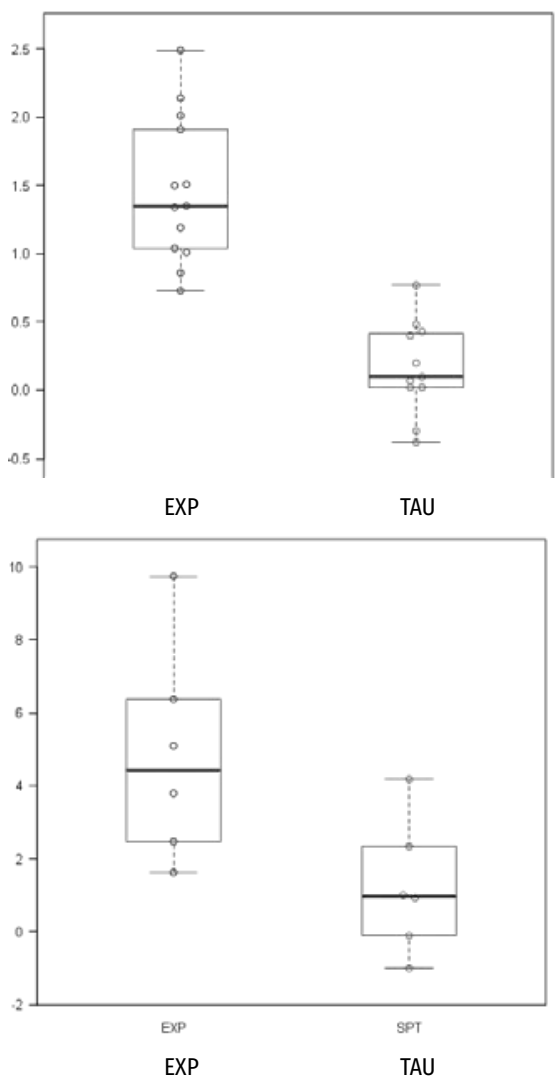
Figure 3. Boxplots depicting individual difference scores (DIF1: pre-to post treatment, DIF2: pre-treatment to 6 months follow up) for all secondary outcome measures from Exposure in vivo (EXP) and Treatment as usual (TAU) with mean and quartiles.

DIF1: Pre- to post treatment

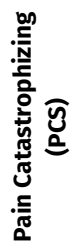

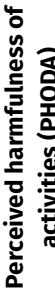

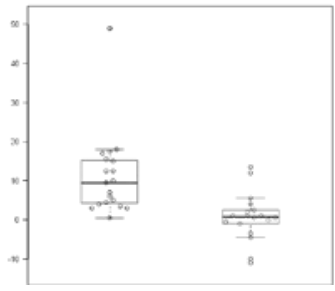

EXP

TAU

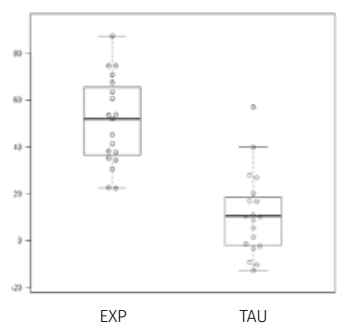

高

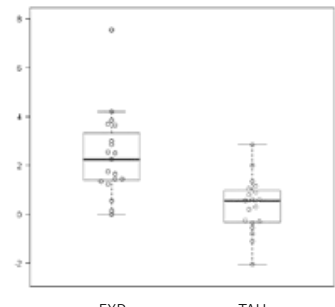

TAU
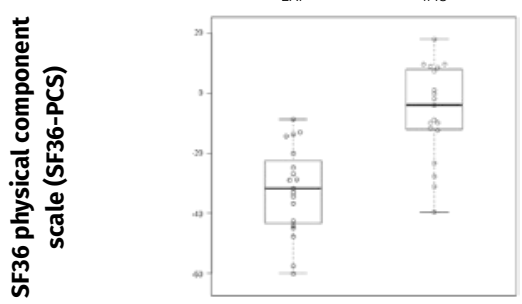

EXP

TAU

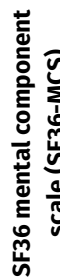

DIF2: Pre-treatment to 6 months FU

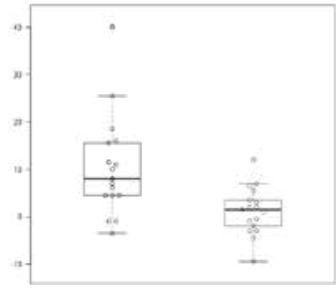

EXP

TAU
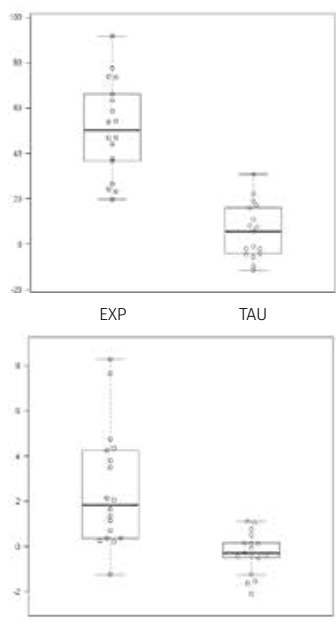

EXP

TAU

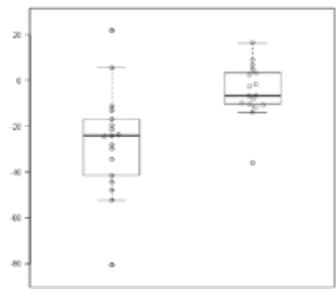

EXP

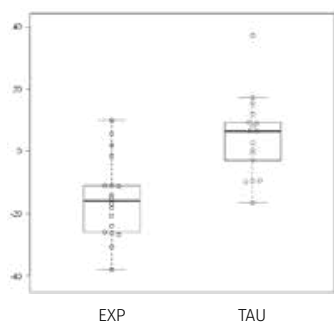


Figure 4. Leeds Reliable Change Indicator: Tramline displays depicting the change in CRPS-I disability for upper (RASQ) and lower (WAQ) extremity, from pre- to post treatment (DIF1) and from pre-treatment to 6 months follow up (DIF2).

EXP

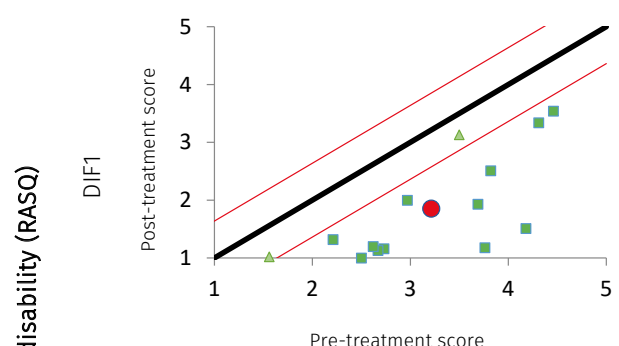

音

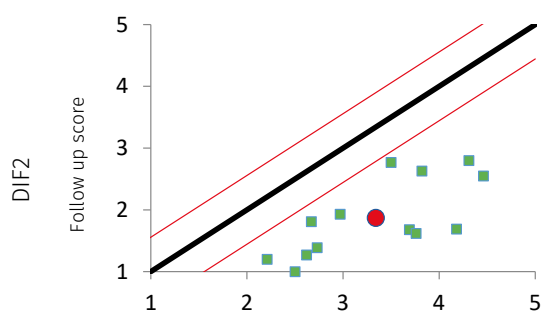

Pre-treatment score
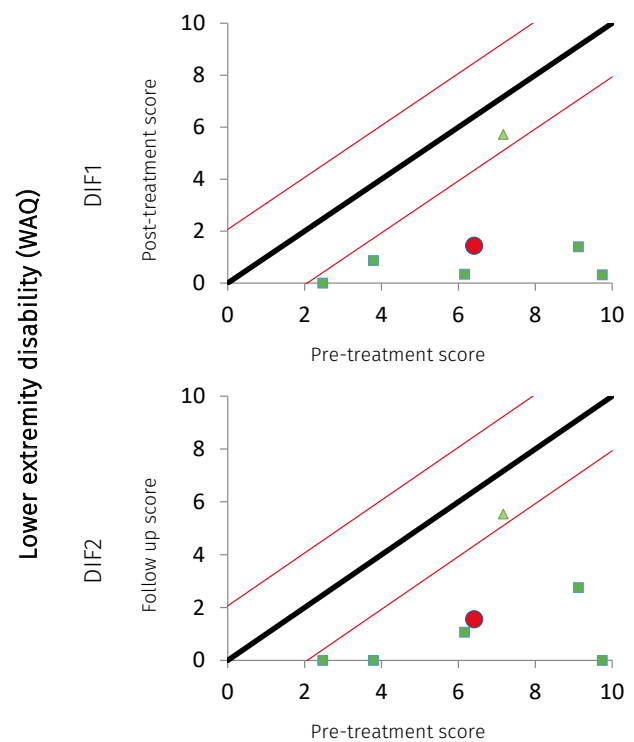

- Average group score

- Line of no change
TAU
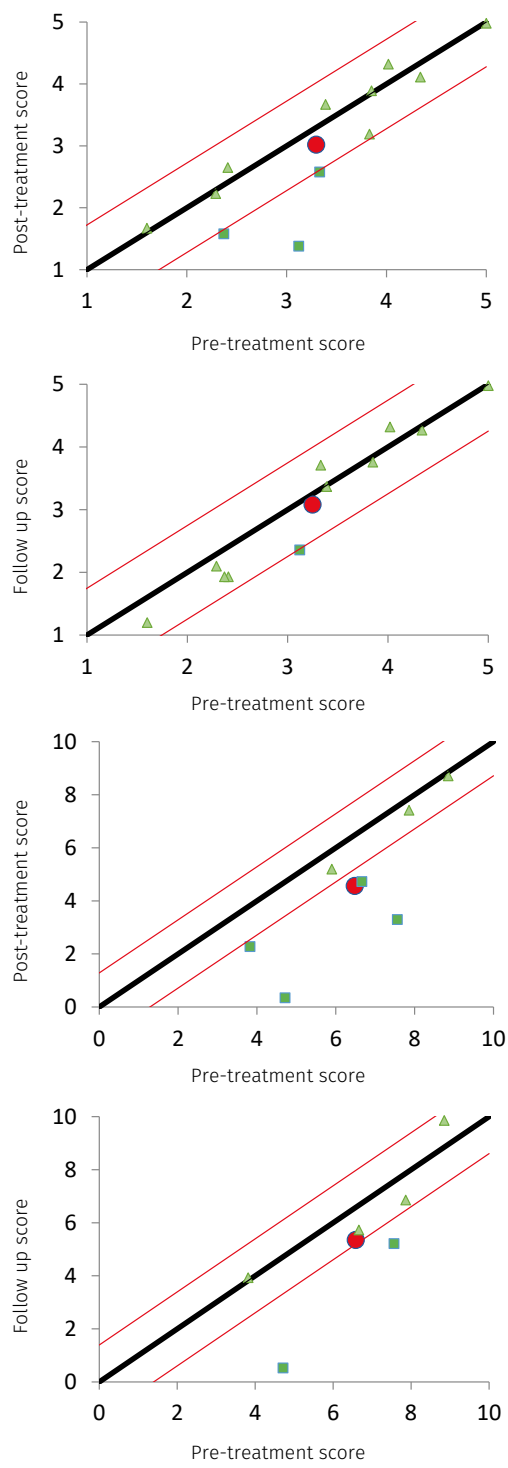

$\square$ Reliable change

$\Delta$ No change 
Fourth, the effects of EXP seem to strengthen with time. The effects sizes at the 6-month follow-up are generally higher than those at post-treatment. This is remarkable as in most RCTs; effects are often weakening after treatment. The current results suggest that EXP changes participants' beliefs from "painful activity is harmful" into "activity is beneficial despite pain", leading to generalization to novel daily life situations after treatment. Fifth, there is evidence that the longer time since diagnosis, the poorer the response to any treatment for CRPS-I (Schwartzman, Erwin, \& Alexander, 2009). A number of earlier TAU studies included participants with early CRPS-I (<1 year), and the favorable results of those studies might be due to the natural recovery in the sub-acute phase (Oerlemans et al., 1999; Oerlemans, Oostendorp, et al., 2000). In our study, many participants suffered quite some time from CRPS-I (74\% > 1 year, $35 \%>5$ years), making it unlikely that our results are related to natural recovery.

Some limitations need to be addressed as well. First, the number of participants was lower than our initial power calculations prescribed. CRPS-I is a severely disabling but not a prevalent condition, and the selection of patients reporting at least moderate levels of pain-related fear made it difficult to reach the sample size target. In addition, drop-out rates were relatively large, but equal across conditions and in line with previous studies (Leeuw et al., 2008). As a consequence, we adjusted our statistical analysis protocol accordingly. Despite the lower sample size, results were statistically significant, enabling us to show that more participants in EXP than in TAU improved in a reliable way. Second, EXP-therapists rated EXP a more credible treatment than TAU-therapists rated TAU. Although patients rated both treatments equally credible, and our fidelity check confirmed that treatments were delivered according to the protocolized manuals, we do not know if the differential treatment credibility influenced overall quality of treatment delivery, possibly favoring EXP. Third, the generalizability towards other treatment settings might be questioned since EXP was delivered in a tertiary care center by experienced EXP-therapists. Currently, EXP is a non-conventional treatment in CRPS-I, and therapists may need extensive additional training. Nevertheless, in a previous EXP-study for patients with chronic low back pain, therapists' experience did not predict treatment outcome (Leeuw et al., 2008). 


\section{Acknowledgements}

We are grateful for the support of all participating CRPS-I patients, specialists and therapists, our research assistants, referrers to the trial and staff. We thank Stephen Morley for his help with the Reliable Change Index calculations, and Tory Madden for her help with the systematic review. This study was supported by a grant from Profileringsfonds azM and governmental funding for Maastricht University, Faculty of Psychology. Johan W.S. Vlaeyen was also supported by the Odysseus Grant G090208N "The Psychology of Pain and Disability Research Program" funded by the Research Foundation Flanders (FWO Vlaanderen), Belgium. Funders had no role in study design, data collection and analysis, decision to publish, or preparation of the manuscript.

\section{Role of the funding source}

The study sponsor had no role in the study design, collection, analysis and interpretation of data, the writing of the report, or in the decision to submit for publication. The corresponding author had full access to all data and final responsibility for the decision to submit for publication.

\section{Conflicts of interest statement}

We declare that we have no conflicts of interest. 


\section{SUPPLEMENTARY MATERIAL}

\section{Brief systematic review on evidence for CBT in CRPS-I before this study}

At the start of our trial, the literature suggested cognitive-behavioral treatments (CBT) to be considered in CRPS-I, despite the absence of firm empirical evidence (Bruehl \& Chung, 2006). We carried out a systematic review on CBT in CRPS-I, and adopted the CBT definition of Morley et al. (1999). Three types of treatment were considered: Biofeedback and relaxation, Behaviour Therapy (the managed approach to behavioural change using the basic concepts and principles of operant psychology), and Cognitive Behaviour Therapy (primary focus on changing cognitive activity to achieve changes in behaviour, thought, and emotion) (Morley, Eccleston, \& Williams, 1999). In 2013, a Cochrane review of systematic reviews concluded that there was a critical lack of high quality evidence for the effectiveness of most therapies for CRPS (O'Connell et al., 2013). That review reported on one single CBT intervention (Fialka et al., 1996). This $\mathrm{RCT}$ provided very low quality evidence that relaxation therapy does not reduce pain when added to limb elevation, ice and therapeutic exercises (O'Connell et al., 2013).

We performed our own systematic review to update this information. We searched Pubmed, Psyclnfo, Cochrane trials, Cinahl, Embase and Web of Science up to April 20th, 2015, with no date or language restrictions, looking for full papers on CRPS-I and CBT. Because of the content of our intervention, we specifically searched for synonyms of graded exposure and graded activity, and for CBT in general. $\mathrm{MeSH} /$ Thesaurus terms were used if available (full search details are provided in the appendix). We identified 161 records, 19 of which were duplicates. The 142 remaining records were screened independently by two researchers $(\mathrm{MdH}, J \mathrm{~d} J)$. Records were eligible when reporting original research findings from randomised controlled trials on adult human subjects with CRPS-I (not post-stroke), reporting the effects of a CBT intervention (according to the abovementioned definition). 135 records were excluded at this stage. For the remaining seven records, full texts were retrieved and screened for eligibility. All were excluded for the following reasons: overview article $(n=1)$, not reporting on an intervention $(n=1)$, not an $\operatorname{RCT}(n=4)$, not a CBT intervention $(n=1)$. Our updated search did not reveal eligible RCTs additional to the Cochrane review of systematic reviews from 2013. Concluding, there is only one RCT reporting on the effects of CBT in adult CRPS-I patients, providing very low quality evidence that relaxation therapy added to physical therapy techniques does not reduce pain (O'Connell et al., 2013). No evidence is available on other forms of CBT. 


\section{References}

Bailey, K. M., Carleton, R. N., Vlaeyen, J. W. S., \& Asmundson, G. J. G. (2010). Treatments addressing pain-related fear and anxiety in patients with chronic musculoskeletal pain: A preliminary review. Cognitive Behaviour Therapy, 39(1), 46-63

Barnhoorn, K. J., van de Meent, H., van Dongen, R. T. M., Klomp, F. P., Groenewoud, H., Samwel, H., ... Staal, J. B. (2015). Pain exposure physical therapy (PEPT) compared to conventional treatment in complex regional pain syndrome type 1: a randomised controlled trial. BMJ Open, 5(12). doi:10.1136/bmjopen-2015-008283

Bruehl, S. (2015). Complex regional pain syndrome. BMJ, 351. doi:10.1136/bmj.h2730

Bruehl, S., \& Chung, O. Y. (2006). Psychological and behavioral aspects of complex regional pain syndrome management. Clin J Pain, 22(5), 430-437. doi:10.1097/01.ajp.0000194282.82002.79

Cardol, M., de Haan, R. J., van den Bos, G. A. M., de Jong, B. A., \& de Groot, I. J. M. (1999). The development of a handicap assessment questionnaire: the Impact on Participation and Autonomy (IPA). Clin Rehabil, 13(5), 411-419. doi:10.1191/026921599668601325

de Jong, J. R., Vangronsveld, K., Peters, M. L., Goossens, M. E., Onghena, P., Bulte, I., \& Vlaeyen, J. W. (2008). Reduction of pain-related fear and disability in post-traumatic neck pain: a replicated single-case experimental study of exposure in vivo. J Pain, 9(12), 1123-1134. doi:10.1016/j.jpain.2008.06.015

de Jong, J. R., Vlaeyen, J. W., de Gelder, J. M., \& Patijn, J. (2011). Pain-related fear, perceived harmfulness of activities, and functional limitations in complex regional pain syndrome type I. J Pain, 12(12), 1209-1218. doi:10.1016/j.jpain.2011.06.010

de Jong, J. R., Vlaeyen, J. W., Onghena, P., Cuypers, C., den Hollander, M., \& Ruijgrok, J. (2005). Reduction of pain-related fear in complex regional pain syndrome type I: the application of graded exposure in vivo. Pain, 116(3), 264-275. doi:10.1016/j.pain.2005.04.019

de Jong, J. R., Vlaeyen, J. W., van Eijsden, M., Loo, C., \& Onghena, P. (2012). Reduction of pain-related fear and increased function and participation in work-related upper extremity pain (WRUEP): effects of exposure in vivo. Pain, 153(10), 2109-2118. doi:10.1016/j.pain.2012.07.001

de Mos, M., de Bruijn, A. G. J., Huygen, F. J. P. M., Dieleman, J. P., Stricker, C. B. H., \& Sturkenboom, M. C. J. M. (2007). The incidence of complex regional pain syndrome: a population-based study. Pain, 129(1-2), 12-20. doi:10.1016/j.pain.2006.09.008

Derogatis, L. (1977). SCL-90. Administration, scoring and procedures manual-I for the R(evised) version. Baltimore: John Hopkins University School of Medicine, Clinical Psychometrics Research Unit Dubbers, A. T., Vikström, M. H., \& de Jong, J. R. (2003). The Photograph series of Daily Activities (PHODA-UE): cervical spine and shoulder, CD-rom version 1.2. Heerlen/Maastricht, the Netherlands: Zuyd University, Institute for Rehabilitation Research (iRv), Maastricht University Edgington, E. S., \& Onghena, P. (2007). Randomization Tests (4 ed.). Boca Raton: Chapman \& Hall/CRC, Taylor \& Francis Group 
Fialka, V., Korpan, M., Saradeth, T., Paternostro-Slugo, T., Hexel, O., \& Frischenschlager, O. (1996). Autogenic training for reflex sympathetic dystrophy: A pilot study. Complementary Therapies in Medicine, 4, 103-105

Fishbain, D. A., Lewis, J. E., Cutler, R., Cole, B., Rosomoff, H. L., \& Rosomoff, R. S. (2008). Can the neuropathic pain scale discriminate between non-neuropathic and neuropathic pain? Pain Med, 9(2), 149-160. doi:10.1111/j.1526-4637.2007.00302.x

Galer, B. S., \& Jensen, M. P. (1997). Development and preliminary validation of a pain measure specific to neuropathic pain: the Neuropathic Pain Scale. Neurology, 48(2), 332-338

Geha, P. Y., Baliki, M. N., Harden, R. N., Bauer, W. R., Parrish, T. B., \& Apkarian, A. V. (2008). The brain in chronic CRPS pain: abnormal gray-white matter interactions in emotional and autonomic regions. Neuron, 60(4), 570-581. doi:10.1016/j.neuron.2008.08.022

Goubert, L., Crombez, G., Van Damme, S., Vlaeyen, J. W., Bijttebier, P., \& Roelofs, J. (2004). Confirmatory factor analysis of the Tampa Scale for Kinesiophobia: invariant two-factor model across low back pain patients and fibromyalgia patients. Clin J Pain, 20(2), 103-110

Guttmann, O., \& Wykes, V. (2008). Complex Regional Pain Syndrome Type 1. New England Journal of Medicine, 359(5), 508. doi:doi:10.1056/NEJMicm060173

Harden, R. N., Oaklander, A. L., Burton, A. W., Perez, R. S. G. M., Richardson, K., Swan, M., ... Bruehl, S. (2013). Complex Regional Pain Syndrome: Practical Diagnostic and Treatment Guidelines, 4th Edition. Pain Medicine, 14(2), 180-229. doi:10.1111/pme.12033

Hayes, D., \& Northoff, G. (2012). Common brain activations for painful and non-painful aversive stimuli. BMC Neuroscience, 13(1), 60

Huo, M., \& Onghena, P. (2012). RT4Win: A Windows-based program for randomization tests. Psychologica Belgica, 52(4), 387-406

Janssen, R. (2005). Electronic Measurement Instrument: EMIUM. Maastricht: Department of Medical, Clinical and Experimental Psychology, Maastricht University, the Netherlands

Jelinek, S., Germes, D., Leyckes, N., \& de Jong, J. R. (2003). The photograph series of Daily Activities (PHODA-LE): lower extremities CD-rom version 1.2. Heerlen/Maastricht, the Netherlands: Zuyd University, Institute for Rehabilitation Research (iRv), Maastricht University

Leeuw, M., Goossens, M. E., de Vet, H. C., \& Vlaeyen, J. W. (2009). The fidelity of treatment delivery can be assessed in treatment outcome studies: a successful illustration from behavioral medicine. J Clin Epidemiol, 62(1), 81-90. doi:10.1016/j.jclinepi.2008.03.008

Leeuw, M., Goossens, M. E., Linton, S. J., Crombez, G., Boersma, K., \& Vlaeyen, J. W. (2007). The fearavoidance model of musculoskeletal pain: current state of scientific evidence. J Behav Med, 30(1), 77-94. doi:10.1007/s10865-006-9085-0

Leeuw, M., Goossens, M. E., van Breukelen, G. J., Boersma, K., \& Vlaeyen, J. W. (2007). Measuring perceived harmfulness of physical activities in patients with chronic low back pain: the Photograph Series of Daily Activities-short electronic version. J Pain, 8(11), 840-849. doi:10.1016/j.jpain.2007.05.013 
Leeuw, M., Goossens, M. E., van Breukelen, G. J., de Jong, J. R., Heuts, P. H., Smeets, R. J., .. Vlaeyen, J. W. (2008). Exposure in vivo versus operant graded activity in chronic low back pain patients: results of a randomized controlled trial. Pain, 138(1), 192-207. doi:10.1016/j.pain.2007.12.009

Leeuw, M., Goossens, M. E. J. B., van Breukelen, G. J. P., de Jong, J. R., Heuts, P. H. T. G., Smeets, R. J. E. M., . .. Vlaeyen, J. W. S. (2008). Exposure in vivo versus operant graded activity in chronic low back pain patients: results of a randomized controlled trial. Pain, 138(1), 192-207

Magasi, S., \& Post, M. W. (2010). A Comparative Review of Contemporary Participation Measures' Psychometric Properties and Content Coverage. Arch Phys Med Rehabil, 91(9), S17-S28. doi:http:// dx.doi.org/10.1016/j.apmr.2010.07.011

Marinus, J., Moseley, G. L., Birklein, F., Baron, R., Maihofner, C., Kingery, W. S., \& van Hilten, J. J. (2011). Clinical features and pathophysiology of complex regional pain syndrome. Lancet Neurol, 10(7), 637-648. doi:10.1016/s1474-4422(11)70106-5

Mersky, H., \& Bogduk, N. (Eds.). (1994). Classification of chronic pain: descriptions of chronic pain syndromes and definitions of pain terms (2 ed.). Seattle, WA: IASP Press

Meulders, A., \& Vlaeyen, J. W. S. (2012). Reduction of fear of movement-related pain and pain-related anxiety: an associative learning approach using a voluntary movement paradigm. Pain, 153(7), 1504-1513. doi:http://dx.doi.org/10.1016/j.pain.2012.04.013

Morley, S., \& Dowzer, C. N. (2014). Manual for the Leeds Reliable Change Indicator: Simple Excel ${ }^{\circledR}$ applications for the analysis of individual patient and group data. Retrieved from http://medhealth. leeds.ac.uk/info/618/clinical_psychology_dclinpsychol/797/leeds_reliable_change_index website

Morley, S. A., Eccleston, C. B., \& Williams, A. C. (1999). Systematic review and meta-analysis of randomized controlled trials of cognitive behaviour therapy and behaviour therapy for chronic pain in adults, excluding headache. Pain, 80(1-2)

Nederhand, M. J., IJzerman, M. J., Hermens, H. J., Turk, D. C., \& Zilvold, G. (2004). Predictive value of fear avoidance in developing chronic neck pain disability: consequences for clinical decision making. Arch Phys Med Rehabil, 85(3), 496-501. doi:http://dx.doi.org/10.1016/j.apmr.2003.06.019

O'Connell, N. E., Wand, B. M., McAuley, J., Marston, L., \& Moseley, G. L. (2013). Interventions for treating pain and disability in adults with complex regional pain syndrome- an overview of systematic reviews. Cochrane Database of Systematic Reviews(4). doi:10.1002/14651858.CD009416.pub2

Oerlemans, H. M., Cup, E. H., DeBoo, T., Goris, R. J., \& Oostendorp, R. A. (2000). The Radboud skills questionnaire: construction and reliability in patients with reflex sympathetic dystrophy of one upper extremity. Disabil Rehabil, 22(5), 233-245

Oerlemans, H. M., Oostendorp, R. A., de Boo, T., \& Goris, R. J. (1999). Pain and reduced mobility in complex regional pain syndrome I: outcome of a prospective randomised controlled clinical trial of adjuvant physical therapy versus occupational therapy. Pain, 83(1), 77-83

Oerlemans, H. M., Oostendorp, R. A., de Boo, T., van der Laan, L., Severens, J. L., \& Goris, J. A. (2000). Adjuvant physical therapy versus occupational therapy in patients with reflex sympathetic dystrophy/complex regional pain syndrome type I. Arch Phys Med Rehabil, 81(1), 49-56 
Onghena, P., \& Edgington, E. S. (2005). Customization of Pain Treatments: Single-Case Design and Analysis. Clin J Pain, 21(1), 56-68

Perez, R., Zollinger, P., Dijkstra, P., Thomassen-Hilgersom, I., Zuurmond, W., Rosenbrand, C., \& Geertzen, J. (2007). [Clinical practice guideline 'Complex regional pain syndrome type I']. Ned Tijdschr Geneeskd., 151(30), 1674-1679

Roorda, L. D., Roebroeck, M. E., Lankhorst, G. J., van Tilburg, T., \& Bouter, L. M. (1996). Measuring functional limitations in rising and sitting down: development of a questionnaire. Arch Phys Med Rehabil, 77(7), 663-669

Roorda, L. D., Roebroeck, M. E., van Tilburg, T., Molenaar, I. W., Lankhorst, G. J., Bouter, L. M., ... Rijken, P. M. (2005). Measuring activity limitations in walking: development of a hierarchical scale for patients with lower-extremity disorders who live at home. Arch Phys Med Rehabil, 86(12), 2277-2283. doi:10.1016/j.apmr.2005.06.014

Schouten, H. J. (1995). Adaptive biased urn randomization in small strata when blinding is impossible. Biometrics, 51(4), 1529-1535

Schwartzman, R. J., Erwin, K. L., \& Alexander, G. M. (2009). The natural history of complex regional pain syndrome. Clin J Pain, 25(4), 273-280. doi:10.1097/AJP.0b013e31818ecea5

Sharma, A., Agarwal, S., Broatch, J., \& Raja, S. N. (2009). A web-based cross-sectional epidemiological survey of complex regional pain syndrome. Reg Anesth Pain Med, 34(2), 110-115. doi:10.1097/ AAP.0b013e3181958f90

Simons, L. (2016). Fear of pain in children and adolescents with neuropathic pain and complex regional pain syndrome. Pain, 157 Supplement 1:S90-S97

Simons, L. E., Pielech, M., Erpelding, N., Linnman, C., Moulton, E., Sava, S., . . Borsook, D. (2014). The responsive amygdala: treatment-induced alterations in functional connectivity in pediatric complex regional pain syndrome. Pain, 155(9), 1727-1742. doi:http://dx.doi.org/10.1016/j.pain.2014.05.023

Smeets, R. J., Beelen, S., Goossens, M. E., Schouten, E. G., Knottnerus, J. A., \& Vlaeyen, J. W. (2008). Treatment expectancy and credibility are associated with the outcome of both physical and cognitive-behavioral treatment in chronic low back pain. Clin J Pain, 24(4), 305-315. doi:10.1097/ AJP.0b013e318164aa75

Stanton-Hicks, M., Baron, R., Boas, R., Gordh, T., Harden, R. N., \& Hendler, N. (1998). Complex regional pain syndromes: guidelines for therapy. Clin J Pain, 14, 155-166

Sullivan, M. J. L., Bishop, S. R., \& Pivik, J. (1995). The Pain Catastrophizing Scale: Development and validation. Psychological Assessment, 7(4), 524-532

Turk, D. C., \& Wilson, H. D. (2010). Fear of Pain as a Prognostic Factor in Chronic Pain: Conceptual Models, Assessment, and Treatment Implications. Current Pain and Headache Reports, 14(2), 88-95. doi:10.1007/s11916-010-0094-X

van de Meent, H., Oerlemans, M., Bruggeman, A., Klomp, F., van Dongen, R., Oostendorp, R., \& Frölke, J. P. (2011). Safety of "pain exposure" physical therapy in patients with complex regional pain syndrome type 1. Pain, 152(6), 1431-1438. doi:http://dx.doi.org/10.1016/j.pain.2011.02.032 
Vaneker, M., Wilder-Smith, O. H., Schrombges, P., \& Oerlemans, H. M. (2006). Impairments as measured by ISS do not greatly change between one and eight years after CRPS 1 diagnosis. Eur J Pain, 10(7), 639-644. doi:10.1016/j.ejpain.2005.10.003

Vlaeyen, J. (2015). Learning to predict and control harmful events: chronic pain and conditioning. Pain, 156 Supplement 1:S86-S93

Vlaeyen, J., \& Linton, S. (2012). Fear-avoidance model of chronic musculoskeletal pain: 12 years on. Pain, 153(6), 1144-1147

Vlaeyen, J., Morley, S., Linton, S. J., Boersma, K., \& de Jong, J. (2012). Pain-Related Fear: Exposure-Based Treatment for Chronic Pain: IASP Press

Vlaeyen, J. W., \& Linton, S. J. (2000). Fear-avoidance and its consequences in chronic musculoskeletal pain: a state of the art. Pain, 85(3), 317-332

Vlaeyen, J. W. S., de Jong, J. R., Leeuw, M., \& Crombez, G. (2004). Fear reduction in chronic pain; Graded exposure in vivo with behavioral experiments. In G. J. G. Asmundson, J. W. S. Vlaeyen, \& G. Crombez (Eds.), Understanding and treating fear of pain (pp. 313-343). Oxford: University Press

Vlaeyen, J. W. S., Kole-Snijders, A. M. J., Boeren, R. G. B., \& van Eek, H. (1995). Fear of movement/(re)injury in chronic low back pain and its relation to behavioral performance. Pain, 62(3), 363-372

Vlaeyen, J. W. S., \& Linton, S. J. (2000). Fear-avoidance and its consequences in chronic musculoskeletal pain: a state of the art. Pain, 85(3), 317-332

Vogt, B. A. (2005). Pain and emotion interactions in subregions of the cingulate gyrus. Nat Rev Neurosci, 6(7), 533-544

Ware, J. E., Kosinski, M., \& Keller, S. K. (1994). SF-36 ${ }^{\circledR}$ Physical and Mental Health Summary Scales (2 ed.). Boston, MA: The Health Institute

Woods, M. P., \& Asmundson, G. J. G. (2008). Evaluating the efficacy of graded in vivo exposure for the treatment of fear in patients with chronic back pain: A randomized controlled clinical trial. Pain, 136(3), 271-280

Zale, E. L., Lange, K. L., Fields, S. A., \& Ditre, J. W. (2013). The relation between pain-related fear and disability: a meta-analysis. J Pain, 14(10), 1019-1030. doi:10.1016/j.jpain.2013.05.005 



\section{Chapter 6}

\section{Exposure in vivo versus}

pain-contingent physical therapy in Complex Regional Pain Syndrome Type l: A cost-effectiveness analysis

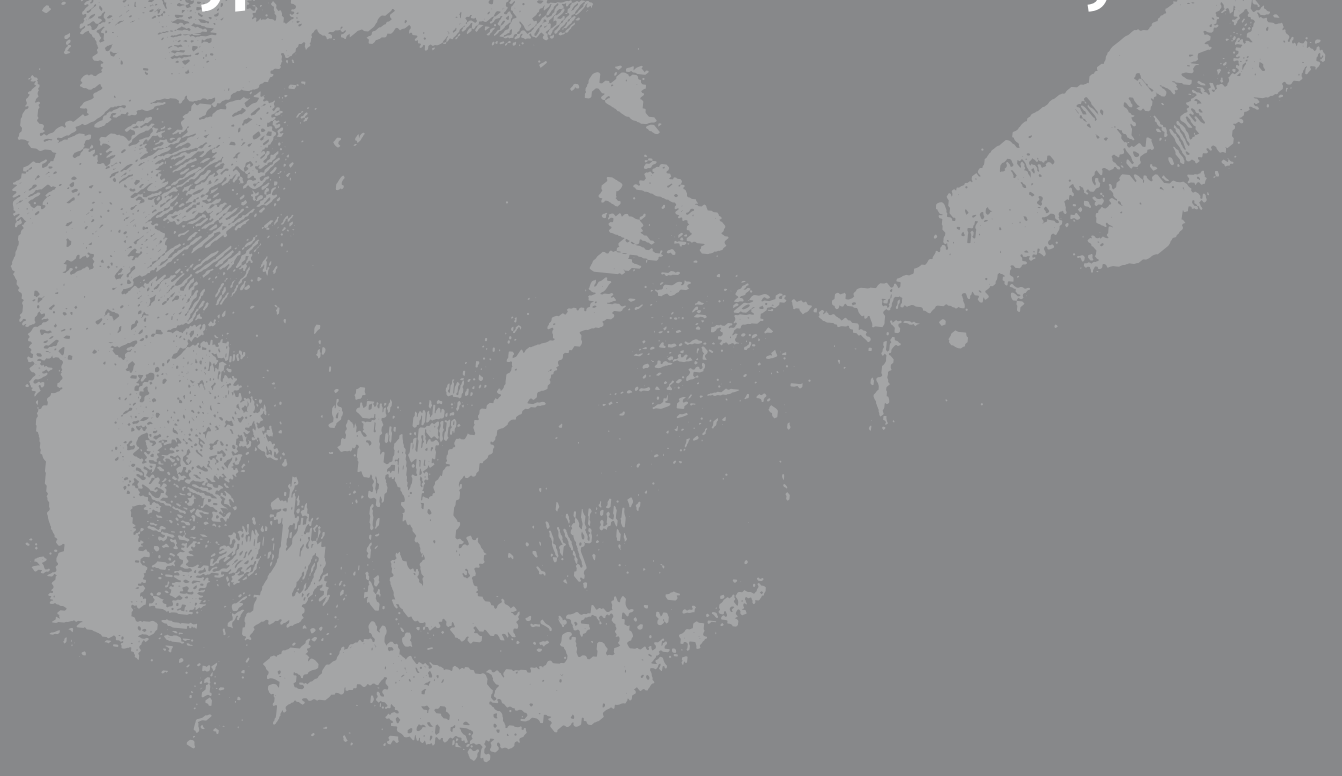

This chapter is published as: den Hollander, M., Heijnders, N., de Jong, J.R., Vlaeyen, J.W.S, Smeets, R.J.E.M. \& Goossens, M.E.J.B. (2018). Exposure in vivo versus pain-contingent physical therapy in Complex

Regional Pain Syndrome Type I: A cost-effectiveness analysis. International Journal of Technology Assessment in Health Care. 


\section{Abstract}

\section{Objectives}

To evaluate the cost-effectiveness of exposure in vivo (EXP, a cognitive-behavioral treatment targeting pain-related fear) in Complex Regional Pain Syndrome Type I (CRPS-I), as compared to pain-contingent physical therapy (PPT).

\section{Methods}

Data from a randomized controlled trial were used to compare the cost-effectiveness of EXP versus PPT from a societal perspective. Intervention costs, other healthcare costs, costs to patient and family and productivity losses were included. The main outcomes were changes in the SF-36 physical component scale and quality-adjusted life years. Changes were followed until six months after treatment. Uncertainty was estimated using non-parametric bootstrap analysis, cost-effectiveness acceptability curves and cost-effectiveness planes. Sensitivity analyses were performed to check robustness of findings.

\section{Results}

Forty-six patients were randomized and 38 completed the study. Over 6 months, EXP resulted in greater improvement in physical health-related quality of life and quality adjusted life years than PPT. Despite higher initial treatment costs, EXP showed a tendency to reduce all costs compared to PPT; healthcare costs were significantly reduced. Furthermore, the cost-effectiveness planes were in favor of EXP. Sensitivity analyses, for different program costs and complete cases only, confirmed robustness of these findings.

\section{Conclusions}

EXP, a cognitive-behavioral treatment, seems more cost-effective than PPT in CRPS patients with pain-related fear. The initial higher costs for EXP are offset by a longterm reduction of costs for health care utilization, and a tendency to lower work absenteeism and reduced societal costs. Due to low sample sizes, replication of findings is required to confirm results. 


\section{Introduction}

Complex Regional Pain Syndrome Type I (CRPS-I) is a chronic pain condition affecting one of the limbs, without peripheral nerve injury, and usually after an injury or trauma. Besides persistent pain, disproportionate in severity to any underlying observable pathology, other signs and symptoms may occur. These include allodynia, profound sweating, abnormal vascular reactivity and functional impairment (Bruehl et al., 2002). Despite the many available medical treatments, there is a critical lack of high quality evidence for the effectiveness of most treatments (O'Connell, Wand, McAuley, Marston, \& Moseley, 2013). Especially in chronic CRPS-I, there is no treatment that guarantees cure or complete pain relief. As a consequence, individuals continue to receive intensive medical care, and they continue to suffer from extensive limitations in daily life activities and social participation (Geertzen, Dijkstra, Groothoff, ten Duis, \& Eisma, 1998; Sharma, Agarwal, Broatch, \& Raja, 2009). This ongoing healthcare utilization is expensive for patients and society. Productivity losses due to CRPS-I (Geertzen et al., 1998; Sharma et al., 2009) seem to have an even higher economic impact. Several studies reporting on work-related disability rates (de Mos et al., 2007; Kemler \& Furnee, 2002; Sandroni, Benrud-Larson, McClelland, \& Low, 2003) showed percentages of individuals completely unable to work varying between 4 (Sandroni et al., 2003) (United States) and 31 (de Mos et al., 2007) (the Netherlands). A large percentage of individuals with CRPS-I is unable to perform household activities as well, resulting in dependence on domestic care (Kemler \& Furnee, 2002).

Pain-related fear (PRF) has been identified as a predictor of poor outcome in CRPS-I (Bean, Johnson, Heiss-Dunlop, Lee, \& Kydd, 2015). PRF has been consistently associated with more severe disability (Zale, Lange, Fields, \& Ditre, 2013), and predicts the progression of disability over time (Zale \& Ditre, 2015). Exposure in vivo (EXP) is a cognitive-behavioral treatment that specifically targets PRF. Studies have shown that EXP not only reduces PRF, but also improves daily life functioning (Vlaeyen, Morley, Linton, Boersma, \& de Jong, 2012). A recent RCT $(n=46)$ showed that EXP is more successful in reducing disability than the pain-contingent physical therapy (PPT) recommended by the previous Dutch Guidelines for CRPS-I patients with elevated levels of PRF (den Hollander et al., 2016). Six months after EXP, 94\% of participants reported a reliable improvement in disability; in PPT this was only $18 \%$. EXP was also superior in reducing pain intensity, perceived harmfulness of activities, and pain catastrophizing, and in increasing quality of life (QoL) (den Hollander et al., 2016). A remaining question is whether the application of EXP is also good value for money from a societal perspective. A positive economic evaluation would further 
support EXP. Therefore, we used data from the aforementioned RCT to examine the cost-effectiveness (CEA) and cost-utility (CUA) of EXP compared to PPT, in individuals with chronic CRPS-I and elevated levels of PRF.

\section{Methods}

\section{Study design and participants}

This economic evaluation uses data derived from a previously-published RCT (den Hollander et al., 2016) comparing the effects of EXP with PPT. The evaluation consists of a cost-effectiveness analysis and a cost-utility analysis, performed from a societal perspective with a time horizon of 6 months after completion of treatment. Individuals were included if they were between 18 and 65 years old. A physiatrist enrolled participants, after having confirmed the diagnosis of CRPS-I using the IASP Orlando criteria. Individuals had to report disability despite former treatment, and at least moderate levels of perceived harmfulness of activities, established with the Photograph Series of Daily Life Activities (PHODA score 234 ). Exclusion criteria were: insufficient comprehension of the Dutch language, pregnancy, CRPS-I in both legs/both arms, generalized pain, dystonia, involvement in a litigation procedure regarding CRPS-I, and severe psychopathology. The Medical Ethics Committee of the University Hospital Maastricht (METC-azM reg.nr.20067) approved the study protocol, and the trial was registered (NCT00625976). All participants provided written informed consent. A pre-determined and computer-generated randomization schedule, only accessible by one researcher, was used to allocate participants to EXP or PPT. Participants were informed about the allocated treatment during the first treatment session (12).

\section{Interventions and setting}

We compared two active treatment approaches. EXP, a cognitive-behavioral intervention, widely applied to a variety of anxiety disorders (Craske, Treanor, Conway, Zbozinek, \& Vervliet, 2014) was compared with PPT, the recommended physical therapy treatment according to the Dutch Guidelines for CRPS-I at the onset of the trial. Therapists were specifically trained to deliver treatment according to the protocols for either EXP or PPT. To prevent contamination, therapists who delivered EXP did not deliver PPT, and vice versa. Extensive treatment manuals were provided 
for each condition. All treatments were delivered in a tertiary care rehabilitation center. A physiatrist was responsible for medical examination and deciding whether to include patients for participation in rehabilitation, and provided supervision to the team (EXP) or physical therapist (PPT) that delivered the intervention.

\section{Intervention: Exposure in vivo (EXP)}

EXP specifically aims at improving functional ability through the violation of negative expectations about the relation between movement and increase in signs and symptoms. In various chronic pain syndromes, e.g. low-back pain (Leeuw et al., 2008), whiplash associated disorder (de Jong et al., 2008), and complaints of arm, neck, and shoulder (CANS; (de Jong, Vlaeyen, van Eijsden, Loo, \& Onghena, 2012)), EXP has been shown to be effective in reducing PRF and disability. EXP is characterized by systematic and repeated exposure to feared movements, activities and/or sensations in order to test and challenge the participants' catastrophic interpretations regarding these stimuli. EXP is described in detail elsewhere (Vlaeyen et al., 2012). A team consisting of a psychologist/behavioral therapist (PSY/BT) and an occupational or physical therapist (OT/PT), delivered EXP. During each one-hour session of EXP, both the PSY/BT and OT/PT assigned to the patient are present, working simultaneously and interdisciplinarily according to the protocol of EXP. In the first session, a cognitive-behavioral analysis of the pain problem is made. In the second session, the PHODA is used to reflect on specific catastrophic cognitions a patient might have about the activities shown in the pictures of the PHODA. In the third session, the therapists, while using the fear avoidance model, construct a personalized fear avoidance model with the patient. This model shows how the patient's cognitions/ fears fuel the vicious circle of pain and disability. In the remaining sessions, the patient is exposed to movements, activities and sensations of which the patient has fearful/catastrophic cognitions in order to test and correct these expectations. Next, the patient is stimulated to perform these activities in his or her daily life, e.g. at home, work and leisure. All therapists were specifically trained to deliver EXP.

\section{Comparator: pain-contingent physical therapy (PPT)}

In CRPS-I of less than one year, PPT was proven to be more effective in reducing pain, signs and symptoms than an active control treatment with occupational therapy and a social-therapy control treatment (Oerlemans, Oostendorp, de Boo, \& Goris, 1999). PPT is a pain-contingent treatment protocol, aiming to increase control over 
pain and optimize coping with CRPS-I. After categorization of the individual's current level of control over pain (low, moderate or high), treatment may focus on extinguishing the source of ongoing pain by rest (locally), connective tissue massage, Transcutaneous Electric Nerve Stimulation (TENS) and pain-reducing exercises (directed to stimulate kinetic receptors type I and II). PPT also aims to improve skills by practicing compensatory activities with instructions regarding ergonomic positioning of the body. PPT was delivered by a physical therapist. Therapists received specific training to deliver PPT.

\section{Data collection}

Demographics (age, gender, education level, employment status and pain duration) were recorded before the start of treatment. Outcome measures were collected electronically during four assessments at Maastricht University; twice at baseline (two identical pre-measurements within two weeks before the start of treatment, a mean score being calculated), directly after completion of treatment (post-treatment) and six months after treatment (follow-up). Cost measures were completed from four weeks before baseline until six months after completion of treatment.

\section{Cost measures}

To evaluate the economic consequences of treatment from a societal perspective, we assessed the intervention costs, other healthcare costs, patient and family costs and productivity losses. Intervention costs were based on the 17 hours of treatment that each patient received according to the protocol. Both treatments were delivered in a rehabilitation setting (with extensive facilities, e.g. therapeutic pool, different gyms, sports hall) under medical supervision of a physiatrist. In the Netherlands standardized costs prices are used for rehabilitation treatment. To calculate treatment costs for EXP and PPT, we used these standardized cost-prices as prescribed in the Dutch manual for cost-analysis in healthcare research (Hakkaart-van Royen, Tan, \& Bouwmans, 2010). For EXP, we added the costs of a psychologist to this standard rehabilitation price, to reflect the presence of two therapists working with one patient at the same time.

Other healthcare costs concerned all CRPS-I-related healthcare utilization, including visits to the general practitioner, medical specialists, hospitalization, professional care, therapeutic consultations, prescribed and/or over-the-counter 
medication, and alternative healthcare. Patient and family costs included out-ofpocket costs, such as costs for home care, informal care, and additional expenses. Productivity losses were calculated based on days absent from paid and unpaid work due to CRPS-I.

Participants used a cost diary to register healthcare utilization (except the intervention), help received from family and/or friends and productivity losses (Goossens, Rutten-van Molken, Vlaeyen, \& van der Linden, 2000). Participants completed this cost diary weekly (at home), starting from four weeks pre-treatment until 6 months after completion of treatment. Every four weeks, the diaries had to be returned in a sealed coded return envelope. Research assistants contacted participants if they did not return their diaries on time.

Total costs were estimated using a bottom-up approach, where information on each element of service used was multiplied by an appropriate standardized unit cost and added up to arrive at an overall total cost (Drummond, Sculpher, Torrance, O'Brien, \& Stoddart, 2005). For the cost valuation, we used standardized cost-prices from the Dutch manual for cost-analysis in healthcare research (Hakkaart-van Royen et al., 2010). Costs for prescribed medication were calculated by multiplying the number of boxes that participants reported in their cost diary, with the price per box provided by the Dutch website 'www.medicijnkosten.nl'. For over-the-counter medication, participants did not provide the number of boxes they used, so we calculated the costs for a standard unit of use as handled by the drugstore and pharmacy. Where medication prices for prescribed- or over-the-counter medication varied, the lowest cost price was used. Additional prescription charges for prescribed medication were also taken into account. Travel expenses were calculated based on the standardized mean distance to a specific healthcare provider in the Netherlands, multiplied by standard cost-prices from the Dutch manual for cost-analysis in healthcare research (Hakkaart-van Royen et al., 2010). Cost-prices for alternative healthcare providers were derived from the ALASCA trial (Moulaert, Goossens, Heijnders, Verbunt, \& Heugten, 2016), as well as CRPS-I-related activities and sports. We calculated prices of informal care using standardized cost prices based on general hourly wages (Hakkaart-van Royen et al., 2010). Additional expenses were determined using the costs participants recorded in their cost diaries; these expenses included orthopedic shoes, braces, wheelchair, voice-recognition software and car adjustments.

To calculate productivity losses, we used a Human Capital Approach (Koopmanschap \& Rutten, 1993), multiplying a standardized cost-price for mean productivity cost per hour per paid employee by the hours absent from work (Hakkaart-van Royen et al., 2010). All costs are presented in euros, using the 2015 price level. If necessary, prices were indexed to 2015 using rates from Statistics Netherlands. 


\section{Outcome measures}

For the cost-effectiveness of this economic evaluation, the physical component scale of the SF-36 was used as primary outcome (this differs from the primary outcome used in the RCT; since in the RCT, upper and lower extremity disability were measured separately with their own specific questionnaire, it was not possible to use these questionnaires to calculate overall economic consequences). The SF-36 is a generic QoL questionnaire, reflecting eight domains of perceived health. Higher scores reflect a better health. A Dutch translation of the SF-36 was found to be reliable and valid (Aaronson et al., 1998). Four domains (physical functioning, physical role limitation, bodily pain, general health perceptions) yield a physical health component scale. The domains vitality, social functioning, emotional role limitations, and general mental health form a mental health component scale. These summary measures are supported by factor analyses (Ware, Kosinski, \& Keller, 1994).

For the cost-utility analysis, we used quality-adjusted life years (QALYS) as primary outcome. First, utilities were derived using an algorithm of the SF-6D, which transforms the health-related QoL preferences (SF-36) into generic utilities scores. Utilities are values assigned to a particular qualitative health status and are expressed on a scale from 0-1 (Brazier, Roberts, \& Deverill, 2002). Higher scores reflect a better health. QALYs were calculated using the derived utilities at the three measurement points multiplied by the amount of time spent in that health state ("area under the curve" method) (Dolan, 1997).

\section{Statistical analysis}

An intention-to-treat principle was used. When both pre-treatment assessments (SF-36 and PHODA) revealed no significant differences at baseline, the mean of both measurements was calculated. Participants who completed at least three cost diaries, as well as pre- and post-treatment measurement (for the main outcomes), were included in the economic analysis. In case of missing outcomes or cost diaries, we chose imputation of the individual mean. Since differences between participants were larger than differences within participants, we anticipated that this method would yield the most reliable estimate (Hendriks et al., 2013). When a main outcome (SF36) was missing at follow-up measurement (6 months post-treatment), we used the last-observation-carried-forward method (e.g. post-treatment score was used as 6 months after treatment score). We checked whether dropout was selective by analyzing if any significant differences occurred at baseline between dropouts and completers for age, gender, educational level, duration of complaints 
or health-related QoL (SF-36 Physical Component Scale/Mental Component Scale). Group differences were calculated using chi-squared tests (categorical variables: gender, education) and t-tests (continuous variables: age, duration of complaints, health-related QoL).

Outcomes on questionnaires were compared using t-tests in IBM SPSS Statistics version 22. Costs were compared using bootstraps (1000 replications) with Microsoft Excel 2010 with mean difference and 95\% confidence interval. Additionally, bootstrapping with Microsoft Excel 2010 was used to explore sample uncertainty (5000 replications) around the incremental cost-effectiveness ratio (ICER). Non-parametric bootstrapping is a method based on random sampling with replacement based on the individual data of participants. The ICER is defined by the difference in costs between EXP and PPT, divided by the difference in their effect. Cost-effectiveness analyses were performed by relating the mean total costs to the health-related QoL physical component (SF-36 PCS) score at six months after treatment. A cost-utility analysis was performed by relating the mean total costs to the mean health-utility (QALY) scores of both groups. The bootstrapped ICERs were subsequently plotted in cost-effectiveness planes consisting of four quadrants. The south-east quadrant represents a more effective intervention that is less costly than usual care, the so-called dominant quadrant. The north-west quadrant represents inferiority: a costlier intervention that is also less effective. In the north-east quadrant, the ICER indicates the additional amount that must be paid to gain one unit of health, and ICERs below the ceiling ratio are considered to be cost-effective. In contrast, the ICER in the south-east quadrant indicates the savings gained for a one-unit loss of health. Subsequently, treatments with high ICERs are preferable to those with low ICERs (more money saved for the same loss of health) and only those treatments with ICERs above the ceiling ratio should be adopted. Additionally, cost-effectiveness acceptability curves (CEAC) were constructed to show the probability that the intervention was cost-effective, given different ceiling ratios. Only treatments resulting in costs between $€ 16,000$ (for the lowest disease burden) and $€ 80,000$ (for the highest burden) per QALY are considered for reimbursement according recommendations of the Dutch Council for Public Health and Healthcare.

\section{Sensitivity analyses}

Two sets of sensitivity analyses were performed to measure the robustness of the economic evaluation. Since several assumptions were made for the calculation of the costs, uncertainty could have been introduced in the analyses. The sensitivity analyses explore the impact of the assumptions on the results from changing the 
value of one parameter while keeping the values of all other parameters unchanged (Drummond, Manca, \& Sculpher, 2005). To improve generalizability to other healthcare settings, we first performed sensitivity analyses with different treatment costs, to reflect that EXP and PPT can be delivered in other healthcare settings against different treatment costs. We performed one sensitivity analysis with the costs for rehabilitation (for EXP), versus a physical therapist in primary care (for PPT), since PPT can be delivered as a primary care intervention. In the second sensitivity analysis, we used the costs for rehabilitation plus an extra psychologist (EXP) versus a physical therapist in primary care for PPT, to capture the maximum contrast in treatment costs between PPT (when delivered as primary care) and EXP (delivered as an interdisciplinary treatment simultaneously delivered by a psychologist and a PT/OT). In the second set of sensitivity analyses, we used data from the complete cases only. A case was considered complete when a participant had completed a minimum of eight cost diaries.

\section{Results}

\section{Participants and comparability}

Forty-six individuals were included: 23 participants were randomized to each condition. The CONSORT flow chart, including number of dropouts per phase with reasons is presented elsewhere (den Hollander et al., 2016). Three participants dropped out between allocation and start of treatment (1 EXP, 2 PPT), and five during treatment (3 EXP, 2 PPT). These participants did not complete post-treatment measurements nor did they complete enough diaries to be included in the economic analysis. Baseline characteristics (age, gender, level of education, pain duration, and health-related $\mathrm{QOL}$ ) of those who dropped out did not significantly differ from participants who completed participation in the study (all $p>0.10$, data not presented). Thirty-eight participants were included in the economic analysis (19 EXP, 19 PPT). The mean number of diaries completed did not significantly differ between conditions; EXP 10.11 (SD 3.38) and PPT 10.00 (SD 2.75), mean difference 0.105 (Cl-1.92 to 2.13). We imputed data (last-observation-carried-forward method) for participants $(n=3)$ whose main outcomes were missing at six-months post-treatment measurement. 
Table 1. Mean (SD) in demographic characteristics, duration of complaints and disability at baseline per treatment condition.

\begin{tabular}{|c|c|c|}
\hline \multirow[b]{3}{*}{ Variables } & & \\
\hline & \multicolumn{2}{|c|}{ Mean (SD) } \\
\hline & $\operatorname{EXP}(n=19)$ & PPT $(n=19)$ \\
\hline Age, mean (SD) & $46.26(12.08)$ & $42.63(10.83)$ \\
\hline Gender (\% male) & $21.1 \%$ (4 of 19) & $10.5 \%(2$ of 19$)$ \\
\hline \multicolumn{3}{|l|}{ Education } \\
\hline$\%$ Low & $52.6 \%(10)$ & $63.2 \%(12)$ \\
\hline$\%$ Middle & $31.6 \%(6)$ & $26.3 \%(5)$ \\
\hline$\%$ High & $15.8 \%(3)$ & $10.5 \%(2)$ \\
\hline \multicolumn{3}{|l|}{ Work status } \\
\hline$\%$ working full contract hours & $5.3 \%(1)$ & $5.3 \%(1)$ \\
\hline$\%$ partly on sick leave & $31.6 \%(6)$ & $36.8 \%(7)$ \\
\hline$\%$ completely on sick leave & $5.3 \%(1)$ & $36.8 \%(7)$ \\
\hline$\%$ disability pension & $47.4 \%(9)$ & $15.8 \%(3)$ \\
\hline$\%$ other & $10.5 \%(2)$ & $5.3 \%(1)$ \\
\hline Mean duration of complaints in years (SD) & $5.93(6.02)$ & $3.74(4.83)$ \\
\hline \multicolumn{3}{|l|}{ Health-related Quality of Life (SF-36) (0-100) } \\
\hline Physical component subscale (SF-36 PCS) & $40.60(13.39)$ & $41.86(16.30)$ \\
\hline Mental component subscale (SF-36 MCS) & $57.08(14.03)$ & $63.92(19.44)$ \\
\hline Perceived harmfulness of activities (PHODA) (0-100) & $64.51(16.49)$ & $65.67(17.02)$ \\
\hline Utility (0-1) & $0.53(0.05)$ & $0.51(0.06)$ \\
\hline
\end{tabular}

$\mathrm{SD}=$ Standard Deviation, $\mathrm{Cl}=$ Confidence Interval, EXP $=$ Exposure in vivo, PPT = Pain-contingent physical therapy, SF36=Short Form 36 (higher scores indicate better health), PHODA= Photographic Series of Daily Activities (lower scores indicate less perceived harmfulness of activities)

The mean age of the 38 participants was 44.4 years (SD =11.47); 84\% were women. At the start of the study, 2 participants worked their regular contract hours, 21 participants were on sick leave (8 completely, 13 partly), 12 received disability pension, 1 studied and 2 were unemployed (not due to CRPS-I). The mean duration of CRPS-I was 5.1 years $(S D=5.45)$. Table 1 presents baseline characteristics and costs for EXP and PPT. Chi-squared tests revealed no significant differences between EXP and PPT regarding demographic variables. Independent samples t-tests showed no significant baseline differences between conditions for duration of complaints, PRF and health-related QoL (all $p>0.10$, results not reported). Table 2 presents baseline costs for EXP and PPT. Bootstrapping of the baseline costs revealed no significant differences between conditions before the start of treatment. 
Table 2. Mean (SD) cost components (in EUR) per treatment condition over a four-week baseline period.

\begin{tabular}{|c|c|c|}
\hline \multirow[b]{3}{*}{ Variables } & & \\
\hline & \multicolumn{2}{|c|}{ Mean (SD) } \\
\hline & $\operatorname{EXP}(n=19)$ & PPT $(n=19)$ \\
\hline Health care costs & $271.79(180.71)$ & $553.90(255.68)$ \\
\hline Patient and family costs & $205.58(74.76)$ & $225.38(79.47)$ \\
\hline Productivity loss & $2687.32(616.73)$ & $3449.10(496.57)$ \\
\hline Total costs & 3178.09 (758.69) & $4220.89(635.05)$ \\
\hline
\end{tabular}

SD $=$ Standard Deviation, EXP = Exposure in vivo, PPT = Pain-contingent Physical Therapy

\section{Costs and effects}

After completion of treatment, EXP participants use significantly less prescribed (between group difference $-11.30, \mathrm{Cl}-21.02$ to -1.57 ) and over-the-counter medication (between group difference $-1.93, \mathrm{Cl}-3.74$ to -0.13 ) than PPT participants.

Table 3. Mean (SD) resource utilization per treatment group over the period from start of treatment to followup measurement 6 months after treatment.

\begin{tabular}{|c|c|c|c|}
\hline \multirow[b]{2}{*}{ Type of utilization } & \multicolumn{2}{|c|}{ Mean (SD) } & \multirow{2}{*}{$\frac{\text { Mean difference }(95 \% \mathrm{Cl})}{\text { EXP vs PPT }}$} \\
\hline & $\operatorname{EXP}(n=19)$ & PPT $(n=19)$ & \\
\hline \multicolumn{4}{|l|}{ Number of contacts: } \\
\hline General practitioner & $0.67(2.13)$ & $0.52(1.46)$ & $0.15(-1.05$ to 1.35$)$ \\
\hline Medical specialist & $0.91(1.88)$ & $2.07(3.00)$ & $-1.16(-2.82$ to 0.50$)$ \\
\hline Other healthcare providers & $6.21(12.32)$ & $8.37(12.66)$ & $-2.16(-10.38$ to 6.06$)$ \\
\hline Alternative healthcare & $0.16(0.69)$ & $0.32(1.16)$ & $-0.16(-0.78$ to 0.47$)$ \\
\hline Prescription of medication (boxes) & $2.85(9.76)$ & $14.15(18.23)$ & $-11.30(-21.02$ to -1.57$) *$ \\
\hline Over-the-counter medication & $0.41(0.99)$ & $2.34(3.65$ & $-1.93(-3.74$ to -0.13$)$ * \\
\hline Hospitalization (in days) & $0(0)$ & $0.09(0.38)$ & $-0.9(-0.27$ to 0.10$)$ \\
\hline \multicolumn{4}{|l|}{ Hours of help } \\
\hline Home care & $14.04(56.99)$ & $86.38(201.19)$ & $-72.34(-172.14$ to 27.46$)$ \\
\hline Domestic care & $23.67(55.33)$ & $75.93(256.65)$ & $-52.26(-174.42$ to 69.89$)$ \\
\hline Informal care & $11.06(24.46)$ & $72.28(112.38)$ & $-61.22(-116.31$ to -6.12$) *$ \\
\hline \multicolumn{4}{|l|}{ Hours absent from: } \\
\hline Paid work & $533.91(647.59)$ & $869.80(628.90)$ & $-335.88(-755.89$ to 84.13$)$ \\
\hline Usual activity & $69.19(194.41)$ & $25.23(65.90)$ & $43.96(-51.55$ to 139.48$)$ \\
\hline Unpaid work & $262.96(367.42)$ & $150.92(215.03)$ & $112.04(-87.70$ to 311.78$)$ \\
\hline
\end{tabular}


Furthermore, EXP participants had, although not statistically significant, fewer visits to medical specialists, and regular visits (physical/occupational therapists and psychologists), as well as to alternative health-care providers, compared to participants who received PPT. The number of visits to the general practitioner is in favor of PPT. No participants were hospitalized due to CRPS-I after EXP, whereas one was after PPT. After EXP, participants needed fewer hours of home- and domestic care, and significantly fewer hours of help from family (between group difference $-61.22, \mathrm{Cl}$ -116.31 to -6.12). Participants receiving EXP were less absent from paid work, but more from usual activities and unpaid work than participants who received PPT, although these differences were not statistically significant. Table 3 shows the mean resource utilization per participant for EXP and PPT. Table 4 provides an overview of outcomes and the overall societal costs six months after completion of treatment for both conditions.

Table 4. Mean scores at 6 months follow-up for mean outcome variables and total costs (EUR) over treatment- and follow-up period.

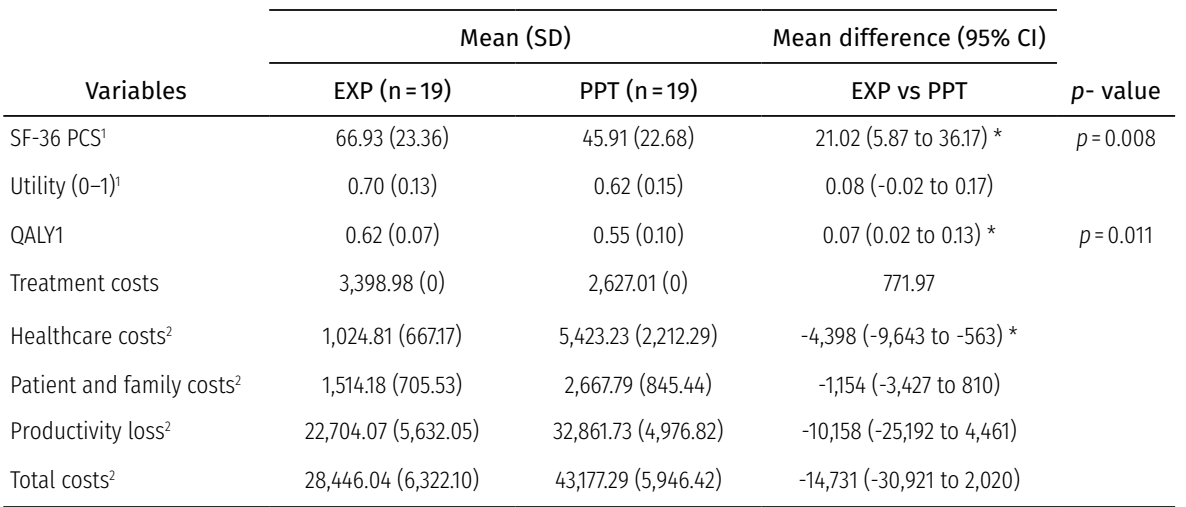

$\mathrm{SD}=$ Standard Deviation, $\mathrm{Cl}=$ Confidence Interval, EXP=Exposure in vivo, PPT =Pain-contingent Physical Therapy, SF-36 $\mathrm{PCS}=$ Short Form-36 Physical Component Scale (higher score indicates health), QALYS = Quality Adjusted Life Year (higher score indicates health).

${ }^{1}$ Difference in mean (95\% confidence interval) derived with independent samples t-test

2 Difference in mean (95\% confidence interval) derived with bootstrapping (1000 replications)

Since pre-treatment measures (SF-36 PCS and MCS) revealed no significant differences at baseline, a mean score was calculated. At the follow-up measurement six months after treatment, participants receiving EXP showed significantly higher scores on the physical component scale of the SF-36 and a higher QALY compared with participants receiving PPT (see Table 4). The utility score was in favor of EXP, but the difference with PPT was not significant. Participants who received EXP had significantly lower 
healthcare costs than participants receiving PPT (see Table 4). Costs for productivity loss, as well as patient and family costs, were in favor of EXP, although the differences were not significant. Overall, the total societal costs for participants receiving EXP were lower than for participants receiving PPT (€28,446 versus €43,177), but bootstrap replications revealed no significant differences between the groups. Productivity loss was the main source of costs in both groups and accounted for approximately $77 \%$ of the total costs (EXP $80 \%$, PPT 76\%).

\section{Cost-utility and cost-effectiveness planes and CEACS}

EXP resulted in a larger health benefit (26.33 points improvement on SF-36 PCS from pre- to post-treatment) than PPT (4.05 points), and, although treatment costs for EXP were higher than for PPT ( $€ 3399$ versus $€ 2627$, difference $€ 772$ ), the total societal costs six months after treatment clearly favored EXP. Figure 1 shows the cost-effectiveness plane (5000 bootstrap replications) and cost-effectiveness acceptability curve (CEAC) for the SF-36 PCS. EXP clearly resulted in a better outcome than PPT: $99.7 \%$ of the bootstrapped cost-effect pairs are located in the eastern part of the plane, implicating higher effects. The majority of these pairs (94.5\%) is located in the south-east quadrant, indicating not only higher effects, but also lower costs. The north-east quadrant contains the remaining 5.2\% of the replications, indicating higher effects but higher costs.

The cost-effectiveness acceptability curve (CEAC), based on 1 point improvement on the SF-36 PCS, shows that the probability of the intervention being costeffective is $100 \%$. To gain 1 additional unit on the SF-36 PCS, it does not matter if the highest (€80000) or lowest (€16000) threshold value is chosen: EXP is more cost-effective than PPT. Figure 2 shows the cost-effectiveness plane (5000 bootstrap replications) and the CEAC for the QALY. EXP resulted in a greater health benefit than PPT: $99.7 \%$ of the bootstrapped ICERs are located in the eastern part of the plane, implicating higher effects. The majority of the ICERs (95.1\%) lies in the southeast quadrant, indicating higher effects with lower costs. The north-east quadrant contains the remaining $4.6 \%$ of the replications, indicating higher effects but higher costs. The probability of the intervention being cost-effective ranges between $95 \%$ and $98 \%$, depending on the threshold value of $€ 16,000$ and $€ 80,000$, respectively. 
Figure 1. Cost-effectiveness plane and cost-effectiveness acceptability curve for SF36-PCS for EXP (delivered as rehabilitation in tertiary care with additional costs for psychologist) vers tion in tertiary care). SF36-PCS $=$ Short Form 36-Physical Component Scale, EXP $=$ Exposure in vivo, PPT $=$ Paincontingent Physical Therapy.
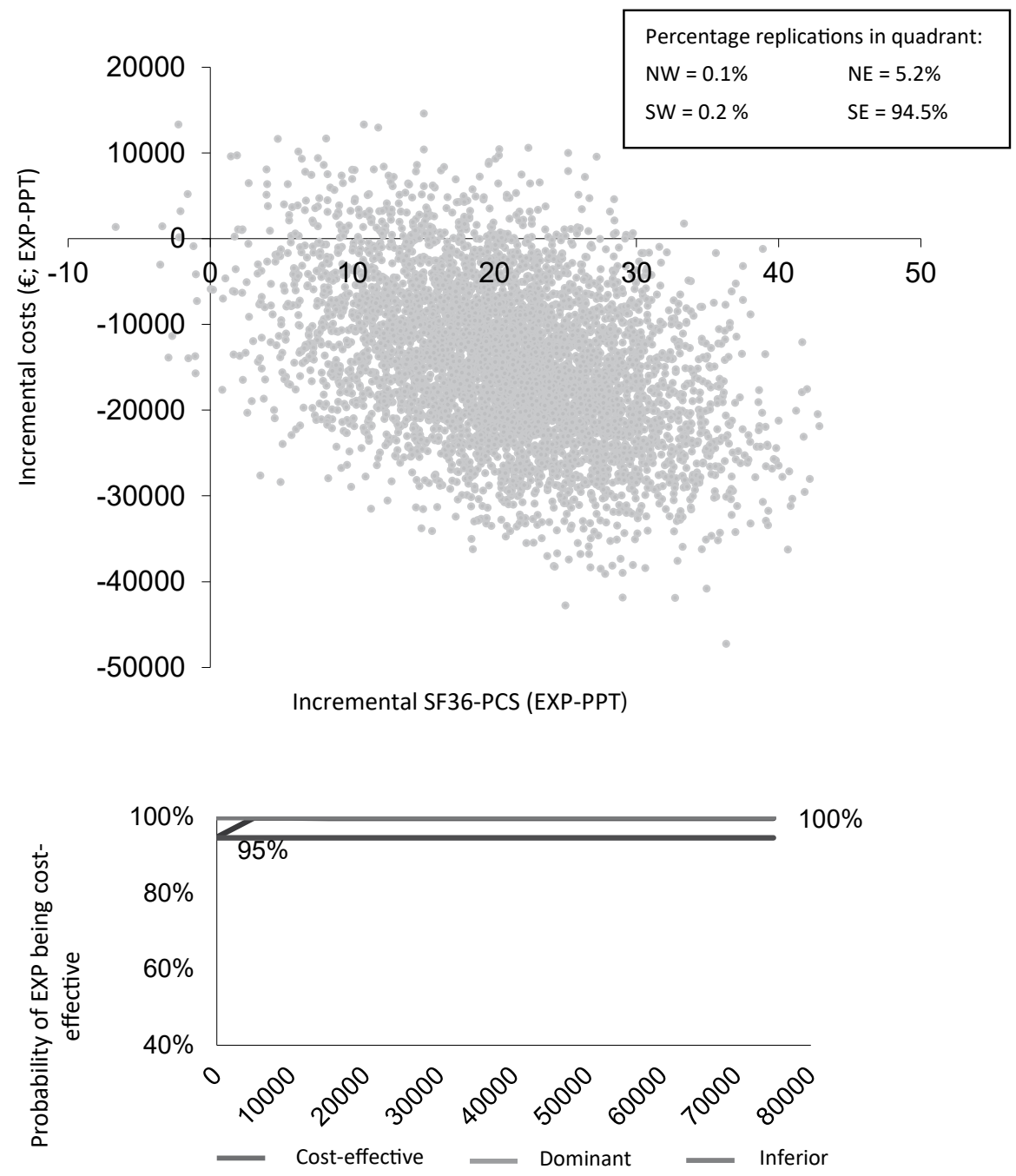

Willingness to pay $(€)$ per 1 point progression on SF36-PCS 
Figure 2. Cost-effectiveness plane and cost-effectiveness acceptability curve for QALYS for EXP (delivered as rehabilitation in tertiary care with additional costs for psychologist) versuS PPT (delivered as rehabilitation in tertiary care). $Q A L Y=$ Quality Adjusted Life Years, EXP $=$ Exposure in vivo, $P P T=$ Pain-contingent Physical Therapy.
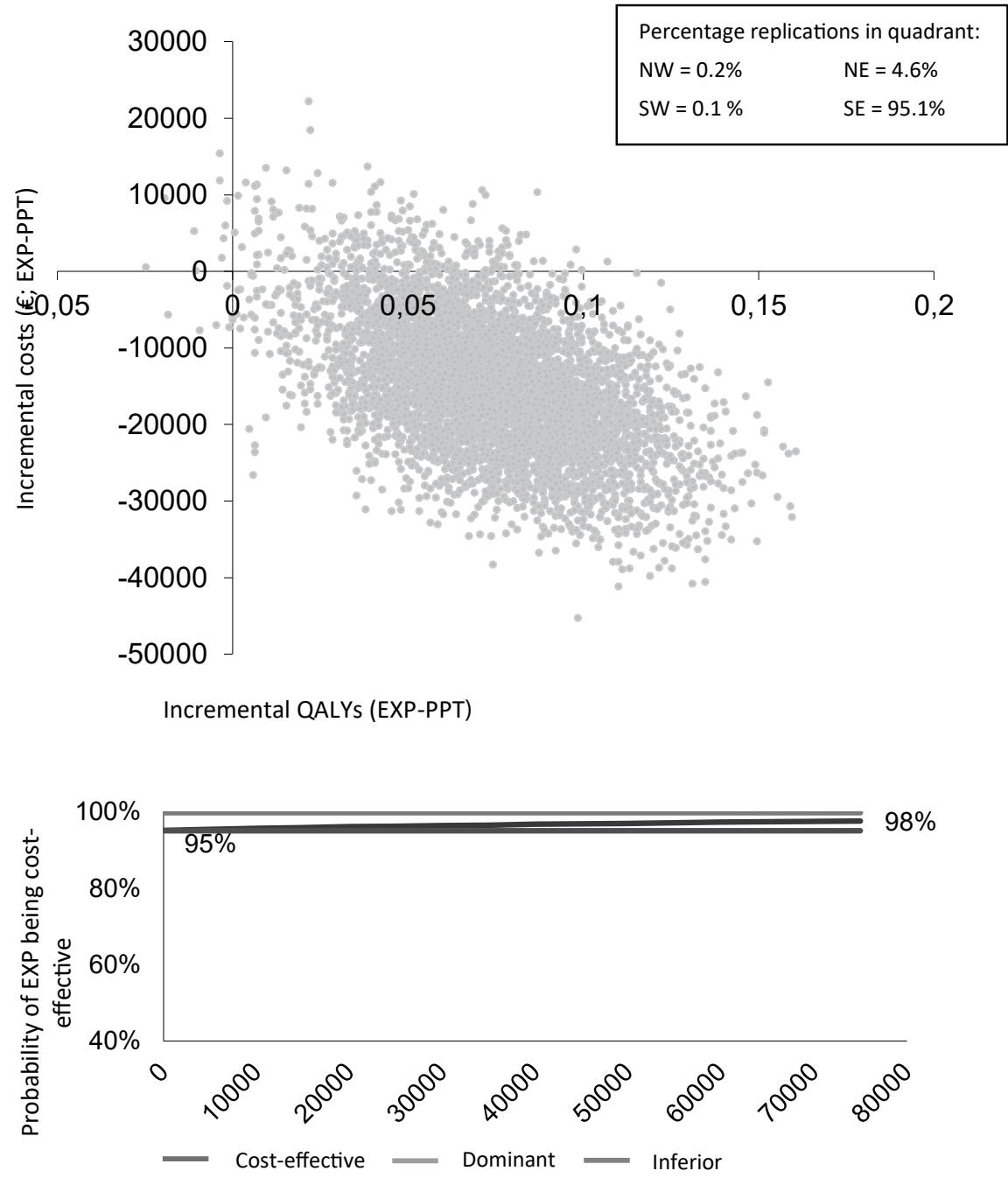

Willingness to pay $(€)$ per QALY 


\section{Sensitivity analyses}

Two sets of sensitivity analyses were performed: one with different treatment costs (recognizing that both EXP and PPT can be delivered in various healthcare settings leading to different cost-prices for treatment) and one with the complete cases only.

\section{Sensitivity analysis with different treatment costs}

In the first sensitivity analysis, the cost-utility analysis (QALY) was repeated using different intervention costs for PPT and EXP. In the first analysis, the reference cost for physical therapy in primary care in the Netherlands was used (PPT: €1,133.22), and compared with the reference price for rehabilitation treatment (EXP: €2,627.01). Again, the dominance of EXP (less disability at lower costs) was shown in $94.8 \%$ of the replications (south-east quadrant). In 5.1\% of the replications, EXP is more effective, but against higher costs (north-east quadrant). The cost-effectiveness plane with CEAC is shown in Figure 3. In the second analysis, the reference cost for physical therapy in primary care was used again for PPT (€1,133.22). For EXP, we now used the reference cost for rehabilitation with additional costs for a psychologist (€3,398.98). Still, 93.8\% of the ICERs are located in the south-east quadrant, with $6 \%$ in the north-east quadrant. For the cost-effectiveness plane with CEAC, see Figure 4.

\section{Sensitivity analysis with complete cases only}

In the complete case analysis, we considered participants who had completed at least eight diaries as complete cases (2 EXP and 4 PPT participants were hence excluded) and repeated the cost-utility analysis (QALY). As in our primary analysis, we first used the standardized rehabilitation price (SRP) for PPT and SRP plus additional costs for a psychologist for EXP. For the complete cases, 83.2\% of the ICERs are located in the south-east quadrant, and $15.8 \%$ in the north-east quadrant. In $0.8 \%$ of the bootstraps, EXP was inferior. For the cost-effectiveness plane with CEAC, see Figure 5. When the contrast between the costs for EXP versus PPT is maximized (costs for a primary care physical therapist versus SRP plus additional costs for a psychologist), $77.9 \%$ of the ICERs are located in the south-east quadrant, and 20.9\% in the north-east quadrant. In $1.1 \%$ of the bootstraps, EXP was inferior. The cost-effectiveness plane with CEAC is shown in Figure 6. 
Figure 3. Sensitivity analysis 1: Cost-effectiveness plane for QALYS for EXP (delivered as rehabilitation in tertiary care) versuS PPT (delivered as primary care physical therapy). QALY=Quality Adjusted Life Years, EXP $=$ Exposure in vivo, PPT $=$ Pain-contingent Physical Therapy.
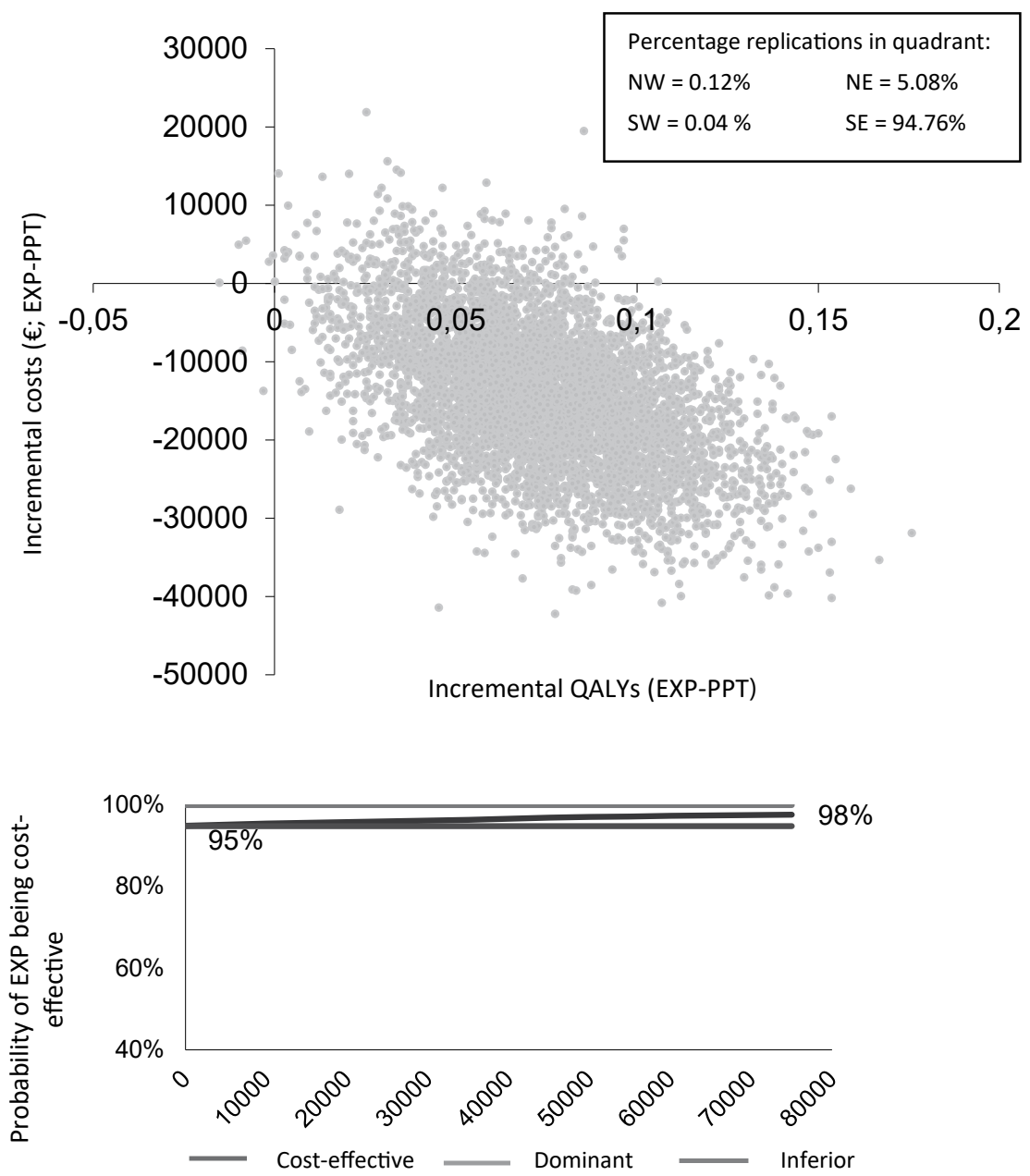

Willingness to pay (€) per QALY 
Figure 4. Sensitivity analysis 2: Cost-effectiveness plane for QALYS for EXP (delivered as rehabilitation in tertiary care with additional costs for psychologist) versus PPT (delivered as primary care physical therapy). $Q A L Y=Q$ uality Adjusted Life Years, EXP = Exposure in vivo, PPT = Pain-contingent Physical Therapy.
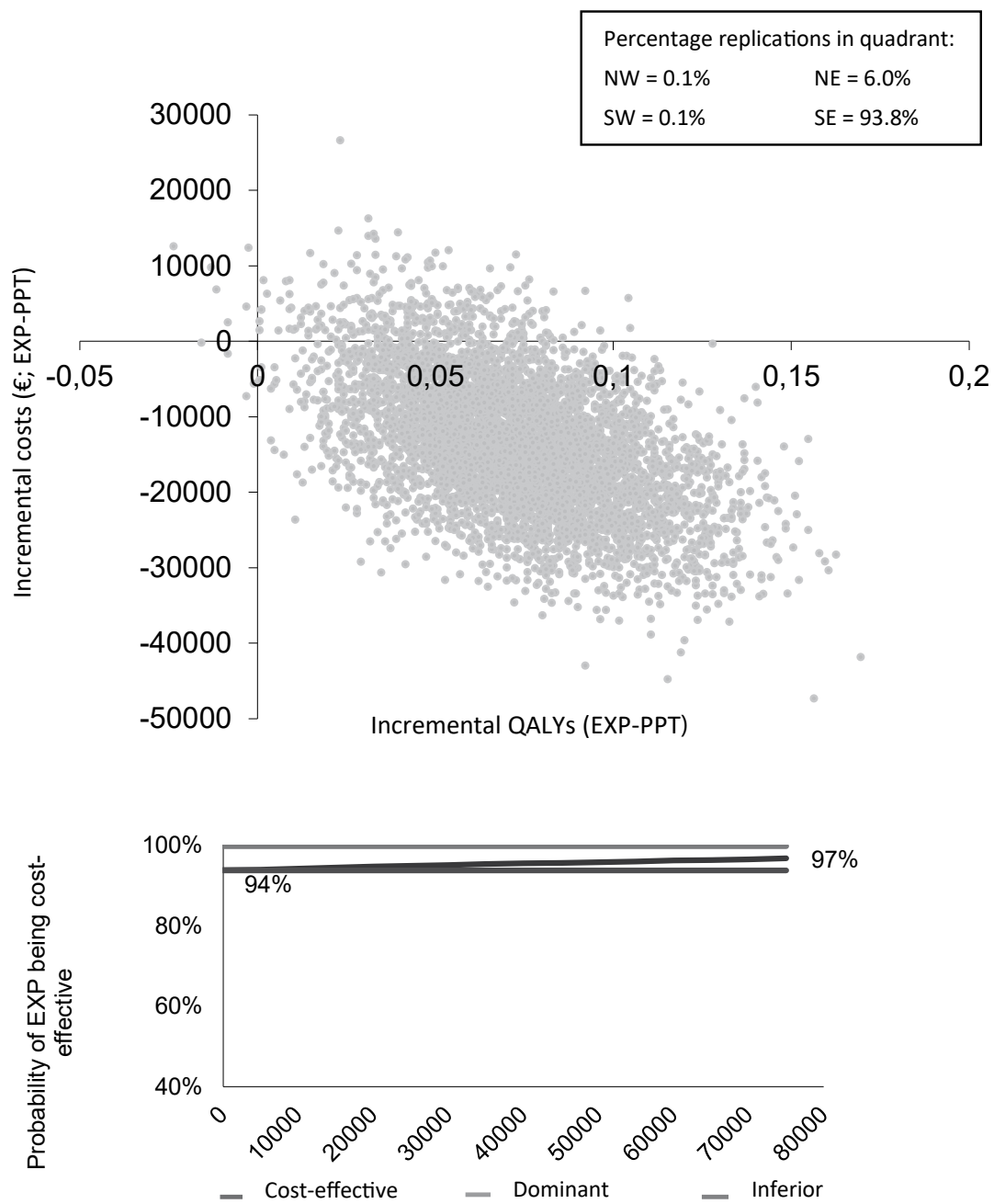

Willingness to pay $(€)$ per QALY 
Figure 5. Sensitivity analysis 3: Cost-effectiveness plane for QALYS for EXP (delivered as rehabilitation in tertiary care with additional costs for psychologist) versuS PPT (delivered as rehabilitation in tertiary care) for complete cases only $(n=32)$. $Q A L Y=$ Quality Adjusted Life Years, EXP=Exposure in vivo, PPT=Paincontingent Physical Therapy.
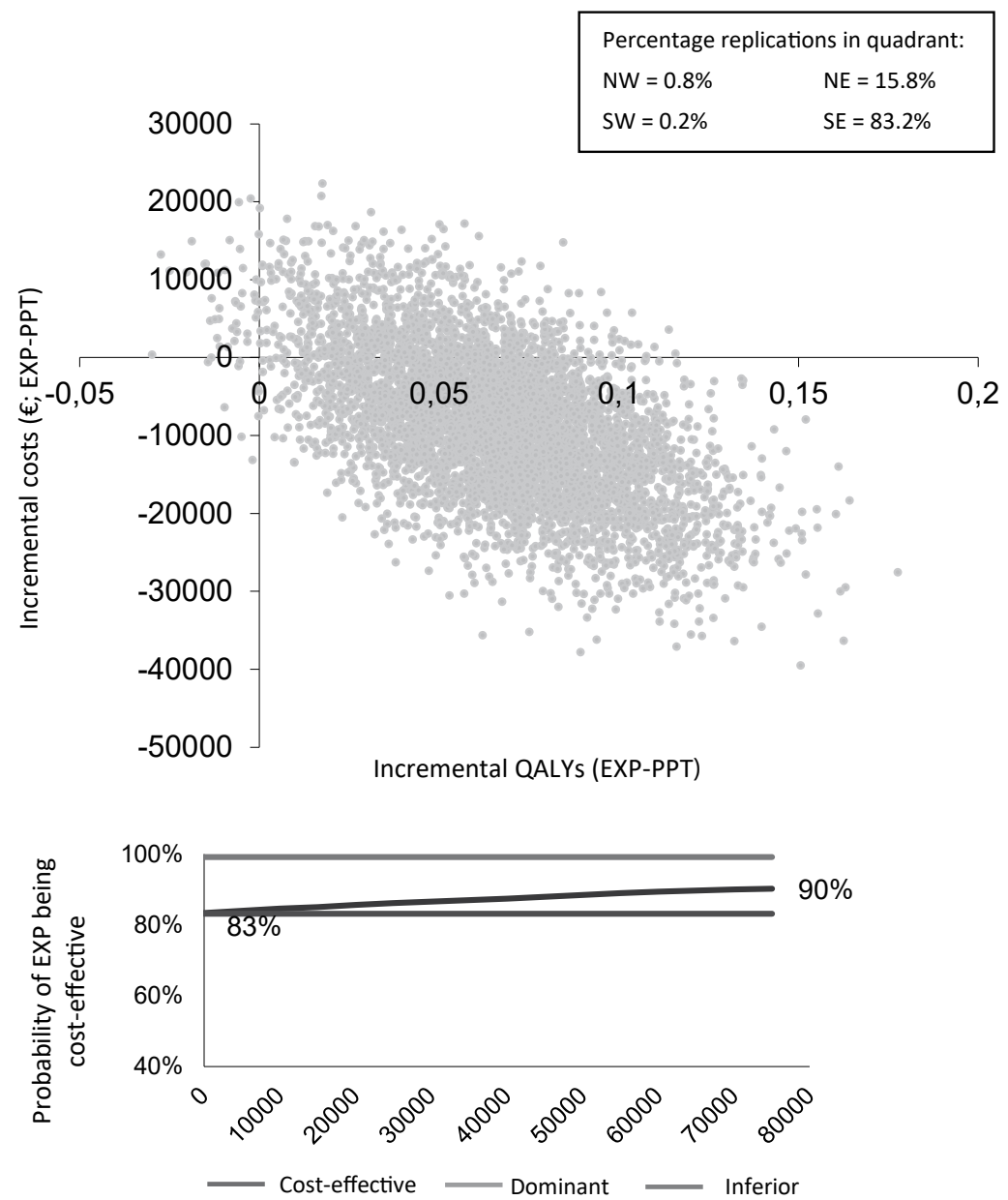

Willingness to pay $(€)$ per QALY 
Figure 6. Sensitivity analysis 4: Cost-effectiveness plane for QALYS for EXP (delivered as rehabilitation in tertiary care with additional costs for psychologist) versuS PPT (delivered as primary care physical therapy ) for complete cases only $(n=32)$. $Q A L Y=$ Quality Adjusted Life Years, EXP = Exposure in vivo, $P P T=P a i n-$ contingent Physical Therapy.
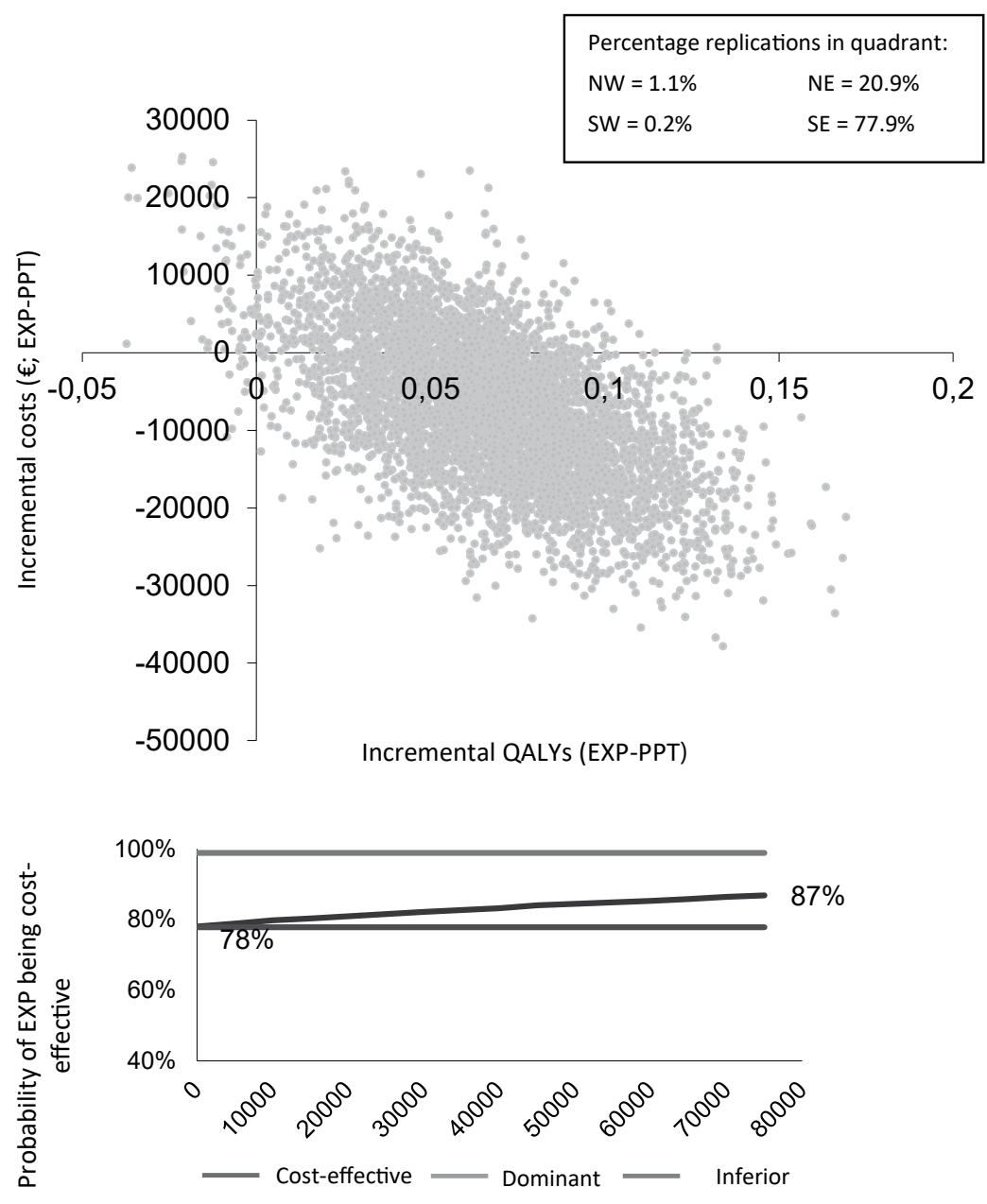

Willingness to pay $(€)$ per QALY 


\section{Discussion}

This economic analysis supports previous findings (den Hollander et al., 2016) that EXP seems superior to pain-contingent physiotherapy. EXP not only resulted in a greater improvement in physical health-related QoL and QALYS than PPT, EXP also seems to reduce societal costs six months after completion of treatment. This despite initially higher treatment costs due to the additional costs of a psychologist. After EXP, healthcare costs were significantly lower than after PPT. Participants used significantly less prescribed and over-the-counter medication after EXP, and needed significantly less informal care. In 95\% of the bootstrap replications, EXP was more effective and had lower costs.

In CRPS-I, no other studies on the cost-effectiveness of rehabilitation are available. The cost-effectiveness of EXP was previously evaluated in a study comparing EXP with graded activity (GA) for individuals with low back pain (Goossens et al., 2015). EXP was the preferred treatment regarding societal costs, but less convincing than in the current study, possibly because the contrast between EXP and GA, two biopsychosocial interventions, is less pronounced than between EXP and PPT, which has a biomedical focus.

We can explain the positive findings of lower costs for the individuals treated by EXP in two ways: the resumption of activities and the decrease in pain experience (den Hollander et al., 2016). First, EXP aims to specifically violate dysfunctional ideas about negative consequences of performing movements and activities. During EXP, individuals are exposed to the full range of activities they used to perform before the onset of CRPS-I, including work-related activities. EXP hereby facilitates and stimulates the resumption of personally relevant activities. When individuals resume self-care and household activities, they become less dependent upon professional care and need less help from their significant others. The resumption of activities might also explain the positive findings for EXP on societal costs, since individuals are more able to return to work. Second, although EXP does not primarily focus on pain reduction, EXP did have pain-reducing effects (de Jong et al., 2005; den Hollander et al., 2016; Leeuw et al., 2008). The current study extends these findings by showing that participants actually take less medication after EXP. An additional effect might be that, when individuals decrease their use of complex pain medication, they need fewer visits to their pain specialist. Actual pain reduction is probably not the only explanation for the decrease in medication use. By the violation of catastrophic assumptions and the reduction in fear, EXP aims to decrease the threat value of pain (den Hollander et al., 2010). As individuals catastrophize less about pain, signs and symptoms after EXP, they may turn to their general practitioner when they do have CRPS-related questions, instead of turning to more expensive medical specialists, as is shown in our sample. 
Participants receiving EXP had fewer hours of work absence than participants receiving PPT. At baseline, the number of participants working or being partly on sick leave was comparable over different conditions. In PPT, more individuals were on complete sick leave, whereas more EXP participants were already receiving a disability pension. In the Netherlands, only individuals on sick leave have the possibility of resuming work, since they are still under contract with their employer. Individuals on disability pension are paid by the government and are no longer employed: in consequence, they cannot just restart work even if willing and able to. Thus, EXP participants had less opportunity to improve on this outcome measure than PPT participants. It suggests that over time, the effect for EXP might even increase, as individuals with a disability pension regard themselves as being able to work again, or when the system establishes that they no longer need a disability pension and provides possibilities to resume work. Kemler and Furnee (2002) showed that not only individuals with CRPS-I lose their jobs or decrease their working hours, but also that, for males with CRPS-I, spouses increased their working hours significantly (Kemler \& Furnee, 2002). This again highlights the importance of performing a full economic analysis, including patient-related costs and indirect costs, instead of just comparing treatment costs that cannot make valid claims for financial benefits to society. Since societal costs due to work loss in participants were found to be $77 \%$ of the total economic costs, in line with cost-effectiveness studies in other chronic pain syndromes (Goossens et al., 2015), treatments reducing work absenteeism are likely to have an enormous positive impact.

First, for individuals with CRPS-I, we showed that the value of EXP is that they will reduce their use of medication and need less informal care. For healthcare insurance companies, EXP is shown to be good value for money, since the initial higher treatment costs clearly pay off in the long run through the reduction of medication and interventions, putting less burden on the total budget. For society in general, EXP enabled patients to stay at work and reduced the costs for workdisability. Policymakers should consider adopting EXP in (inter-)national guidelines for CRPS-I, since this specific protocol of EXP is shown to be effective and costeffective. Second, we performed sensitivity analyses to increase generalizability to other health-care systems than the Dutch, by using different treatment costs reflecting different settings where treatment could be delivered. These sensitivity analyses yielded almost the same results, indicating that the effect is robust and not dependent on relatively small changes in initial treatment costs. Even with the maximal contrast in costs between treatments, primary care physical therapy against rehabilitation with additional costs for a psychologist, EXP remains the preferred treatment. To further reduce the costs of EXP, it would be worthwhile to investigate if it is possible to accomplish comparable effects in primary healthcare. 
Several weaknesses have to be mentioned as well. First, we would have preferred to use disability as our primary outcome, as we did in the previously published RCT. However, since disability was measured for upper $(n=27)$ and lower limb $(n=11)$ CRPS-I separately, this would have resulted in very low power. Since studies are not powered for economic evaluations primarily, statistical power is always low, and we did not want to increase this problem even further. Instead, we chose the Physical Component Scale of the SF-36 as our primary measure of effect, reflecting a combination of disability and pain experience. This choice was justified by high correlations of the formerly used changes on the disability measures with changes in the SF-36 Physical Component Scale (-0.79 for both measures). Second, participants did not always complete their cost diaries conscientiously, resulting in missing data. This forced us to impute data. We choose the most stringent procedure, imputation of the treatment mean (Hendriks et al., 2013). Since the percentage of missing data did not differ between conditions, this should have affected outcomes in both conditions equally. Additionally, a sensitivity analysis showed that even when only complete datasets were used, EXP still is more effective against lower cost than PPT (83\% and $78 \%$ respectively, depending on the treatment costs used). Third, generalizability of our results to other countries might be limited, due to our use of a pain-contingent comparator (PPT), which might not be recommended by guidelines in other countries, as it was in the Netherlands. Future research is needed to draw conclusions about (cost-) effectiveness of EXP against other physiotherapeutic approaches, which may also incorporate principles that are more compatible with EXP and would thus decrease the contrast between treatments. Furthermore, costs are calculated based on the Dutch health care system. With our sensitivity analyses, we contrasted different healthcare settings where treatments could be delivered. Nevertheless, with the current contrast between EXP and PPT, we cannot draw conclusions about the cost-effectiveness of EXP against other biopsychosocial approaches in CRPS-I.

\section{Conclusion}

Earlier findings on the effectiveness of EXP (den Hollander et al., 2016) are now corroborated with positive findings on its cost-effectiveness using a societal perspective, although the sample size of the trial was relatively small. The initial higher costs for EXP paid off in a significant long-term reduction of costs for healthcare consumption and a tendency to reduced costs for work absenteeism. Furthermore, participants 
needed less help from relatives after EXP. This would justify EXP being mentioned as a viable treatment in national and international guidelines for CRPS-I patients with PRF. Future research may replicate our findings in countries with different healthcare systems than the Netherlands, as well as with other comparator treatments.

\section{Acknowledgements}

We are grateful for the support of all individuals with CRPS-I who participated in the study, specialists and therapists, our research assistants, referrers to the trial and staff.

\section{Financial support}

This work was supported by the Profileringsfonds azM (PF 261); governmental funding for Maastricht University, Faculty of Psychology; the Research Foundation Flanders, Belgium, (J.V., Odysseus Grant G090208N “The Psychology of Pain and Disability Research Program"); and the Flemish Government, Belgium (J.V., "Asthenes" longterm structural funding - Methusalem grant METH/15/011). Funders had no role in study design, data collection and analysis, decision to publish, or preparation of the manuscript. The study sponsor had no role in the study design, collection, analysis and interpretation of data, the writing of the report, or in the decision to submit for publication. The corresponding author had full access to all data and final responsibility for the decision to submit for publication.

\section{Conflicts of interest}

None.

\section{Ethical standards}

The authors assert that all procedures contributing to this work comply with the ethical standards of the relevant national and institutional committees on human experimentation and with the Helsinki Declaration of 1975, as revised in 2008. 


\section{References}

Aaronson, N. K., Muller, M., Cohen, P. D. A., Essink-Bot, M.-L., Fekkes, M., Sanderman, R., . . Verrips, E. (1998). Translation, Validation, and Norming of the Dutch Language Version of the SF-36 Health Survey in Community and Chronic Disease Populations. Journal of Clinical Epidemiology, 51(11), 1055-1068. doi:http://dx.doi.org/10.1016/S0895-4356(98)00097-3

Bean, D. J., Johnson, M. H., Heiss-Dunlop, W., Lee, A. C., \& Kydd, R. R. (2015). Do psychological factors influence recovery from complex regional pain syndrome type 1? A prospective study. Pain, 156(11), 2310-2318. doi:10.1097/j.pain.0000000000000282

Brazier, J., Roberts, J., \& Deverill, M. (2002). The estimation of a preference-based measure of health from the SF-36. J Health Econ, 21(2), 271-292

Bruehl, S., Harden, R. N., Galer, B. S., Saltz, S., Backonja, M., \& Stanton-Hicks, M. (2002). Complex regional pain syndrome: are there distinct subtypes and sequential stages of the syndrome? Pain, 95(1-2), 119-124. doi:http://dx.doi.org/10.1016/S0304-3959(01)00387-6

Craske, M., Treanor, M., Conway, C., Zbozinek, T., \& Vervliet, B. (2014). Maximizing exposure therapy: an inhibitory learning approach. Behav Res Ther, 58, 10-23. doi:10.1016/j.brat.2014.04.006

de Jong, J. R., Vangronsveld, K., Peters, M. L., Goossens, M. E. J. B., Onghena, P., Bulté, I., \& Vlaeyen, J. W. S. (2008). Reduction of Pain-Related Fear and Disability in Post-Traumatic Neck Pain: A Replicated Single-Case Experimental Study of Exposure In Vivo. The Journal of Pain, 9(12), 1123-1134

de Jong, J. R., Vlaeyen, J. W. S., Onghena, P., Cuypers, C., den Hollander, M., \& Ruijgrok, J. (2005). Reduction of pain-related fear in complex regional pain syndrome type I: the application of graded exposure in vivo. Pain, 116(3), 264-275. doi:10.1016/j.pain.2005.04.019

de Jong, J. R., Vlaeyen, J. W. S., van Eijsden, M., Loo, C., \& Onghena, P. (2012). Reduction of pain-related fear and increased function and participation in work-related upper extremity pain (WRUEP): Effects of exposure in vivo. Pain, 153(10), 2109-2118. doi:http://dx.doi.org/10.1016/j.pain.2012.07.001 de Mos, M., de Bruijn, A. G. J., Huygen, F. J. P. M., Dieleman, J. P., Stricker, C. B. H., \& Sturkenboom, M. C. J. M. (2007). The incidence of complex regional pain syndrome: a population-based study. Pain, 129(1-2), 12-20. doi:10.1016/j.pain.2006.09.008

den Hollander, M., de Jong, J. R., Volders, S., Goossens, M. E. J. B., Smeets, R. J. E. M., \& Vlaeyen, J. W. S. (2010). Fear reduction in patients with chronic pain: a learning theory perspective. Expert Review of Neurotherapeutics, 10(11), 1733-1745. doi:10.1586/ern.10.115

den Hollander, M., Goossens, M. E. J. B., de Jong, J. R., Ruijgrok, J., Oosterhof, J., Onghena, P., ... Vlaeyen,

J. W. S. (2016). Expose or protect? A randomized controlled trial of exposure in vivo vs pain-contingent treatment as usual in patients with complex regional pain syndrome type 1. Pain, 157(10), 2318-2329. doi:10.1097/j.pain.0000000000000651

Dolan, P. (1997). Modeling valuations for EuroQol health states. Med Care, 35(11), 1095-1108

Drummond, M., Manca, A., \& Sculpher, M. (2005). Increasing the generalizability of economic evaluations: recommendations for the design, analysis, and reporting of studies. Int I Technol Assess Health Care, 21(2), 165-171 
Drummond, M., Sculpher, M., Torrance, G., O'Brien, B., \& Stoddart, G. (2005). Methods for the economic evaluation of health care programmes. Oxford: Oxford University Press

Geertzen, J., Dijkstra, P., Groothoff, J., ten Duis, H., \& Eisma, W. (1998). Reflex sympathetic dystrophy of the upper extremity-a 5.5-year follow-up. Part I. Impairments and perceived disability. Acta Orthop ScandSuppl, 279, 12-18

Goossens, M. E., Rutten-van Molken, M. P., Vlaeyen, J. W., \& van der Linden, S. M. (2000). The cost diary: a method to measure direct and indirect costs in cost-effectiveness research. J Clin Epidemiol, 53(7), 688-695

Goossens, M. E., de Kinderen, R. J., Leeuw, M., de Jong, J. R., Ruijgrok, J., Evers, S. M., \& Vlaeyen, J. W. S. (2015). Is exposure in vivo cost-effective for chronic low back pain? A trial-based economic evaluation. BMC Health Serv Res, 15, 549. doi:10.1186/s12913-015-1212-6

Handleiding voor kostenonderzoek. Methoden en standaardkostenprijzen voor economische evaluaties in de gezondheidszorg., (2010)

Hendriks, M. R., Al, M. J., Bleijlevens, M. H., van Haastregt, J. C., Crebolder, H. F., van Eijk, J. T., \& Evers, S. M. (2013). Continuous versus intermittent data collection of health care utilization. Med Decis Making, 33(8), 998-1008. doi:10.1177/0272989x13482045

Kemler, M. A., \& Furnee, C. A. (2002). The impact of chronic pain on life in the household. J Pain Symptom Manage, 23(5), 433-441

Koopmanschap, M. A., \& Rutten, F. F. (1993). Indirect costs in economic studies: confronting the confusion. Pharmacoeconomics, 4(6), 446-454

Leeuw, M., Goossens, M. E., van Breukelen, G. J., de Jong, J. R., Heuts, P. H., Smeets, R. J., . . Vlaeyen, J. W. (2008). Exposure in vivo versus operant graded activity in chronic low back pain patients: results of a randomized controlled trial. Pain, 138(1), 192-207. doi:10.1016/j.pain.2007.12.009

Leeuw, M., Goossens, M. E. J. B., van Breukelen, G. J. P., de Jong, J. R., Heuts, P. H. T. G., Smeets, R. J. E. M., . .. Vlaeyen, J. W. S. (2008). Exposure in vivo versus operant graded activity in chronic low back pain patients: results of a randomized controlled trial. Pain, 138(1), 192-207

Moulaert, V. R., Goossens, M., Heijnders, I. L., Verbunt, J. A., \& Heugten, C. M. (2016). Early neurologically focused follow-up after cardiac arrest is cost-effective: A trial-based economic evaluation. Resuscitation, 106, 30-36. doi:10.1016/j.resuscitation.2016.06.015

O'Connell, N. E., Wand, B. M., McAuley, J., Marston, L., \& Moseley, G. L. (2013). Interventions for treating pain and disability in adults with complex regional pain syndrome. Cochrane Database Syst Rev(4), CD009416. doi:10.1002/14651858.CD009416.pub2

Oerlemans, H. M., Oostendorp, R. A., de Boo, T., \& Goris, R. J. (1999). Pain and reduced mobility in complex regional pain syndrome I: outcome of a prospective randomised controlled clinical trial of adjuvant physical therapy versus occupational therapy. Pain, 83(1), 77-83

Sandroni, P., Benrud-Larson, L. M., McClelland, R. L., \& Low, P. A. (2003). Complex regional pain syndrome type I: incidence and prevalence in Olmsted county, a population-based study. Pain, 103(1-2), 199-207. doi:http://dx.doi.org/10.1016/S0304-3959(03)00065-4 
Sharma, A., Agarwal, S., Broatch, J., \& Raja, S. N. (2009). A web-based cross-sectional epidemiological survey of complex regional pain syndrome. Reg Anesth Pain Med, 34(2), 110-115. doi:10.1097/ AAP.0b013e3181958f90

Vlaeyen, J. W. S., Morley, S., Linton, S. J., Boersma, K., \& de Jong, J. R. (2012). Pain-Related Fear: ExposureBased Treatment for Chronic Pain: IASP Press

Ware, J. E., Kosinski, M., \& Keller, S. K. (1994). SF-36 ${ }^{\circledR}$ Physical and Mental Health Summary Scales (2 ed.). Boston, MA: The Health Institute

Zale, E. L., \& Ditre, J. W. (2015). Pain-Related Fear, Disability, and the Fear-Avoidance Model of Chronic Pain. Curr Opin Psychol, 5, 24-30. doi:10.1016/j.copsyc.2015.03.014

Zale, E. L., Lange, K. L., Fields, S. A., \& Ditre, J. W. (2013). The relation between pain-related fear and disability: a meta-analysis. J Pain, 14(10), 1019-1030. doi:10.1016/j.jpain.2013.05.005 


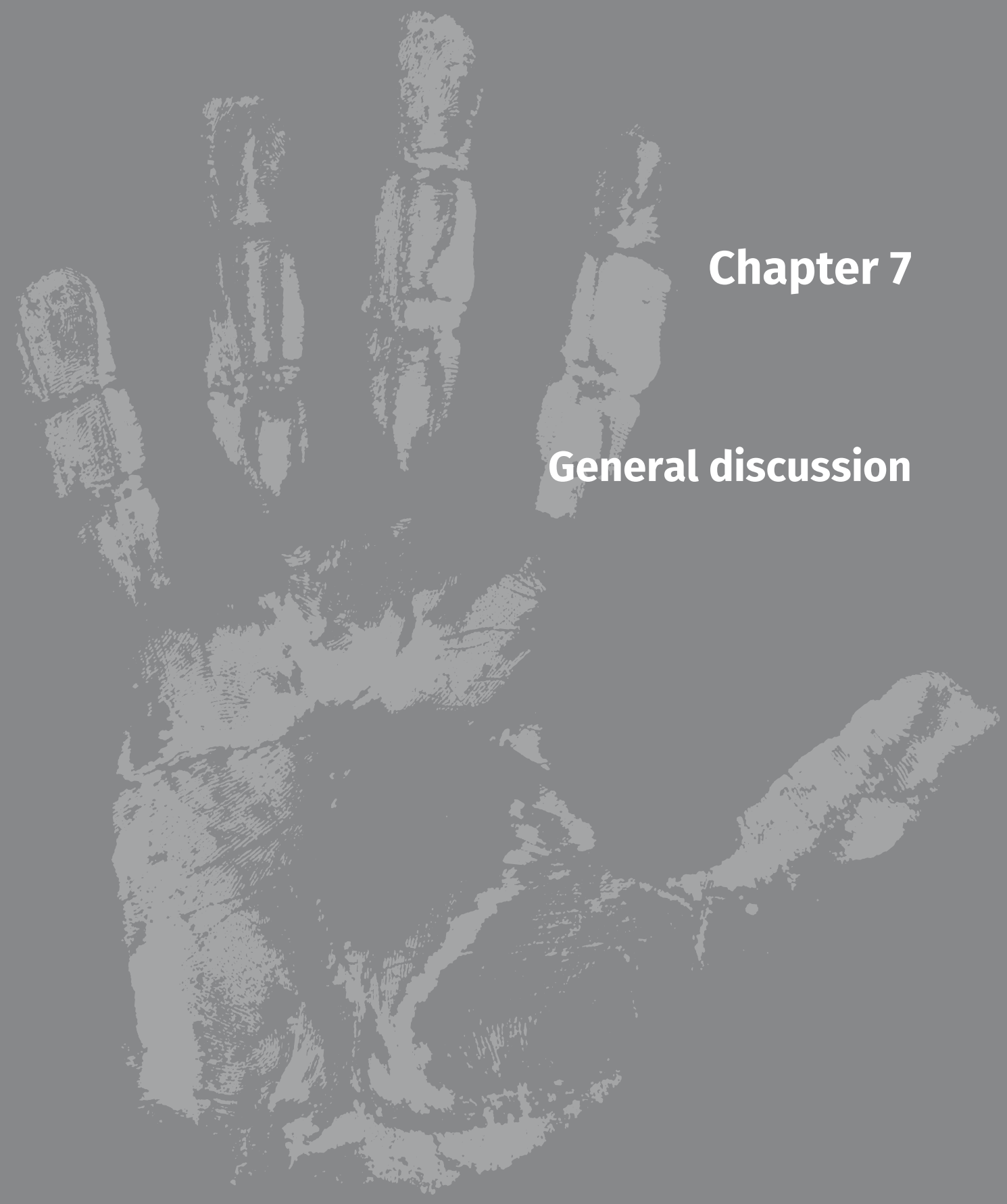





\section{General discussion}

\section{Scope of this thesis}

From childhood on we learn to detect events in our environment that might compromise the integrity of our body, to escape from threats when it comes to an unwanted confrontation, and to avoid these threatening events in the future. Pain is crucial in this learning process, as it signals that the body might be or become injured. Acute pain urges humans to take action, and is usually followed by behaviors aiming to promote optimal conditions for healing, such as taking rest, or consulting a health care provider. However, in many cases the relation between pain and bodily harm is not that clear (Jensen et al., 1994; Waddell, 2004). Pain might exist beyond the initial time for healing of an acute injury, or it might be unclear whether or what biomedical pathology causes pain and symptoms, as is the case in Complex Regional Pain Syndrome Type I (CRPS-I). CRPS-I is a highly disabling chronic pain condition with a poorly understood pathophysiology, leading to extensive suffering, especially in those with chronic CRPS-I. Currently, CRPS-I cannot be cured, and its symptoms are difficult to treat. It is generally accepted that, for CRPS-I as well as for other chronic pain syndromes, pain becomes a problem when the responses to anticipated pain become similar to the responses after actual confrontation with a harmful stimulus.

This thesis aimed to contribute to a better understanding of pain-related fear from a learning theory perspective, as well as to explore elements of the process of acquisition and extinction of pain-related fear. Furthermore, a corresponding exposure in vivo intervention was introduced, and its effectiveness and cost-effectiveness, were studied in CRPS-I. In the introduction, we describe several unresolved issues that warranted further examination, and formulate the following research questions to be addressed in this thesis:

1. How can we understand the acquisition and extinction of pain-related fear from a learning theory perspective?

2. Does verbal and visual manipulation of threat influence acquisition, extinction and return of fear in pain-free individuals?

3. Numbers or repetitions? Is generalization of exposure in vivo treatment facilitated when a number of different activities are performed versus when a few activities are repeated several times?

4. Expose or protect? Is exposure in vivo an effective treatment (in reducing disability as primary outcome, but also in reducing pain-related fear and pain intensity, 
as well as in improving quality of life) in patients with CRPS-I and pain-related fear, compared to treatment as usual (pain-contingent physical therapy as recommended by the Dutch guidelines)?

5. Is exposure in vivo cost-effective in CRPS-I patients with pain-related fear, compared to pain-contingent physical therapy?

This final chapter starts with a summary of the main findings of this thesis, which consists of a review of the literature (Chapter II, research question 1: how can we understand the acquisition and extinction of pain-related fear from a learning theory perspective?), an experimental study on the effect of induced threat on painrelated fear (Chapter III, research question 2: does verbal and visual manipulation of threat influence acquisition, extinction and return of fear in pain-free individuals?), a repeated single case experimental design on the generalization of extinction in chronic pain patients reporting increased pain-related fear (Chapter IV, research question 3: is generalization of exposure in vivo treatment facilitated when many different activities are performed or when the same activities are repeated several times?), a randomized controlled trial comparing exposure in vivo with paincontingent treatment as usual in patients with CRPS-I and pain-related fear (Chapter $V$, research question 4: is exposure in vivo an effective treatment in patients with CRPS-I and pain-related fear, compared to treatment as usual?). Finally, a cost-effectiveness study of exposure in vivo versus treatment as usual is presented (Chapter VI, research question 5: is exposure in vivo cost-effective in CRPS-I patients with pain-related fear, compared to pain-contingent physical therapy?).

\section{Summary of the study aims and main findings}

\section{Question 1: How can we understand the acquisition and extinction of pain-related fear from a learning theory perspective?}

In the first chapter, we describe how fear could be acquired, maintained and extinguished from a learning theory-perspective, based on the principles of classical and operant conditioning. We applied these general principles to pain-related fear. This chapter provides the theoretical background for the following chapters, in presenting a helpful and well-studied perspective that we applied to pain-related fear in patients with chronic pain. We describe how pain-related fear can be assessed with questionnaires, such as the Fear Avoidance Beliefs Questionnaire (Waddell, Newton, 
Henderson, Somerville, \& Main, 1993), Pain Anxiety and Symptoms Scale (McCracken, Zayfert, \& Gross, 1992) and the Tampa Scale for Kinesiophobia (Miller, Kori, \& Todd, 1991). Since these questionnaires do not address the exact conditioned stimuli (CSs) that patients fear or avoid, the Photograph Series of Daily Life Activities or PHODA (Leeuw, Goossens, van Breukelen, Boersma, \& Vlaeyen, 2007) is more suitable to assess which movements and activities are expected to be harmful. We contend that verbal learning (during the educational sessions), observational learning (by the therapists modeling activities) and direct experience (behavioral experiments) can foster fear reduction. The actual exposure in vivo treatment was described as gradually working through the fear hierarchy as established with the PHODA.

Since the publication of our topical review (chapter 2), the conduction of the generalization study (chapter IV) and the RCT (chapter V), insights in the mechanism of exposure treatment have evolved. In our review, we described the aim of exposure mainly as reducing disability through the reduction of pain-related fear, the conditioned response (CR). This was in line with the emotional processing theory (Foa \& Kozak, 1986) that provided the theoretical base for exposure treatment for years. The emotional processing theory states that confrontation with a feared stimulus (CS) activates memories (US representations) and physiological reactions (CRs). Repeated confrontation with a feared stimulus is supposed to result in a decrease in the CR by habituation, the long-presumed underlying mechanism of exposure. In line with this theory, and in order to decrease pain-related fear during exposure in vivo, a fearhierarchy was followed stepwise, starting with the least fear evoking movements/ activities and gradually working to movements and activities higher on the hierarchy. Therapists first showed these movements and activities (modelling), before patients were invited to perform these themselves. Patients subsequently scored the credibility of the expected US, since behavioral experiments have always been an essential component of exposure in vivo for pain-related fear. Besides the credibility score, alternative thoughts were formulated, and fear levels were monitored. However, after we started our generalizability and RCT studies, it became clear that fear reduction during exposure is not a reliable indicator of learning (Meuret, Seidel, Rosenfield, Hofmann, \& Rosenfield, 2012). Exposure in vivo is currently regarded as a method to disconfirm negative, fearful expectancies by experiencing disconfirmation between the expectancy and experience (expectancy violation) (Craske, Treanor, Conway, Zbozinek, \& Vervliet, 2014). By experiencing disconfirmation of expectancies during exposure, learned responses such as avoidance behavior decrease. The process of learning those new associations is referred to as inhibitory learning (Craske et al., 2008). Specifically this inhibitory learning mechanism might be hampered in patients with anxiety disorders or anxious personality traits (Craske, Liao, Brown, \& Vervliet, 2012). Not only can these disturbed mechanisms form the basis of anxiousness 
in the first place, they can also explain why these patients do not respond well to treatment (such as exposure). Optimizing inhibitory learning during exposure might compensate for these deficits and neutralize return of fear after exposure (such as spontaneous recovery, renewal, reinstatement and rapid reacquisition). Valuable suggestions for optimizing exposure have been made (Craske et al., 2014; Vervliet, craske, \& Hermans, 2013). These suggestions are also relevant to the area of chronic pain, and most of them can be easily integrated in the protocol of exposure in vivo for pain-related fear. We will highlight some techniques that have been modified due to these suggestions, and which have been applied in current exposure in vivo treatment for pain-related fear*.

First, there is evidence that the more pronounced the mismatch between expectancy and actual outcome, the stronger the inhibitory learning of the CS-no US association will be. This argues for the use of behavioral experiments that are as "extreme" as possible (of course, the patient should still be willing to exposure himself to the feared (S), to maximize the mismatch between expectancy and outcome. Exposure focuses on the non-occurrence of the expected negative outcome and whether the outcome was as negative as expected or was actually tolerable. It is known that high levels of fear during extinction learning predict lower fear at retest, as well as that arousal enhances the storage of memory. Therefore, reaching agreement between patient and therapist on duration and number of repetitions, needed to maximize the change on the expected negative outcome of the patient, might be highly relevant during exposure treatment.

Second, since the expectancy-outcome mismatch is crucial for learning CS-no US associations, techniques that potentially decrease the "surprise-value" of the mismatch are to be avoided, such as the formulation of alternative thoughts or preexposure attempts to make the CS less aversive before the actual exposure should be used. Another element that is refrained from for the same reason is that the therapist first models the activity. Arguably, the educational session also provides information that might compromise the mismatch. This indicates the precarious balance of the educational session in chronic pain rehabilitation: would patients be willing to test their expectancy that for example harm will occur, without an explanation of the physiatrist about this dysfunctional idea? Previous research showed that the educational session-which consisted of medical information on one hand, and a personalized explanation of the fear-avoidance model on the other hand-does reduce self-reported pain-related fear and catastrophizing, but not actual behavior (de Jong et al., 2005b). Whether the education specifically changes the perceived probability of the negative outcome has not yet been studied in pain-related fear.

* However, these changes were only recently implemented, after conductance of the generalization study (chapter 4) and the RCT (chapter 5). 
Third, retrieval cues or the instruction to mentally reinstate the exposurecontext in case of a return of fear can also be easily integrated in exposure for painrelated fear, as well as performing exposure in multiple contexts, as we also showed in chapter 4, and with a variety of fear-levels (instead of following a fear hierarchy as it was previously performed) and durations of exposures.

Another strategy that could strengthen the associative inhibitory processes of extinction is affect-labeling. Affect labeling refers to verbalization of current emotional experience; putting feeling into words (Kircanski, Lieberman, \& Craske, 2012). By activating cortical brain areas involved in executive functioning, the amount of activity in the limbic system (associated with fear) could be reduced (Liebermann, Giesbrecht, \& Müller, 2007). Verbalizing emotional reactions during exposure can help to enlarge its effect (Kircanski, Lieberman, et al., 2012). This was shown by comparing verbalizing emotional reactions with other affect regulating techniques such as reappraisal, distraction and pure exposure, in a study with individuals with a fear of spiders. The affect labeling group showed reduced skin-conductance compared to the other groups and greater approach behavior than the distraction groups, although fear reports did not differ between groups. Greater use of anxiety and fear words was associated with greater reductions in fear responding. The authors conclude that affect labeling might help to regulate aspects of emotion in a clinical context (Kircanski, Lieberman, et al., 2012). This could be translated to the context of exposure in vivo for pain-related fear. While performing activities during the behavioral experiments, patients could for example receive instructions to explicitly reflect on or tell the therapists about their emotional state. Of course, studies are warranted to evaluate whether this technique is also of additional value for patients in exposure in vivo treatment for pain-related fear.

Last, advising patients to focus on the non-occurrence of the expected outcome is another relevant change that is easy to apply during exposure. Attentional strategies or even talking with the therapist might be contra-productive for new learning of the CS-no US association. After exposure, the patient is invited to reflect on the non-occurrence of the US, since rehearsal of the CS-no US association is known to enhance storage of the memory (Joos, Vansteenwegen, \& Hermans, 2012). As stated previously, these suggestions to enhance inhibitory learning were only applied by our clinical (treatment) team after finishing the generalization study in chapter IV and the RCT that is described in chapter V.

Recent adaptations to the original fear-avoidance model (Vlaeyen \& Linton, 2000) suggest that persons preferring control over pain tend to avoid activities, whereas persons who do have other goals, such as accomplishing a relevant task might show confrontation with painful activities (Vlaeyen, Crombez, \& Linton, 2016). 
Patients with chronic pain might experience goal-conflicts, for example between behavior aimed to prevent harm or to control pain, but on the other hand helping to keep them engaged in relevant and valued daily activities (Claes, Crombez, Meulders, \& Vlaeyen, 2016; Crombez, Eccleston, Van Damme, Vlaeyen, \& Karoly, 2012). Cross-sectional evidence suggests that goal conflicts are associated with pain-related fear (Karoly, Okun, Ruehlman, \& Pugliese, 2008), higher pain intensity (Hardy, Crofford, \& Segerstrom, 2011) and negative affect (Goossens et al., 2010). A recent experimental study showed that healthy participants experience painrelated fear when they expect a painful electrocutaneous stimulus, but are more willing to perform a painful movement when they receive a personalized reward than when no reward is present (Claes et al., 2016). Therefore, it seems relevant that from the start of treatment, the patient is exposed not only to activities that are chosen to create a maximum mismatch between expectancy and experience, but also to activities that the patient considers relevant and rewarding. This could probably counter or restore the balance between positive and negative consequences, such as increased pain. For this purpose it could be helpful that therapists delivering exposure in vivo treatment do not only assess the USS and their predictors (CSs), but also aspects such as personal importance and reward to perform these CSs. In clinical practice, the Canadian Occupational Performance Model (Law et al., 2005) is used to discuss and prioritize issues that impact a patients' performance in activities of daily life, providing information about what is of personal importance to the patient. Combining information from PHODA and COPM could help to optimize the choice of activities in exposure in vivo for pain-related fear. In an experimental context, rewards immediately follow performance of the painful task. In a clinical context, when patients report an activity as important, they do not necessarily experience immediate reward. First, chosen activities are often related to valued life-roles, and reward for activities related to these can be more abstract, not immediately given, or simply be not rewarding in the context of the clinic. For example, vacuum cleaning in a hospital context during a treatment session might challenge dysfunctional ideas for a patient with chronic back pain, but it might not be as rewarding as vacuum cleaning in the home situation, where it is considered important to fulfill the patients' role as a mother. Reward could be enhanced if exposure sessions can be conducted in the home- or work situation. Second, personal relevance is different from "likeable", or fun. In a clinical context, it seems that for the first sessions it helps creating therapy compliance when the patient experiences immediate reward ("I could do this and it was fun"). Of course, activities in an exposure treatment for pain-related fear are and should be primarily chosen based on the mismatch they create between expectancy and actual experience, but the additional role of importance or likeability hasn't been studied yet. 


\section{Question 2: Does verbal and visual manipulation of threat influence acquisition, extinction and return of fear in pain-free individuals?}

Messages conveyed by health-care professionals or (social) media, are often used by individuals with chronic pain as a source of information to estimate the threat value of pain-related stimuli. For example, a patient with CRPS-I might be fearful to lift his child, because he might have read on an internet forum not to carry heavy weights, since it might trigger exacerbation of CRPS-symptoms. Threatening information can be acquired directly by experience, but also indirectly by observation or verbal instruction. Would it be possible to indirectly manipulate the threat-value of pain during the acquisition, extinction and return of pain-related fear in pain-free individuals by providing verbal instructions?

An experimental study adopting the Voluntary Movement Joystick Paradigm (VMJP) (Meulders, Vansteenwegen, \& Vlaeyen, 2011; Meulders \& Vlaeyen, 2012) was conducted in Chapter III. Here we experimentally examined whether different verbal instructions about the threat-value of a painful stimulus could influence acquisition, extinction and return of fear in pain-free volunteers. First, all participants received an initial verbal threat-induction about the harmfulness of a painful stimulus. Second, during the acquisition and extinction phase, we provided visual information (a skindamage indicator), which was intended to make the US more threatening (inflationcondition), less threatening (deflation-condition), or to keep the threat-value of the US constant (constant-condition). Third, we also investigated if fear would return after extinction when participants were again confronted with the US (reinstatement procedure). Because previous studies with the VIMP showed a pain-sensitization effect in women (Meulders, Vansteenwegen, \& Vlaeyen, 2012), we included only male participants, since a pain-sensitization effect would interfere with the hypothesized effect of our threat manipulation.

We found a return of fear after reinstatement, but we failed to find differential effects for our threat manipulation on acquisition, extinction and reinstatement. Unexpectedly, a pain-sensitization effect occurred over time for all conditions in our male sample. This might indicate that our initial threat manipulation, given to all participants, raised perceived threat in all groups, and that the subsequent between groups manipulation of threat (inflation-neutral-deflation) was not strong enough to overrule this initial effect.

The initial threat instruction informed participants that the painful stimulus they were about to receive could be harmful to the skin, and that visual feedback about their personal risk was measured and visually shown on the computer screen in a colored bar. In the first block of acquisition, "mediate threat" (orange colored 
bar) was provided for all participants. In the second block, threat value was manipulated in the randomized direction (deflation, constant, inflation). Since only one block provided the same information for all participants, this makes it impossible to establish if the pain-sensitization effect that we unexpectedly found was due to the initial verbal threat-manipulation, or to the secondary visual threat-manipulation. It could be that the initial verbal threat manipulation raised the threat-value of pain in all conditions, and that the visual threat manipulation did not sort any additional effects. Unfortunately we cannot draw conclusions about this possibility, since we did not measure the threat value of pain between the initial verbal threat manipulation and the visual threat manipulation in the first block of acquisition. Retrospectively, it would have been interesting to have participants score the threat value of pain after the verbal threat manipulation, and again after the first block of acquisition. In all conditions, we observed increasing pain reports over time in our male sample. This suggests that our threat manipulation might have increased the perceived threat overall, independent of whether the initial threatening instruction about the painful stimulus decreased. This might also indicate that participants believed the initial verbal threat manipulation, but not the visual online skindamage indicator.

Probably, a within-subject design with variations in the level of threat in randomized order would have been better to detect inflation and deflation effect. The current between-subject design does not enable us to rule out inter-individual differences that might have been distributed unequally over conditions. We choose not to ask participants whether or not they believed the threat-manipulation, since we were worried that in this group mainly consisting of students, only asking this question would raise suspiciousness in conversations about the study, and this could compromise our manipulation.

Indeed, it has been shown that words related to pain can activate regions of the pain matrix (Richter, Eck, Straube, Miltner, \& Weiss, 2010), even when the words are presented outside awareness (Swannell, Brown, Jones, \& Brown, 2016). In the latter study, healthy participants experienced a heat stimulus as more painful when they were subliminally confronted with words highly related to pain than with words less related to pain (Swannell et al., 2016). In a clinical setting of venous blood sampling, just saying the word "sting" increased the perception of pain, in contrast to the word "beware". These studies seem to indicate that the pain-experience can be altered by threatening information, which might be an explanation for the sensitization effect we found in our experimental study, and more general, confirm that verbal information adds to the threat value and intensity of pain (Ott, Aust, Nouri, \& Promberger, 2012). 


\section{Question 3: Numbers or repetitions? Is generalization of exposure in vivo treatment facilitated when many different activities are performed or when the same activities are repeated several times?}

Experimental studies in pain-related fear with pain-free participants (Meulders, Meulders, Stouten, De Bie, \& Vlaeyen, 2017) as well as with patients with chronic low back pain (Crombez et al., 2002; Goubert, Crombez, \& Danneels, 2005; Goubert, Francken, Crombez, Vansteenwegen, \& Lysens, 2002) showed that generalization of extinction of pain-related fear is a fragile process. From the aforementioned studies, only one experimental study found successful generalization from one movement to another (Trost, France, \& Thomas, 2008). Generalization of exposure in pain-related fear had never been studied in a clinical setting, where variation in the number of activities performed, as well as variations in contexts is provided. From a clinical perspective, it seems evident that in order to perform a broad variety of activities over a range of contexts, as normal daily life functioning requires, patients need to generalize what they experience during exposure treatment to new situations outside the treatment sessions.

A randomized replicated single case experimental design was used to study generalization from exposure in vivo treatment in a group of CPRS-I patients with elevated levels of pain-related fear. The ingredients of this exposure treatment varied: 15 activities that patients were exposed to only once (multiple exposure condition), or 3 activities that patients were repeatedly exposed to during 5 sessions each (repeated exposure condition). Generalization was tested directly after completion of treatment as well as 6 months later, when both groups were confronted with new activities, selected based on a supposed high threat-value (a headlong fall, doing push-ups, boxing against a punching bag, receive a Chinese burn). Whereas the experimental studies chose pain expectancy scores or perceived harmfulness as indicators of generalization, we decided to choose actual performance of the generalization tests as our primary outcome. Since patients present themselves for rehabilitation treatment because of their experienced disability, and not because they experience pain-related fear, we reasoned that the outcome of our generalization study should be an indicator of behavior.

We hypothesized that exposure to a variety of different activities during treatment, as in the multiple exposure condition, would enhance generalization given that it would provide multiple prediction errors. Contrary to our expectations, all patients performed the new activities during the generalization tests, regardless if their treatment had consisted of many different activities or of only three activities that were 
repeatedly performed over several sessions, both directly after finishing exposure as well as 6 months later. Furthermore, effect sizes as well as meta-analytic procedures over the daily measures revealed that both conditions significantly improved in their ability to perform personally relevant daily activities. To significantly decrease reports of pain, fear of movement and catastrophizing, exposure to multiple stimuli is to be preferred, as indicated by meta-analytical procedures.

The study reveals that the current exposure in vivo protocol for pain-related fear contains provides enough disconfirming evidence for the patient to generalize the newly learned, inhibitory CS-no US association to a new context (outside treatment, no therapists present) and to an activity they did not perform during treatment ("if I perform this NEW activity, no catastrophe will take place"). Although patients who received exposure to multiple stimuli, as well as patients exposed to a limited number of stimuli that were repeated, both performed a new, threatening activity (behavioral outcome), exposure to many different activities seems to be preferred when other outcomes, such as pain relief and measures of pain-related fear are also taken into account.

This study showed that generalization of extinction took place after several sessions of exposure, a relevant clinical finding contrasting earlier laboratory studies, which presumably showed no generalization of fear extinction. Patients perform highly threatening activities after treatment, and they rate the perceived harmfulness of this activity as lower than at the start of exposure treatment. Several explanations might account for these unexpected findings as well as for the differences with earlier studies. First, there is a difference in operationalization of the final test of extinction: pain- and harm expectancy corrections in the experimental studies versus a dichotomous outcome of performance (yes/no) in our generalization test. We reasoned that a behavioral indicator of performance was in line with disability as the main outcome of treatment in a rehabilitation setting. Furthermore, fear scores might not show strong associations with actual performance, as reflected by the current emphasis on inhibitory learning instead of fear reduction for long term treatment success during exposure treatment. In the experimental studies, as far as described, patients also performed the required activities, even though their pain and/or harm expectancy scores did not reflect generalization of the fearreduction they experienced during the first trial.

We did not collect pain expectancy ratings, as did the previous studies. During exposure treatment, patients are prepared that pain might increase (presumably in the short run) as well as decrease (probably in the long run), helping them not to focus on pain as an outcome of the behavioral experiments during exposure treatment. To compare with the experimental studies, it would have been interesting to 
compare pain expectancy ratings of the test-activities, before treatment (T0), before actual performance at test ( $\mathrm{T} 1$ ) and after performance (T2). It is worthwhile to understand why exposure in vivo results in decreased disability: are corrections of overpredictions regarding either pain or harm the most important predictors of long-term treatment success? Future research could compare an exposure treatment focusing on predictions of pain, with an exposure treatment focusing on predictions of harm or inability. The key to treatment success could also be in tailoring expectancy ratings on the specific outcome that a patient fears per activity. This would help to concentrate on the mismatch between expectancy and outcome, as the current inhibitory learning model requests.

Second, in our study, patients were exposed to relevant daily activities, chosen on the basis of personal goals and threat value, instead of simple movements, as in the experimental studies. Exposure to activities might have created a more salient mismatch between expectancy and experience. New knowledge about the importance of this mismatch could explain the differences between conditions. Possibly, in the multiple exposure condition, this mismatch might have been experienced repeatedly since in each session, patients were exposed to a new activity. Patients in the repeated activities condition had fewer opportunities to experience a large mismatch between what they expected and what actually happened.

A third difference might be in the educational session, which might help patients understand the principles of exposure and might help to reflect on their behavior. In the experimental studies, patients just experience the movements, without additional education. Probably, the educational session creates knowledge that what is expected is probably not going to be experienced, and this might affect the score before actual performance. On the other hand, the beneficial effects of education might be questioned in the current light of research on inhibitory learning. If the strongest inhibitory associations might be learned when the mismatch between expectation and actual experience is optimized, it is questionable to reduce for example harm-expectancies by giving information about expected harm during the medical education. From an inhibitory learning approach, it might be preferred to have the patient actually experience that no harm occurs, without already reducing the threat value of activities by reassuring information (Linton, McCracken, \& Vlaeyen, 2008). Although the medical education seems an important step to enhance willingness in patients to subsequently expose themselves to activities that they conceive as harmful, future research might study if at least some patients are willing to experience that no negative consequences will occur without having education first, and if this will lead to stronger treatment effects. 
To properly compare this study with the previously published studies on generalization, we should not only consider actual performance, but also the perceived harmfulness of the activities. Perceived harmfulness was registered 3 times: before treatment (T0; BAS), after treatment but before actual performance ( $\mathrm{T} 1$; baseline threat) and after actual performance when it was suggested that the activity had to be performed again (T2; experienced threat). In both conditions, perceived harmfulness scores of a headlong fall were higher at T0, than at T1, indicating that exposure treatment resulted in a decrease of the perceived threat, despite that this specific activity was not performed yet. Although both conditions showed a comparable mean reduction between T0 and T1, differences between conditions were observed regarding perceived harmfulness scores between T1 and T2. In the multiple exposure condition, actual performance of the headlong fall did not further reduce the perceived harmfulness between $\mathrm{T} 1$ and $\mathrm{T} 2$, so participants did not further correct their perceived harmfulness scores after actual performance (no reduction in threat scores between $\mathrm{T} 1$ and $\mathrm{T} 2$ ). In the repeated exposure condition, all participants scored the headlong fall as less harmful after actual performance (reduction in perceived harmfulness scores between T1 and T2). Probably, participants in the repeated exposure condition learned to more accurately estimate threat than participants in the multiple activities exposure condition. The same pattern emerged for the specific activity. At FU, the baseline perceived harmfulness for the patients in the multiple exposure condition seems to return to the level that the patient scored before performing the post-test (only one exception), indicating a return of fear for the majority of patients. The repeated exposure condition keeps the low scores that were observed at the post-treatment test. Still, all participants perform the requested activities at FU. This reflects the question which changes should be marked as "relapse" in a clinical setting: a return of fear or when fear again gives rise to experienced disability? Furthermore, patients often define relapse as experiencing increases in pain. Relapse (in pain, fear or disability) seems a scarcely studied subject after exposure in vivo for pain-related fear, and seems important for future studies. Research in this area could help to provide tools for therapists to specifically counter relapse in patients with pain-related fear.

Since the difference between a single exposure to one movement and 15 sessions of exposure is large, an interesting question remains on how many sessions are needed to accomplish generalization. There might be additional ways to improve generalization of extinction that might easily be integrated in the current treatment protocol. Experimental studies showed that after sleep, extinction memory for a specific extinguished CS generalized to a similar but not extinguished CS. The authors suggest that promoting good sleep quality as well as scheduling sessions late in the day might maximize the generalization of extinction memory (Pace-Schott 
et al., 2009). Experimental studies in PTSD, spider phobia and social anxiety confirm that it seems worthwhile to further explore the memory enhancing function of sleep to strengthen therapeutic extinction learning from exposure therapy by using strategically timed sleep (Pace-Schott, Germain, \& Milad, 2015).

Recent findings all point at individual differences in fear extinction. Individuals with chronic pain might differ from healthy individuals in their ability to identify indicators of threat and safety; they show reduced differential learning and flatter generalization-gradients with respect to US-expectancy (Harvie, Moseley, Hillier, \& Meulders, 2017). Fibromyalgia patients showed impaired extinction of stimuli resembling the stimulus originally paired with the US (Meulders, Boddez, Blanco, Van Den Houte, \& Vlaeyen, 2018). Recent studies revealed that higher extinction learning capacity in the laboratory (discrimination between CS + and CS-) would predict successful fear reduction over the course of an exposure treatment (Forcadell et al., 2017). In our study, we also noticed individual differences in treatment-responses. Although the predictive validity of a conditioning procedure in the laboratory would certainly have to be thoroughly studied, it would be relevant if discrimination between responders and non-responders for exposure treatment becomes possible and treatments can be customized accordingly, for example in the number of sessions.

\section{Question 4: Expose or protect? Is exposure in vivo an effective treatment (in reducing disability as primary outcome, but also in reducing pain-related fear and pain intensity, as well as in improving quality of life) in patients with Complex Regional Pain Syndrome Type 1 and pain-related fear?}

Based on the successful exposure in eight patients with CRPS-I (de Jong et al., 2005a), and replication of these results in our generalization study, we decided to further evaluate the effectiveness of exposure in vivo in a larger group of patients with CRPS-I using a group-based randomized controlled trial (chapter 5). We compared the effects of exposure in vivo with pain-contingent treatment as usual (TAU) on disability in CRPS-I patients with substantial levels of pain-related fear.

We found that after exposure in vivo, patients with upper extremity CRPS-I reported a more substantial decrease in disability than patients did after TAU, both directly after treatment as well as six months later. For patients with lower extremity CRPS-I there was no difference between exposure in vivo and TAU directly after treatment and both conditions showed a decrease in disability. However, the difference reached statistical significance at 6 months' follow-up favoring exposure in vivo. Exposure was statistically dominant over TAU directly and six months after treatment 
in reducing self-reported pain, pain catastrophizing, perceived harmfulness of physical activity, and health-related quality of life. Cohen's $d$ of the differences between exposure in vivo and TAU all indicate large effect sizes (> .50). Extending these findings on the individual level, we evaluated if treatments resulted in a reliable change (Morley \& Dowzer, 2014), beyond the "noise" or measuring "error" , and found that the proportion of patients improving in a reliable way, was higher for exposure in vivo than for TAU on all measures (disability, perceived harmfulness of activities, pain-catastrophizing, physical and mental health-related quality of life and experienced pain).

Exposure in vivo was delivered according to the protocol also used by Leeuw et al. (Leeuw et al., 2008; Vlaeyen, de Jong, Leeuw, \& Crombez, 2004; Vlaeyen, de Jong, Sieben, \& Crombez, 2002). The suggestions to enhance the effects of exposure treatment by focusing on inhibitory learning were not yet integrated at the time. Nevertheless, this study clearly shows that exposure in vivo is more effective in fearful CRPS-I patients than a usual pain-contingent treatment, in reducing disability, pain-related fear and pain intensity, and in improving health-related quality of life. All changes were found to be clinically relevant.

The greatest challenge we encountered was the inclusion of a sufficient number of patients for the RCT. We extended our options for recruitment during the trial (from several hospital departments, to rehabilitation departments and then anesthesiology departments in the region, to general practitioners and physical therapist), but still included a smaller number of patients than we initially based our power-calculations on. Several factors might account for this lower number of participants. First, in the years before the RCT started, the number of CRPS-I patients referred to the Department of Rehabilitation Medicine increased substantially probably because referring physicians were aware of this new treatment through various presentations, and the published repeated single case experimental design (de Jong et al., 2005a). By the time the RCT started, a substantial part of CRPS-patients living in the catchment area of our hospital might have been successfully treated already, which reduced the number of potential participants. Second, for the inclusion criteria of the repeated single case experimental study (de Jong et al., 2005a) and the RCT, different measurements were used to evaluate the presence of pain-related fear. In the RCT we used the mean PHODA-score; for the repeated single case experimental study the Tampa Scale for Kinesiophobia was used. When administered as originally described, the PHODA measures perceived harmfulness of specific activities, whereas the TSK measures a more general fear of movement, not specifically relating to certain movements or activities. Use of the PHODA is directly related to the content 
of exposure in vivo treatment; whereas the TSK only provides a global indication that a patient believes that moving causes bodily harm. Probably, using the TSK instead of PHODA would have resulted in a larger number of patients suitable for inclusion. Third, it also seemed that a treatment aimed at functional improvement, such as exposure in vivo, did not attract all patients with CRPS-I. Some restrict their treatment goals to pain reduction, or the total removal of pain. This is also reflected in the number of patients who declined to participate in the trial $(N=13)$.

Nevertheless, we found statistically significant differences in pre-post changes, as well as clinically relevant changes in the majority of patients on all outcome measures up till 6 months after treatment, even though we had to adjust our statistical analyses according to the lower inclusion rate. This relates to the question whether we complied with the gold standard of RCTs in rehabilitation and psychology research. Group designs are still professed to be superior because they minimize the major validity threats to drawing scientifically valid inferences from the results (Shadish, Cook, \& Campbell, 2002). Single-Case Experimental Designs (SCEDs) provide a rigorous, and methodologically sound alternative method for evaluation (e.g., Barlow, Nock, \& Hersen, 2008; Horner et al., 2005; Kazdin, 2010; Kratochwill \& Levin, 2010; Shadish et al., 2002). Especially in less prevalent conditions such as CRPS-I, and for research where the focus is on the process of change of the particular treatment, SCEDs may be preferable (Onghena \& Edgington, 1994, 2005). These designs include the repeated observation of outcomes (dependent variables) over time under different levels of at least one intervention (manipulated independent variable). In contrast to an experimental group design, in which one group is compared to another, participants in a SCED serve as their own control for the purpose of comparison (within-subject comparisons). SCEDs typically compare at least two experimental time periods, known as phases. Typically, these phase designs include the collection of a representative baseline phase, to serve as a comparison with subsequent phases. Randomization of the start of the second phase, improves methodological rigor and experimentally controls internal validity (Kratochwill \& Levin, 2010). External validity can be enhanced by successful replications in subsequent participants (Horner et al., 2005).

In the following paragraphs we will focus on a number of methodological issues that we encountered throughout the RCT. We will discuss the use of the PHODA as an instrument for the inclusion of participants for exposure in vivo treatment, we will reflect on the reliable change index, and interrogate the use of pain-contingent physical therapy as control treatment. 


\section{Inclusion for exposure treatment based on the PHODA}

Some patients were included by the physiatrist, since they reported increased disability levels that were disproportionate to the biomedical findings, if any. Nevertheless, some of these patients were later excluded based on low PHODA scores $(N=9)$, suggestive of low pain-related fear. These patients reported: "I'm not afraid that moving the affected extremity can be harmful, but I'm simply not able to do that". Since we hypothesized that the expectation of "being unable" could be challenged (patients might not yet recognize that their inability was not absolute), we offered exposure in vivo to these patients outside the trial. Our assumption was indeed confirmed; the expectancy that they were unable to move their affected extremity could be violated during the exposure treatment. This raises some questions about using the PHODA to include patients for exposure treatment. The PHODA was specifically designed to measure the perceived harmfulness (US) of movement and activities (CSS) (Leeuw et al., 2007) and hence could be used to create a fear hierarchy. Some possible adaptations to optimize the use of the PHODA will be discussed here.

First, with the current emphasis on inhibitory learning instead of fear reduction, and the abandonment of following a fear-hierarchy (Kircanski, Mortazavi, et al., 2012; Lang \& Craske, 2000), a score for perceived harmfulness is less interesting than knowing the specific expectations a patient has about performing a specific activity. Patients might have other negative outcome expectancies than harm or injury that would still justify the choice for an exposure treatment. For example, negative expectations, such as "If I lift a heavy bag like that, then my hand will swell and I won't be able to do anything for the rest of the day" can typically be challenged. PHODA could be used as an instrument to map a broad range of expected negative consequences (USS). It could be claimed that when these US-expectations are overestimations of threat, the patient might benefit from exposure in vivo treatment, since violations of these irrational expectations may lead to improved functioning. Second, therapists might take into account that pain can serve as an occasion setter (de Gier, Peters, \& Vlaeyen, 2003) for the occurrence of the US: only in the presence of pain, activities are thought to have negative consequences. Whereas PHODA is only developed to measure perceived harmfulness if the patient was to perform the activity "right now", it could easily be extended to gather information about occasion setters as well. Exposure might only be relevant when the occasion setter is present. This implicates that maximizing chances for the presence of pain as occasion setter, for example ceasing medication, is likely to lead to more effective expectancy violation during exposure. Third, patients often spontaneously reflect on the particular way they 
perform the activity as shown on the PHODA pictures, and this can be helpful to detect safety-behaviors and its underlying motives. Moving images would even be more valid in this respect. Video clips of 3D animated characters (avatars) performing activities that typically raise fear in patients with CLBP have been developed and found to be realistic and acceptable (Springer, George, \& Robinson, 2016). The clips in that study were only used to create a fear-hierarchy, so whether video clips increase insight in motives underlying a patient's behavior warrants future research. Fourth, a Behavioral Avoidance Task, such as the BAT-BACK (Holzapfel, Riecke, Rief, Schneider, \& Glombiewski, 2016) could be added to existing self-report measures. In the BAT-BACK, patients are observed during the actual performance of movements (repetitions of bending forward, lift a crate and rotate), their performance is scored, and a total score classifies their performance as "regular", "using safety behavior" or "avoidance". For other chronic pain diagnoses, similar behavioral tasks could be designed to add a behavioral measure to the existing self-reports.

\section{Reliable Change Index}

In order to estimate the clinical significance of the outcomes of the trial, we calculated the Reliable Change Index (RCI) (Morley \& Dowzer, 2014). Due to unknown cut-off scores of the questionnaires used for our main outcome disability (RASQ (Oerlemans, Cup, DeBoo, Goris, \& Oostendorp, 2000) and WAQ (Roorda, Roebroeck, Lankhorst, van Tilburg, \& Bouter, 1996; Roorda et al., 2005)), we were unable to establish whether improvement was "clinically" significant. Nevertheless, we wanted to move beyond statistical significance and large effect sizes as indicators of effectiveness, and we choose the RCl (Morley \& Dowzer, 2014), in order to calculate for each outcome variable whether patients have "improved", "remained unchanged" or "deteriorated", while taking into account the reliability of that particular outcome measure. Still, this does not reflect what would be an acceptable outcome for patients. An elegant way of establishing this is described by Thorne and Morley (Thorne \& Morley, 2009): they asked patients at the start of treatment to complete a questionnaire on their current situation, and the same questionnaire for how they would score at the end of a successful treatment. Patients indicated a median change between 44 and $75 \%$ as acceptable. In our RCT, all EXP patients except one fulfilled this criterion for lower extremity disability (Walking Ability Questionnaire), 7 out of 14 for upper extremity disability (Radboud Skills Questionnaire), and 11 out of 19 on the Neuropathic Pain Scale (NPS). So, despite the convincing results of our RCT, this indicates that from the patient's perspective there still is room for improvement. 


\section{Control treatment}

CRPS-I has been a diagnosis under debate for many years, reflected in different sets of criteria to diagnose CRPS-I (Harden \& Bruehl, 2005; Mersky \& Bogduk, 1994) and a variety of assumed underlying mechanisms (Schwartzman \& Popescu, 2002; TurnerStokes, 2002). Up to date, some authors criticize the diagnosis of CRPS-I (Borchers \& Gershwin, 2017) or even doubt that it is an illness or mere a syndrome of disuse (Frölke, van Dongen, \& van de Meent, 2015). The controversies can be illustrated by two topical reviews from 2002, taking a completely different perspective on RSD (Reflex Sympathetic Dystrophy, one of the former names of Complex Regional Pain Syndrome). One review states "RSD is caused by an injury to a specific nerve or the $\mathrm{C}$ - and A-delta fibers that innervate the involved tissue. It is a progressive illness that spreads with time and may encompass the entire body. There is no psychological disposition to the problem, but all patients are severely depressed because of the constant pain, lack of sleep, and complete disruption of their lifestyle" (Schwartzman \& Popescu, 2002) (page 165). The other review states "RSD is a complex and poorlyunderstood condition..., ... rarely, it affects more than one limb, ...neurological symptoms typically do not conform to any particular pattern of nerve damage, ...emphasize the complex interaction of somatic, psychological and behavioral factors" (TurnerStokes, 2002) (page 939). These different opinions on CRPS have led to different treatment approaches, which were subsequently reflected in former national treatment guidelines. In the Netherlands, a pain-contingent approach was advocated in the acute phase, mainly based on the results of the studies by Oerlemans (Oerlemans, Oostendorp, de Boo, \& Goris, 1999; Oerlemans, Oostendorp, et al., 2000). Strict recommendation to deal with increased pain is provided for this phase: "high treatment intensity resulting in an increased pain-experience should be avoided; only increases in pain that last no longer than 1 or 2 hours after treatment are considered nonharmful“ (CBO Kwaliteitsinstituut voor de Gezondheidszorg, 2009) (page 83). In a later phase, when our trial had already started, a time-contingent treatment approach was recommended (CBO Kwaliteitsinstituut voor de Gezondheidszorg, 2009).

It seems that medical and research professionals in the Netherlands (contrasting e.g. the United States and Australia) were more persistent in conceiving CRPS-I as a biomedical problem for which the underlying pathophysiological mechanism should be studied, explained and solved. This led to a pain-contingent approach with a focus on pain-relief, not only from medication; pain relief or pain control was also aimed for in physical or occupational therapy (Oerlemans, Oostendorp, et al., 2000). As in other countries, a non-pain contingent approach for CRPS has been applied for several years, the pain-contingent treatment we choose as a control treatment for the RCT seems somewhat outdated (Moseley, 2016). Although also in the 
Netherlands, this purely medical approach is changing to a broader perspective, the pain-contingent treatment is still prevailing in the Netherlands. The research group on PEPT even considered that it was necessary to defend that their approach was "safe" (van de Meent et al., 2011), which adequately reflects the public opinion that we encountered with our application of exposure in vivo as well.

After our first SCED (single-case experimental design) on exposure in vivo in CRPS-I in 2005 (de Jong et al., 2005a), another treatment not adhering to this pain-contingent approach arose. Pain Exposure Physical Therapy (PEPT) was inspired by a forced-use (e.g. restraint of the non-CRPS limb, to force the use of the affected limb (Taub et al., 1993), hands-on physical therapy program that some Dutch patients underwent abroad (Ek et al., 2009). PEPT consists of a progressive-loading exercise program and sensory stimulation (touching, stroking, moving the limb) beyond the patient pain limits (Barnhoorn et al., 2012), is delivered by physical therapists and aims to decrease pain-avoidance behavior without the use of specific CRPS-1 medication or analgesics. The safety of the PEPT protocol was assessed in a group of 20 patients, and showed positive results for pain intensity, disability and kinesiophobia (van de Meent et al., 2011). A Randomized Controlled Trial compared PEPT with pain-contingent physical therapy and found that PEPT was only more effective in improving active range of motion (Barnhoorn et al., 2015). These authors performed not only an intention to treat analysis, but also a per protocol analysis, and in the latter PEPT showed larger and significant between group effects on disability, experienced pain, impairment and health-related quality of life.

Comparing the results of our RCT (den Hollander et al., 2016) and the PEPT-RCT (Barnhoorn et al., 2015) at follow up (which was 6 months after posttreatment measurement in our study, and 9 months after inclusion for PEPT), our EXP group reported a reduction in experienced pain of $47 \%$ (from 5.48 to 2.88 on the 0-10 neuropathic pain scale. In the PEPT study, patients report a pain-reduction of $43 \%$ (from 6.18 to 3.52) on a 0-10 Visual Analogue Scale. In the PEPT study, the Pain Disability Scale was used to measure disability and patients improved with $59 \%$. We used separate measures for upper- and lower extremity disability. Norm scores are not available for these questionnaires, but we calculated percentages of improvement between baseline and follow-up, as the authors of the PEPT study did for their outcomes. Patients with lower level extremity disability improved with $77 \%$ on the Walking Ability Scale; patients with upper activity disability improved $40 \%$ on the Radboud Skills Questionnaire. On health-related quality of life, it is unclear if the PEPT study uses the Physical Component Subscale, or a mean score for the aforementioned scale and the Mental Component Scale. The authors report an improvement in quality of life of $52 \%$. We found an increase of $65 \%$ on the Physical Component Scale, and a mean overall improvement on both scales of $35 \%$. In the 
mediation analysis of PEPT (Barnhoorn et al., 2014), the authors describe that the scores on the Pain Catastrophizing Scale were 64\% lower at follow up (from 22.81 to 8.24), whereas their safety-study reported a decrease in pain catastrophizing of only $18 \%$. In our study, we found a reduction of $52 \%$ (from 17.15 to 8.11 ) on the same scale.

Concluding, the percentages of improvement on pain and disability are comparable for EXP and PEPT. Although we both used the IASP-criteria for CRPS-I, inclusion criteria differed for the duration of CRPS-I (time since event was 7.2 (SD 4.1) months for PEPT, with a maximum of 24 months after inciting event at inclusion, and 5.2 (SD 5.4) years for exposure in vivo, no maximum) and the presence of pain-related fear (only required for inclusion in the exposure in vivo trail). From the duration of complaints, it seems that we included a group of patients with more chronic CRPS-I, and in this group it is more unlikely that spontaneous recovery occurred (Bean, Johnson, Heiss-Dunlop, \& Kydd, 2016), and patients are more likely to have developed secondary problems (Bean, Johnson, \& Kydd, 2014). The current studies on PEPT do not answer the question if PEPT is also successful in CRPS-I patients who have had complaints for several years. It would be interesting to directly compare exposure in vivo and PEPT in patients with CRPS-I in a future RCT, to evaluate both treatments on the same outcome measures. Furthermore, it should be assessed which ingredients are necessary to achieve changes in fear, disability and quality of life.

PEPT consists of fewer sessions than EXP and could be conceived as exposure as well, albeit without the explicit expectancy violation. Inclusion of the PEPT studies was based on a diagnosis of CRPS-I, and the first assessment had to be within 3 to 24 months after the initial injury. Neither the RCT, nor the other two studies based inclusion on the presence of pain-related fear (Ek et al., 2009; van de Meent et al., 2011). Early publications describe that PEPT aims to decrease kinesiophobia, pain behavior and learned non-use (Barnhoorn et al., 2012), but in a later mediation analysis the same authors conclude that treatment does not need to exclusively focus on painrelated fear to be successful in reducing CRPS-I-related disability (Barnhoorn et al., 2014). However, their analyses do not seem to justify these conclusions; the authors performed an overall mediation analysis, assessing only that the difference in disability and pain between PEPT and control treatment is not mediated by painrelated fear. A mediation analysis per treatment would be necessary to evaluate if the change in disability or pain was mediated by pain-related fear (Smeets, den Hollander, \& de Jong, 2015). With the current emphasis on inhibitory learning, the fact that PEPT is a "just do it" treatment would make it interesting to compare the rate of patients experiencing relapse after each treatment in the long run.

Strikingly, recent research on CRPS seems to have contributed to a more optimistic conception of the prognosis of CRPS-I (Birklein, O'Neill, \& Schlereth, 2015). For a long time, CRPS-I was seen as a chronic condition that would most likely 
deteriorate over time (Schwartzman, Erwin, \& Alexander, 2009). Patients were advised to be very careful and not to provoke pain. Therefore they missed out on relevant daily life activities, adding disability and suffering to their already existing painproblem. Treatments reducing disability are important additions to the current options for patients with CRPS-I, which are mainly pharmacological, and for which the evidence for its effectiveness is at best weak (Bussa, Guttilla, Lucia, Mascaro, \& Rinaldi, 2015). The approach changed from putting all effort in pain-reduction, to a more functional approach from the moment of diagnosis. The current guidelines for CRPS emphasize to focus on functional restoration; only when patients cannot begin or fail to progress, pharmacological options can be added (Harden et al., 2013) (page 187). Hopefully, these recommendations will prevent newly diagnosed patients from developing severe disability and associated levels of suffering. The resumption of normal life activities might contribute to reduced pain in the long run.

From a theoretical point of view, the choice for exposure in patients who report to be "unable" (to perform a specific activity) might be questionable, since problems with motor control have been found in CRPS-I (Schilder et al., 2012) and this in the absence of an immobilization or a functional movement disorder (van velzen et al., 2015). In other words, there is no guarantee that if the patients' expectation is "being unable", this "US" will not occur. However, based on our clinical experience, most of these patients experienced that they were able to perform activities anyway, although the quality of movement varied widely. This requires future research on the interplay among fear, low motor performance efficacy, and problems with motorcontrol in CRPS-I.

We showed that exposure in vivo is a powerful intervention to reduce disability in CRPS-I. The majority of patients reported a reliable change in disability, and a substantial part of participants experienced a decrease in pain as well. Given the size of the effects, the results warrant implementation in clinical practice. Nevertheless, there is always room for improvement. On disability, the Leeds Reliable Change Indicator shows that although all patients receiving EXP improved, some experienced no disability anymore (a 0-score on the horizontal axis). Even more interesting, and although it is not a specific goal of exposure to reduce the pain experience, it is notable that $40 \%$ of patients also reported a reliable reduction in pain intensity (one patient scored 0 after treatment). Studying the differences between patients who experienced success on a specific outcome (for example on baseline-variables) and those who report no or a smaller success, may help us to identify predictors of treatment success for specific outcomes. Such information could be used to give patients a perspective of what might be achieved with treatment on a specific outcome, for example disability or reduction of the pain experience. It would also be interesting to study if a residual amount of disability and pain 
(after exposure in vivo) is mediated by other factors than pain-related fear, as an additional treatment aiming at this mediator could help to further reduce disability and pain. A problem with studying prognostic factors and mediators is that a large number of participants is needed to identify these factors. Another option to study in the future would be broadened inclusion criteria: does exposure in vivo only help to reduce disability in CRPS-I patients with substantial pain-related fear, or could inclusion be extended to patients with lower levels of pain-related fear?

\section{Question 5: Is exposure in vivo cost-effective in CRPS-I patients with pain-related fear, compared to pain-contingent physical therapy?}

CRPS-I not only puts a tremendous burden on the individual patient in being such a painful and disabling condition, it also comes with high costs for society as well. In chapter VI, we evaluated if exposure in vivo would also be preferred over paincontingent treatment from a health-economic and societal perspective. We measured these different cost-aspects in relation to their gain on measures of physical health and quality of life during participation in the RCT up to six months after treatment with a weekly cost-diary.

Since exposure in vivo successfully reduced disability in the RCT, we hypothesized that patients would reduce their health-care use, help from relatives, and productivity loss, resulting in a reduction of costs in the long run. Due to the multidisciplinary character of EXP, being delivered by a physical or occupational therapist together with a psychologist, initial treatment costs are higher for EXP. But importantly, six months after treatment, all cost-aspects favored EXP, with a significant difference between TAU and EXP for health-care costs. Patients after EXP use significantly less medication and needed significantly less hours of informal care. Bootstrap replications revealed that combining costs and effects, exposure was more effective against lower costs compared to treatment as usual.

Depending on the amount of money society is willing to pay for an additional life-year in good health (QALY), the probability of EXP being cost-effective varies between 95\% (for the lowest threshold of 16000 euro) and 98\% (for the highest threshold of 80000 euro). It seems reasonable to implement exposure for CRPS-I patients with pain-related fear, since our earlier study on clinical effectiveness is further corroborated by findings on its cost-effectiveness using a societal perspective. Of course, the results are based on a small group of patients and need replication in future studies. 
Our findings are partly in line with Goossens et al. (2015), who studied whether exposure in vivo was more cost-effective than graded activity in patients with Chronic Low Back Pain (CLBP). In that study exposure only showed a tendency to reduce disability, increase quality adjusted life years and decrease costs compared to graded activity (Goossens et al., 2015). The larger differences in costs between exposure and the respective control condition in both studies might be explained by the differences between the two control treatments: graded activity and pain-contingent physical therapy. The control treatment in our study aimed to reduce pain and stems from a biomedical explanation of CRPS-I. The control treatment in Goossens et al, 2015 (Graded Activity) is a behavioral treatment also primarily aimed at reducing disability and not pain. Therefore it is not surprising that the higher contrast between conditions in our study also lead to better cost-effectiveness. Nevertheless, in both studies the effects and costs, as well as the incremental cost-effectiveness ratios are in favor of the exposure intervention.

The current evidence suggests that in order to reduce both the impact as well as the costs of CRPS-I, treatment aimed to restore function, such as exposure in vivo, should be offered as early as possible. In CRPS-I, a range of possible medication is usually tried to accomplish a reduction in experienced pain. Since there is no gold standard-medication that works for everyone, it takes time to try several options. In many cases, only when it becomes clear that pain-reduction will not be accomplished, patients are referred to a rehabilitation department to reduce disability. The current results imply that, specifically for the group of patients with elevated levels of pain-related fear, it might be worthwhile to offer exposure in vivo much earlier, preferably in their first year of work-absenteeism, instead of pain-reducing treatments, since exposure in vivo seems to target a mechanism reversing CRPS-I related disability and in some also pain reduction. Complications of CRPS-I such as dystonia and contractures might be prevented if an activating treatment is offered in an earlier stage.

Since in the majority of patients with CRPS-I, a clear biomedical explanation for the observed disability is absent permanently, it could be argued that all effort should be focused on offering patients treatment that reduces disability and prevent chronicity in an early phase. Exposure has shown to be effective in increasing functional levels, and when offered when a patient still has a job, stimulates to stay at work and will result in an enormous decrease of CRPS-I related health-care and productivity loss costs. Not only from the viewpoint of the patient, also from a health care perspective and a societal viewpoint exposure seems to give value for money. 


\section{Directions for future research to improve exposure in vivo for pain-related fear}

to maximize treatment results in chronic pain patients with pain-related fear and disability, the implementation various techniques that have already shown to be promising in related areas of research seems timely. Specifically, two domains are of interest: the broader area of exposure for anxiety disorders, and the broader area of chronic pain:

1. Implementing techniques that have shown to be effective in fear extinction learning or strengthening inhibitory learning in other anxiety problems.

For example, adding techniques such as counterconditioning or pharmacological enhancers of extinction learning that can be integrated or delivered parallel to exposure treatment. These additional techniques might help to chance the affective valence of the CS or help to make the US less threatening.

2. Implementing techniques that have shown to be promising in chronic pain patients in general, such as resilience and acceptance strategies.

Adding these techniques before or after exposure, might extend effects, or tap in underlying mechanisms that exposure does not specifically address. Relapse in patients with chronic pain and pain-related fear after exposure might not only be in a return of fear, but also in their ongoing goal-conflict between controlling pain and controlling life. It is known that optimism may foster the priority to valued life goals (Hanssen, Peters, Vlaeyen, Meevissen, \& Vancleef, 2013). Furthermore, living with chronic pain may confront patients with other challenges than fear and disability, such as how to accept pain. Treatments aimed at resilience and acceptance can be taken into account for a serial approach after exposure.

If moderators and mediators of treatment success could be identified, this could probably help to compose the optimal mix of treatment ingredients to maximize the patients' chances for a long term positive effect on reducing disability, fear and pain.

\section{Counterconditioning}

After successful exposure treatment, although patients do no longer avoid activities because they corrected their expectancy that activities are harmful, patients might still dislike certain activities because of their previous negative associations. In other words, the "affective valence" of the CS is still negative. Whereas exposure treatment is based on extinction; counterconditioning is an alternative fear reducing 
technique that changes this affective valence, by pairing the (disliked) CS with a US of opposing (in this case: positive) valence (De Houwer, Thomas, \& Baeyens, 2001; Hofmann, De Houwer, Perugini, Baeyens, \& Crombez, 2010). In the area of (chronic) pain, counterconditioning has not been extensively studied yet. One study has examined the effects of counterconditioning, in combination with other strategies such as exposure and distraction to reduce fear expression and behavior complicating medical procedures involving needles (Slifer et al., 2011). The combination of the different techniques led to less behavioral distress and improved cooperation with medical procedures in pediatric patients with intellectual and developmental disabilities. Since counterconditioning was part of a multidimensional intervention, that study does not provide sufficient evidence whether counterconditioning itself was effective in changing the affective valence of stimuli involved in the medical procedure. In another, experimental setting, counterconditioning and exposure were compared using a proprioceptive fear conditioning paradigm (Meulders, Karsdorp, Claes, \& Vlaeyen, 2015). During acquisition, two joystick movements (CS+'s) were followed by pain (US), and two other (CS-) movements with the same joystick were not. During fear reduction, one CS + was extinguished, and the other CS + remained reinforced for the Extinction condition. In the Counterconditioning condition, one CS + was followed by a monetary reward-US, and another CS + was followed by both USs (pain and reward US). Counterconditioning rendered comparable effects as extinction in the reduction of pain-related fear, and both procedures changed the affective valence of the CS. Adding a reward-US to a painful movement did not influence fear, nor pain intensity and unpleasantness of pain. Since the authors suggest that methods explicitly focusing on altering the affective valence of feared movements may improve the long-term effectiveness of fear reduction and prevent relapse, clinical research on the effects of counterconditioning is warranted. Focus group interviews after exposure in vivo delivered as a group-treatment to patients with back pain (van Melick, den Hollander, Satink, Andresen, \& Smeets) (manuscript in preparation), revealed that in some patients, counterconditioning is a process that takes place naturally during exposure: patients reported that the experience that there are no negative consequences from performing activities, and being able to perform those activities independently again, can be positive in itself and make activities "likeable" again. Counterconditioning could be a relevant addition for patients not reporting this effect, and especially for patients who do not experience pain-reduction during or after exposure in vivo, since it could help them in the long run to keep on active despite pain. It would be worthwhile to document this effect during and after exposure treatment, specifically how the pain-experience interacts with the affective valence of activities. This might be done using a repeated single case experimental design (SCED). SCEDs can be used to evaluate the effect 
of an intervention for a single subject by comparing the repeated measurements of a dependent variable under at least two manipulated conditions, typically a baseline and a treatment condition (Heyvaert et al., 2017).

\section{Pharmacological enhancers}

Another direction to improve the effects of exposure therapy is the addition of pharmacological enhancers. Basic research across a variety of anxiety disorders found that pharmacological agents might enhance the results of exposure treatment. The pharmacological enhancer in itself has no effect, but is administered as a supplement to exposure treatment. The enhancer is expected to positively affect outcomes, since those agents enhance inhibitory learning and memory processes during exposure. And although it is not yet fully understood how both processes contribute to the effects of exposure treatment (Kindt \& Soeter, 2013); both extinction and reconsolidation are supposed to benefit (Debiec \& Ledoux, 2004; Walker, Ressler, Lu, \& Davis, 2002). As stated before, during extinction a conditioned stimulus (CS; i.e., activities) is repeatedly presented in absence of the unconditioned stimulus (US; i.e., the catastrophe) resulting in the learning of a new association (CS-no US). Nevertheless, the original fear-memory (CS-US) stays intact besides this newly learned meaning (Bouton, 1993). Reconsolidation is different in that it actually changes the original fear memory. When a consolidated fear-memory (CS-US) is retrieved from memory, for example during an exposure treatment session, it is thought to be instable and sensible to permanent changes. The enhancing effects of several pharmacological agents have been studied in a variety of anxiety disorders, but so far, no studies have been conducted in exposure treatment for pain-related fear.

Examples of pharmacological enhancers are propranolol (interferes with memory-reconsolidation), hydrocortisones (enhanced consolidation of extinction learning, and inhibition of emotional memory retrieval), oxytocin (hypothesized to positively affect the therapeutic alliance, which could help to prevent early dropout) and D-cycloserine (hypothesized to facilitate memory consolidation of new learning that takes place during extinction (Richardson, Ledgerwood, \& Cranney, 2004). D-cycloserine seems the most extensively studied enhancer, but it is still under debate if it really strengthens the overall effect of exposure treatment, and for all patients (Otto et al., 2016). D-cycloserine seems to accelerate treatment effects in early sessions, the memory augmentation effect only seems present for sessions effective in reducing fear (Otto et al., 2016). Furthermore, it might be helpful for the group of patients who would otherwise not experience success of exposure treatment (Otto et al., 2016). A recent systematic review shows that a small augmentation 
effect is associated with D-cycloserine on exposure treatment (Mataix-Cols et al., 2017). More research on this topic is warranted in anxiety disorders in general, and depending on the outcomes, it might be worthwhile to study possible effects for exposure in pain-related fear.

A difference between pain-related fear and other anxiety disorders (for example panic disorder) could be that the CS-US memory retrieval is gradually learned, whereas in many anxiety disorders patients might recall a specific traumatic event (for example in PTSD or panic disorder). Before taking the step of administering a pharmacological enhancer, it would be important to find out if adverse events are reported about the interaction with concurrent pain-medication. An even more promising (since it would be very easy to integrate in clinical treatment), but less explored possibility is that just remembering the CS just before (Agren et al., 2012; Schiller et al., 2010) or even just after (Baker, McNally, \& Richardson, 2013) exposure, could also open the reconsolidation-window and modify the original CS-US memory. Telling a patient $30 \mathrm{~min}$. in advance of the session to which CSs he will be exposed during the session could impair the original fear-memory, although more research on this subject is absolutely warranted.

\section{Strengthening factors that might protect against chronic pain (resilience factors)}

So far, the emphasis has been on factors that negatively influence problems of fear and disability. Recently, mechanisms related to resilience are distinguished from mechanism related to risk and vulnerability. Several studies have shown that a subgroup of patients keeps on functioning well despite high intensity pain (Hauser et al., 2014; Reid et al., 2011). A cohort study in Scotland identified a group of "resilient" chronic pain patients, characterized by low disability despite high pain, and this group was found to have a significant reduced risk of death over the subsequent 10 years (Elliott, Burton, \& Hannaford, 2014). Resilience is hard to define, but is describing more than hardness or coping; it implies "effective functioning despite exposure to stressful circumstances and/or internal distress" (Sturgeon \& Zautra, 2010) and is also defined as "the ability to maintain positive emotional and physical functioning despite physical or psychological adversity" (Slepian, Ankawi, Himawan, \& France, 2016). Resilient individuals do not only differ from non-resilient individuals on risk factors, but also on positive attributes, suggesting that resilience and risk are not "two sides of the same coin" (Goubert \& Trompetter, 2017). Since resilience and risk factors are distinct entities, scoring high on one does not exclude scoring high on the other (Alschuler, Kratz, \& Ehde, 2016). This implicates that not only negative 
outcomes, such as disability and pain-related fear need to be taken into account in research and treatment, but also positive outcomes. Psychological flexibility, positive affect and basic psychological needs satisfaction are possible important resilience mechanisms in chronic pain (Goubert \& Trompetter, 2017).

A reliable and valid questionnaire, that excludes items related to functional disability, is the Resilience Scale (Ruiz-Parraga, Lopez-Martinez, \& Gomez-Perez, 2012). Consideration of resiliency factors might help to understand how individuals can live with chronic pain without concurrently experiencing disability. Positive activity interventions have been developed to increase resilience (for an overview, see Hassett \& Finan (Hassett \& Finan, 2016)). These interventions could be delivered stand-alone or as an addition to a regular intervention. One of the advantages is that they don't require a health-professional to deliver the intervention, since they can be delivered online. If such interventions would increase the positive effects of current treatments for pain-related disability, as well as the optimal moment for delivery when combined with exposure in vivo, warrants further research.

\section{Acceptance strategies}

As already stated in Chapter 2 (topical review), if a patient holds unrealistic CS-US expectancies that can be disconfirmed, this opportunity should not be missed and exposure in vivo should be the treatment of choice. It is important to critically evaluate, together with the patient, which mechanism is mainly responsible for the experienced disability. When disability is fueled by unrealistic expectancies about the consequences of performing activities, exposure helps to correct these expectancies. We know that in a substantial group of patients, pain will decrease as a result of exposure as well. For the group where this does not happen, pain can still be experienced as a "punishment" upon being active. To this group, operant principles might be explained and patients might use the principles of graded activity. In other patients, pain can still be interfering with life, especially when people keep on ruminating about pain and its future consequences. Acceptance and commitment therapy (ACT) and mindfulness-based approaches could be helpful in this group of patients. ACT is rooted in learning theory as well as in laboratory studies of basic behavioral processes, and extends this tradition with laboratory research into processes of language and cognition (McCracken \& Vowles, 2014). ACT is based on the relational frame theory (Hayes, Barnes-Holmes, \& Roche, 2001) and combines acceptance strategies and mindfulness methods with activation and behavior change methods (McCracken \& Vowles, 2014). ACT focuses on psychological flexibility, the capacity to continue with or change behavior, guided by one's goals, in a context 
of interacting cognitive and direct non-cognitive influences (McCracken \& Vowles, 2014). A systematic review (Hughes, Clark, Colclough, Dale, \& McMillan, 2017) shows that acceptance and commitment therapy is successful in increasing cognitive flexibility and pain acceptance, its intended processes (medium to large effect sizes), and to a lesser extent in functioning, anxiety and depression (small to medium effect sizes). ACT did not reduce pain intensity or improve quality of life. Another systematic review concludes that effect sizes ranged from small (on all outcome measures except anxiety and pain interference) to moderate (on anxiety and pain interference) at post-treatment, and from small (on pain intensity and disability) to large (on pain interference) at follow-up. ACT showed significantly higher effects on depression and anxiety, when compared to other acceptance-based techniques such as Mindfulness Based Stress Reduction and Mindfulness Based Cognitive Therapy (Veehof, Trompetter, Bohlmeijer, \& Schreurs, 2016). Defining mindfulness is problematic (McCracken \& Vowles, 2014; Van Dam et al., 2017), but one of the most frequently used definitions states that mindfulness is a moment-to-moment awareness, cultivated by paying attention in a specific way, in the present moment as non-reactively, nonjudgmentally and open-heartedly as possible (Kabat-Zinn, 2011).

ACT and mindfulness have gained considerable attention in the last decade, resulting in what some authors even consider a "hype" (Van Dam et al., 2017). Despite the general adoption or embracement of acceptance- and mindfulness based approaches in the media, researchers in the field acknowledge that the evidence is not yet inconclusive (McCracken \& Vowles, 2014; Van Dam et al., 2017). ACT is rarely compared to active treatments (Hughes et al., 2017) and its effectiveness is comparable with other cognitive behavioral treatments (Veehof et al., 2016). A critical review about mindfulness addresses concerns about the rigor of methods used in mindfulness research, and the accuracy of news publicity. The authors argue for more precisely focused terminology and advocate preregistered experiments and openscience replications. Regarding generalizability to clinical practice, they advocate more uniformity and experimental studies to provide warnings, for example about adverse events and the value of neuroimaging findings (Van Dam et al., 2017).

Concluding, the effective components and underlying mechanisms of ACT and mindfulness need further research. A serial deliverance of cognitive behavioral treatments, fine-tuned to the mechanism that at that specific moment causes highest suffering in the patient, would be a promising research avenue to go. Relating to exposure in pain-related fear, it would be interesting to study if a combination of treatments (for example exposure in vivo with ACT) would enhance progression on disability, fear or pain, or positive outcomes such as resilience. Again, single case experimental designs could help to disentangle what works for whom, and in which order. 


\section{Conclusion}

The studies in this thesis convincingly show that a learning theory perspective on pain-related fear helps to understand and treat disability in patients with chronic pain. We provided a theoretical framework and an overview of the literature on painrelated fear and its treatment in a topical review. An experimental study investigated the effect of threatening information on the acquisition and extinction of fear of movement related pain, and the return of fear. The main part of this thesis further explored the application of exposure in vivo, specifically in Complex Regional Pain Syndrome Type I, a chronic pain syndrome for which no medical cure is currently available. We specifically studied the generalization of exposure in vivo, its effectiveness and cost-effectiveness in CRPS-I.

The experimental study, using the Voluntary Joystick Movement Paradigm to assess the effect of a verbal threat manipulation on acquisition, extinction and reinstatement showed a return of fear after reinstatement. This effect did not depend on the threat level of the information given. We failed to find differential effects for our threat manipulation on acquisition and extinction.

We showed that exposure in vivo is an effective as well as cost-effective treatment to reduce disability in a CRPS-I, and that the results generalize beyond the activities performed during the treatment sessions. After exposure in vivo, the vast majority of patients experienced a reliable change in disability up to six months after treatment, and all patients experienced a reliably decreased perceived harmfulness of activities. Despite that patients resume daily life activities, including work and sports; no one experienced increased pain in the long run. A substantial part of participants even reports a reliable decrease in pain, and this was also reflected in the decreased use of pain-medication after exposure in vivo. Exposure in vivo enables CRPS-I patients to decrease their dependency upon relatives and professional care givers. This is not only a benefit for patients and their family members, but also for society since it reduces the costs for CRPS-I. Another promising finding was that the costs for productivity loss were lower after exposure in vivo compared to a pain-contingent treatment. We were the first to show generalization from exposure in vivo as a treatment (in contrast to a single exposure to a specific movement in an experimental setting), independent if treatment emphasized maximal variation in activities, or maximal variation in physical contexts. Concluding, based on its effectiveness compared to usual care, as well as on its cost-effectiveness and the fact that we showed generalization of treatment, exposure in vivo warrants further implementation in clinical practice for patients with CRPS-I and pain-related fear, since it has positive effects for the patient, health-care resources and society. 
In this discussion, I raised several issues that could improve exposure in vivo for pain-related fear even further. Using techniques that could optimize inhibitory learning seems promising, since their effectiveness has been shown across several anxiety disorders. I highlighted some of the techniques that could possibly be integrated in the current protocol of exposure in vivo in pain-related fear. Counterconditioning could help to change the affective valence of activities, and make it easier to comply to being active after treatment, because activities might become more "likeable" again through counterconditioning. Pharmacological enhancers might actually change CS-US associations in memory, although more research on this topic is warranted especially in pain-related fear where the effect has not been studied yet. Another technique, using multiple contexts during exposure in vivo, was shown to be transferable to patients with pain-related fear in our generalization study. A difficulty in pain-related fear is that chronic pain might be a challenge to struggle with, even after successful exposure, at least for a group of patients. Depending of the outcome of further research, additional techniques enhancing resilience, such as ACT, might help those patients to reduce the impact of the ongoing pain experience. 


\section{References}

Agren, T., Engman, J., Frick, A., Bjorkstrand, J., Larsson, E. M., Furmark, T., \& Fredrikson, M. (2012). Disruption of reconsolidation erases a fear memory trace in the human amygdala. Science, 337(6101), 1550-1552. doi:10.1126/science.1223006

Alschuler, K. N., Kratz, A. L., \& Ehde, D. M. (2016). Resilience and vulnerability in individuals with chronic pain and physical disability. Rehabil Psychol, 61(1), 7-18. doi:10.1037/rep0000055

Baker, K. D., McNally, G. P., \& Richardson, R. (2013). Memory retrieval before or after extinction reduces recovery of fear in adolescent rats. Learn Mem, 20(9), 467-473. doi:10.1101/lm.031989.113

Barnhoorn, K. J., Oostendorp, R. A., van Dongen, R. T., Klomp, F. P., Samwel, H., van der Wilt, G. J., ... Frolke, J. P. (2012). The effectiveness and cost evaluation of pain exposure physical therapy and conventional therapy in patients with complex regional pain syndrome type 1. Rationale and design of a randomized controlled trial. BMC Musculoskelet Disord, 13, 58. doi:10.1186/1471-2474-13-58

Barnhoorn, K. J., Staal, J. B., van Dongen, R. T., Frolke, J. P., Klomp, F. P., van de Meent, H., ... Nijhuis-van der Sanden, M. W. (2014). Are pain-related fears mediators for reducing disability and pain in patients with complex regional pain syndrome type 1? An explorative analysis on pain exposure physical therapy. PLoS One, 10(4), e0123008. doi:10.1371/journal.pone.0123008

Barnhoorn, K. J., van de Meent, H., van Dongen, R. T., Klomp, F. P., Groenewoud, H., Samwel, H., ... Staal, J. B. (2015). Pain exposure physical therapy (PEPT) compared to conventional treatment in complex regional pain syndrome type 1: a randomised controlled trial. BMJ Open, 5(12), e008283. doi:10.1136/ bmjopen-2015-008283

Bean, D. J., Johnson, M. H., Heiss-Dunlop, W., \& Kydd, R. R. (2016). Extent of recovery in the first 12 months of complex regional pain syndrome type-1: A prospective study. Eur J Pain, 20(6), 884-894. doi:10.1002/ejp.813

Bean, D. J., Johnson, M. H., \& Kydd, R. R. (2014). The outcome of complex regional pain syndrome type 1: a systematic review. J Pain, 15(7), 677-690. doi:10.1016/j.jpain.2014.01.500

Birklein, F., O’Neill, D., \& Schlereth, T. (2015). Complex regional pain syndrome: An optimistic perspective. Neurology, 84(1), 89-96. doi:10.1212/wnl.0000000000001095

Borchers, A. T., \& Gershwin, M. E. (2017). The clinical relevance of complex regional pain syndrome type I: The Emperor's New Clothes. Autoimmun Rev, 16(1), 22-33. doi:10.1016/j.autrev.2016.09.024

Bouton, M. E. (1993). Context, time, and memory retrieval in the interference paradigms of Pavlovian learning. Psychol Bull, 114(1), 80-99

Bussa, M., Guttilla, D., Lucia, M., Mascaro, A., \& Rinaldi, S. (2015). Complex regional pain syndrome type I: a comprehensive review. Acta Anaesthesiol Scand, 59(6), 685-697. doi:10.1111/aas.12489

CBO Kwaliteitsinstituut voor de Gezondheidszorg. (2009). Richtlijn Complex Regionaal Pijn Syndroom type 1. Utrecht

Claes, N., Crombez, G., Meulders, A., \& Vlaeyen, J. W. (2016). Between the Devil and the Deep Blue Sea: Avoidance-Avoidance Competition Increases Pain-Related Fear and Slows Decision-Making. J Pain, 17(4), 424-435. doi:10.1016/j.jpain.2015.12.005 
Craske, M., Kircanski, K., Zelikowsky, M., Mystkowski, J., Chowdhury, N., \& Baker, A. (2008). Optimizing inhibitory learning during exposure therapy. Behav Res Ther, 46(1), 5-27. doi:10.1016/j.brat.2007.10.003

Craske, M., Liao, B., Brown, L., \& Vervliet, B. (2012). Role of inhibition in exposure therapy. Journal of Experimental Psychopathology, 3(3), 322-345. doi:10.5127/jep.026511

Craske, M., Treanor, M., Conway, C., Zbozinek, T., \& Vervliet, B. (2014). Maximizing exposure therapy: an inhibitory learning approach. Behav Res Ther, 58, 10-23. doi:10.1016/j.brat.2014.04.006

Crombez, G., Eccleston, C., Van Damme, S., Vlaeyen, J., \& Karoly, P. (2012). Fear-avoidance model of chronic pain: the next generation. Clin J Pain, 28(6), 475-483. doi:10.1097/AJP.0b013e3182385392

Crombez, G., Eccleston, C., Vlaeyen, J., Vansteenwegen, D., Lysens, R., \& Eelen, P. (2002). Exposure to physical movements in low back pain patients: restricted effects of generalization. Health Psychol, 21(6), 573-578

de Gier, M., Peters, M. L., \& Vlaeyen, J. W. (2003). Fear of pain, physical performance, and attentional processes in patients with fibromyalgia. Pain, 104(1-2), 121-130

De Houwer, J., Thomas, S., \& Baeyens, F. (2001). Associative learning of likes and dislikes: a review of 25 years of research on human evaluative conditioning. Psychol Bull, 127(6), 853-869

de Jong, J. R., Vlaeyen, J., Onghena, P., Cuypers, C., den Hollander, M., \& Ruijgrok, J. (2005a). Reduction of pain-related fear in complex regional pain syndrome type I: the application of graded exposure in vivo. Pain, 116(3), 264-275. doi:10.1016/j.pain.2005.04.019

de Jong, J. R., Vlaeyen, J., Onghena, P., Goossens, M. E., Geilen, M., \& Mulder, H. (2005b). Fear of movement/(re)injury in chronic low back pain: education or exposure in vivo as mediator to fear reduction? Clin J Pain, 21(1), 9-17; discussion 69-72

Debiec, J., \& Ledoux, J. E. (2004). Disruption of reconsolidation but not consolidation of auditory fear conditioning by noradrenergic blockade in the amygdala. Neuroscience, 129(2), 267-272. doi:10.1016/j.neuroscience.2004.08.018

den Hollander, M., Goossens, M., de Jong, J., Ruijgrok, J., Oosterhof, J., Onghena, P., . . Vlaeyen, J. (2016). Expose or protect? A randomized controlled trial of exposure in vivo vs pain-contingent treatment as usual in patients with complex regional pain syndrome type 1. Pain, 157(10), 2318-2329. doi:10.1097/j.pain.0000000000000651

Ek, J. W., van Gijn, J. C., Samwel, H., van Egmond, J., Klomp, F. P., \& van Dongen, R. T. (2009). Pain exposure physical therapy may be a safe and effective treatment for longstanding complex regional pain syndrome type 1: a case series. Clin Rehabil, 23(12), 1059-1066. doi:10.1177/0269215509339875

Elliott, A. M., Burton, C. D., \& Hannaford, P. C. (2014). Resilience does matter: evidence from a 10-year cohort record linkage study. BMJ Open, 4(1), e003917. doi:10.1136/bmjopen-2013-003917

Foa, E. B., \& Kozak, M. J. (1986). Emotional processing of fear: exposure to corrective information. Psychol Bull, 99(1), 20-35

Forcadell, E., Torrents-Rodas, D., Vervliet, B., Leiva, D., Tortella-Feliu, M., \& Fullana, M. A. (2017). Does fear extinction in the laboratory predict outcomes of exposure therapy? A treatment analog study. Int J Psychophysiol, 121, 63-71. doi:10.1016/j.ijpsycho.2017.09.001 
Frölke, J. P., van Dongen, R. T., \& van de Meent, H. (2015). [Complex regional pain syndrome type 1: negating the myth]. Ned Tijdschr Geneeskd, 159, A8370

Goossens, M. E., de Kinderen, R. J., Leeuw, M., de Jong, J. R., Ruijgrok, J., Evers, S. M., \& Vlaeyen, J. W. (2015). Is exposure in vivo cost-effective for chronic low back pain? A trial-based economic evaluation. BMC Health Serv Res, 15, 549. doi:10.1186/s12913-015-1212-6

Goossens, M. E., Kindermans, H. P., Morley, S. J., Roelofs, J., Verbunt, J., \& Vlaeyen, J. W. (2010). Selfdiscrepancies in work-related upper extremity pain: relation to emotions and flexible-goal adjustment. Eur J Pain, 14(7), 764-770. doi:10.1016/j.ejpain.2009.11.012

Goubert, L., Crombez, G., \& Danneels, L. (2005). The reluctance to generalize corrective experiences in chronic low back pain patients: a questionnaire study of dysfunctional cognitions. Behav Res Ther, 43(8), 1055-1067. doi:10.1016/j.brat.2004.07.005

Goubert, L., Francken, G., Crombez, G., Vansteenwegen, D., \& Lysens, R. (2002). Exposure to physical movement in chronic back pain patients: no evidence for generalization across different movements. Behav Res Ther, 40(4), 415-429

Goubert, L., \& Trompetter, H. (2017). Towards a science and practice of resilience in the face of pain. Eur J Pain, 21(8), 1301-1315. doi:10.1002/ejp.1062

Hanssen, M. M., Peters, M. L., Vlaeyen, J. W., Meevissen, Y. M., \& Vancleef, L. M. (2013). Optimism lowers pain: evidence of the causal status and underlying mechanisms. Pain, 154(1), 53-58. doi:10.1016/j. pain.2012.08.006

Harden, R. N., \& Bruehl, S. (2005). Diagnostic criteria: the statistical derivation of the four criterion factors. In P. R. Wilson, M. D. Stanton-Hicks, \& R. N. Harden (Eds.), CRPS: Current Diagnosis and Therapy (pp. 45-58). Seattle, Washington: IASP Press

Harden, R. N., Oaklander, A. L., Burton, A. W., Perez, R. S. G. M., Richardson, K., Swan, M., ... Bruehl, S. (2013). Complex Regional Pain Syndrome: Practical Diagnostic and Treatment Guidelines, 4th Edition. Pain Medicine, 14(2), 180-229. doi:10.1111/pme.12033

Hardy, J. K., Crofford, L. J., \& Segerstrom, S. C. (2011). Goal conflict, distress, and pain in women with fibromyalgia: a daily diary study. J Psychosom Res, 70(6), 534-540. doi:10.1016/j.jpsychores.2010.10.013 Harvie, D. S., Moseley, G. L., Hillier, S. L., \& Meulders, A. (2017). Classical Conditioning Differences Associated With Chronic Pain: A Systematic Review. J Pain, 18(8), 889-898. doi:10.1016/j.jpain.2017.02.430

Hauser, W., Wolfe, F., Henningsen, P., Schmutzer, G., Brahler, E., \& Hinz, A. (2014). Untying chronic pain: prevalence and societal burden of chronic pain stages in the general population-a cross-sectional survey. BMC Public Health, 14, 352. doi:10.1186/1471-2458-14-352

Hayes, S. C., Barnes-Holmes, D., \& Roche, B. (2001). Relational frame theory: a post-Skinnerian account of human language and cognition (Vol. 28). New York: Kluwer Academic/Plenum Heyvaert, M., Moeyaert, M., Verkempynck, P., Van den Noortgate, W., Vervloet, M., Ugille, M., \& Onghena, p. (2017). Testing the Intervention Effect in Single-Case Experiments: A Monte Carlo Simulation Study. The Journal of Experimental Education, 85(2), 175-196. doi:DOI: 10.1080/00220973.2015.1123667 Hofmann, W., De Houwer, J., Perugini, M., Baeyens, F., \& Crombez, G. (2010). Evaluative conditioning in humans: a meta-analysis. Psychol Bull, 136(3), 390-421. doi:10.1037/a0018916 
Holzapfel, S., Riecke, J., Rief, W., Schneider, J., \& Glombiewski, J. A. (2016). Development and Validation of the Behavioral Avoidance Test-Back Pain (BAT-Back) for Patients With Chronic Low Back Pain. Clin J Pain, 32(11), 940-947. doi:10.1097/ajp.0000000000000349

Hughes, L. S., Clark, J., Colclough, J. A., Dale, E., \& McMillan, D. (2017). Acceptance and Commitment Therapy (ACT) for Chronic Pain: A Systematic Review and Meta-Analyses. Clin J Pain, 33(6), 552-568. doi:10.1097/ajp.0000000000000425

Jensen, M. C., Brant-Zawadzki, M. N., Obuchowski, N., Modic, M. T., Malkasian, D., \& Ross, J. S. (1994). Magnetic resonance imaging of the lumbar spine in people without back pain. N Engl J Med, 331(2), 69-73. doi:10.1056/nejm199407143310201

Joos, E., Vansteenwegen, D., \& Hermans, D. (2012). Post-acquisition repetitive thought in fear conditioning: an experimental investigation of the effect of CS-US-rehearsal. J Behav Ther Exp Psychiatry, 43(2), 737-744. doi:10.1016/j.jbtep.2011.10.011

Kabat-Zinn, J. (2011). Some reflections on the origins of MBSR, skillful means, and the trouble with maps. Contemporary Buddhism, 12, 281-306

Karoly, P., Okun, M. A., Ruehlman, L. S., \& Pugliese, J. A. (2008). The impact of goal cognition and pain severity on disability and depression in adults with chronic pain: An examination of direct effects and mediated effects via pain-induced fear. Cognitive Therapy and Research, 32(3), 418-433

Kindt, M., \& Soeter, M. (2013). Reconsolidation in a human fear conditioning study: a test of extinction as updating mechanism. Biol Psychol, 92(1), 43-50. doi:10.1016/j.biopsycho.2011.09.016

Kircanski, K., Lieberman, M. D., \& Craske, M. G. (2012). Feelings into words: contributions of language to exposure therapy. Psychol Sci, 23(10), 1086-1091. doi:10.1177/0956797612443830

Kircanski, K., Mortazavi, A., Castriotta, N., Baker, A. S., Mystkowski, J. L., Yi, R., \& Craske, M. G. (2012). Challenges to the traditional exposure paradigm: variability in exposure therapy for contamination fears. J Behav Ther Exp Psychiatry, 43(2), 745-751. doi:10.1016/j.jbtep.2011.10.010

Kratochwill, T. R., \& Levin, J. R. (2010). Enhancing the scientific credibility of single-case intervention research: randomization to the rescue. Psychol Methods, 15(2), 124-144. doi:10.1037/a0017736

Lang, A. J., \& Craske, M. G. (2000). Manipulations of exposure-based therapy to reduce return of fear: A replication. Behav Res Ther, 38(1), 1-12. doi:10.1016/S0005-7967(99)00031-5

Law, M., Baptiste, S., Carswell, A., McColl, M. A., Polatajko, H. J., \& Pollock, N. (2005). Canadian Occupational Performance Measure (4 ed.). Ottawa, Ontario: CAOT Publications ACE

Leeuw, M., Goossens, M. E., van Breukelen, G. J., Boersma, K., \& Vlaeyen, J. W. (2007). Measuring perceived harmfulness of physical activities in patients with chronic low back pain: the Photograph Series of Daily Activities-short electronic version. J Pain, 8(11), 840-849. doi:10.1016/j.jpain.2007.05.013

Leeuw, M., Goossens, M. E., van Breukelen, G. J., de Jong, J. R., Heuts, P. H., Smeets, R. J., . . Vlaeyen, J. (2008). Exposure in vivo versus operant graded activity in chronic low back pain patients: results of a randomized controlled trial. Pain, 138(1), 192-207. doi:10.1016/j.pain.2007.12.009

Liebermann, D., Giesbrecht, G. F., \& Müller, U. (2007). Cognitive and emotional aspects of self-regulation in preschoolers. Cognitive Development, 22(4), 511-529. doi:10.1016/j.cogdev.2007.08.005 
Linton, S. J., McCracken, L. M., \& Vlaeyen, J. W. (2008). Reassurance: help or hinder in the treatment of pain. Pain, 134(1-2), 5-8. doi:10.1016/j.pain.2007.10.002

Mataix-Cols, D., Fernandez de la Cruz, L., Monzani, B., Rosenfield, D., Andersson, E., Perez-Vigil, A., . . Thuras, P. (2017). D-Cycloserine Augmentation of Exposure-Based Cognitive Behavior Therapy for Anxiety, Obsessive-Compulsive, and Posttraumatic Stress Disorders: A Systematic Review and Meta-analysis of Individual Participant Data. JAMA Psychiatry, 74(5), 501-510. doi:10.1001/ jamapsychiatry.2016.3955

McCracken, L. M., \& Vowles, K. E. (2014). Acceptance and commitment therapy and mindfulness for chronic pain: model, process, and progress. Am Psychol, 69(2), 178-187. doi:10.1037/a0035623

McCracken, L. M., Zayfert, C., \& Gross, R. T. (1992). The Pain Anxiety Symptoms Scale: development and validation of a scale to measure fear of pain. Pain, 50(1), 67-73

Mersky, H., \& Bogduk, N. (Eds.). (1994). Classification of chronic pain: descriptions of chronic pain syndromes and definitions of pain terms (2 ed.). Seattle, WA: IASP Press

Meulders, A., Boddez, Y., Blanco, F., Van Den Houte, M., \& Vlaeyen, J. (2018). Reduced Selective Learning in Fibromyalgia Patients Versus Healthy Controls. Pain. doi:10.1097/j.pain.0000000000001207

Meulders, A., Karsdorp, P. A., Claes, N., \& Vlaeyen, J. W. (2015). Comparing Counterconditioning and Extinction as Methods to Reduce Fear of Movement-Related Pain. J Pain, 16(12), 1353-1365. doi:10.1016/j.jpain.2015.09.007

Meulders, A., Meulders, M., Stouten, I., De Bie, J., \& Vlaeyen, J. W. (2017). Extinction of Fear Generalization: A Comparison Between Fibromyalgia Patients and Healthy Control Participants. J Pain, 18(1), 79-95. doi:10.1016/j.jpain.2016.10.004

Meulders, A., Vansteenwegen, D., \& Vlaeyen, J. (2011). The acquisition of fear of movement-related pain and associative learning: a novel pain-relevant human fear conditioning paradigm. Pain, 152(11), 2460-2469. doi:10.1016/j.pain.2011.05.015

Meulders, A., Vansteenwegen, D., \& Vlaeyen, J. W. (2012). Women, but not men, report increasingly more pain during repeated (un)predictable painful electrocutaneous stimulation: Evidence for mediation by fear of pain. Pain, 153(5), 1030-1041. doi:10.1016/j.pain.2012.02.005

Meulders, A., \& Vlaeyen, J. W. (2012). Reduction of fear of movement-related pain and pain-related anxiety: An associative learning approach using a voluntary movement paradigm. Pain, 153(7), 1504-1513. doi:10.1016/j.pain.2012.04.013

Meuret, A. E., Seidel, A., Rosenfield, B., Hofmann, S. G., \& Rosenfield, D. (2012). Does fear reactivity during exposure predict panic symptom reduction? J Consult Clin Psychol, 80(5), 773-785. doi:10.1037/ a0028032

Miller, R. P., Kori, S. H., \& Todd, D. D. (1991). The Tampa Scale

Morley, S., \& Dowzer, C. N. (2014). Manual for the Leeds Reliable Change Indicator: Simple Excel ${ }^{\circledR}$ applications for the analysis of individual patient and group data. Retrieved from http://medhealth. leeds.ac.uk/info/618/clinical_psychology_dclinpsychol/797/leeds_reliable_change_index website

Moseley, G. L. (2016). More than “just do it"-fear-based exposure for complex regional pain syndrome. Pain, 157(10), 2145-2147. doi:10.1097/j.pain.0000000000000667 
Oerlemans, H. M., Cup, E. H., DeBoo, T., Goris, R. J., \& Oostendorp, R. A. (2000). The Radboud skills questionnaire: construction and reliability in patients with reflex sympathetic dystrophy of one upper extremity. Disabil Rehabil, 22(5), 233-245

Oerlemans, H. M., Oostendorp, R. A., de Boo, T., \& Goris, R. J. (1999). Pain and reduced mobility in complex regional pain syndrome I: outcome of a prospective randomised controlled clinical trial of adjuvant physical therapy versus occupational therapy. Pain, 83(1), 77-83

Oerlemans, H. M., Oostendorp, R. A., de Boo, T., van der Laan, L., Severens, J. L., \& Goris, J. A. (2000). Adjuvant physical therapy versus occupational therapy in patients with reflex sympathetic dystrophy/complex regional pain syndrome type I. Arch Phys Med Rehabil, 81(1), 49-56

Onghena, P., \& Edgington, E. S. (1994). Randomization tests for restricted alternating treatments designs. Behav Res Ther, 32(7), 783-786

Onghena, P., \& Edgington, E. S. (2005). Customization of pain treatments: single-case design and analysis. Clin J Pain, 21(1), 56-68; discussion 69-72

Ott, J., Aust, S., Nouri, K., \& Promberger, R. (2012). An everyday phrase may harm your patients: the influence of negative words on pain during venous blood sampling. Clin J Pain, 28(4), 324-328. doi:10.1097/AJP.0b013e3182321cc3

Otto, M. W., Kredlow, M. A., Smits, J. A., Hofmann, S. G., Tolin, D. F., de Kleine, R. A., .. Pollack, M. H. (2016). Enhancement of Psychosocial Treatment With D-Cycloserine: Models, Moderators, and Future Directions. Biol Psychiatry, 80(4), 274-283. doi:10.1016/j.biopsych.2015.09.007

Pace-Schott, E. F., Germain, A., \& Milad, M. R. (2015). Effects of sleep on memory for conditioned fear and fear extinction. Psychol Bull, 141(4), 835-857. doi:10.1037/bul0000014

Pace-Schott, E. F., Milad, M. R., Orr, S. P., Rauch, S. L., Stickgold, R., \& Pitman, R. K. (2009). Sleep promotes generalization of extinction of conditioned fear. Sleep, 32(1), 19-26

Reid, K. J., Harker, J., Bala, M. M., Truyers, C., Kellen, E., Bekkering, G. E., \& Kleijnen, J. (2011). Epidemiology of chronic non-cancer pain in Europe: narrative review of prevalence, pain treatments and pain impact. Curr Med Res Opin, 27(2), 449-462. doi:10.1185/03007995.2010.545813

Richardson, R., Ledgerwood, L., \& Cranney, J. (2004). Facilitation of fear extinction by D-cycloserine: theoretical and clinical implications. Learn Mem, 11(5), 510-516. doi:10.1101//m.78204

Richter, M., Eck, J., Straube, T., Miltner, W. H., \& Weiss, T. (2010). Do words hurt? Brain activation during the processing of pain-related words. Pain, 148(2), 198-205. doi:10.1016/j.pain.2009.08.009

Roorda, L. D., Roebroeck, M. E., Lankhorst, G. J., van Tilburg, T., \& Bouter, L. M. (1996). Measuring functional limitations in rising and sitting down: development of a questionnaire. Arch Phys Med Rehabil, 77(7), 663-669

Roorda, L. D., Roebroeck, M. E., van Tilburg, T., Molenaar, I. W., Lankhorst, G. J., Bouter, L. M., . . Rijken, P. M. (2005). Measuring activity limitations in walking: development of a hierarchical scale for patients with lower-extremity disorders who live at home. Arch Phys Med Rehabil, 86(12), 2277-2283. doi:10.1016/j.apmr.2005.06.014 
Ruiz-Parraga, G. T., Lopez-Martinez, A. E., \& Gomez-Perez, L. (2012). Factor structure and psychometric properties of the resilience scale in a spanish chronic musculoskeletal pain sample. J Pain, 13(11), 1090-1098. doi:10.1016/j.jpain.2012.08.005

Schilder, J. C., Schouten, A. C., Perez, R. S., Huygen, F. J., Dahan, A., Noldus, L. P., . . Marinus, J. (2012). Motor control in complex regional pain syndrome: a kinematic analysis. Pain, 153(4), 805-812. doi:10.1016/j.pain.2011.12.018

Schiller, D., Monfils, M. H., Raio, C. M., Johnson, D. C., Ledoux, J. E., \& Phelps, E. A. (2010). Preventing the return of fear in humans using reconsolidation update mechanisms. Nature, 463(7277), 49-53. doi:10.1038/nature08637

Schwartzman, R. J., Erwin, K. L., \& Alexander, G. M. (2009). The natural history of complex regional pain syndrome. Clin J Pain, 25(4), 273-280. doi:10.1097/AJP.0b013e31818ecea5

Schwartzman, R. J., \& Popescu, A. (2002). Reflex sympathetic dystrophy. Curr Rheumatol Rep, 4(2), 165-169

Shadish, W. R., Cook, T. D., \& Campbell, D. T. (2002). Experimental and Quasi-Experimental Designs for Generalized Causal Inference (2 ed.): Wadsworth Publishing

Slepian, P. M., Ankawi, B., Himawan, L. K., \& France, C. R. (2016). Development and Initial Validation of the Pain Resilience Scale. J Pain, 17(4), 462-472. doi:10.1016/j.jpain.2015.12.010

Slifer, K. J., Hankinson, J. C., Zettler, M. A., Frutchey, R. A., Hendricks, M. C., Ward, C. M., \& Reesman, J. (2011). Distraction, exposure therapy, counterconditioning, and topical anesthetic for acute pain management during needle sticks in children with intellectual and developmental disabilities. Clin Pediatr (Phila), 50(8), 688-697. doi:10.1177/0009922811398959

Smeets, R., den Hollander, M., \& de Jong, J. R. (2015). Fear does matter! Comment on Plos one DOI:10.1371/ journal.pone.0123008: Are pain-related fears mediators for reducing disability and pain in patients with complex regional pain syndrome type 1? An explorative analysis of pain exposure physical therapy by Barnhoorn et al. (2015). Retrieved from http://journals.plos.org/plosone/article/ comment?id = 10.1371/annotation/ f4742347-4af8-41ba-a84f-03e0d6c34d45

Springer, K. S., George, S. Z., \& Robinson, M. E. (2016). The Development of a Technology-Based Hierarchy to Assess Chronic Low Back Pain and Pain-Related Anxiety From a Fear-Avoidance Model. J Pain, 17(8), 904-910. doi:10.1016/j.jpain.2016.04.004

Sturgeon, J. A., \& Zautra, A. J. (2010). Resilience: a new paradigm for adaptation to chronic pain. Curr Pain Headache Rep, 14(2), 105-112. doi:10.1007/s11916-010-0095-9

Swannell, E. R., Brown, C. A., Jones, A. K., \& Brown, R. J. (2016). Some Words Hurt More Than Others: Semantic Activation of Pain Concepts in Memory and Subsequent Experiences of Pain. J Pain, 17(3), 336-349. doi:10.1016/j.jpain.2015.11.004

Taub, E., Miller, N. E., Novack, T. A., Cook, E. W., 3rd, Fleming, W. C., Nepomuceno, C. S., . . Crago, J. E. (1993). Technique to improve chronic motor deficit after stroke. Arch Phys Med Rehabil, 74(4), 347-354

Thorne, F. M., \& Morley, S. (2009). Prospective judgments of acceptable outcomes for pain, interference and activity: Patient-determined outcome criteria. Pain, 144(3), 262-269. doi:10.1016/j. pain.2009.04.004 
Trost, Z., France, C. R., \& Thomas, J. S. (2008). Exposure to movement in chronic back pain: evidence of successful generalization across a reaching task. Pain, 137(1), 26-33. doi:10.1016/j.pain.2007.08.005

Turner-Stokes, L. (2002). Reflex sympathetic dystrophy-a complex regional pain syndrome. Disabil Rehabil, 24(18), 939-947. doi:10.1080/0963828021000007950

Van Dam, N. T., van Vugt, M. K., Vago, D. R., Schmalzl, L., Saron, C. D., Olendzki, A., .. Meyer, D. E. (2017). Mind the Hype: A Critical Evaluation and Prescriptive Agenda for Research on Mindfulness and Meditation. Perspect Psychol Sci, 1745691617709589. doi:10.1177/1745691617709589

van de Meent, H., Oerlemans, M., Bruggeman, A., Klomp, F., van Dongen, R., Oostendorp, R., \& Frolke, J. P. (2011). Safety of "pain exposure" physical therapy in patients with complex regional pain syndrome type 1. Pain, 152(6), 1431-1438. doi:10.1016/j.pain.2011.02.032

van Melick, M., den Hollander, M., Satink, T., Andresen, M., \& Smeets, R. Life after group-based exposure program for pain-related fear: patients' strategies and underlying motives in occupational performance

van Velzen, G. A., Marinus, J., van Dijk, J. G., van Zwet, E. W., Schipper, I. B., \& van Hilten, J. J. (2015). Motor cortical activity during motor tasks is normal in patients with complex regional pain syndrome. J Pain, 16(1), 87-94. doi:10.1016/j.jpain.2014.10.010

Veehof, M. M., Trompetter, H. R., Bohlmeijer, E. T., \& Schreurs, K. M. (2016). Acceptance- and mindfulness-based interventions for the treatment of chronic pain: a meta-analytic review. Cogn Behav Ther, 45(1), 5-31. doi:10.1080/16506073.2015.1098724

Vervliet, B., Craske, M. G., \& Hermans, D. (2013). Fear extinction and relapse: state of the art. Annu Rev Clin Psychol, 9, 215-248. doi:10.1146/annurev-clinpsy-050212-185542

Vlaeyen, J., Crombez, G., \& Linton, S. J. (2016). The fear-avoidance model of pain. Pain, 157(8), 1588-1589. doi:10.1097/j.pain.0000000000000574

Vlaeyen, J., de Jong, J., Leeuw, M., \& Crombez, G. (2004). Fear reduction in chronic pain; Graded exposure in vivo with behavioral experiments. In G. Asmundson, J. Vlaeyen, \& G. Crombez (Eds.), Understanding and treating fear of pain (pp. 313-343). Oxford: University Press

Vlaeyen, J., de Jong, J. R., Sieben, J. M., \& Crombez, G. (2002). Graded Exposure in Vivo for Pain-related Fear. Psychological approaches to pain management. A practitioner's handbook. New York: Guilford Press

Vlaeyen, J., \& Linton, S. (2000). Fear-avoidance and its consequences in chronic musculoskeletal pain: a state of the art. Pain, 85(3), 317-332

Waddell, G. (2004). The biopsychosocial model. In G. Waddell (Ed.), The Back Pain Revolution (pp. 265-282). Edinburgh: Churchill Livingston

Waddell, G., Newton, M., Henderson, I., Somerville, D., \& Main, C. J. (1993). A Fear-Avoidance Beliefs Questionnaire (FABQ) and the role of fear-avoidance beliefs in chronic low back pain and disability. Pain, 52(2), 157-168

Walker, D. L., Ressler, K. J., Lu, K. T., \& Davis, M. (2002). Facilitation of conditioned fear extinction by systemic administration or intra-amygdala infusions of D-cycloserine as assessed with fearpotentiated startle in rats. J Neurosci, 22(6), 2343-2351 



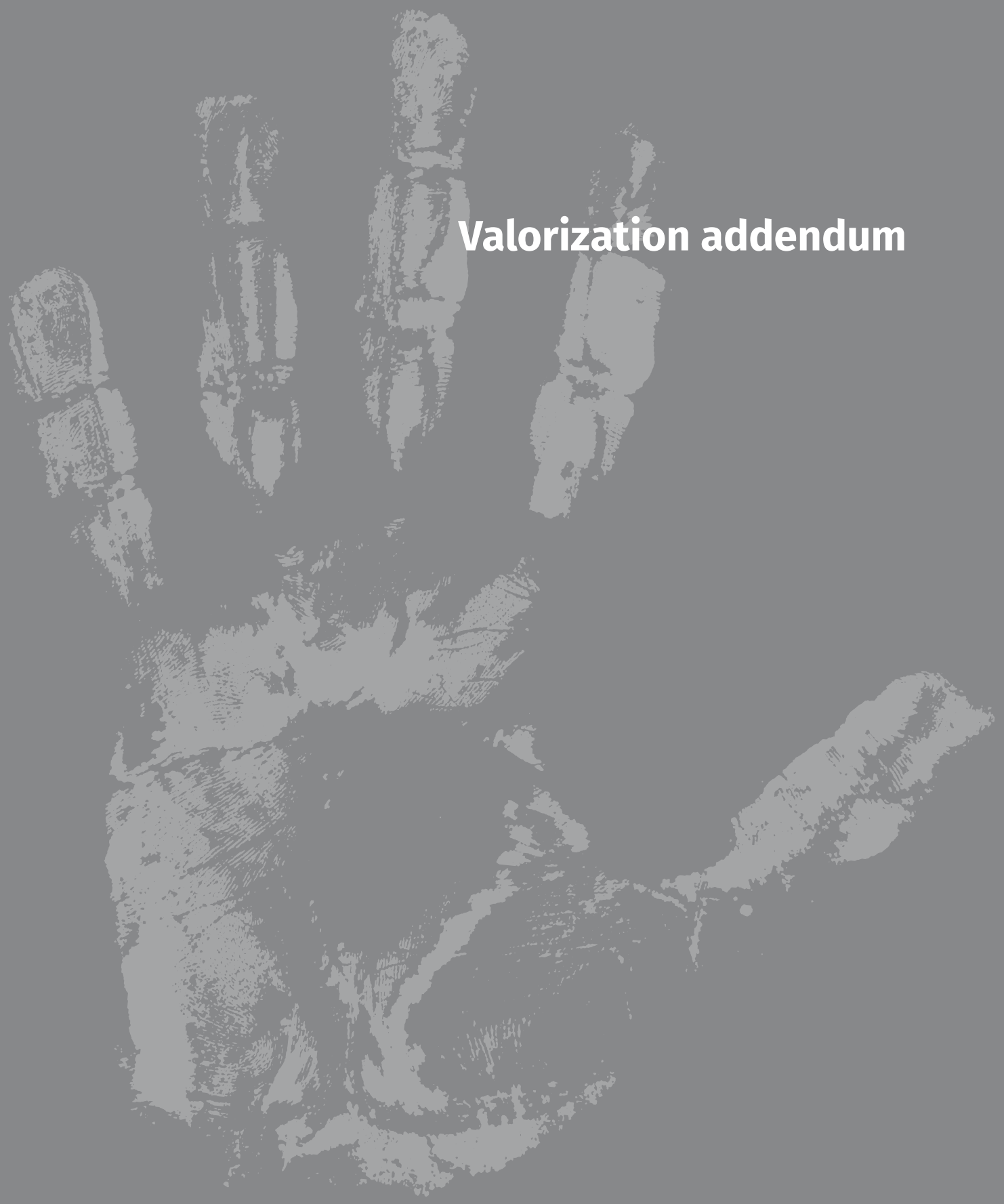



Beside scientific knowledge, the results of this thesis represent a societal value that will be reflected on in this valorization addendum. Whereas the previous chapters focused on the findings of studies, this valorization addendum aims to describe the relevance of findings for individuals and organizations outside the academia, and how findings can be applied, implemented, and translated into products, services and activities.

\section{Relevance}

Pain is an experience that any person is highly likely to encounter. In a smaller number of individuals, the pain complaints persist, and may cause suffering due to pain-related interruption of tasks, interference with daily activities and social roles, and erosion of the sense of self (Vlaeyen, Morley, \& Crombez, 2016). Many professionals working with patients with chronic pain consent, in line with the growing body of evidence, that pain is a unique experience, influenced by biological, psychological and social factors. Still, when confronted with pain, most people will focus on the biological origin of their pain and how to solve it, being unaware about the psychological and social experience that pain always is.

Long before my interest in chronic pain or even psychology was raised, I had a friend who was suffering from CRPS-I. At that time, it seemed completely normal that she putted all her energy into finding a medical solution for her pain. We all agreed with her that the therapist who forced her to walk on her extremely painful foot followed an almost inhumane approach. This protective way of dealing with (chronic) pain caused a lot of damage both for people who suffer from pain and for the society that bears the costs (Verbunt \& Smeets, 2016), and is currently outdated. If pain cannot be solved within a few weeks or months, health-care providers should start to provide information that helps patients to choose their own balance between controlling the pain experience and controlling life with the activities that are relevant for that person (Vlaeyen, Crombez, \& Linton, 2016). With this thesis, the focus is on the latter, and with my current knowledge, I would say exposure is a very humane approach when a patient is provided with a clear rationale, certainly better than hopeless attempts for pain control.

Studies in this thesis show that exposure in vivo helps to reduce disability, fear of movement-related pain and the experience of pain in CRPS-I patients. We were able to show that CRPS-patients reduce the consumption of medication and informal care after exposure, compared to a pain-contingent approach. Overall, health-care costs are lower after exposure than after pain-contingent physical therapy, which was the recommended treatment for CRPS-I by the Dutch Guidelines 
when the trial started in 2008 (Perez et al., 2007). The next sections will describe for whom further implementation of exposure in vivo could have beneficial effects, and how implementation can be optimized.

\section{Target groups}

\section{CRPS-I patients and other patients with chronic pain}

A randomized single case experimental design, a randomized controlled trial and a cost-effectiveness study in this thesis show that exposure in vivo is an effective treatment for CRPS-I patients who have complaints about their ability to perform relevant daily life activities. It was shown that exposure in vivo is successful in reducing this disability, when fear of movement related pain plays a role in the maintenance of disability. Whereas we used instruments (TSK for the generalization study, PHODA for the RCT and CEA) to establish pain-related fear as an inclusion criterion, also patients with lower scores might benefit from exposure treatment. Patients do not always present with a clear pain-related fear, but as long as they experience disability, it is worthwhile to thoroughly assess their underlying motives for avoidance or adjustments of activities. Irrational ideas about what they cannot do might emerge and justify exposure treatment.

We showed that exposure in vivo reduces disability, fear and pain. Note that the findings were not only scientifically significant, but also clinically reliable. Using the Leeds Reliable Change Index (Morley \& Dowzer, 2014), we demonstrated a difference in the percentage of patients with a reliable change in disability after exposure compared to pain-contingent physical therapy. For exposure in vivo, all patients except one reported a reliable change in disability. For the broader population of patients with chronic pain, from ununderstood or neuropathic origin, the findings in this thesis add to the emerging evidence that to reduce disability and in the long run probably even pain, painful activities should not be avoided. With the current knowledge, we cannot predict who will report decreases in pain-experience as well. Since clinical experience seems to indicate that pain reduction is only accomplished when patients focus on reducing disability instead of on finding a solution for their pain, it seems wise to interpret pain-reduction as an advantageous side-effect of a treatment primarily aiming to reduce disability. If patients who desire painreduction only will also benefit from disability-focused pain rehabilitation is still unclear. The exclusive focus on the pain-experience might prevent pain-reduction in the long run. 


\section{Family members of CRPS-I patients}

The cost-effectiveness study in this thesis showed that the support CRPS-I patients receive from informal caregivers, such as family members and friends, is lower after exposure than after a pain-contingent treatment. The burden of CRPS-I not only weighs on patients, but also on their family and friends. They might also have irrational cognitions about pain, and therefor encourage patients NOT to be active. When a patient is unable to work, spouses have to bear the task to ensure minimum income for their family. Besides that, patients might need assistance in performing daily household and personal care. Altogether this is time-consuming, and this can be experienced as burdensome. After exposure in vivo, this actual burden might be reduced and increase the quality of life of partners and family members as well. Additionally, how pain is perceived in a patient seems to be taken over by other family members (including children), reflected in higher scores on pain catastrophizing, raising the probability that they will also develop chronic pain. It is therefore important to include family members in any exposure treatment.

\section{Health-care providers in chronic pain rehabilitation}

Results from the current research support the implementation of exposure in vivo in chronic pain rehabilitation. Whereas many centers apply a mix of graded activity-, exposure and ACT principles, and sometimes even pain-contingent principles as ergonomics or energy-consuming principles (Anamkath et al., 2018; Goossens, Köke, \& Tilli, 2002; Stein \& Miclescu, 2013), we showed that a short, standalone exposure treatment significantly reduces disability. Not every professional feels confident to deliver exposure. If health care professionals working with chronic pain patients recognize pain-related fear and provide or refer to appropriate exposure-base care, this will significantly lighten the burden of chronic pain for the patients concerned. Continuous education for health care providers in the pain field is highly recommended to achieve this goal.

\section{Generalization beyond chronic pain health care}

A broader group of health-care professionals might benefit from the growing body of evidence showing that behavioral approaches, such as exposure in vivo, help patients with pain to reach optimal functioning in their daily lives. Knowledge from chronic pain research can be translated to other groups of patients, for which pain 
relief is unlikely, but for which optimizing daily life functioning might be an important focus as well. This requires a different way of assessment by medical specialists: not only finding out the cause and, if possible, resolving pain, but also being clear that the patient can safely do much more than he is currently doing, despite the pain complaints. Prevention of disability is likely to happen when already at an early stage, health care professionals encourage a patient to remain active despite pain. This leaves the patient in control over what he wants to put his effort in: control over pain or control over functioning. For complex cases, referral to rehabilitation specialists might be warranted. A physiatrist may evaluate if the reported disability can be adequately reduced in primary care, or in a multidisciplinary painrehabilitation setting.

\section{Health-care insurance companies}

Our research showed that exposure in vivo reduces health-care related costs in CRPS-I patients, and this makes it relevant for health-care insurance companies. If insurers have insight into the cost-effectiveness of the treatment they reimburse, the successful treatment will become available to a larger group of patients who are expected to benefit from it. Given the enormous range of available pain treatments and the diversity in duration and content, it is often difficult for insurers to assess which pain treatment they can cover best. Also, the effectiveness of most treatments is unknown. Is the most expensive the best? The CEA has clearly shown that despite higher initial treatment costs of exposure as compared to common treatment, exposure provides better effects and lower costs in the long term. The CEA also provides insight into which health care is still being consumed after exposure treatment. For insurers, these results will be a clear incentive to reimburse exposure treatment for CRPS-I patients. The treatment is short in duration and well documented. Insurers therefore know what they will reimburse.

\section{General population}

By offering patients with chronic pain a treatment that helps them to resume important daily-life activities they might increase their social participation, for example in work or volunteer activities. It is known that this will enhance feelings of wellbeing, and eventually society might benefit by reduced health care consumption and -costs. Furthermore, it seems important to supply the general population with knowledge about the biopsychosocial origin of (chronic) pain (Buchbinder et al., 
2018). It would actually make sense to include this in the biology lessons about the human body in primary or high school. When children are raised with awareness that pain is not always sign of damage, but a complex experience in which biological, psychological and social factors play a role, they might behave differently than the current generation when they are confronted with pain later in life. In the long run, this might reduce the societal burden of pain.

\section{Innovative products}

The current thesis shows that the treatment protocol for exposure in vivo, as it was tested in a trial with chronic low back pain patients before, has now proven to be cost-effective in CRPS-I as well. To have more patients benefit from this treatment, Dutch and international guidelines should include the treatment in subsequent updates. Courses are already set up by our experienced team, to enable multidisciplinary rehabilitation teams to use the exposure in vivo protocol for CRPS-I and other chronic pain conditions. We also provide an introduction for professionals in primary care to enable them to recognize fear of movement-related pain, and decide adequately when referral to a secondary or tertiary care is warranted. Our researchers and clinicians wrote a book about exposure, addressing both clinical issues as well as implementation issues. We contributed to several books on rehabilitation medicine, cognitive-behavioral therapy and unexplained somatic complaints with chapters about exposure in vivo. We provided many lectures, not only for the international scientific community, but also for medical and psychology students, students physical- and occupational therapy, medical and paramedical health-care professionals (including insurance physicians), and patient associations.

\section{Implementation}

The treatment manual of the exposure in vivo, which we demonstrated to be costeffective for CRPS-I and chronic low back pain (Goossens et al., 2015), is available in the literature (Vlaeyen, Morley, Linton, Boersma, \& de Jong, 2012). In clinical practice, this protocol might not always be delivered as described, which might influence its effectiveness. Multidisciplinary pain rehabilitation commonly offers a mix of treatment techniques (Goossens et al., 2002; Scascighini, Toma, Dober-Spielmann, \& Sprott, 2008), instead of choosing a theoretical approach, assumed to tap in on the assumed underlying mechanism of disability or chronic pain. This eclectic approach is likely to lead to programs that are more extensive (Reneman et al., 2018; 
Waterschoot et al., 2014) and therefore more expensive than the strict stand-alone exposure treatment we studied. Specifically for exposure in pain-related fear, a short treatment duration even outperformed a longer treatment duration (Glombiewski et al., 2018). It could also be confusing for patients to have multiple messages, and this could weaken the clear message of exposure in vivo. Adelante offers a course on exposure in vivo, delivered by experts from our group. If demands would increase, more members of the team, efficiently trained to deliver courses on exposure, will be needed. This raises the question how to widely implement professional training in exposure treatment for this particular patient group. Another challenge is that in most health-care settings, it is currently unusual that a psychologist and a physical or occupational therapist work together and simultaneously with one patient. It might also be unusual to choose a specific approach and provide exposure as a stand-alone treatment for chronic pain patients with pain-related fear. A thorough assessment of underlying maintaining processes for disability and pain helps to choose the approach that will most likely counteract the most prominent process. Single-case experimental designs (Edgington \& Onghena, 2007), measuring indexes of the various processes and outcomes, can provide insight whether the chosen treatment indeed taps in on the intended process. If a certain approach shows not to be successful in a specific patient, a switch in approach might be appropriate. Even after education, teams just starting to deliver exposure might feel the need for supervision. It would be worthwhile to explore how this can be optimized. 


\section{References}

Anamkath, N. S., Palyo, S. A., Jacobs, S. C., Lartigue, A., Schopmeyer, K., \& Strigo, I. A. (2018). An Interdisciplinary Pain Rehabilitation Program for Veterans with Chronic Pain: Description and Initial Evaluation of Outcomes. Pain Res Manag, 2018, 3941682. doi:10.1155/2018/3941682

Buchbinder, R., van Tulder, M., Oberg, B., Costa, L. M., Woolf, A., Schoene, M., \& Croft, P. (2018). Low back pain: a call for action. Lancet, 391(10137), 2384-2388. doi:10.1016/s0140-6736(18)30488-4

Edgington, E. S., \& Onghena, P. (2007). Randomization Tests (4 ed.). Boca Raton: Chapman \& Hall/CRC, Taylor \& Francis Group

Glombiewski, J. A., Holzapfel, S., Riecke, J., Vlaeyen, J. W. S., de Jong, J., Lemmer, G., \& Rief, W. (2018). Exposure and CBT for chronic back pain: An RCT on differential efficacy and optimal length of treatment. J Consult Clin Psychol, 86(6), 533-545. doi:10.1037/ccp0000298

Goossens, M. E., de Kinderen, R. J., Leeuw, M., de Jong, J. R., Ruijgrok, J., Evers, S. M., \& Vlaeyen, J. W. (2015). Is exposure in vivo cost-effective for chronic low back pain? A trial-based economic evaluation. BMC Health Serv Res, 15, 549. doi:10.1186/s12913-015-1212-6

Goossens, M. E., Köke, A., \& Tilli, D. (2002). Multidisciplinaire pijnrevalidatie in Nederland. Resultaten van een enquête naar plaats en inhoud van multidisciplinaire pijnrevalidatieprogramma's. Nederlands Tijdschrift voor Pijn en Pijnbestrijding, 22(11), 7-13

Morley, S., \& Dowzer, C. N. (2014). Manual for the Leeds Reliable Change Indicator: Simple Excel ${ }^{\circledR}$ applications for the analysis of individual patient and group data. Retrieved from http://medhealth. leeds.ac.uk/info/618/clinical_psychology_dclinpsychol/797/leeds_reliable_change_index website

Perez, R., Zollinger, P., Dijkstra, P., Thomassen-Hilgersom, I., Zuurmond, W., Rosenbrand, C., \& Geertzen, J. (2007). [Clinical practice guideline 'Complex regional pain syndrome type I']. Ned Tijdschr Geneeskd., 151(30), 1674-1679

Reneman, M. F., Waterschoot, F. P. C., Bennen, E., Schiphorst Preuper, H. R., Dijkstra, P. U., \& Geertzen, J. H. B. (2018). Dosage of pain rehabilitation programs: a qualitative study from patient and professionals' perspectives. BMC Musculoskelet Disord, 19(1), 206. doi:10.1186/s12891-018-2125-4

Scascighini, L., Toma, V., Dober-Spielmann, S., \& Sprott, H. (2008). Multidisciplinary treatment for chronic pain: a systematic review of interventions and outcomes. Rheumatology (Oxford), 47(5), 670-678. doi:10.1093/rheumatology/ken021

Stein, K. F., \& Miclescu, A. (2013). Effectiveness of multidisciplinary rehabilitation treatment for patients with chronic pain in a primary health care unit. Scand J Pain, 4(4), 190-197. doi:10.1016/j. sjpain.2013.06.003

Verbunt, J. A., \& Smeets, R. J. E. M. (2016). Graded Exposure. Houten: Bohn Stafleu van Loghum

Vlaeyen, J., Crombez, G., \& Linton, S. J. (2016). The fear-avoidance model of pain. Pain, 157(8), 1588-1589. doi:10.1097/j.pain.0000000000000574

Vlaeyen, J., Morley, S., \& Crombez, G. (2016). The experimental analysis of the interruptive, interfering, and identity-distorting effects of chronic pain. Behav Res Ther, 86, 23-34. doi:10.1016/j. brat.2016.08.016 
Vlaeyen, J., Morley, S., Linton, S. J., Boersma, K., \& de Jong, J. R. (2012). Pain-Related Fear: Exposure-Based Treatment for Chronic Pain: IASP Press

Waterschoot, F. P., Dijkstra, P. U., Hollak, N., de Vries, H. J., Geertzen, J. H., \& Reneman, M. F. (2014). Dose or content? Effectiveness of pain rehabilitation programs for patients with chronic low back pain: a systematic review. Pain, 155(1), 179-189. doi:10.1016/j.pain.2013.10.006 


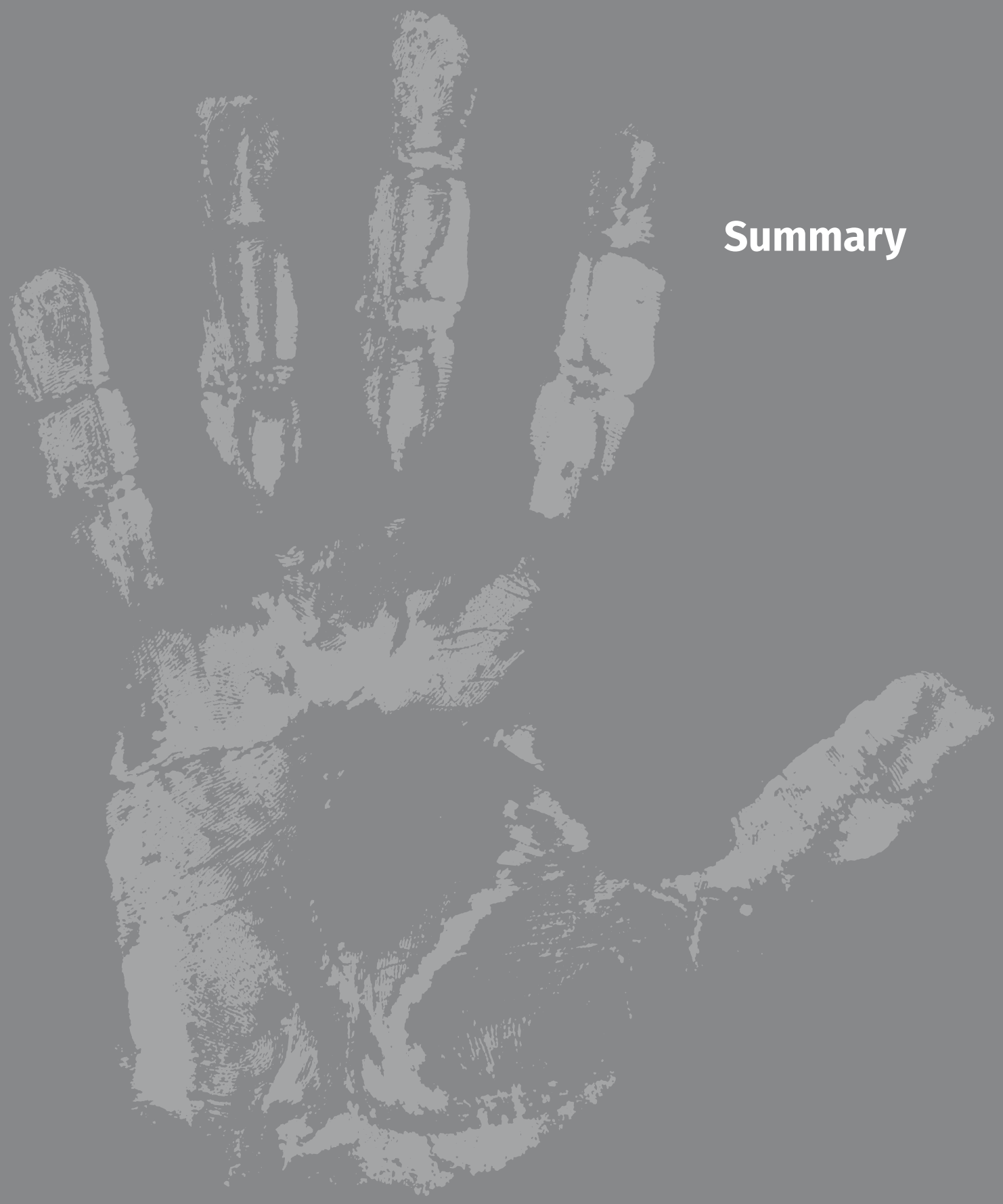


This thesis focusses on pain-related fear in patients with chronic pain, more specifically on extinction of fear via exposure in vivo treatment in patients with Complex Regional Pain Syndrome Type I. Chapter $\mathbf{1}$ starts with a general introduction on pain, fear, learning and exposure in vivo treatment. Following a biomedical approach, pain is traditionally defined as a signal of injury or tissue damage, suggesting a oneto-one relationship between the extent of injury, and the intensity of pain. It has now been demonstrated that the experience of pain is much more complex: on the one hand tissue damage is not always painful (e.g. MRI techniques confirmed that abnormalities are quite common in pain-free individuals), and on the other hand, pain can occur without injury (in most cases of low-back pain, no pathology can be detected). Pain can be better understood as a signal that encourages behavior aimed at escaping a dangerous situation than as a sign of tissue damage. The experience of pain is also modulated by central psychological mechanisms as cognitions and emotions. For example, a constant physiological pain stimulus can be experienced as more or less painful, depending on the instruction that this stimulus is safe or harmful. The interaction of physiological and psychological factors shows that a biopsychosocial perspective is needed to understand the complexity of pain. From that perspective, pain is currently defined as "an unpleasant sensory and emotional experience associated with actual or potential tissue damage or described in terms of such damage". In addition, the complexity of pain increases when over the course of time, the presumed relationship between tissue damage and pain becomes more doubtful. When pain "exists beyond the expected period for healing" it is defined as chronic pain. Paradoxically, protective behaviors, which were adaptive in an acute pain context where tissue damage occurred, can exacerbate the problem once the pain is chronic.

The fear-avoidance model states that the reaction of an individual to pain might either be confrontation or avoidance. Most people will evaluate pain as unpleasant, but not as a threat or catastrophe. That is why they proactively confront their pain, resume daily activities and report a reduction in perceived pain in the long run. However, there are also individuals who attribute a catastrophic meaning to the pain experience, for example as a sign of injury or a predictor of aggravating pain. Such catastrophic interpretations give rise to pain-related fear (e.g. fear of pain, fear of movement, fear of (re-)injury). Fear then causes hypervigilance, an elevated state of sensory sensitivity, accompanied by behavior aimed at detecting and avoiding threat. Hypervigilance interferes with attention for the performance of relevant activities and might increase the detection of pain and other aversive bodily signals. An anxious person will also be inclined to respond defensively to pain and, for example, show avoidance behavior. In chronic pain patients, avoidance behavior loses its adaptive function as a protective strategy; the injury has healed, despite 
persistent pain, and pain is typically no longer a sign of actual danger. Avoidance of relevant daily life activities results in disability, has a negative impact on mood and compromises quality of life. These negative effects of avoidance in turn enhance the pain experience, fueling the vicious fear-avoidance circle.

Learning theories help to understand why people become fearful of innocuous stimuli. Acquisition, generalization and extinction of fear can be understood from the principles of classical conditioning (learning associations); the influence this subsequently has on behavior can be understood from operant learning principles (behavior in- or decreases when it is reinforced or punished, respectively). Exposure in vivo is based on classical conditioning principles and is the preferred treatment for pathological fear. In pain-related fear, this treatment aims to reduce disability by challenging and correcting erroneous expectancies about pain and activities. Several RCTs have shown that exposure in vivo is effective in reducing disability, painrelated fear and experienced pain in patients with chronic low back pain. Repeated single-case experimental designs showed comparable results not only for chronic low back pain, but also for other chronic pain conditions, such as whiplash associated disorder, complaints of arm neck and shoulder (CANS), and Complex Regional Pain Syndrome Type I (CRPS-I). CRPS-I is an intriguing clinical manifestation of chronic pain with an unknown pathophysiology. It is characterized by severe pain that is disproportionate to the inciting event, localized in a distal part of an extremity and accompanied by abnormal swelling, changes in skin-color and temperature, as well as in sweating patterns that deviate from normal. When CRPS-I becomes a chronic condition, disability is often progressive over time, despite a variety of medical treatments. As in other chronic pain patients experiencing disability, pain-related fear was found to be present in CRPS-I patients as well, and a first repeated single case experimental design on exposure in vivo showed promising results.

Next, a number of points concerning pain-related fear and exposure in vivo are mentioned that require further investigation. These points have been translated into the following research questions, to which this dissertation aims to provide an answer:

1. How can we understand the acquisition and extinction of pain-related fear from a learning theory perspective?

2. Does verbal and visual manipulation of threat influence acquisition, extinction and return of fear in pain-free individuals?

3. Is generalization of exposure in vivo treatment facilitated when many different activities are performed or when a few activities are repeated several times?

4. Is exposure in vivo an effective treatment in reducing disability as primary outcome, but also in reducing pain-related fear and pain intensity, as well as in improving quality of life in patients with CRPS- 1 and pain-related fear? 
5. Is exposure in vivo cost-effective in CRPS-I patients with pain-related fear, compared to pain-contingent physical therapy?

In each subsequent chapter, one of the above-mentioned research questions is addressed.

Chapter 2 focusses on the mechanisms underlying acquisition and extinction of pain-related fear. A narrative review of the literature on fear conditioning and extinction specifically applied to pain-related fear is presented. Classical fear conditioning occurs when an emotionally neutral stimulus becomes associated with an inherently aversive experience, thereby acquiring the capability of evoking a fearful response on its own. The inherently aversive experience is the unconditioned stimulus (US, e.g. pain associated with harm or (re-)injury). The initially neutral stimulus that becomes associated with the aversive experience is the conditioned stimulus (CS, e.g. movements and activities), and the fear it subsequently elicits is the conditioned response (CR). People might learn CS-US associations by actual experience, but also through receiving verbal threat information and by observing someone else experiencing a CS-US association (modelling). In general, fear conditioning is an adaptive form of learning, but it can become pathological when fearful responses to a CS persist, while the CS-US contingency is no longer present. For example, in the case of pain-related fear, an individual may still experience pain, but when no injury or damage (US) is present anymore, it does not help to avoid movements or activities (CS).

Various tools to assess pain-related fear are available. Questionnaires can help to specify the patient's fear; does the patient expect damage, (re) injury, increasing pain, loss of a job or loss of independence (USS)? Pictorial stimuli of movements and activities help to assess which different stimuli (CSs) evoke fear and which specific expectations the patient has regarding a specific activity. The PHODA (Photograph Series of Daily Life Activities) is an instrument that is used for this purpose within exposure in vivo. An interview is used to gather information about the interrupting, interfering and identity-distorting effects of chronic pain, and the associations amongst them. After the assessment, when it is concluded that pain-related fear plays an important role in maintaining disability, exposure in vivo treatment is preferred.

During exposure in vivo treatment behavioral experiments are prepared in which the patient is exposed to the CS (in case of pain-related fear to movements or activities), so that he can experience that his expectation regarding the occurrence of the US (the feared consequence such as damage or excruciating pain) is incorrect. This process is referred to as extinction. However, extinction does not lead 
to the forgetting or "unlearning" of the CS-US association; a new, "safe" association comes to exist alongside the old, "threatening" association. The CS thus becomes an ambiguous stimulus.

Subsequently, in this chapter, scientific evidence obtained from other anxiety disorders is summarized and applied to the exposure treatment for pain-related fear. All components of treatment focus on learning that movements and activities are safe. This provides a patient with a new prediction that activities do not cause damage, although pain can occur. For example, education is given about the fearavoidance model so that the patient can understand how his pain and disability are maintained. After this, the behavioral experiments will provide the patient with actual experiences violating the idea that painful movements are harmful.

This chapter also discusses the effectiveness of exposure in pain-related fear, and identifies topics that have not yet sufficiently been studied scientifically, such as the role of pain-related fear in the transition from acute to chronic pain; other treatments than exposure in vivo that may also reduce pain-related fear, such as Acceptance and Commitment Therapy (ACT); the role of modelling within exposure and the application of exposure by non-psychologists; and generalization of exposure. Also, the role of safety behavior and whether exposure should focus on fear reduction or facilitating inhibitory learning has not yet been sufficiently investigated for pain-related anxiety. Addition of interoceptive exposure and paying attention to the personal goals of the patient could further enhance the effects of exposure for pain-related fear.

The results of an experimental study on the role of information on the threat value of pain in healthy individuals are presented in chapter 3. Studies with the Voluntary Joystick Movement (VJM) paradigm confirmed that healthy participants can acquire fear for a painful movement in an experimental setting. The VJM paradigm uses a differential proprioceptive fear conditioning paradigm: one movement (Conditioned Stimulus, CS+) is repeatedly paired with a painful stimulus (Unconditioned Stimulus, Pain-US), and another (CS-) movement is not. In response to the $\mathrm{CS}+$, defensive fear/avoidance responses (CRs) emerged. Defensive responses may arise from direct experience with a CS-US relation, but individuals also learn from verbal information and observation. The current study examined whether the acquisition of pain-related fear through direct experience can be intensified or weakened by verbally and visually transmitted information about the meaning of pain.

A (bogus) sensor was attached to all participants' skin at the start of the experiment. To determine the intensity of the pain stimulus, participants received pain stimuli of increasing intensity. In this phase, the administration of these pain stimuli is not yet associated with movements. After the calibration phase, the researcher inspected the skin and told participants that an increased skin reactivity 
was observed. Therefore, "skin reactivity measurement" would be shown during the task, which reflects the fragility of the skin for damage, such as blisters or burns. Participants were asked to carefully monitor the information from the sensor on the computer screen during the execution of the task. Participants saw a bar on the computer screen, varying in color from green via orange to red, containing a pointer that indicated the fragility of the skin. At the start of the task, the pointer was orange for all participants. Depending on the randomly assigned condition, the visual information differed during the task: participants in the inflation condition saw the pointer shift from orange to almost red, informing the participant about an increasing threat of skin damage. In the deflation condition, the pointer gradually shifted to almost green, informing the participants that the skin was safe. In the stable condition, the pointer remained in the orange zone throughout the experiment, keeping the threat to the skin equal with the previously given information. During extinction, the pointer remained in the red zone for participants in the inflation condition, in green for the deflation condition and in orange for the stable condition. In addition, the return of anxiety after a reinstatement procedure was investigated: after the extinction phase, two painful stimuli were given to half of the participants in each condition (reinstatement group), and not to the other half (control group).

Participants' verbal reports and physiological measures showed acquisition and extinction of experimentally induced fear of movement-related pain. However, no effect of the threatening information about skin reactivity (inflation, deflation or stable) was found on acquisition, extinction or return of fear. However, a sensitization effect was observed: although the pain stimuli provided were of identical intensity, participants experienced them as increasingly painful over the course of the experiment. This suggests that the information about the fragility of skin may have increased the perceived threat in all groups. Furthermore, it was found that the fear of the painful movement returned in the reinstatement group after the administration of two additional pain stimuli post-extinction (a differential return of anxiety). In the physiological measurements (eye-blinking reflex), this group showed a (non-differential) return of fear for both the painful and the non-painful movement. It did not make a difference whether the participant was faced with an increasing, decreasing or stable threat during the task. The results suggest that the threat manipulation might not have worked or that it was not sensitive enough to yield group-specific effects. We replicated acquisition, extinction, and return of experimentally conditioned fear of movement-related pain, but the visual and verbal threat manipulation failed to generate additional effects.

In chapter 4, a study on the generalization of extinction after exposure in vivo treatment is presented. Exposure in vivo has been shown to be a successful treatment in reducing pain-related fear, disability and experienced pain in chronic pain 
patients with pain-related fear. Experimental studies, however, show that extinction learning is context-dependent; there is a difference between learning in the treatment context, and apply what was learned in the home or work situation. This raises doubts whether post-treatment patients can generalize the extinction of painrelated fear for movements or activities that were performed during treatment to new activities that they may re-interpret as threatening.

This study examined whether generalization to new threatening situations is promoted by exposure treatment (15 sessions) exposing patients to a variety of activities (Multiple Exposure condition), compared to a treatment exposing patients to the same set of activities several times in a row (Repeated Exposure condition). In the Multiple Exposure condition $(\mathrm{N}=4)$, patients were exposed once to at least 15 activities. In the Repeated Exposure condition $(N=4)$, patients were exposed to only three activities during five sessions each. Generalization of extinction to new activities was tested by an independent observer who asked patients to perform several new activities, directly after treatment and at 6 months follow-up. Patients scored these activities (that were not addressed during treatment) as very threatening before the start of treatment. In addition, randomized replicated single case experimental designs were used to evaluate the effects of treatment on pain-related fear, personal relevant activities and experienced pain. Included were patients with CRPS-I reporting high levels of pain-related fear.

It was hypothesized that the Multiple Exposure condition would facilitate generalization, but patients from both conditions performed equally well at both generalization tests. All patients performed the requested activities both immediately after treatment and 6 months after completion of treatment. Daily measures showed that the Multiple Exposure condition is preferred to reduce pain-related fear, pain catastrophizing and experienced pain. Patients in both conditions indicate that they can perform relevant personally activities again after treatment. This was also determined by an independent observer. Almost all patients showed a reliable improvement on the Leeds Reliable Change Index with respect to perceived disability, fear of (re-)injury, catastrophizing about pain and the threat value of activities, both after treatment and at 6 months follow-up.

In conclusion, patients dare to perform new activities that were not performed during treatment after exposure in vivo treatment, irrespective of whether they have performed only a few activities during treatment, or many different activities only once. To improve other outcome measures, such as pain-related fear, catastrophizing about pain, and experienced pain, exposure to different activities is to be preferred over exposure to repeated activities.

Chapter 5 presents a randomized controlled trial comparing exposure in vivo with pain-contingent physical therapy ("care as usual"), for CRPS-I patients with at 
least moderate levels of self-reported pain-related fear. CRPS-I highly affects patients' ability to perform daily life activities and pain-related fear might be a key target in order to reduce their disability levels and improve their quality of life. Treatments such as pain-contingent physical therapy, aiming at reducing pain have shown little improvements on pain and disability in CRPS-I, whereas novel exposure-based treatments targeting pain-related fears have shown to be promising. Therefore, a randomized controlled trial was conducted including 46 patients. The primary outcome was self-reported disability, for upper and lower extremity respectively. Secondary outcomes were self-reported pain-intensity, pain-catastrophizing, perceived harmfulness of physical activity, and health-related quality of life. Patients in both treatment conditions were offered 17 hours of treatment over a 17-week period.

The results were striking. Exposure in vivo was superior to pain-contingent treatment as usual in reducing upper extremity disability from pre- to post-treatment and from pre-treatment to 6-months follow-up. Exposure in vivo was also superior in reducing lower extremity disability from pre-treatment to 6-months follow-up, but not from pre- to post-treatment. Also, more patients from the exposure condition showed reliable progression on the Leeds Reliable Change Index than patients who received pain-contingent physiotherapy. All secondary outcomes significantly favored exposure pre- to post-treatment, as well as pre-treatment to 6-months follow-up: self-reported pain-intensity, pain-catastrophizing, perceived harmfulness of physical activity, and health-related quality of life.

Concluding, exposure to daily activities shows to be more effective than a protective pain-contingent treatment in reducing self-reported disability in daily life, as well as in reducing pain-related fear, experienced pain and in improving quality of life, for CRPS-I patients with at least moderate levels of pain-related fear. A remaining question is if exposure is cost-effective as well; for example in reducing the use of health-care or increased participation in work.

Therefore, chapter 6 evaluates the cost-effectiveness of exposure in vivo in patients with Complex Regional Pain Syndrome Type I (CRPS-I) and elevated levels of pain-related fear, compared to pain-contingent physical therapy. Data from the randomized controlled trial presented in chapter 5 were used to compare the cost-effectiveness of exposure in vivo versus pain-contingent physical therapy from a societal perspective. Interventions such as exposure in vivo and physiotherapy influence the quality of life of patients. Improvements in quality of life can justify the costs of an intervention. An effect on the quality of life can be regarded as the "usefulness" or utility of the intervention, and the value of this must outweigh the costs. In order to operationalize utility, the outcome measure "Quality-Adjusted Life Years" (QALY) is used. The main outcomes were changes in the SF-36 physical component scale and quality-adjusted life years. To calculate costs, intervention 
costs, other healthcare costs, other costs to patient and family and productivity losses were included. Patients completed cost diaries every month, up to six months after the end of treatment. In economic evaluations, it is common to determine the degree of uncertainty in costs and effects. Uncertainty was estimated using non-parametric bootstrap analysis, cost-effectiveness acceptability curves and costeffectiveness planes.

Over 6 months after treatment, exposure in vivo resulted in greater improvement in physical health-related quality of life and quality adjusted life years than pain-contingent physical therapy. Despite higher initial treatment costs, healthcare costs were significantly reduced, and exposure in vivo showed a tendency to reduce total societal costs compared to pain-contingent physical therapy. Patients used significantly less medication after exposure in vivo than after pain-contingent physical therapy (medication on prescription as well as over-the-counter medication). They also need significantly less help from family members. The results of the bootstrap analyses showed that in 95\%, exposure gives significantly better effects at lower costs for the physical health-related quality of life and the quality-adjusted life years. Sensitivity analyses, one with different treatment costs and one with complete cases only, confirmed robustness of these findings. Concluding, exposure in vivo is more cost-effective than PPT in CRPS patients with pain-related fear. The initial higher costs for exposure in vivo, explained by the additional costs for a psychologist, are offset by a significant long-term reduction of costs for health care utilization. Furthermore, tendencies to reduce hours absent from work and total societal costs were found. The results justify reimbursement of exposure treatment by insurance companies and incorporation of exposure in vivo as a viable treatment for patients with CRPS-I and pain-related fear in national and international clinical guidelines.

In chapter $\mathbf{7}$ provides a general discussion, summarizing the main findings of the studies. In addition, recent developments are discussed that are related to the topics described in this thesis. Since the conduction of the studies in this thesis, insights in the mechanism of exposure treatment have evolved. The emotional processing theory presumed that habituation was the mechanism by which exposure was effective: repeated confrontation with a feared stimulus was supposed to result in a decrease in fear. Recently, it became clear that fear-reduction is not a reliable indicator of learning during exposure. This led to a changed perspective on the underlying mechanism of exposure, which is currently regarded as a method to disconfirm negative, fearful expectancies by experiencing disconfirmation between the expectancy and experience (expectancy violation). Due to the learning of new CS-US associations, the meaning of the CS becomes ambiguous; besides the old excitatory meaning the CS (predicting the US) now also holds an inhibitory meaning 
as well (predicting absence of the US). However, in patients with elevated anxiety levels (due to anxious personality traits or anxiety disorders), this inhibitory learning mechanism may be hampered. Techniques to optimize inhibitory learning have been described, and several techniques can be easily integrated in exposure for patients with pain-related fear. For example, designing more "extreme" behavioral experiments that are likely to provide a pronounced mismatch between expectancy and experience, instead of stepwise following a fear hierarchy. In addition, patients should be instructed to focus on the non-occurrence of the feared outcome (no mental distraction, no talking during the performance of threatening activities). Exploring alternative outcomes before actual performance of activities might reduce the surprise-value of the outcome of a behavioral experiment, so formulating alternative hypothesis and showing the activity by the therapist before performance of the patient is currently omitted. Exposure can easily be provided in multiple contexts, with varying levels of fear, and patients might be advised to mentally reinstate the exposure-context. Affect labeling, verbalization of one's current emotional experience, is another technique to optimize inhibitory learning.

Activities in an exposure treatment for pain-related fear are and should be primarily chosen based on the mismatch they create between expectancy and actual experience, but personal relevance and likeability might also be important, although this subject has not been extensively studied yet. Recent adaptations to the fearavoidance model suggest that when patients prefer control over pain, they tend to avoid activities. When patients have other goals, such as accomplishing personal relevant tasks, this results in confrontation with painful activities. Cross-sectional studies show that these goal-conflicts experienced by chronic pain patients (between avoidance behavior aimed to prevent harm or pain, and confronting activities, helping them to engage in valued daily activities) are associated with pain-related fear, higher pain-intensity and negative affect. Furthermore, compliance with exposure treatment might be enhanced when a patient experiences immediate reward in the first sessions.

Finally, directions for future research are discussed. Besides integrating the insights on inhibitory learning that are previously addressed, it might be worthwhile to implement additional techniques to exposure in vivo. For example, counterconditioning might help to restore the affective value of activities that are not avoided any more after exposure but might still be disliked because of their previous negative association with pain and/or harm. Another direction to improve the effects of exposure is the addition of pharmacological enhancers; agents that might enhance inhibitory learning and memory-processes during exposure treatment. Furthermore, it seems also important to strengthen positive, protecting mechanisms in chronic pain patient, for example resilience and acceptance. 
Based on the abovementioned findings, it is concluded that exposure in vivo is successful in reducing disability, pain-related fear and the pain-experience in patients with CRPS-I. Furthermore, this novel behavioral treatment reduces healthcare costs. It seems to be preferred to include multiple activities in an exposure in vivo treatment for pain-related fear, creating multiple mismatches between the negative outcome a patient is expecting, and the actual experience of performing the activity without the expected negative consequences. Techniques to optimize inhibitory learning are recently implemented, and future studies specifically in painrelated fear should examine if these further improve the effects of treatment for fearful chronic pain patients. 


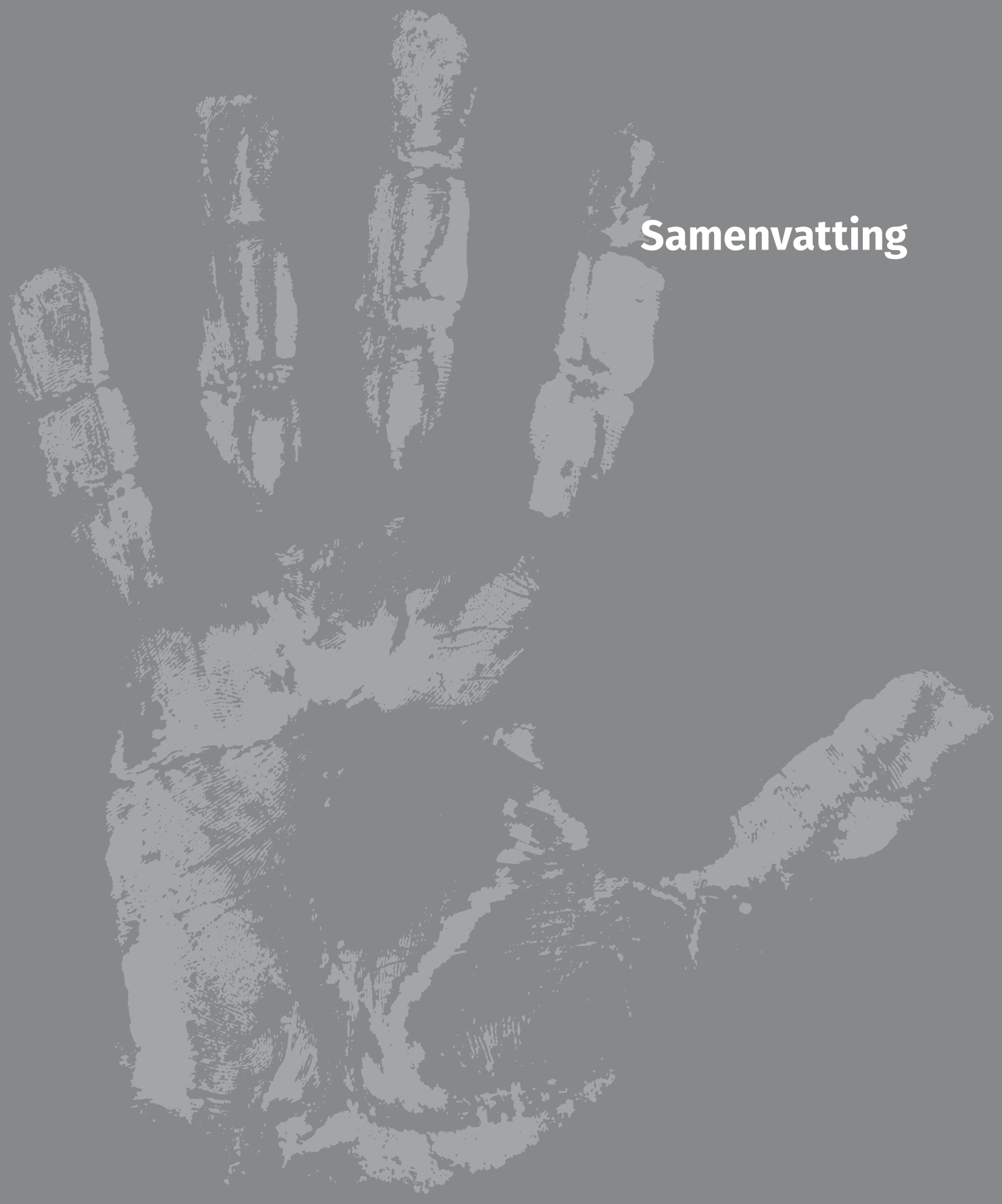



Dit proefschrift richt zich op pijn-gerelateerde angst bij patiënten met chronische pijn, en meer specifiek op de extinctie van angst middels de exposure in vivo behandeling bij patiënten met Complex Regionaal Pijn Syndroom Type I. Hoofdstuk 1 begint met een algemene inleiding over pijn, angst, leren en de exposure in vivo behandeling. Pijn wordt vanuit het biomedische model van oudsher gedefinieerd als een signaal van letsel of weefselschade. Hierdoor wordt een één-op-één-relatie gesuggereerd tussen de mate van letsel en de intensiteit van pijn. Inmiddels is echter aangetoond dat de ervaring van pijn veel complexer is: weefselbeschadiging is niet altijd pijnlijk (MRI-technieken bevestigen dat afwijkingen heel gebruikelijk zijn bij pijnvrije personen), en aan de andere kant kan pijn optreden zonder letsel (in de meeste gevallen van lage rugpijn wordt geen pathologie gedetecteerd). Pijn kan daarom beter niet worden opgevat als een teken van weefselbeschadiging, maar als een signaal dat gedrag aanmoedigt wat erop gericht is te ontsnappen aan een gevaarlijke situatie. De ervaring van pijn wordt naast lichamelijke factoren óók beïnvloed door centrale psychologische mechanismen als cognities en emoties. Zo kan bijvoorbeeld een constante fysiologische pijnstimulus als meer of minder pijnlijk worden ervaren, afhankelijk van de instructie dat deze stimulus veilig of juist schadelijk is. De interactie van fysiologische en psychologische factoren toont aan dat een biopsychosociaal perspectief nodig is om de complexiteit van pijn te begrijpen. Vanuit dat perspectief wordt pijn momenteel gedefinieerd als "een onplezierige sensorische en emotionele ervaring geassocieerd met feitelijke of potentiële weefselbeschadiging, of beschreven in termen van beschadiging". Daarnaast neemt de complexiteit van pijn toe als in de loop van de tijd de veronderstelde relatie tussen weefselbeschadiging en pijn twijfelachtiger wordt. Wanneer pijn "na de verwachte periode voor genezing" blijft bestaan, wordt deze gedefinieerd als chronische pijn. Paradoxaal genoeg kunnen beschermende gedragingen, die adaptief waren in een situatie van acute pijn met weefselbeschadiging, het probleem verergeren wanneer de pijn eenmaal chronisch is.

Het vrees-vermijdingsmodel stelt dat de reactie van een individu op pijn zowel confrontatie als vermijding kan zijn. De meeste mensen beoordelen pijn als onaangenaam, maar niet als een bedreiging of catastrofe. Daarom gaan ze proactief de confrontatie met de pijn aan, hervatten ze dagelijkse activiteiten en rapporteren op de lange termijn een afname van de ervaren pijn. Er zijn echter ook individuen die een catastrofale betekenis toeschrijven aan de pijnervaring, bijvoorbeeld als een teken van schade of een voorspeller van verergerende pijn. Deze catastrofale interpretaties geven aanleiding tot pijn-gerelateerde angst (bijvoorbeeld angst voor pijn, bewegingsangst, angst voor (hernieuwd) letsel). Angst veroorzaakt hypervigilantie: een verhoogde staat van sensorische gevoeligheid, die gepaard gaat met gedrag gericht op het detecteren en vermijden van dreiging. Hypervigilantie verstoort de aandacht voor de uitvoer van relevante activiteiten, en kan de detectie van pijn en 
andere aversieve lichaamssignalen versterken. Een angstig iemand zal daarnaast geneigd zijn defensief te reageren op pijn, bijvoorbeeld door vermijdingsgedrag te vertonen. Bij chronische pijnpatiënten verliest vermijdingsgedrag echter zijn adaptieve functie als beschermende strategie. Het letsel is namelijk genezen, ondanks aanhoudende pijn, en pijn is meestal geen teken meer van daadwerkelijk gevaar. Daardoor resulteert het vermijden van relevante dagelijkse activiteiten in het ervaren van beperkingen in dagelijkse activiteiten, en heeft het een negatief effect op stemming en kwaliteit van het leven. Deze negatieve gevolgen van vermijding versterken op hun beurt de pijnervaring, waardoor de vicieuze cirkel die het vrees-vermijdingmodel beschrijft in stand gehouden wordt.

Leertheorieën helpen te begrijpen waarom mensen angstig worden van onschadelijke stimuli. Acquisitie (aanleren), generalisatie (uitbreiden) en extinctie (uitdoving) van angst kunnen worden begrepen vanuit de principes van klassieke conditionering (het leren van verbanden) en de invloed die dit vervolgens heeft op het gedrag vanuit operante leerprincipes (gedrag neemt toe of juist af door respectievelijk beloning en straf). Exposure in vivo is gebaseerd op klassieke conditioneringsprincipes en is de aangewezen behandeling wanneer er sprake is van pathologische angst. Bij pijn-gerelateerde angst is deze behandeling er op gericht beperkingen in de uitvoer van activiteiten te verminderen door catastrofale verwachtingen ten aanzien van pijn en activiteiten uit te dagen en te corrigeren.

Verschillende Randomized Controlled Trials (RCT's, de gouden standaard binnen onderzoek) hebben aangetoond dat exposure in vivo effectief is in het verminderen van beperkingen, pijn-gerelateerde angst en de ervaren pijn bij patiënten met chronische lage rugpijn. Herhaalde experimentele single-case studies lieten vergelijkbare resultaten zien, niet alleen voor chronische lage rugpijn, maar ook voor andere chronische pijnaandoeningen, zoals whiplash, KANS (klachten van armen, nek en schouder) en Complex Regionaal Pijn Syndroom Type I (CRPS-I). CRPS-I is een intrigerende klinische manifestatie van chronische pijn met een onbekende pathofysiologie. CRPS-I wordt gekenmerkt door hevige pijn die niet in verhouding staat tot de uitlokkende gebeurtenis en die gelokaliseerd is in een distaal deel van een ledemaat. Daarnaast gaat CRPS-I vergezeld met abnormale zwelling, veranderingen in huidskleur en temperatuur, en een afwijkende transpiratie. Ondanks een verscheidenheid aan medische behandelingen zijn de beperkingen die CRPS-I patiënten in hun dagelijks leven ervaren vaak progressief. Net als bij andere chronische pijnpatiënten bleek ook bij CRPS-I-patiënten pijn-gerelateerde angst een rol te spelen in de beperkingen die werden ervaren. Een eerste herhaalde experimentele single-case studie liet zien dat exposure in vivo een veelbelovende behandeling kan zijn voor deze groep. 
Vervolgens worden in dit hoofdstuk een aantal punten met betrekking tot pijn-gerelateerde angst en exposure in vivo genoemd die verder onderzoek vragen. Deze punten zijn vertaald in de volgende vragen, waarop dit proefschrift een antwoord wil geven:

1. Hoe kunnen we acquisitie (het verwerven) en extinctie (het uitdoven) van pijn-gerelateerde angst begrijpen vanuit een leertheoretisch perspectief?

2. Kan verbale en visuele manipulatie van pijn-gerelateerde dreiging de acquisitie, extinctie en terugkeer van angst bij pijnvrije individuen beïnvloeden?

3. Wordt generalisatie van de exposure in vivo behandeling vergemakkelijkt wanneer veel verschillende activiteiten worden uitgevoerd of wanneer een paar activiteiten verschillende keren worden herhaald?

4. Is exposure in vivo een effectieve behandeling om beperkingen in activiteiten te verminderen (primaire uitkomstmaat), en daarnaast in het reduceren van pijn-gerelateerde angst, pijnintensiteit, en het verbeteren van de kwaliteit van leven bij patiënten met CRPS-I en pijn-gerelateerde angst?

5. Is exposure in vivo in vergelijking met pijn-contingente fysiotherapie kosteneffectief bij CRPS-I-patiënten met pijn-gerelateerde angst?

In de achtereenvolgende hoofdstukken wordt steeds een van deze onderzoeksvragen behandeld.

Hoofdstuk 2 richt zich op de mechanismen die ten grondslag liggen aan de acquisitie en extinctie van pijn-gerelateerde angst. Er wordt een beschrijvend overzicht van de literatuur over angstconditionering en extinctie gepresenteerd, specifiek toegepast op pijn-gerelateerde angst. Klassieke conditionering van angst vindt plaats wanneer een emotioneel neutrale stimulus geassocieerd wordt met een inherent aversieve ervaring, waardoor deze stimulus de mogelijkheid verwerft om zelf een angstige reactie op te roepen. De inherent aversieve ervaring is de ongeconditioneerde stimulus (US, bijvoorbeeld pijn geassocieerd met schade of (hernieuwd) letsel). De aanvankelijk neutrale stimulus die geassocieerd wordt met de aversieve ervaring is de geconditioneerde stimulus (CS, bijvoorbeeld bewegingen en activiteiten), en de angst die vervolgens opgeroepen wordt is de geconditioneerde respons (CR).

Mensen kunnen CS-US-associaties leren door feitelijke ervaringen, maar ook door het krijgen van mondelinge informatie, en door iemand anders te observeren die een CS-US-verband ervaart ("modelling"). Over het algemeen is angstconditionering een adaptieve vorm van leren, maar het kan pathologisch worden wanneer angstige reacties op een CS aanhouden, terwijl de CS-US-contingentie niet langer aanwezig is. In het geval van pijn-gerelateerde angst kan een persoon bijvoorbeeld nog steeds pijn ervaren, maar wanneer er geen letsel of beschadiging meer is, helpt het niet om bewegingen of activiteiten te vermijden. 
Er zijn verschillende instrumenten beschikbaar om vast te stellen of er sprake is van pijn-gerelateerde angst. Vragenlijsten kunnen helpen om de angst van de patiënt specifiek te maken; verwacht de patiënt bijvoorbeeld schade, letsel of verwonding, toenemende pijn, verlies van werk of het verliezen van onafhankelijkheid (US)? Foto's van bewegingen en activiteiten helpen te beoordelen welke verschillende stimuli (CS-en) angst oproepen en welke verwachtingen (US) de patiënt heeft bij een specifieke activiteit. De PHODA (Photographic Series of Daily Life Activities), een serie foto's waarop activiteiten uit het dagelijks leven afgebeeld staan, is een instrument wat hiervoor gebruikt wordt binnen exposure in vivo. Een interview wordt gebruikt om informatie te verzamelen over de verstoren effecten van het chronische pijnprobleem en de samenhang tussen de verschillende aspecten. Wanneer geconcludeerd wordt dat pijn-gerelateerde angst een belangrijke rol speelt bij het in stand houden van de beperkingen, dan is een exposure in vivo behandeling geïndiceerd.

Tijdens een exposure in vivo behandeling worden gedragsexperimenten opgesteld waarin de patiënt wordt blootgesteld aan de CS, in het geval van pijn-gerelateerde angst dus aan een beweging of activiteit, zodat hij kan ervaren dat zijn verwachting ten aanzien van het optreden van de US, de gevreesde consequentie zoals schade of ondraaglijke pijn, niet kloppen. Dit proces wordt extinctie genoemd. Extinctie leidt echter niet tot het vergeten of "ontleren" van de CS-US-associatie. Er ontstaat een nieuwe, "veilige" associatie die bestaat naast de oude, bedreigende associatie. De CS wordt na exposure in vivo dus een ambigue stimulus.

Vervolgens wordt in dit hoofdstuk wetenschappelijk bewijs, verkregen bij andere angststoornissen, samengevat en toegepast op de exposure behandeling voor pijn-gerelateerde angst. Alle onderdelen van de behandeling zijn er op gericht dat de patiënt leert dat bewegen veilig is. Naast aannames van de patiënt dat activiteiten schadelijk en gevaarlijk zijn, worden nieuwe ervaringen opgedaan; bewegingen veroorzaken geen schade, hoewel er wel pijn kan optreden. Zo wordt er educatie gegeven over het vrees-vermijdingsmodel zodat de patiënt kan begrijpen hoe zijn pijn en beperkingen in stand worden gehouden. Hierna gaat de patiënt tijdens de gedragsexperimenten daadwerkelijk ervaren dat de gedachte dat pijnlijke bewegingen schadelijk zijn niet klopt.

Ook wordt in dit hoofdstuk ingegaan op de effectiviteit van exposure bij pijn-gerelateerde angst, en daarnaast worden onderwerpen benoemd waar nog onvoldoende wetenschappelijk onderzoek naar verricht is, zoals de rol van pijn-gerelateerde angst bij de overgang van acute naar chronische pijn, behandelingen anders dan exposure in vivo die mogelijk ook pijn-gerelateerde angst reduceren, zoals bijvoorbeeld Acceptance and Commitment Therapy (ACT), de rol van modelling binnen exposure, het toepassen van exposure door niet-psychologen, en de generalisatie van exposure. De rol van veiligheidsgedrag binnen exposure en of exposure 
gericht moet zijn op angstreductie of op het faciliteren van inhibitorisch leren is voor pijn-gerelateerde angst ook nog onvoldoende onderzocht. Toevoeging van interoceptieve exposure en het hebben van aandacht voor de persoonlijke doelen van de patiënt zouden de effecten van exposure voor pijn-gerelateerde angst verder kunnen versterken.

De resultaten van een experimenteel onderzoek naar de invloed van informatie op de dreigwaarde van pijn bij gezonde individuen worden gepresenteerd in hoofdstuk 3. Studies met het Voluntary Joystick Movement (VJM)-paradigma bevestigen dat gezonde proefpersonen angst kunnen verwerven voor een pijnlijke beweging in een experimentele context. Het VJM-paradigma maakt gebruik van differentiële proprioceptieve conditionering van angst: één beweging (geconditioneerde stimulus, CS+) wordt herhaaldelijk tegelijkertijd aangeboden met een pijnlijke stimulus (ongeconditioneerde stimulus, pijn-US) en een andere beweging (CS-) wordt dat niet. Als reactie op de CS+ verschijnen defensieve angst en vermijdingsreacties (CR's). Defensieve reacties kunnen voortkomen uit directe ervaring met een CS-US-relatie, maar individuen leren ook van verbale informatie en observatie. Het doel van deze studie was onderzoeken of de acquisitie van pijn-gerelateerde angst door directe ervaring, kan worden geïntensiveerd of verzwakt door verbaal en visueel overgedragen informatie over de betekenis van de pijn.

Bij alle deelnemers werd bij aanvang van het experiment een (nep) sensor op de huid bevestigd. Om de intensiteit van de pijn te bepalen kregen deelnemers pijnstimuli van oplopende intensiteit aangeboden, in deze fase hing het toedienen van deze pijnstimuli nog niet samen met bewegingen. Na deze kalibratiefase inspecteerde de onderzoeker de huid en vertelde de deelnemer dat er een verhoogde huidreactiviteit werd waargenomen en dat er daarom tijdens de taak een "huid-reactiviteitsmeting" te zien zal zijn, die de kwetsbaarheid van de huid voor schade, zoals blaren of verbranding weergeeft. Deelnemers werd gevraagd om tijdens de uitvoering van de taak de informatie van de sensor op het computerscherm zorgvuldig te bewaken. Op het computerscherm werd een balk getoond, in kleur variërend van groen via oranje naar rood, met daarin een pointer die de kwetsbaarheid van de huid aangeeft. Bij aanvang van de taak stond de pointer voor alle deelnemers op oranje. Afhankelijk van de willekeurig toegewezen conditie verschilde de visuele informatie tijdens de taak: deelnemers in de inflatieconditie zagen de pointer verschuiven van oranje naar bijna-rood, de deelnemer informerend over een toenemende dreiging voor beschadiging van de huid. In de deflatieconditie verschoof de pointer geleidelijk naar bijna groen, wat de deelnemers informeert dat de huid veilig is. In de stabiele conditie bleef de pointer gedurende het hele experiment in de oranje zone, waarbij de dreiging voor de huid gelijk werd gehouden met de eerder gegeven informatie. Tijdens extinctie bleef de pointer in de rode 
zone voor deelnemers in de inflatie-conditie, in groen voor de deflatie-conditie en in oranje voor de stabiele conditie. Daarnaast werd de terugkeer van angst na een reinstatement procedure onderzocht: na de extinctiefase werden twee pijnprikkels gegeven aan de helft van de deelnemers in elke conditie (reinstatement groep), en niet aan de andere helft (controlegroep).

De verbale rapporten en fysiologische metingen van de deelnemers toonden acquisitie en extinctie van experimenteel verworven angst voor bewegingsgerelateerde pijn aan. Er werd echter geen effect gevonden van de verschillende soorten informatie (inflatie, deflatie en stabiel) over de kwetsbaarheid van de huid op de acquisitie, extinctie of terugkeer van de angst. Wel werd een sensitisatie effect waargenomen: hoewel de gegeven pijnprikkels constant waren, werden de prikkels door de deelnemers als steeds pijnlijker ervaren in de loop van het experiment. Dit suggereert dat de informatie over de huidgevoeligheid de waargenomen dreiging in alle groepen kan hebben verhoogd. Verder bleek dat de angst voor de pijnlijke beweging terugkeerde in de reinstatement groep nadat na extinctie opnieuw twee pijnprikkels werden toegediend (een differentiële terugkeer van angst). In de fysiologische metingen (oogknipperreflex) toonde deze groep een (niet-differentiële) terugkeer van angst voor zowel de pijnlijke als de niet-pijnlijke beweging. Het maakte hiervoor geen verschil of de deelnemer tijdens de taak met toenemende, afnemende of constante dreiging was geconfronteerd.

Deze resultaten suggereren dat de dreigmanipulatie mogelijk niet werkte of dat deze niet onderscheidend genoeg was om per groep specifieke effecten te produceren. We repliceerden de acquisitie, extinctie en terugkeer van experimenteel geconditioneerde angst voor bewegingsgerelateerde pijn, maar de visuele en verbale dreigmanipulatie van de pijn kon geen extra effecten genereren.

In hoofdstuk 4 wordt een onderzoek gepresenteerd naar de generalisatie van extinctie na een exposure in vivo behandeling. Exposure in vivo is een succesvolle behandeling gebleken in het verminderen van pijn-gerelateerde angst, beperkingen en ervaren pijn bij chronische pijnpatiënten met pijn-gerelateerde angst. Experimentele studies tonen echter aan dat extinctie-leren afhankelijk is van de context; er is bijvoorbeeld een verschil tussen leren binnen de behandeling en het toepassen van het geleerde in de thuis- of werksituatie. Dit roept twijfels op of patiënten na de behandeling de extinctie van pijn-gerelateerde angst voor de bewegingen of activiteiten die tijdens de behandeling werden uitgevoerd, kunnen generaliseren naar nieuwe activiteiten die zij wellicht opnieuw als bedreigend interpreteren. Deze studie onderzocht of generalisatie naar nieuwe bedreigende situaties wordt bevorderd door een exposure behandeling (15 sessies) die patiënten aan veel verschillende activiteiten blootstelt (Multiple Exposure-conditie), in vergelijking met een behandeling die patiënten herhaaldelijk blootstelt aan dezelfde reeks 
activiteiten (Repeated Exposure-conditie). In de Multiple Exposure-conditie ( $\mathrm{N}=4)$ werden patiënten eenmalig blootgesteld aan minstens 15 activiteiten. In de Multiple Exposure-conditie $(\mathrm{N}=4)$ werden patiënten gedurende vijf sessies aan slechts drie verschillende activiteiten blootgesteld. Generalisatie van extinctie naar nieuwe activiteiten werd getest door een onafhankelijk observator, die elke patiënt vroeg om verschillende nieuwe activiteiten uit te voeren. Dit gebeurde direct na afronding van de behandeling en 6 maanden later (follow-up). Patiënten hadden deze activiteiten (die niet aan de orde kwamen tijdens de behandeling) als zeer bedreigend gescoord vóór aanvang van de behandeling. Naast de generalisatietesten werden gerandomiseerde, gerepliceerde, single case experimenten met dagelijkse metingen gebruikt om de effecten van de behandeling te evalueren op pijn-gerelateerde angst, persoonlijk relevante doelen en de ervaren pijn. Patiënten met CRPS-I en een hoge mate van pijn-gerelateerde angst werden geïncludeerd voor deze studie.

De hypothese was dat meervoudige blootstelling generalisatie zou bevorderen, maar patiënten uit beide behandelcondities presteerden even goed bij de generalisatietesten. Alle patiënten voerden de gevraagde activiteiten uit, zowel direct na behandeling als 6 maanden na afronding van de behandeling. De dagelijkse metingen toonden aan dat de Multiple Exposure-conditie de voorkeur heeft boven de Repeated Exposure-conditie om pijn-gerelateerde angst, catastroferen over pijn en de ervaren pijn te verminderen. Patiënten in beide condities gaven aan dat zij weer persoonlijk relevante activiteiten kunnen uitvoeren na de behandeling. Dit werd ook door een onafhankelijke observator vastgesteld. Bijna alle patiënten lieten, zowel na behandeling als 6 maanden daarna, een betrouwbare verbetering zien op de Leeds Reliable Change Index ten aanzien van ervaren beperkingen, angst voor (hernieuwd) letsel, catastroferen over pijn en de dreigwaarde van activiteiten. Concluderend durven patiënten na exposure in vivo nieuwe activiteiten uit te voeren die niet aan de orde kwamen tijdens de behandeling. Het maakt daarvoor niet uit of ze tijdens de behandeling slechts enkele activiteiten herhaald hebben uitgevoerd, of veel verschillende activiteiten eenmalig. Om een verbetering te geven op uitkomstmaten als pijn-gerelateerde angst catastroferen over pijn, en ervaren pijn heeft blootstelling aan verschillende activiteiten de voorkeur boven blootstelling aan herhaalde activiteiten.

Hoofdstuk 5 beschrijft een Randomized Controlled Trial waarin exposure in vivo wordt vergeleken met pijn-contingente fysiotherapie ("care as usual": gebruikelijke zorg), voor CRPS-I-patiënten die een verhoogde mate van pijn-gerelateerde angst rapporteren. CRPS-I verstoort het vermogen van patiënten om dagelijkse activiteiten uit te voeren in hoge mate. Pijn-gerelateerde angst kan een belangrijk aangrijpingspunt zijn om deze beperkingen te verminderen en de kwaliteit van leven te verbeteren. Behandelingen zoals pijn-contingente fysiotherapie, gericht op het 
verminderen van pijn geven juist weinig verbetering op ervaren pijn en beperkingen bij CRPS-I patiënten, terwijl exposure behandelingen die de focus leggen op pijn-gerelateerde angst veelbelovend zijn gebleken. Daarom werd een gerandomiseerde gecontroleerde studie uitgevoerd, waarvoor 46 patiënten werden geïncludeerd. De belangrijkste uitkomstmaat was de mate van ervaren beperkingen, voor zowel de bovenste- als onderste ledematen. Daarnaast werden zelf-gerapporteerde pijn-intensiteit, catastroferen over pijn, waargenomen schadelijkheid van activiteiten en gezondheids-gerelateerde kwaliteit van leven gemeten. Patiënten in beide behandelcondities kregen 17 uur behandeling aangeboden over een periode van 17 weken.

De resultaten waren opvallend. Exposure in vivo was significant beter dan pijn-contingente fysiotherapie in het verminderen van beperkingen van de bovenste ledematen, zowel wanneer de score van vóór en na de behandeling vergeleken werd, als de score vóór behandeling met de score 6 maanden follow-up. Exposure in vivo was ook superieur in het verminderen van de beperkingen van de onderste ledematen vóór behandeling vergeleken met 6 maanden follow-up, maar niet in de scores tussen vóór en na de behandeling. Ook laten structureel meer patiënten uit de exposure conditie een betrouwbare vooruitgang zien op de Leeds Reliable Change Index, dan patiënten die pijn-contingente fysiotherapie kregen. Exposure in vivo gaf verder significant betere uitkomsten op de zelf-gerapporteerde pijn-intensiteit, catastroferen over pijn, waargenomen schadelijkheid van activiteiten en gezondheids-gerelateerde kwaliteit van leven, zowel wanneer het verschil voor en na behandeling vergeleken wordt, als bij vergelijken van de verschilscore bij aanvang van de behandeling met 6 maanden follow-up.

De conclusie van deze studie is dat exposure in vivo effectiever is dan een beschermende pijn-contingente behandeling in het verminderen van beperkingen in het dagelijks leven, en daarnaast ook in het verminderen van pijn-gerelateerde angst, pijn en het verbeteren van de kwaliteit van leven, bij CRPS-I-patiënten met een verhoogde mate van pijn-gerelateerde angst. Een resterende vraag is of exposure ook kosteneffectief is, door bijvoorbeeld een verminderd gebruik van gezondheidszorg of een toegenomen participatie in het arbeidsproces.

Daarom evalueert hoofdstuk 6 de kosteneffectiviteit van exposure in vivo in vergelijking met pijn-contingente fysiotherapie bij patiënten met Complex Regionaal Pijn Syndroom Type I (CRPS-I) en verhoogde niveaus van pijn-gerelateerde angst. Gegevens uit de RCT gepresenteerd in hoofdstuk 5 werden gebruikt om de kosteneffectiviteit van beide behandelingen vanuit een maatschappelijk perspectief te vergelijken. Interventies als exposure in vivo en fysiotherapie hebben effect op de kwaliteit van leven van patiënten. Verbeteringen in de kwaliteit kunnen de kosten van een behandeling rechtvaardigen. Een effect op de levenskwaliteit kan gezien worden als het "nut" of utiliteit van de interventie, waarvan de waarde moet opwegen 
tegen de kosten. Om de utiliteit te operationaliseren wordt de uitkomstmaat "voor kwaliteit gecorrigeerde levensjaren" gebruikt. De belangrijkste uitkomstmaten voor deze studie waren veranderingen in de fysieke componentschaal van de SF-36 (een vragenlijst die de gezondheids-gerelateerde kwaliteit van leven meet) en de voor kwaliteit gecorrigeerde levensjaren (QALY). Qua kosten werden de kostprijs voor de interventie, overige kosten die patiënten maakten binnen de gezondheidszorg, andere kosten als gevolg van CRPS-I (bijvoorbeeld huishoudelijke hulp, inzet van familieleden of hulpmiddelen) en de kosten voor verlies van productiviteit meegenomen. Patiënten leverden maandelijks kostendagboekjes aan tot zes maanden na afloop van de behandeling. In economische evaluaties is het gebruikelijk de mate van onzekerheid rond kosten en effecten te bepalen. De mate van onzekerheid werd geschat met behulp van non-parametrische bootstrapanalyses, kosteneffectiviteitscurves en kosteneffectiviteitsvlakken.

Exposure in vivo resulteerde in de periode tot 6 maanden na behandeling in een grotere verbetering van de fysieke gezondheids-gerelateerde kwaliteit van leven dan pijn-contingente fysiotherapie. Ook leverde exposure in vivo meer voor kwaliteit gecorrigeerde levensjaren op. De aanvankelijke kosten voor een exposure behandeling zijn hoger dan de kosten voor pijn-contingente fysiotherapie, maar patiënten na exposure in vivo neigen ernaar minder maatschappelijke kosten te maken dan patiënten na pijn-contingente fysiotherapie. De kosten die patiënten na exposure maakten voor gezondheidszorg waren zelfs significant lager. Patiënten die met exposure werden behandeld gebruiken significant minder medicatie dan patiënten na pijn-contingente fysiotherapie (zowel medicatie op recept en vrij verkrijgbare medicatie). Ook hebben zij significant minder hulp van naasten nodig. De uitkomsten van de bootstrap analyses laten zien dat exposure in 95\% significant betere effecten geeft tegen lagere kosten voor de fysieke gezondheids-gerelateerde kwaliteit van leven en de voor kwaliteit gecorrigeerde levensjaren. Sensitiviteitsanalyses, met verschillende kosten voor de behandeling en met alleen complete data, bevestigden de robuustheid van deze bevindingen. Concluderend is exposure in vivo kosten-effectiever dan pijn-contingente fysiotherapie bij CRPS-patiënten met pijn-gerelateerde angst. De aanvankelijk hogere kosten voor exposure, door de extra inzet van een psycholoog, worden gecompenseerd door op de langere termijn de kosten voor gezondheidszorggebruik significant te verlagen. Ook werd een tendens gezien dat exposure in vivo de uren ziekteverzuim en de totale maatschappelijke kosten kan verminderen. De resultaten rechtvaardigen het opnemen van exposure als geschikte behandeling voor CRPS-I patiënten met pijn-gerelateerde angst voor vergoeding via zorgverzekeraars, en in nationale en internationale richtlijnen.

Hoofdstuk 7 bevat een algemene discussie, waarin de belangrijkste bevindingen van de verschillende studies worden samengevat. Daarnaast worden recente 
ontwikkelingen besproken die samenhangen met de onderwerpen die in dit proefschrift worden beschreven. Sinds de uitvoering van de studies in dit proefschrift zijn de inzichten in het mechanisme van de exposurebehandeling geëvolueerd. De emotionele verwerkingstheorie veronderstelde dat gewenning het mechanisme was waarmee exposure in vivo effectief was: herhaalde confrontatie met een gevreesde stimulus moest leiden tot een afname van angst. Het is echter duidelijk geworden dat angstreductie geen betrouwbare indicator is voor leren tijdens exposure. Dit leidde tot een veranderd perspectief op het onderliggende mechanisme van exposure, dat nu wordt beschouwd als een methode om negatieve, angstige verwachtingen te ontkrachten door het ervaren van disconfirmatie tussen verwachting en ervaring ("expectancy-violation"). Door het leren van nieuwe CS-US-associaties wordt de betekenis van de CS ambigu; naast de oude, exciterende betekenis (CS voorspelt het optreden van de US) heeft de CS nu ook een inhiberende betekenis (CS voorspelt het uitblijven van de US). Echter, bij patiënten met verhoogde angstniveaus (vanwege angstige persoonlijkheidskenmerken of angststoornissen) kan dit inhiberende leermechanisme belemmerd zijn. Technieken voor het optimaliseren van inhibitorisch leren zijn beschreven en verschillende technieken kunnen eenvoudig worden geïntegreerd in exposure in vivo voor patiënten met pijn-gerelateerde angst. Bijvoorbeeld meer "extreme" gedragsexperimenten opzetten, die waarschijnlijk een meer uitgesproken mismatch bieden tussen verwachting en ervaring, dan het stapsgewijs volgen van een angsthiërarchie. Bovendien moeten patiënten de instructie krijgen om zich te concentreren op het niet optreden van de gevreesde uitkomst (dus geen mentale afleiding, niet praten tijdens de uitvoering van bedreigende activiteiten). Het exploreren van alternatieve uitkomsten vóór de daadwerkelijke uitvoering zou de verrassingswaarde van de uitkomst van een gedragsexperiment kunnen verminderen, dus het formuleren van een alternatieve hypothese en het voordoen van de activiteit door de therapeut worden momenteel weggelaten. Exposure kan eenvoudig worden verstrekt in meerdere contexten, met verschillende niveaus van angst, en patiënten kunnen worden geadviseerd om de exposurecontext mentaal te herhalen. Affect-labeling, het verwoorden van de emotionele ervaring, is een andere techniek om inhibitorisch leren te optimaliseren.

Activiteiten moeten in een exposure-behandeling voor pijn-gerelateerde angst primair gekozen worden op basis van de mismatch die ze creëren tussen verwachting en feitelijke ervaring. Dat de patiënt de activiteit leuk vindt of dat 
deze persoonlijk relevant is, kan ook belangrijk zijn, hoewel dit onderwerp nog niet uitgebreid is bestudeerd. Recente aanpassingen aan het vrees-vermijdingsmodel suggereren dat wanneer patiënten de voorkeur geven aan controle over pijn, ze de neiging hebben om activiteiten te vermijden. Wanneer patiënten andere doelen hebben, zoals het uitvoeren van persoonlijke relevante taken, resulteert dit in confrontatie met pijnlijke activiteiten. Dwarsdoorsnede onderzoek toont aan dat dergelijke doelconflicten (tussen vermijdingsgedrag gericht op het voorkomen van schade of pijn, en confrontatie met activiteiten die hen helpen om waardevolle dagelijkse activiteiten uit te voeren) worden geassocieerd met pijn-gerelateerde angst, hogere pijn- intensiteit en negatief effect. Bovendien kan de therapietrouw voor de exposure behandeling worden verbeterd wanneer een patiënt onmiddellijk beloond wordt in de eerste sessies.

Ten slotte worden aanwijzingen voor toekomstig onderzoek besproken. Naast het integreren van de inzichten over inhibitorisch leren die eerder zijn behandeld, kan het de moeite lonen om aanvullende technieken toe te passen naast exposure in vivo. Contraconditionering kan bijvoorbeeld helpen de affectieve waarde te herstellen van activiteiten die na een exposure behandeling niet meer worden vermeden, maar die mogelijk nog steeds niet worden gewaardeerd vanwege hun eerdere negatieve associatie met pijn en/of letsel. Een andere mogelijkheid om de effecten van exposure in vivo te verbeteren is de toevoeging van farmacologische versterkers; middelen die inhiberende leer- en geheugenprocessen tijdens de behandeling kunnen versterken. verder lijkt het ook belangrijk om positieve, beschermende mechanismen bij chronische pijnpatiënten te versterken, bijvoorbeeld veerkracht en acceptatie.

Op basis van de bovengenoemde bevindingen wordt geconcludeerd dat exposure in vivo succesvol is in het verminderen van beperkingen, pijn-gerelateerde angst en ervaren pijn bij patiënten met CRPS-I. Bovendien vermindert deze gedragsmatige interventie de kosten voor gezondheidszorg. Bij voorkeur worden meerdere activiteiten opgenomen in een exposure in vivo behandeling zodat meerdere mismatches gecreëerd worden tussen de negatieve uitkomst die een patiënt verwacht, en de feitelijke ervaring van het uitvoeren van de activiteit zonder de verwachte negatieve gevolgen. Technieken voor het optimaliseren van inhibitorisch leren zijn onlangs geïmplementeerd en in toekomstige studies, specifiek bij patiënten met pijn-gerelateerde angst, moet onderzocht worden of deze de effecten van behandeling voor angstige chronische pijnpatiënten verder verbeteren. 



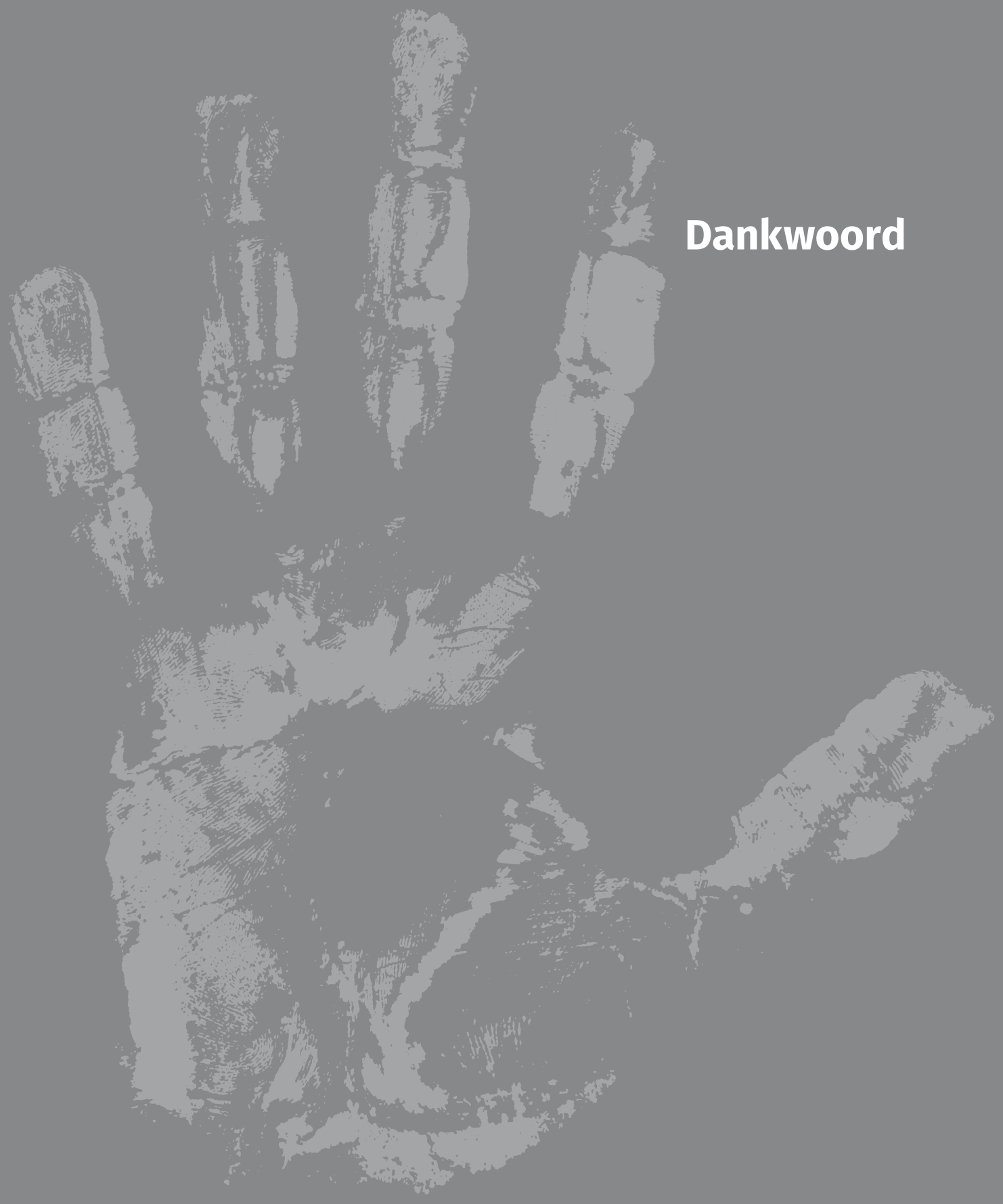



So it's been kind of a long road, but it was a good journey altogether (Sidney Poitier)

En toen...was er een boekje! En dat klinkt simpel, maar dat was het natuurlijk niet! In de bijna 10 jaar die ik aan dit proefschrift heb gewerkt hebben ontelbaar veel mensen mij gesteund, begeleid, kansen geboden, geholpen, geadviseerd, geïnspireerd, moed ingesproken en afleiding geboden. En nu ik bezig was om dat stukje proefschrift te schrijven waar ik me altijd op verheugd had, besef ik me dat het onmogelijk is om iedereen afzonderlijk te bedanken op een manier die recht doet aan wat jullie voor mij gedaan en betekend hebben in deze periode... Ik zou zó veel pagina's nodig hebben... Dus, lieve iedereen die een bijdrage heeft geleverd aan dit proefschrift, ik hoop dat jullie tevreden zijn met het eindresultaat en trots op jullie bijdrage, hoe tastbaar, abstract of op afstand, hoe groot of klein ook! Zonder jullie steun, begeleiding, adviezen, hulp, gezelligheid, luisterend oor, humor en geloof in mij was dit proefschrift er niet geweest!

ENORM BEDANKT voor ALLES!!! 



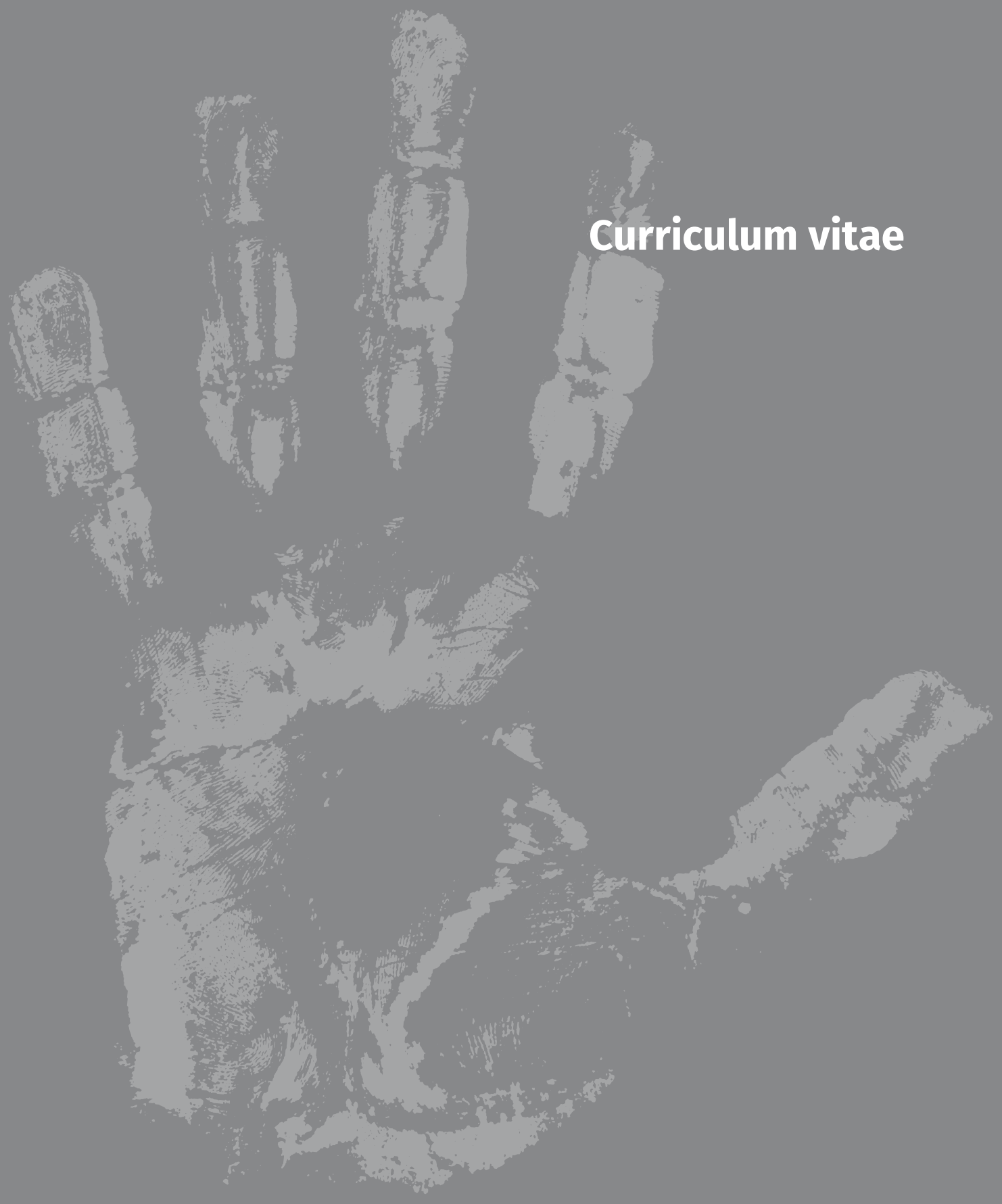



Marlies den Hollander was born on November $15^{\text {th }} 1974$ in Oosterhout, the Netherlands. After obtaining her athenaeum diploma at the Nassau Scholengemeenschap in Breda, she started to study Occupational Therapy at the Hogeschool Zuyd in Hoensbroek. During this study, she became interested in Evidence Based Practice. After obtaining her degree, she started to work as an Occupational Therapist and also started a part-time study Health Sciences at Maastricht University. In 2000, she started to work as an occupational therapist in Maastricht University Medical Center. Her interest in chronic pain began with the participation in the Back-Active trial, in which she was one of the therapists providing exposure in vivo and graded activity in patients with chronic low back pain. After obtaining her Master's degree in Mental Health in 2005, Marlies started to work as a psychologist in the Rehabilitation team of Maastricht University Medical Center and also in the internal work reintegration team for employees.

The opportunity to take over the RE-move project arose, and from December 2009 she joined this project as a part-time PhD-student. Due to the cooperation in an additional experimental study at the Research Group on Health Psychology at Leuven University, her project became a joint doctorate with Leuven University.

Since 2017, Marlies is working as a senior-researcher at Adelante Centre of Excellence in Rehabilitation. In this role, she investigates whether current knowledge on fear of movement related pain and exposure in vivo treatment can be applied to other diagnoses associated with chronic pain, such as patients who suffered from breast-cancer. She continuous her clinical work as a psychologist in pain-rehabilitation at Adelante Rehabilitation location Maastricht University Medical Center. Furthermore, she gives courses on exposure in vivo and is regularly invited for national and international lectures. 


\section{Peer reviewed publications}

den Hollander, M., Heijnders, N., de Jong, J.R., Vlaeyen, J.W.S., Smeets, R.J.E.M. \& Goossens, M.E.J.B. (in press). Exposure in vivo versus pain-contingent physical therapy in Complex Regional Pain Syndrome Type I: A cost-effectiveness analysis. International Journal of Technology Assessment in Health Care.

den Hollander, M., Goossens, M.E.J.B., de Jong, J.R., Ruijgrok, J.M., Oosterhof, J., Onghena, P., Smeets, R.J.E.M. \& Vlaeyen, J.W.S. (2016). Expose or protect? A randomized controlled trial of exposure in vivo vs pain-contingent treatment as usual in patients with complex regional pain syndrome type 1. Pain, 157, 2318-2329.

Lotzke, H., Jakobsson, M., Brisby, H., Gutke, A., Hagg, O., Smeets, R.J.E.M., den Hollander, M., Olsson, L.E. \& Lundberg, M. (2016). Use of the PREPARE (PREhabilitation, Physical Activity and exeRcisE) program to improve outcomes after lumbar fusion surgery for severe low back pain: a study protocol of a person-centred randomised controlled trial. BMC Musculoskeletal Disorders, 17, 349.

van Erp, R., Huijnen, I.P., Köke, A.J., Abbink, F.E., den Hollander, M. \& Smeets, R.J.E.M. (2016). Development and content of the biopsychosocial primary care intervention 'Back on Track' for a subgroup of people with chronic low back pain. Physiotherapy, 103, 160-166.

den Hollander, M., Meulders, A., Jakobs, M. \& Vlaeyen, J.W.S. (2015). The Effect of Threat Information on Acquisition, Extinction, and Reinstatement of Experimentally Conditioned Fear of Movement-Related Pain. Pain Medicine, 16, 2302-2315.

den Hollander, M., de Jong, J.R., Volders, S., Goossens, M.E.J.B., Smeets R.J.E.M. \& Vlaeyen, J.W.S. (2010). Fear reduction in patients with chronic pain: a learning theory perspective. Expert Reviews of Neurotherapeutics, 10, 1733-1745.

de Jong, J.R., Vlaeyen, J.W.S., Onghena, P., Cuijpers, C.J., den Hollander, M. \& Ruijgrok, J.M. (2005). Reduction of pain-related fear in complex regional pain syndrome type I: the application of graded exposure in vivo. Pain, 116, 264-275. 


\section{Submitted manuscripts}

den Hollander, M., de Jong, J.R. (shared first authorship), Onghena ,P. \& Vlaeyen, J.W.S. (submitted). Generalization of Exposure in Vivo in Complex Regional Pain Syndrome type I.

van Laake-Geelen, C.C.M., Smeets, R.J.E.M., van Meulenbroek, T., den Hollander, M., Goossens, M.E.J.B. \& Verbunt, J.A. (submitted). Exposure in vivo in patients with Painful Diabetic Neuropathy: Development of a treatment protocol.

Lotzke, H., Gutke, A., den Hollander, M., Smeets, R.J.E.M. \& Lundberg, M. (submitted). Lessons learned from developing PREPARE (PREhabilitation, Physical Activity and exeRcisE) an evidence-based prehabilitation program designed to improve functional outcomes after lumbar fusion surgery.

\section{Other publications}

Birklein, F., Huygen, F.J., Moseley, G.L., McCabe, C. \& den Hollander, M. (2012). Treatment of Complex Regional Pain syndrome: Where are we at, and where to now? IASP Press.

Ruijgrok, J.M., de Jong, J.R., Cuijpers, C.J., den Hollander, M. \& Loo, C.A (2007). Nieuwe behandelmethoden bij chronische pijn: "graded exposure in vivo". GAV Scoop, 11, 37-39.

den Hollander, M., de Jong, J.R. (2006). Graduele exposure in vivo voor pijngerelateerde angst bij patiënten met chronische pijn aan het bewegingsapparaat. Pijn Info, 11, $51-65$.

\section{Book chapters}

Köke, A., Huijnen, I.P., Geilen, M. \& den Hollander, M. (2017). Graded Activity en Exposure in Vivo. In: Handboek Behandeling van somatisch onvoldoende verklaarde lichamelijke klachten. Uitgeverij Lannoo Campus, red: Spaans, J., Rosmalen, J., van Rood, Y., van der Horst, H. \& Visser, S., pp. 365-376. 
den Hollander, M., Volders, S. \& Vlaeyen, J.W.S. (2017). Protocollaire behandeling van patiënten met chronische lage rugpijn: Exposure-in-vivotherapie. In: Protocollaire behandeling voor volwassenen met psychische klachten-Deel 3, Editie 2. Uitgeverij Boom, red: Keijsers, G., van Minnen, A., Verbraak, M., Hoogduin, K. \& Emmelkamp, P., pp. 395-429.

den Hollander, M. \& Vlaeyen, J.W.S. (2017). Richtlijnen bij moeizaam verlopende behandelingen van patiënten met chronische lage rugpijn. In: Protocollaire behandeling voor volwassenen met psychische klachten-Deel 3, Editie 2. Uitgeverij Boom, Uitgeverij Boom, red: Keijsers, G., van Minnen, A., Verbraak, M., Hoogduin, K. \& Emmelkamp, P., pp. 429-443.

den Hollander, M., Hermans, T.E. \& Strackke, R.P. (2016). De educatie voor volwassenen. In: Graded Exposure: een cognitief gedragsmatige aanpak van chronische pijn. Uitgeverij Bohn Stafleu en van Loghum, red: Verbunt, J. \& Smeets, R.J.E.M., pp. 29-46.

den Hollander, M., Huijnen, I.P. \& Smeets, R.J.E.M. (2016). Graded exposure in de praktijk: de behandeling bij volwassenen. In: Graded Exposure: een cognitief gedragsmatige aanpak van chronische pijn. Uitgeverij Bohn Stafleu en van Loghum, red: Verbunt, J. \& Smeets, R.J.E.M., pp. 47-59.

den Hollander, M. \& Smeets, R.J.E.M. (2016). Graded exposure bij complex regionaal pijn syndroom type1. In: Graded Exposure: een cognitief gedragsmatige aanpak van chronische pijn. Uitgeverij Bohn Stafleu en van Loghum, red: Verbunt, J. \& Smeets, R.J.E.M., pp. 69-77.

van Melick, M.B., den Hollander, M., Hermans, T.E. \& Smeets, R.J.E.M. (2016). Groepsbehandeling graded exposure. In: Graded Exposure: een cognitief gedragsmatige aanpak van chronische pijn. Uitgeverij Bohn Stafleu en van Loghum, red: Verbunt, J. \& Smeets, R.J.E.M., pp. 157-169.

Volders, S., de Peuter, S., den Hollander, M. \& Vlaeyen, J.W.S (2011). Protocollaire behandeling van patiënten met chronische lage rugpijn: Exposure in vivo therapie. In: Protocollaire behandelingen voor volwassenen met psychische klachten. Uitgeverij Boom, red: Keijsers, G., van Minnen, A. \& Hoogduin, K., pp. 169-196. 


\section{Presentations at international scientific meetings}

May 2017: Clinical workshop "Exposure in vivo in pain-related fear", in collaboration with prof. dr. J. Vlaeyen \& prof. dr. M. Craske, Genk, Belgium.

June 2016: World Congress of Behaviour and Cognitive Therapy", Melbourne, Australia. Oral presentation "Exposure in vivo in Complex Regional Pain Syndrome Type I", in workshop "Cognitive-Behavioral Treatment Approaches to Chronic Pain: Recent Theoretical and Clinical Developments", i.c.w. dr. A. Meulders, prof. dr. L. Moseley \& prof. dr. L. McCracken,

September 2015: International Summer School on Emotional Learning and Memory in Health and Psychopathology, Leuven, Belgium. Workshop "Exposure treatment in Patients with Chronic Pain", i.c.W. prof. dr. J.W.S Vlaeyen. Poster presentation "Considerations on exposure in pain-related fear".

November 2014: DCRM congress, Rotterdam, the Netherlands. Oral presentation "Effectiveness of exposure in vivo for patients with CRPS-I compared to standardized physical therapy".

May 2014: World Congress of the World Institute of Pain (WIP), Maastricht, the Netherlands. Oral presentation "Effectiveness of exposure in vivo for patients with CRPS-I, compared to physical therapy based on the current Dutch guidelines",

November 2013: International Scientific and Clinical Meeting Complex Regional Pain Syndrome 2013, Bath, United Kingdom. Oral presentation “Graded Exposure Therapy".

April 2013: Rheumatology Congress 2013, Birmingham, United Kingdom. Oral presentation "Graded exposure therapy: an approach to functional pain treatment", i.c.w. dr. J. Lewis.

April 2013: Annual Meeting of the British Pain Society, Bournemouth, United Kingdom. Oral presentation "Graded exposure in-vivo in CRPS" in workshop "Enhancing the self-management ability of chronic pain patients", i.c.w. prof. dr. C. McCabe en dr. K. Rodham. 
October 2012: International Pain Research Meeting, Marburg, Germany. Oral presentation "Acquisition and extinction of experimentally conditioned fear of movementrelated pain: Effects of US revaluation and reinstatement",

May 2012: Congress of the American Association for Psychological Science, Chicago, United States. Oral presentation "Graded exposure in-vivo for pain-related fear" in workshop "Pain, fear and suffering”, i.c.w. dr. A. Meulders, dr. P. Karsdorp \& dr. K. Wiech.

September 2011: European Federation of IASP Chapters, Hamburg, Germany. Poster presentation "Graded Exposure in Vivo: a case study of a 10-year old girl with Complex Regional Pain Syndrome Type I".

May 2011: National Complex Regional Pain Syndrome Conference "Advances in Science and Treatment", Bath, United Kingdom. Oral presentation "Theory of Graded Exposure in Vivo in Complex Regional Pain Syndrome Type I" and workshop "How to recognize pain-related fear in patients with CRPS-I".

August 2010: World Congress of the International Association for the Study of Pain, Montreal. Poster presentation "Generalization of graded exposure in vivo in Complex Regional Pain Syndrome Type I (CRPS-I)".

July 2006: World Congress Occupational Therapy, Sydney, Australia. Oral presentation "Occupational therapy outcomes of graded exposure in vivo in CRPS-I". 


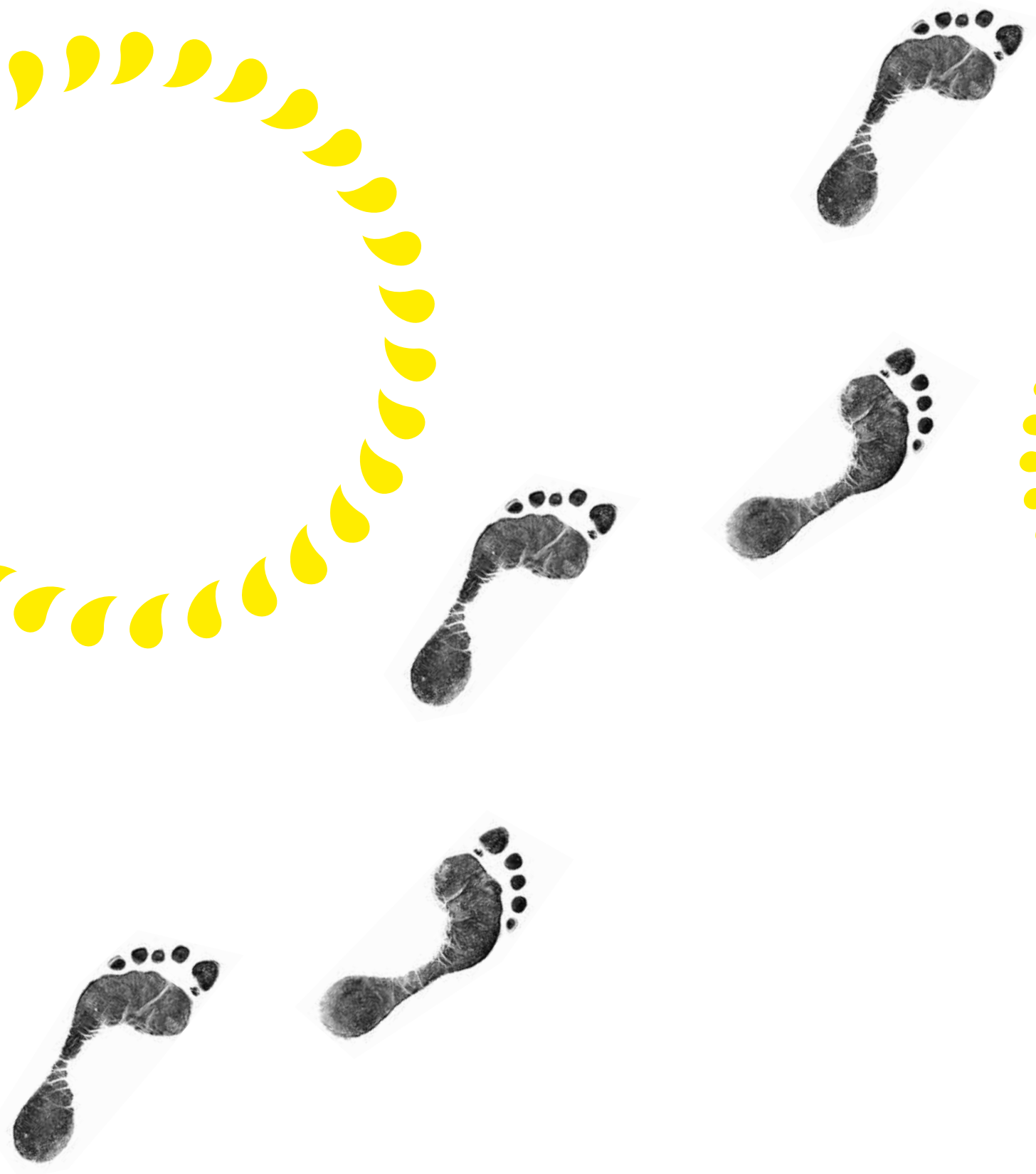

Nothing diminishes anxiety faster than action

- WALter ANDERSON - 